\title{
Plant and Laboratory Scale Studies of High Performance Concrete for Bridge Decks in West Virginia
}

\author{
Santiago Velez \\ West Virginia University
}

Follow this and additional works at: https://researchrepository.wvu.edu/etd

\section{Recommended Citation}

Velez, Santiago, "Plant and Laboratory Scale Studies of High Performance Concrete for Bridge Decks in West Virginia" (2009). Graduate Theses, Dissertations, and Problem Reports. 2165.

https://researchrepository.wvu.edu/etd/2165

This Thesis is protected by copyright and/or related rights. It has been brought to you by the The Research Repository @ WVU with permission from the rights-holder(s). You are free to use this Thesis in any way that is permitted by the copyright and related rights legislation that applies to your use. For other uses you must obtain permission from the rights-holder(s) directly, unless additional rights are indicated by a Creative Commons license in the record and/ or on the work itself. This Thesis has been accepted for inclusion in WVU Graduate Theses, Dissertations, and Problem Reports collection by an authorized administrator of The Research Repository @ WVU. For more information, please contact researchrepository@mail.wvu.edu. 


\title{
Plant and Laboratory Scale Studies of High Performance Concrete for Bridge Decks in West Virginia
}

\author{
by \\ Santiago Velez \\ Thesis \\ Submitted to the \\ College of Engineering and Mineral Resources \\ at West Virginia University \\ in partial fulfillment of the requirements \\ for the degree of \\ Master of Science \\ in \\ Civil Engineering
}

Julio F. Davalos, Ph.D., Chair

Indrajit Ray, PhD., Co-Chair

Udaya Halabe, PhD.

Department of Civil and Environmental Engineering

Morgantown, West Virginia

2009

Keywords: Admixtures, Aggregates, Fresh Properties, Hardened Properties, Durability, Strength, Air-Void, Petrographic, High Performance Concrete, HPC, Supplementary Cementitious Materials (SCM), Maturity. 


\section{ABSTRACT \\ Plant and Laboratory Scale Studies of High Performance Concrete for Bridge Decks in \\ West Virginia}

Santiago Velez

High-performance concrete (HPC) is increasingly used in bridge decks due to its high strength, superior durability and low maintenance resulting in durable and cost effective bridges. FHWA strongly recommended developing suitable HPC mixtures using local material sources and construction technologies for a specific location or state.

As part of a comprehensive R\&D program, a field implementation of laboratory developed HPC mixtures was proposed. From a total of eight mixtures developed in the lab with $\mathrm{w} / \mathrm{cm}=0.40$, three HPC mixtures were selected using specific local aggregates, in addition to supplementary cementitious materials and chemical admixtures. From these mixtures, three test slabs were produced at a concrete plant in West Virginia, by simulating typical construction practices. The plant-produced slabs were monitored and evaluated for temperature, weather, fresh, hardened, and durability properties for over 90 days from summer to early winter. Maturity-strength relationships were established. Microscopic determination of air-void parameters were conducted using a proposed new method and compared with standard method. Finally, concrete cores were examined by petrography to determine w/cm ratio, compositional variations, and other possible depositions within hardened slabs. The properties of field-mixed match-cured, field-mixed laboratory-cured and laboratory-mixed specimens were compared to check the performance of concrete designed in the laboratory and used in the field.

The results showed that all combinations performed well, with slag + silica fume combinations being the best in terms of compressive strength, resistance to freezing and thawing, and chloride ions penetration. The proposed new method for estimating the air-void parameters was found to be more representative than standard methods. The petrographic examination revealed that aggregates, w/cm ratio, and cementitious materials contents were consistent with the original mixture design. This study will be used to develop guidelines for full-scale demonstration projects for the state of West Virginia. 


\section{ACKNOWLEDGEMENT}

I would like to express my endless gratitude to my advisor Dr Julio F. Davalos for his continuing support, guidance and encouragement during these two years. I feel very fortunate to have a mentor like Dr. Davalos, who gave me the opportunity to be part of this interesting project and the opportunity to be a graduate student at West Virginia University.

I would like to sincerely thank Dr. Indrajit Ray, who wonderfully guided me for the thesis in this field of advanced concrete science and technology. Without his advice and support, it would not have been possible to complete t he project. He was always available when I needed help and he always made time to answer my questions no matter what time it was. Working in the laboratory without much previous experience was a lot easier with his guidance. Thanks to his technical support and advice. Because of him now I consider myself an expert performing many tests on concrete. I consider Dr. Ray not only just my advisor, or my teacher, but also my personal friend.

I would also like to express my sincere thanks to Dr. Udaya Halabe who extended his support from the very moment I requested him to be one of my committee members. His recommendations were an important part on the development of this work.

I gratefully acknowledge the support provided by West Virginia Department of Transportation, Division of Highways (WVDOT-DOH) on this project. The support provided by Arrow Concrete Company, Mr. Mike Dougan, and Mr. Greg Damis is also gratefully acknowledged. Their technical support and experience with concrete were absolutely necessary for the successful completion of the plant-scale testing phase of this project. I also acknowledge Dr. Mike Patton for his kind input and information on concrete petrography.

I would like to thank my fellow graduate students who always supported me. They were always willing to help me not only in the laboratory but also in the field work - no matter the time or weather condition.

I dedicate this work to my parents Doris Molina and J. Fabio Velez, to my brother Juan E. Velez, and to my girlfriend Paula A. Tamayo who were always supporting me no matter what. They always made everything they could to make me feel much more confident and to bring me up whenever I was not feeling good. 


\section{TABLE OF CONTENTS}

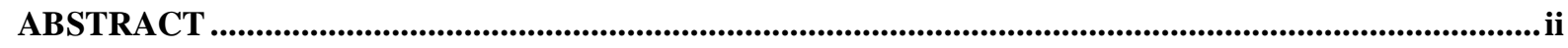

ACKNOWLEDGEMENT ...................................................................................................................................

TABLE OF CONTENTS .....................................................................................................................................

LIST OF TABLES

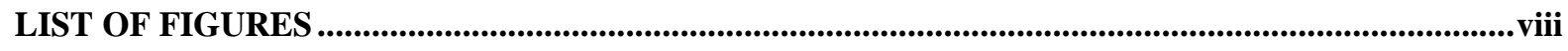

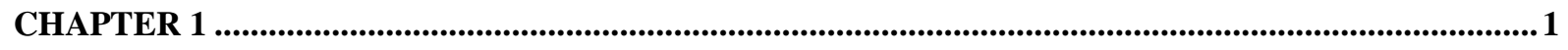

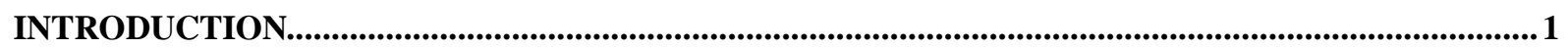

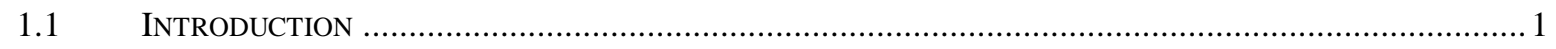

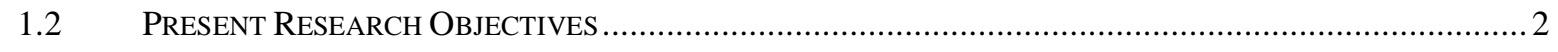

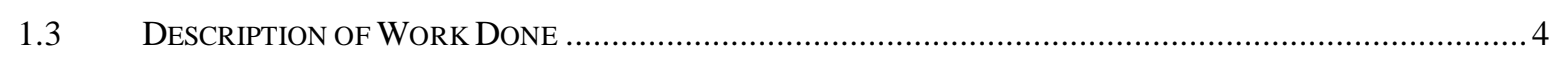

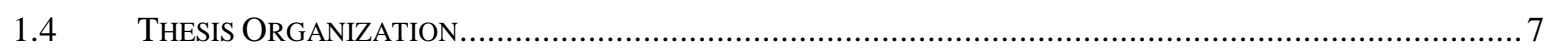

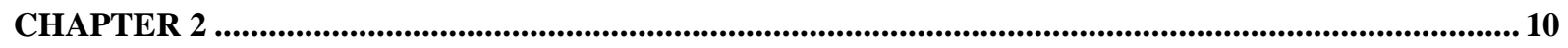

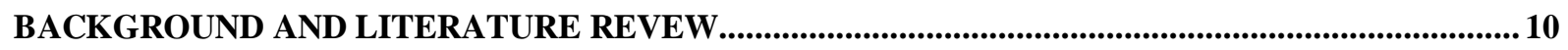

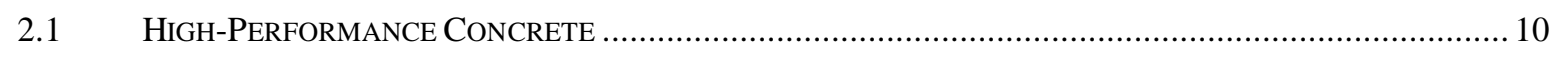

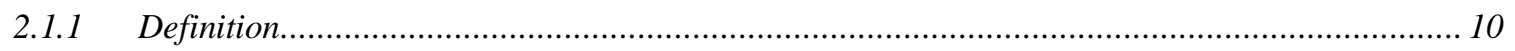

2.1.2 Supplementary Cementitious Materials in HPC .................................................................... 11

2.1.3 West Virginia Division of Highways Class H Concrete Specifications ....................................... 14

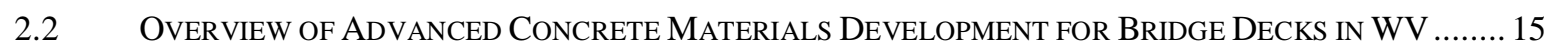

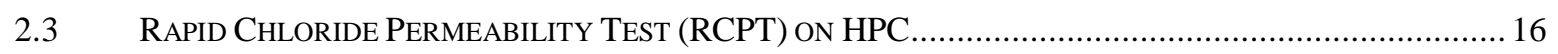

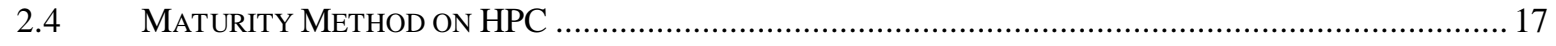

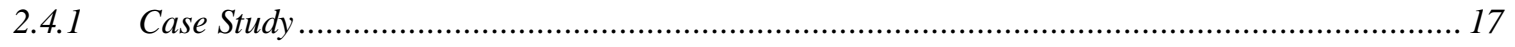

2.5 Microscopical Determination of THE Air-Void SYSTEM AND PETROGRAPHic EXAMinAtion OF

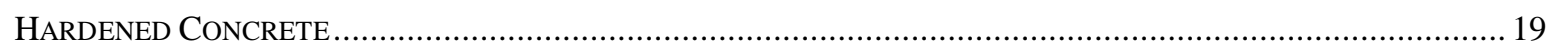

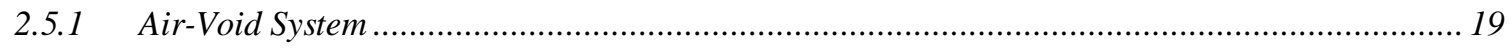

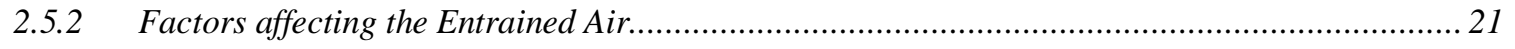

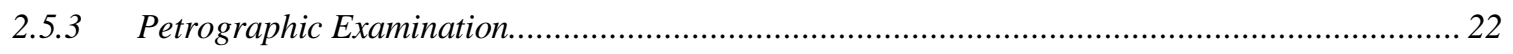

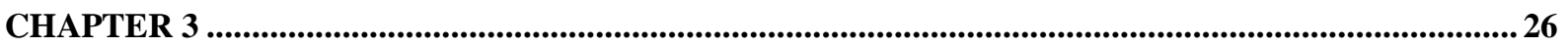

MATERIALS, MIXTURES PROPORTIONS, AND CONCRETE MAKING ............................................26 


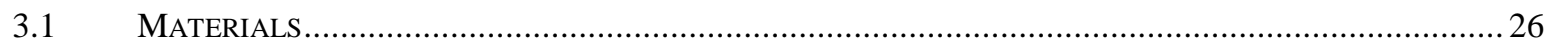

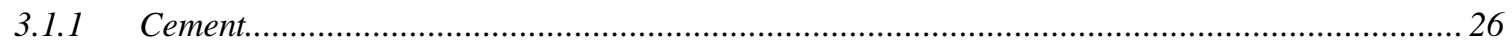

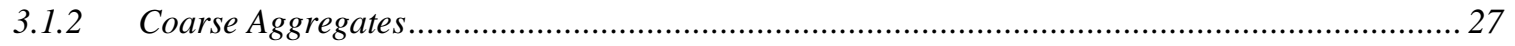

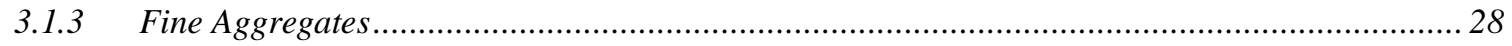

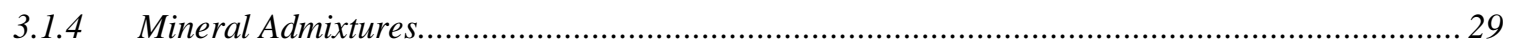

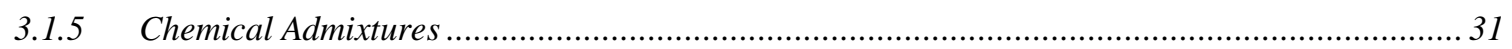

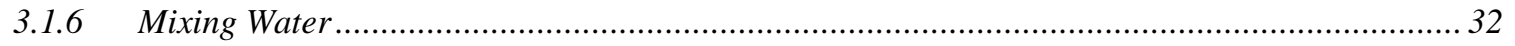

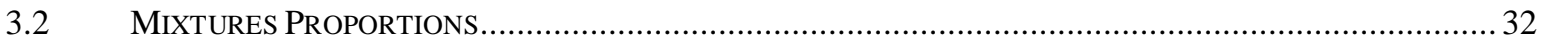

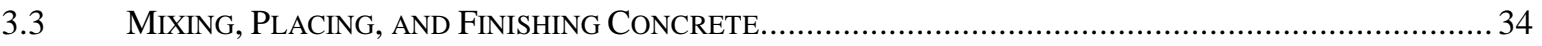

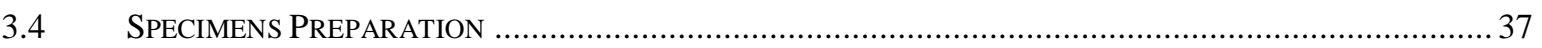

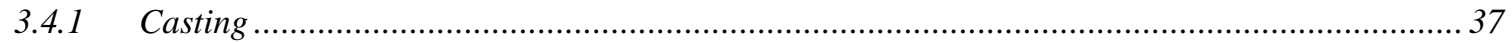

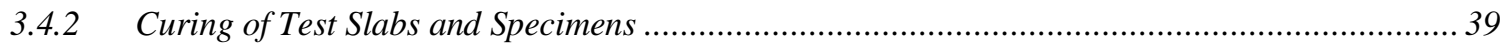

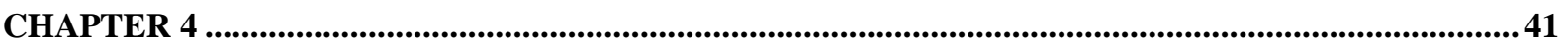

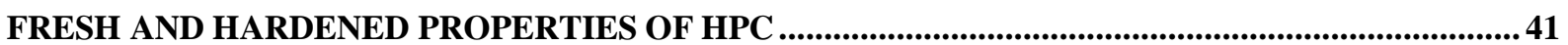

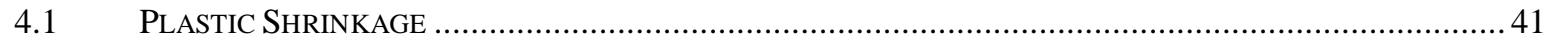

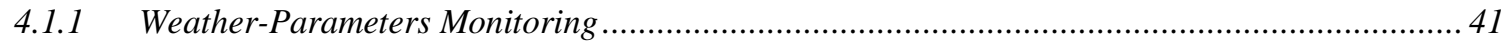

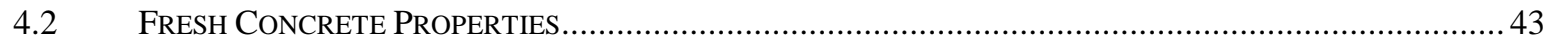

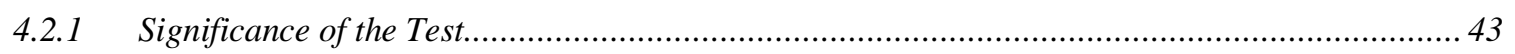

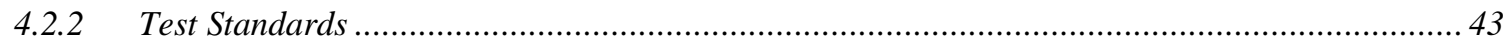

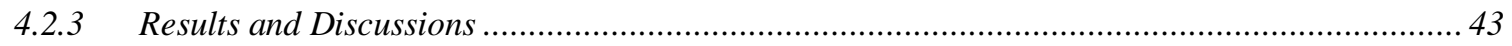

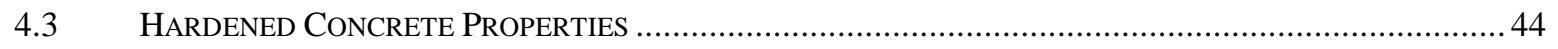

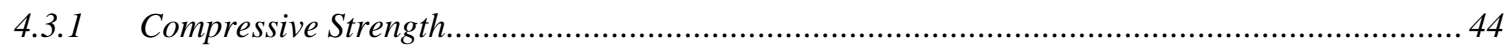

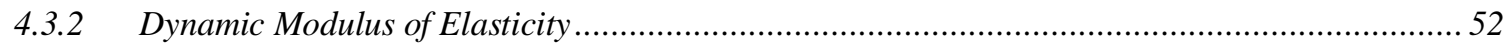

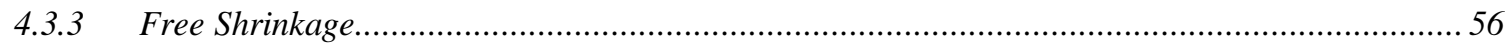

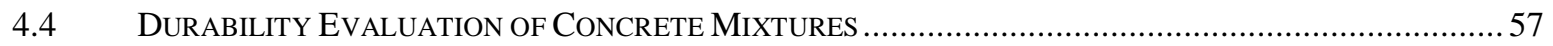

4.4.1 Resistance of Concrete to Rapid Freezing and Thawing .......................................................57

4.4.2 Electrical Indication of Concrete's Ability to Resist Chloride Ion Penetration............................ 63

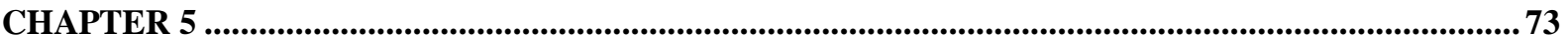

ESTIMATION OF CONCRETE STRENGTH BY THE MATURITY METHOD ....................................73

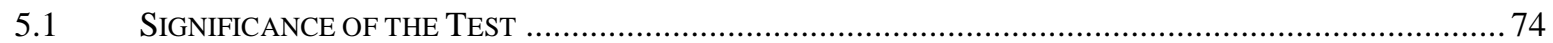

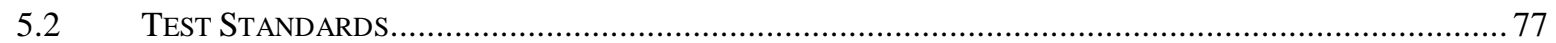

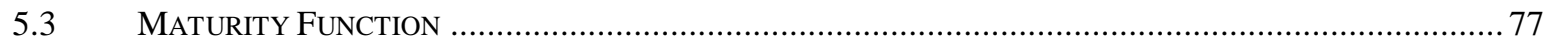

5.4 DEVElopment OF THE MATURITy CALIBRATION CURVE.............................................................. 78

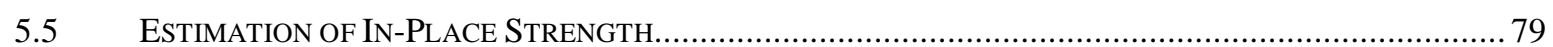

5.6 VERIFICATION OF THE STRENGTH-MATURITY RELATIONSHIP....................................................... 79 


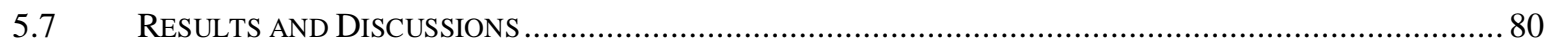

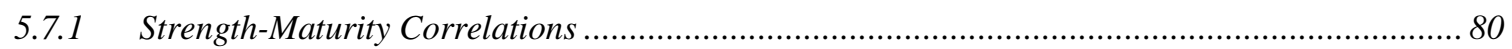

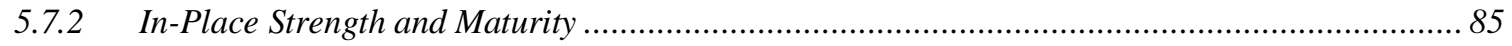

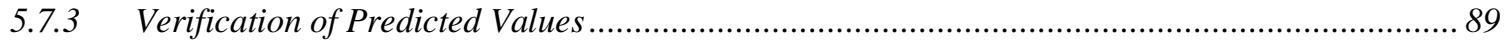

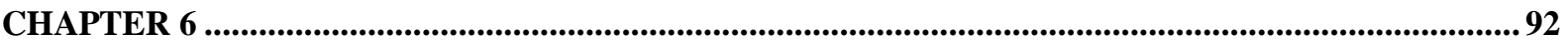

DETAILED AIR-VOID ANALYSIS AND PETROGRAPHIC EXAMINATIONS OF CONCRETE CORE

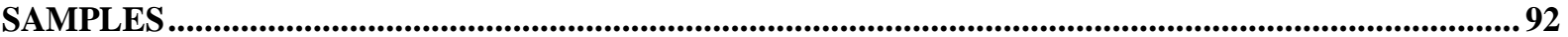

6.1 MicroscopicAl DETERMinATION OF THE AIR-VoId SYSTEM PARAMETERS IN HARDENED HPC ...... 92

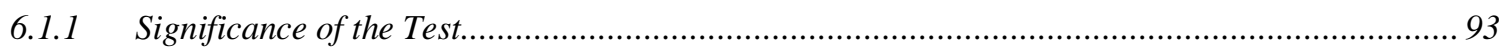

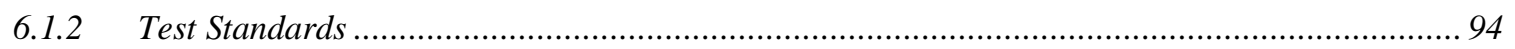

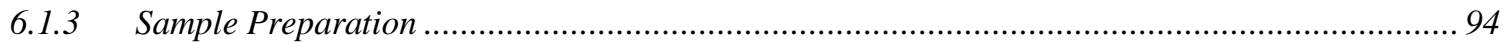

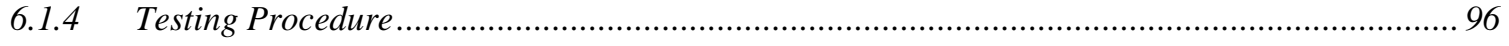

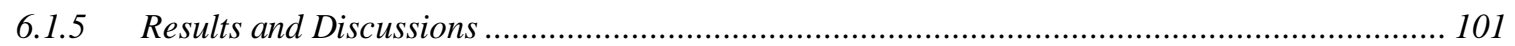

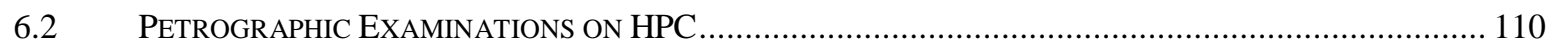

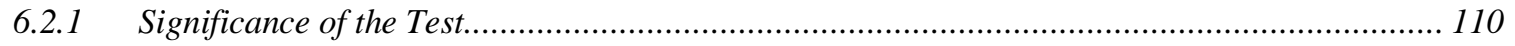

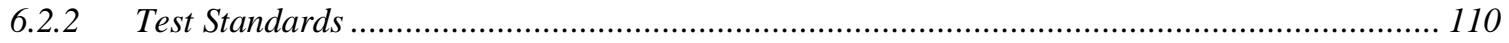

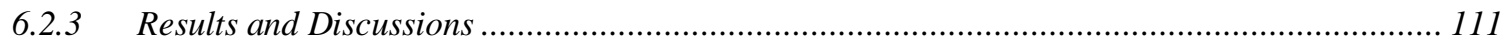

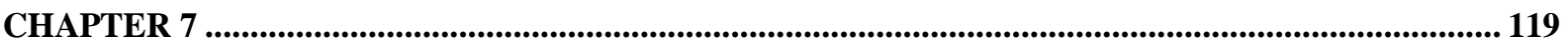

CONCLUSIONS AND RECOMMENDATIONS FOR FUTURE WORK ............................................ 119

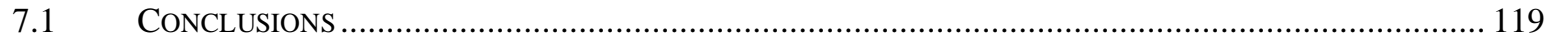

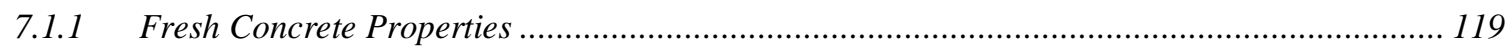

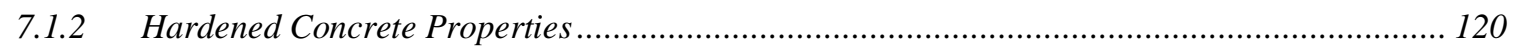

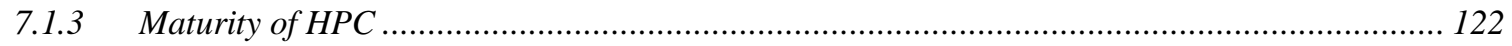

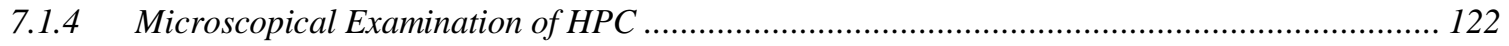

7.1.5 FHWA Grades of Performance Characteristics for HPC............................................ 124

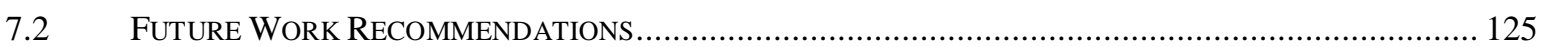

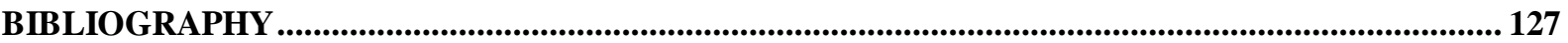

APPENDIX A A........................................................................................................................................... 133

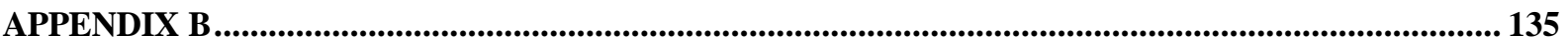

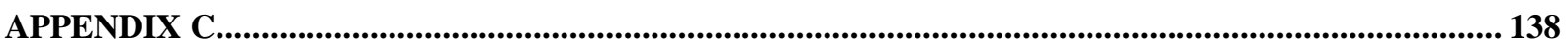

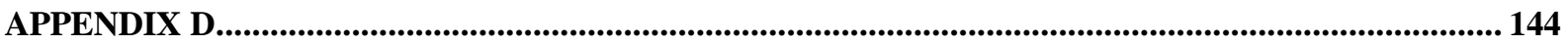




\section{LIST OF TABLES}

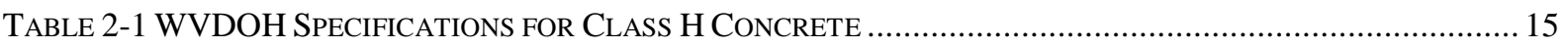

TABLE 3-1 BASIC PHYSICAL PROPERTIES OF TYPE I PORTLAND CEMENT USED ..................................................... 26

TABLE 3-2 COMPOUND COMPOSITION OF TYPE I PORTLAND CEMENT USED ................................................... 27

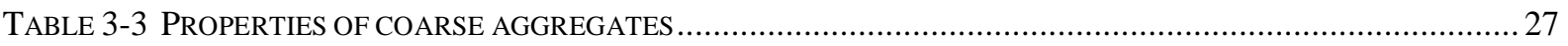

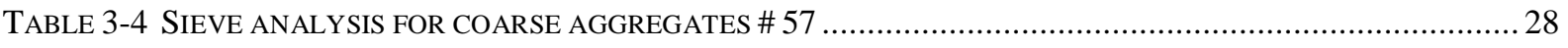

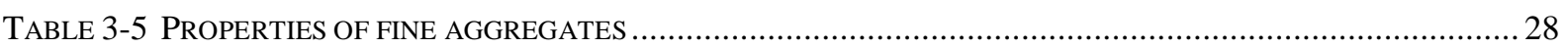

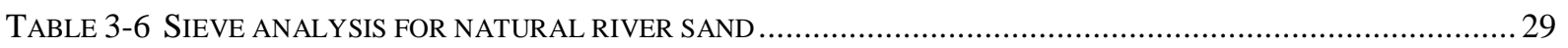

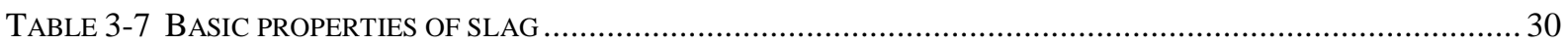

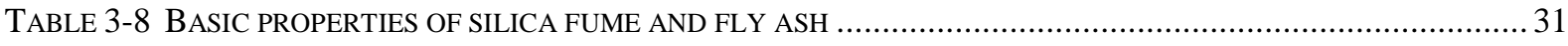

TABLE 3-9 MiXTURE TYPES AND PERCENTAGE OF SCM USED IN FIELD PROJECT …............................................... 33

TABLE 3-10 MixtURE TYPES AND PERCENTAGE OF SCM USED IN WVU LABORATORY ........................................ 33

TABLE 3-11 MIXTURE PROPORTIONS OF CONCRETE AND BASIC FRESH PROPERTIES .......................................... 34

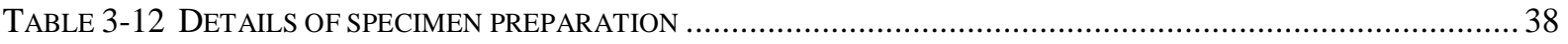

TABLE 3-13 SPECIMENS TYPE, METHOD OF CURING AND SPECIMENS DESIGNATION ......................................... 40

TABLE 4-1 WEATHER PARAMETERS AND EVAPORATION RATE...................................................................... 42

TABle 4-2 Compressive Strength DeVelopment (a) Slab 1, (B) Slab 2, (c) Slab 3 ................................... 48

Table 4-3 Dynamic modulus of Elasticity (a) Slab 1, (B) SLAB 2 AND (C) SLAB 3 .................................... 55

Table 4-4 Freezing and thawing test data (a) Slab 1, (B) Slab 2, and (C) Slab $3 \ldots \ldots \ldots \ldots . . . . . . . . . . . . . . . . . . .62$

TABLE 4-5 CHLORIDE ION PENETRABILITY BASED ON CHARGE PASSED ............................................................... 64

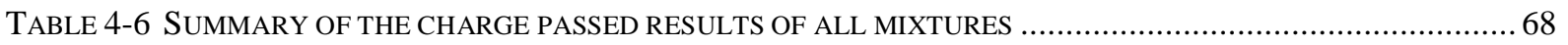

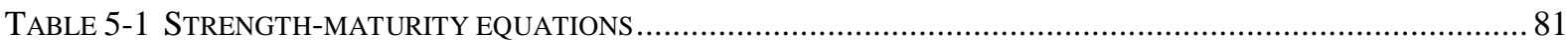

Table 5-2 Maturity and compressive strength data (a) Slab 1, (b) Slab 2 and (C) Slab $3 \ldots . . . . . . . . . . . . . . .82$

TABLE 6-1 AIR-VOID PARAMETERS DETERMINED BY THE POINT-COUNT METHOD …............................................ 102

TABLE 6-2 AIR-VOID PARAMETERS DETERMINED BY THE SECTION-ANALYSIS METHOD .................................. 104

TABLE 6-3 AIR-VOID PARAMETERS DETERMINED BY THE MODIFIED LINEAR-TRANSVERSE METHOD ................... 107

TABLE 7-1 FHWA PERFORMANCE GRADES FOR THE FIELD-MIXED HPC …............................................... 124

TABLE 7-2 FHWA PERFORMANCE GRADES FOR THE LABORATORY MIXED HPC .............................................. 125 


\section{LIST OF FIGURES}

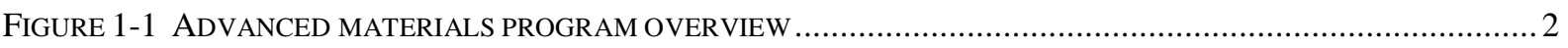

Figure 1-2 Mixtures DEVELOPED AT WVU AND STUdiED UNDER LABORATORY CONDITIONS ............................ 4

FIGURE 1-3 REINFORCEMENT LAYOUT FOR CONCRETE SLABS _......................................................................... 5

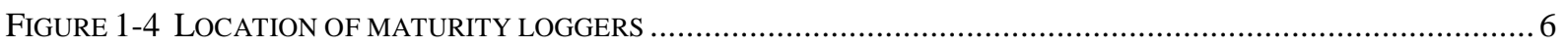

FIGURE 1-5 FORM-WORK, STEEL PLACEMEN AND POURING OF THE IN-PLACE SLABS ……................................. 8

FIGURE 1-6 PREPARATION OF SPECIMENS AND CURING UNDER WET BURLAP .................................................... 8

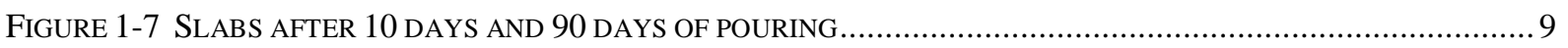

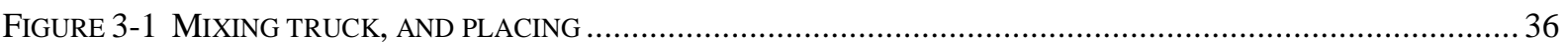

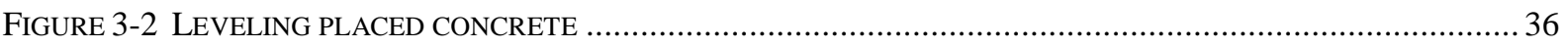

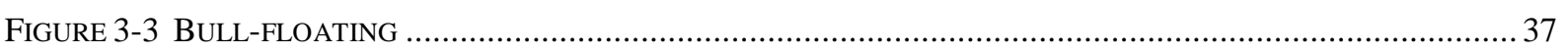

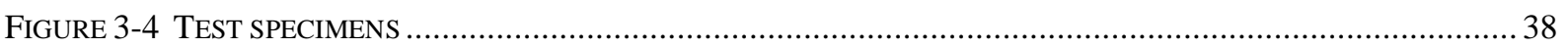

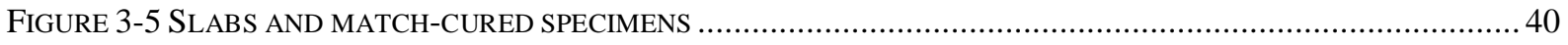

FIGURE 4-1 DEVICE USED FOR AIR CONTENT TEST BY PRESSURE METHOD .................................................... 44

Figure 4-2 Percentage Of COMPRESSIVE STRENGTH DEVELoPMENT AT EVERY AGE ....................................... 47

FIGURE 4-3 COMPRESSIVE STRENGTH COMPARISON FOR FIELD-MC SPECIMENS UP TO 90 DAYS........................... 49

FIGURE 4-4 COMPRESSIVE STRENGTH COMPARISON FOR FIELD-LC SPECIMENS UP TO 90 DAYS.......................... 49

FIGURE 4-5 COMPRESSIVE STRENGTH COMPARISON FOR FIELD-CORE SPECIMENS FOR 28 AND 56 DAYS ............... 50

FIGURE 4-6 COMPRESSIVE STRENGTH COMPARISON FOR LAB-MIX SPECIMENS UP TO 90 DAYS .......................... 50

FIGURE 4-7 COMPRESSIVE STRENGTH DEVELOPMENT FOR EACH TYPE OF CONCRETE MIXTURE ........................... 52

FIGURE 4-8 TEMPERATURE CYCLES FOR FREEZING AND THAWING TEST .......................................................... 59

FIGURE 4-9 RELATIVE DYNAMIC MODULUS OF ELASTICITY VERSUS NUMBER OF CYCLES .................................. 61

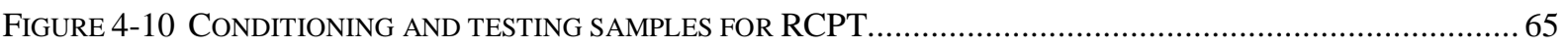

Figure 4-11 Charge Passed versus time (A) Slab 1 at 35 days (B) Slab 1 At 60 days .............................. 69

Figure 4-12 Charge Passed versus time (A) Slab 2 at 35 days (B) Slab 2 at 60 days ............................ 70

Figure 4-13 Charge PasSEd versus time (A) Slab 3 at 35 days (B) Slab 3 AT 60 days ............................ 71

FIGURE 4-14 COMPARISON OF NORMAL RCPT AND SUGGESTED EXTRAPOLATION FOR 35 DAYS........................ 72

FIGURE 4-15 COMPARISON OF NORMAL RCPT AND SUGGESTED EXTRAPOLATION FOR 60 DAYS ......................... 72

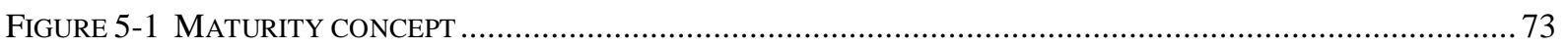

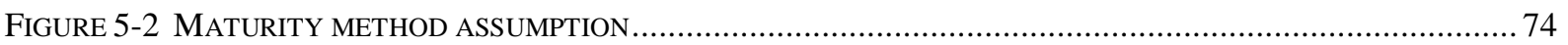

Figure 5-3 Maturity Loggers Attached to the ToP And Bottom SteEl Reinforcement ....................... 76

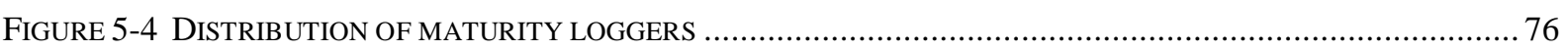

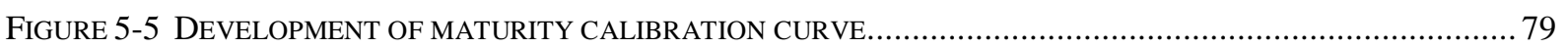

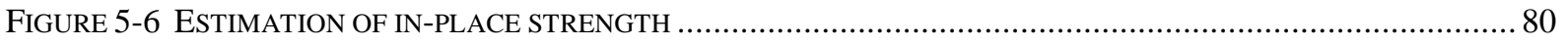

Figure 5-7 Strength-maturity Relationship curves (a) Slab 1, (b) Slab 2 and (c) Slab 3 .................... 84 
FiguRE 5-8 CONCRETE AND AMBIENT TEMPERATURE EVOLUTION FOR 20 DAYS AFTER POURING .86

FIGURE 5-9 CONCRETE AND AMBIENT TEMPERATURE EVOLUTION FOR THE FIRST 48 HOURS ............................... 86

FIGURE 5-10 CONCRETE AND AMBIENT TEMPERATURE EVOLUTION FOR THE 10 DAYS CURING PERIOD.................. 87

FIGURE 5-11 CONCRETE AND AMBIENT TEMPERATURE EVOLUTION AFTER BURLAP WAS REMOVED ..................... 87

FIGURE 5-12 LABORATORY AND FIELD TEMPERATURE COMPARISON …............................................................ 88

FIGURE 5-13 MATURITY DEVELOPMENT OF CONCRETE SLABS AND LAB-CURED SPECIMENS................................. 89

Figure 5-14 TeSted AND PREDicted Compressive StRength (a) Slab 1, (B) Slab 2, AND (C) Slab 3 ........... 91

FIGURE 6-1 CONCRETE SECTIONS USED FOR MICROSCOPICAL ANALYSIS ....................................................... 95

FIGURE 6-2 CONCRETE SPECIMENS AFTER SAWING, GRINDING AND POLISHING ............................................... 96

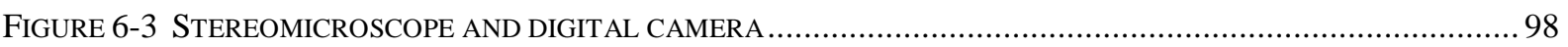

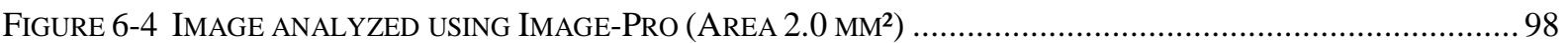

FIGURE 6-5 IMAGE ANALYZED WITH IMAGE-PRO BY THE MODIFIED LINEAR-TRANSVERSE METHOD ..................... 101

FIGURE 6-6 Air CONTENT FROM THE CUMULATIVE ANALYZED AREA …................................................... 105

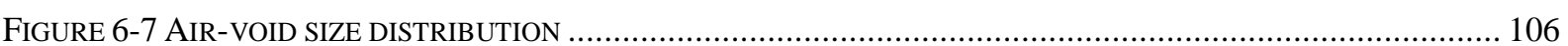

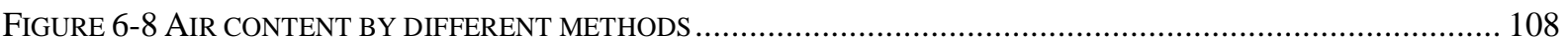

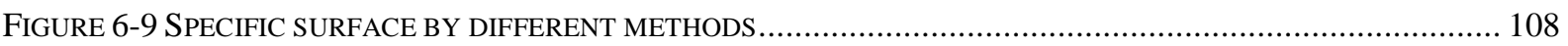

FIGURE 6-10 VOID SPACING FACTOR BY DIFFERENT METHODS ............................................................... 109

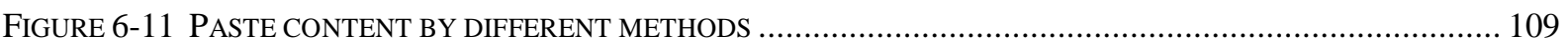

FIGURE 6-12 VIEW OF A POWDER MOUNT FROM THE PASTE FROM SLAB 1 ...................................................... 114

FIGURE 6-13 VIEWS OF PORTIONS OF THE THIN SECTION FROM SLAB 1 AT 100X …….................................... 115

FIGURE 6-14 VIEWS OF THE THIN SECTION FROM SLAB 2 AT 100X ….................................................... 116

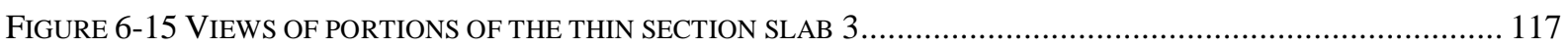

FIGURE 6-16 VIEWS OF PORTIONS OF THE THIN SECTION SLAB 3 (GYPSUM PLATE) ............................................. 118

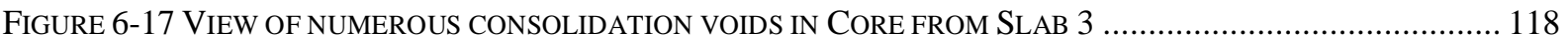

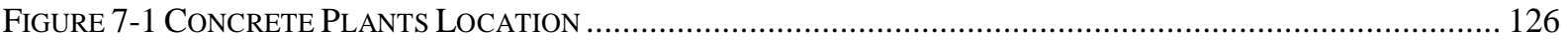




\section{CHAPTER 1}

\section{INTRODUCTION}

\subsection{Introduction}

Supported by the West Virginia Department of Transportation (WVDOT) - Division of Highways (WVDOH), West Virginia University (WVU) has undertaken a state-wide and large-scale research program on development, evaluation, and implementation of advanced materials program for bridge decks for the state. The execution of this program is planned in close collaborations with the industry, Contractors Associations, and Builders Supply Associations of West Virginia as members of the Project's Advisory Panel. The ultimate goal is to develop performance based specifications of High-Performance Concrete (HPC) and specialized overlays for the state of West Virginia. The phases of this advanced material program are presented in Figure 1-1.

A comprehensive laboratory scale study including development and evaluations of optimum HPC and its fresh, hardened, and durability properties has been completed. A number of different mixtures have been developed using West Virginia sources of aggregates and local materials. Now, the research project requires producing and evaluating test slabs to qualify lab mixtures at different locations in the state of West Virginia with the help and collaborations of ready mix concrete plants. Finally, field implementation for demonstration projects will be undertaken by WVU in the future

According to the proposed work, trial mixtures were developed using specified types of coarse aggregates and sand from West Virginia sources. The aggregates and the supplementary cementing materials (SCM) were selected from an approved WVDOH list, after consulting with the Advisory Panel.

There exists no standard evaluation method to select potentially low-cracking HPC. Also, the present WVDOH Class $\mathrm{H}$ concrete has several limitations in terms of specifications. Thus in 
conclusion this project is aimed to recommend field-monitoring of cast in place HPC for bridge decks using the HPC mixtures developed and evaluated in the laboratory, and then at plant scale using representative aggregates, various SCM available, and construction practices of West Virginia.

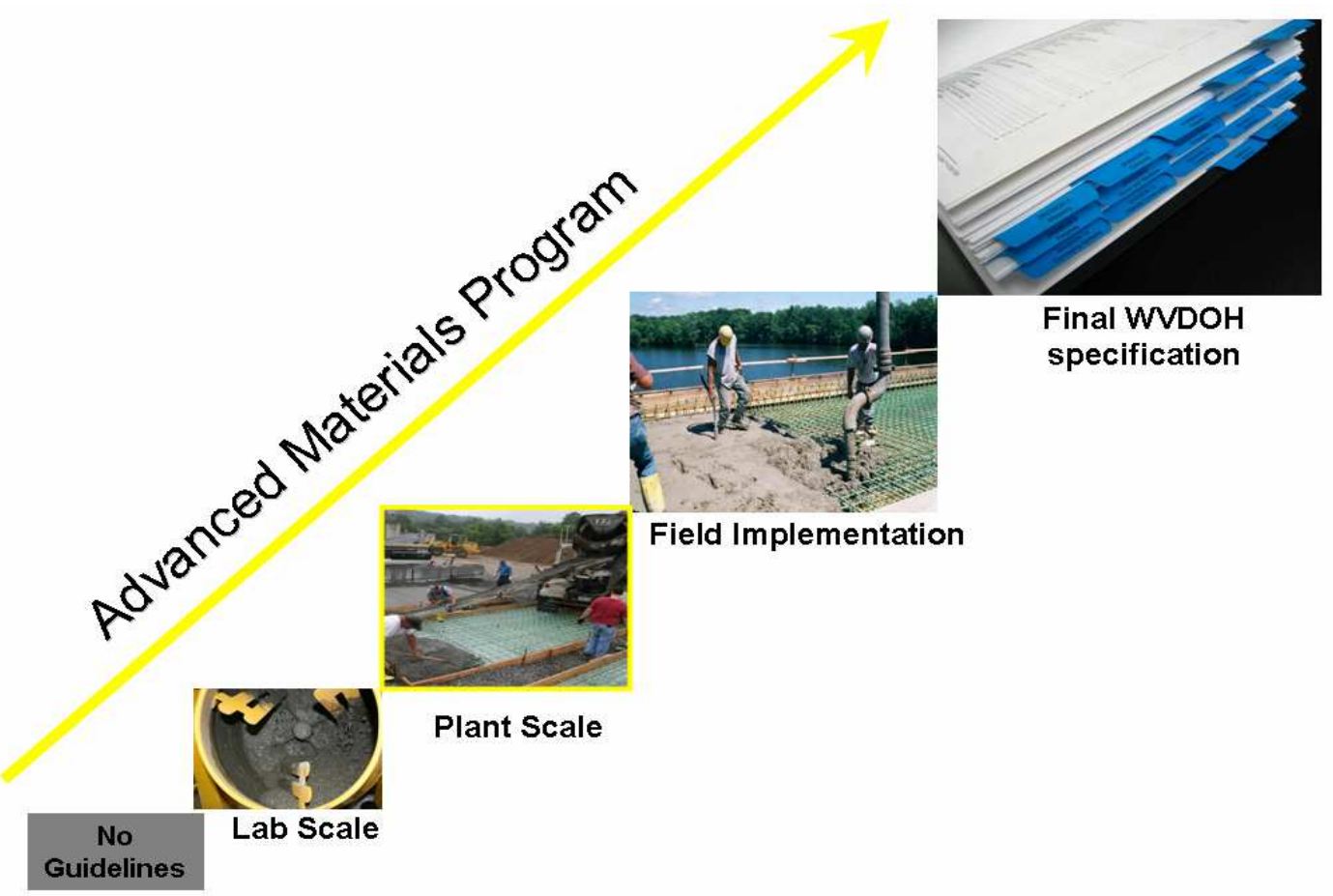

Figure 1-1 Advanced materials program overview

\subsection{Present Research Objectives}

The present study is part of a comprehensive project on the development of HPC mixtures for cast-in-place bridge decks (slabs) in the state of West Virginia, using locally available aggregate materials such as limestone and natural sand from different locations within the state, also using mineral admixtures such as fly ash, slag, silica fume and metakaolin available in the state, and chemical admixtures. The WVDOH specifications for Class $\mathrm{H}$ concrete (HPC) are used to establish threshold mixture proportions. The proposed HPC mixtures are studied for various parameters relevant to bridge concrete decks, including strength, chloride permeability, and freeze-thaw (durability). In this research from the results of the different 
mixtures studied, the best possible combinations are selected and used as prototypes to focus a subsequent global research program on HPC for the state of West Virginia.

The primary objective of this research is to monitor the construction, instrumentation, and performance of the cast-in-place slabs. Other main objective is to evaluate the plant-produced HPC mixtures properties such as fresh properties (slump, air content, plastic shrinkage), hardened properties (compressive strengths, shrinkage, and modulus of elasticity at different ages) and durability (air-void parameters, chloride permeability, and freezing and thawing).

The properties evaluated for HPC from cored specimens, field-mixed and match or fieldcured specimens (Field-MC), field-mixed and laboratory-cured specimens (Field-LC), and laboratory-mixed and laboratory-cured specimens (Lab-Mix) are compared in this work in order to establish the correlations among them. Through this study the acceptance criteria as proposed in preliminary specifications are modified, whenever necessary.

Another important objective of this research is to develop a strength-maturity relationship for each concrete mixture studied in this research. These calibration relationships are developed to have the possibility of predicting compressive strength by the maturity method for future applications of similar mixtures. The development is to be done using the field-mixed HPC specimens cured and tested in the laboratory creating functions that allows the prediction of the compressive strength of the concrete using the maturity reading obtained from the maturity sensors.

This research further attempts to provide a detailed characterization of the concrete slabs by a microscopic determination of air-void parameters conducted by using standard methods, and a proposed new method that involves section analysis and images analysis of drilled cores. Standard and thin sections of cored specimens are to be examined using petrography to determine water to cementitious material ratios $(\mathrm{w} / \mathrm{cm})$, cementitious material contents, distribution of hydrated structures, and other depositions within hardened concrete. The petrographic examinations are done in order to check the compliance of the mixtures with the specifications and to study the deterioration and failures for quality control. 


\subsection{Description of Work Done}

From a total of 24 different mixtures (Figure 1-2) those were developed at WVU and studied under laboratory conditions, a total of three mixtures were selected, studied and evaluated at plant scale. The three test slabs were produced following the WVDOH specification 601.10.1.2 at Arrow Concrete co. in Morgantown, WV. These slabs were similar to typical reinforced concrete bridge decks regarding its depth and reinforcements, and the dimensions are $3.05 \mathrm{~m}$ (10 ft) width (one-traffic lane-width) by $6.1 \mathrm{~m}$ ( $20 \mathrm{ft}$ ) long. The mixtures used for making the test slabs and specimens were made of Type I cement, local aggregates, commercial high-range water reducing admixtures, air-entraining admixtures and the following combinations of SCM: (1) slag + metakaolin, (2) fly ash + silica fume, (3) slag + silica fume. The mixture proportions are presented in details in Chapter 3.

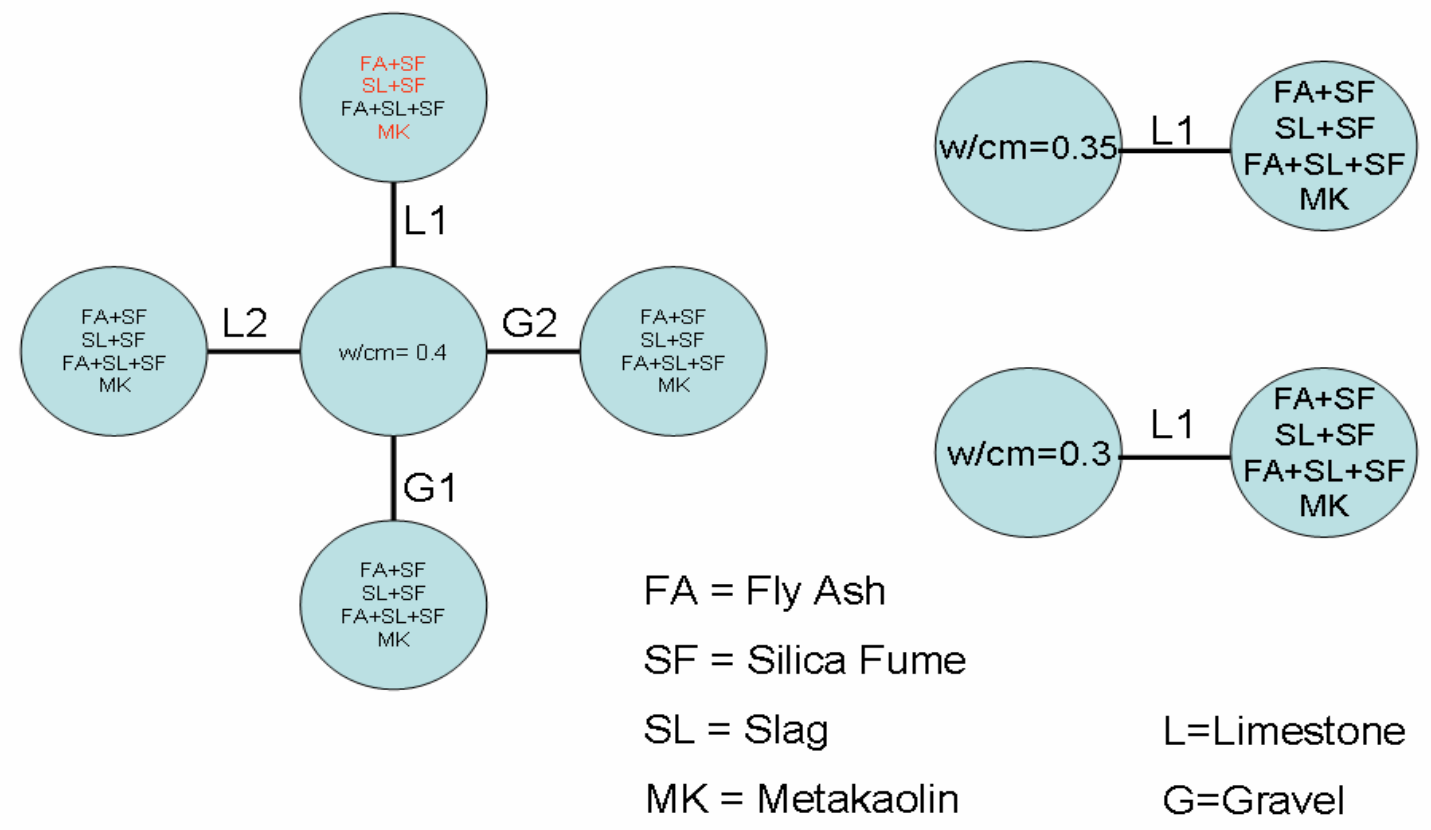

Figure 1-2 Mixtures developed at WVU and studied under laboratory conditions

The three slabs were placed in the Arrow Concrete Plant in a convenient location. It covered an area of about $15 \times 10 \mathrm{~m}(49.20 \times 32.80 \mathrm{ft})$. The location was quite flat but still the areas were leveled by placing coarse aggregates. Formwork made of wood was placed on the sides creating a box of $3.05 \times 6.10 \mathrm{~m}$ and $228 \mathrm{~mm}$ height $(10 \times 20 \mathrm{ft}$ and 9 in. height). For the 
bottom of the concrete slab, Q-Decking was placed to simulate a real bridge deck. The height of this Q-Decking was $12 \mathrm{~mm}$ (0.5 in.) creating a slab thickness of $216 \mathrm{~mm}$ (8.5 in.).

After the formwork and the Q-Decking were completed, two layers of No 4 epoxy coated steel reinforcing bars were placed in both directions creating a grid with a separation of 203 $\mathrm{mm}(8 \mathrm{in}$.) in between the bars. By placing on chairs, the bottom grid was separated $51 \mathrm{~mm}(2$ in.) from the top face of the Q-decking and the top grid was located $51 \mathrm{~mm}$ (2 in) from the top finished surface of the concrete, and thus creating a cover of $51 \mathrm{~mm}$ (2 in). The separation from one grid to the other was made $115 \mathrm{~mm}$ (4.5 in.) and the clear cover to the wooden formwork was $76 \mathrm{~mm}$ (3 in.). Figure 1-3 presents the reinforcement plan.

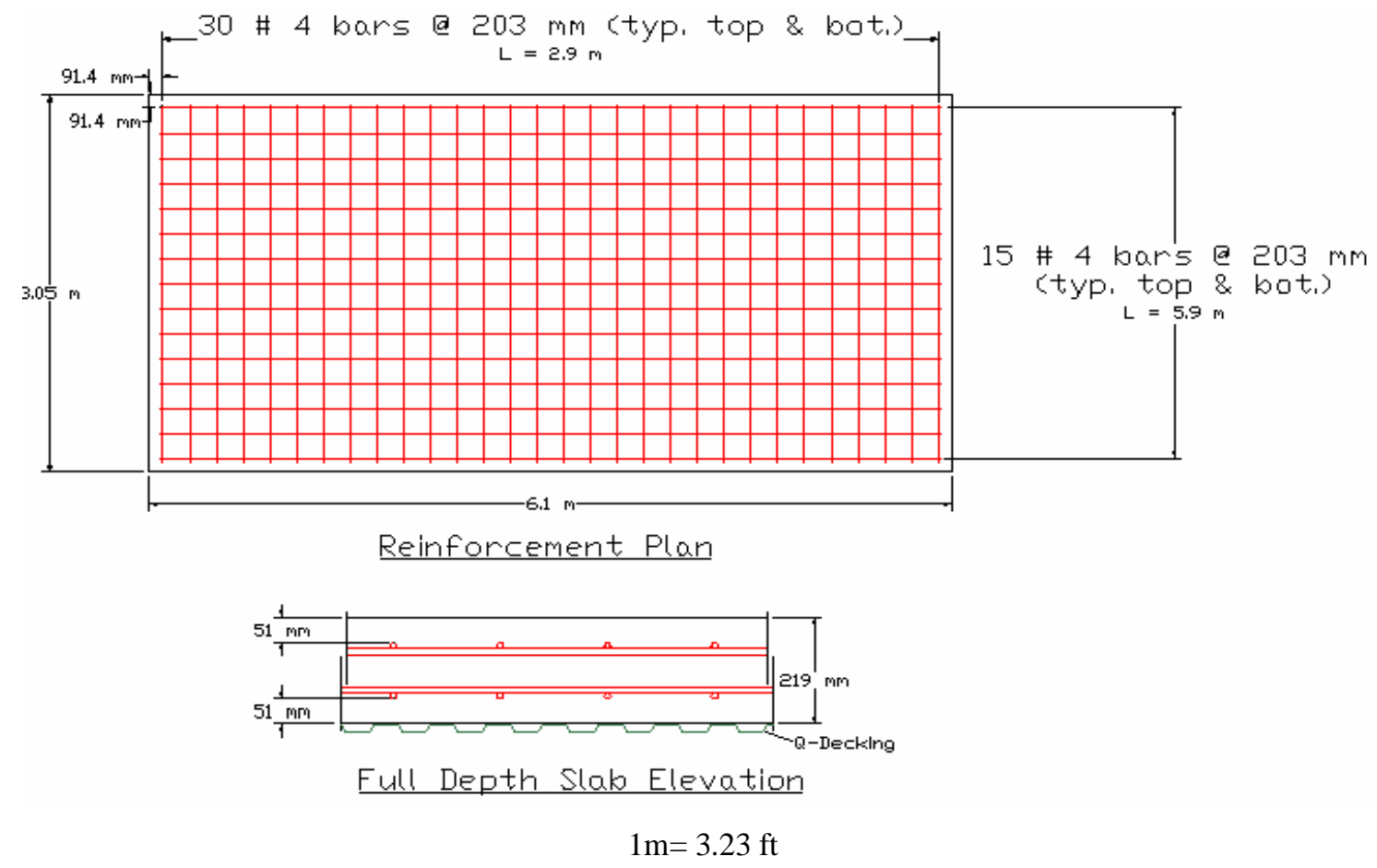

Figure 1-3 Reinforcement layout for concrete slabs

After the reinforcement was placed, maturity loggers with a capacity of reading temperature and maturity every hour for 90 days were installed at 7 different location of each slab. The loggers were located in two levels by tying them to the steel reinforcement, and two more loggers were placed inside cylindrical specimens of 152 × $305 \mathrm{~mm}(6 \times 12$ in.) for the 
development of a strength-maturity relationship. Figure 1-4 presents the location of the maturity loggers in the slabs.
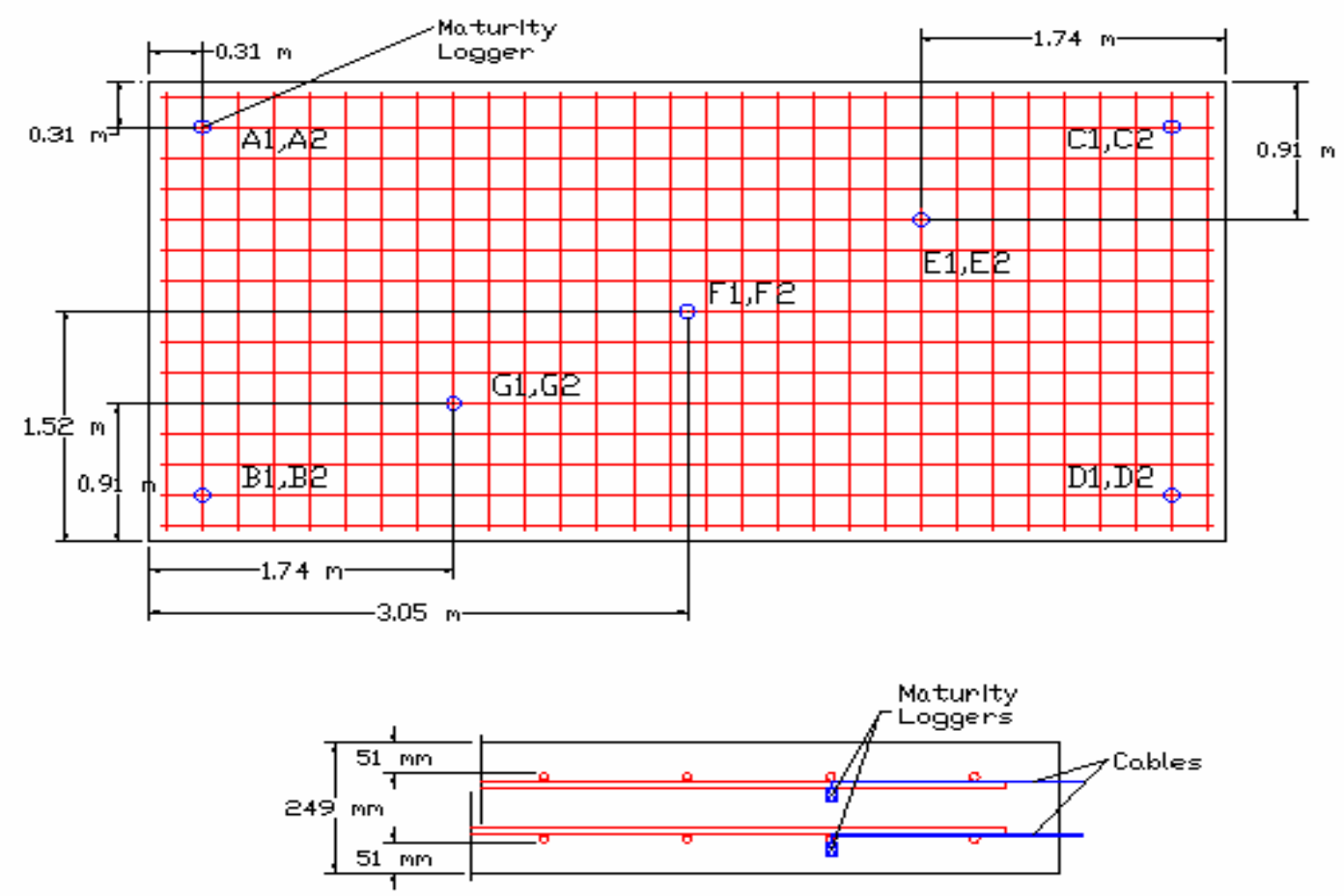

$1 \mathrm{~m}=3.23 \mathrm{ft}$

Figure 1-4 Location of maturity loggers

After the preliminary work was done and all the loggers were placed, the wooden formwork was sprayed with MBT Rheofinish 211 form releasing agent. All cylindrical and prism molds were also sprayed with the same form releasing agent. For each slab, a total of thirty eight 152 x 305 mm (6 x12 in.) cylindrical specimens were cast for compressive strength, static modulus of elasticity and maturity test; five 102 x $203 \mathrm{~mm}$ (4x8 in.) cylinder specimens were cast for rapid chloride permeability test (RCPT); three 76 × 76 x $283 \mathrm{~mm}(3 \times 3 \times 11.25$ in.) prism specimens were cast for shrinkage test, and three 76 × 106 × 406 mm (3 x 4 x 16 in.) prisms were cast for freeze-thawing test. The volume of concrete needed for each slab including the test specimens was of $4.28 \mathrm{~m}^{3}\left(5.6 \mathrm{yd}^{3}\right)$. 
The mixture containing the slag + metakaolin, fly ash + silica fume, and slag + silica fume was designated as slab 1, slab 2, and slab 3, respectively. The slabs were poured in the morning simulating transportation and job site conditions. It utilized local materials and methods of placing. It was finished and cured in collaboration with personnel from Arrow Concrete Co. and local contractors. Figure 1-5 and Figure 1-6 present pictures of some of the steps followed.

After the concrete was poured, the curing was started immediately and continued for 10 days under wet burlap with continuous supply of water. As mentioned above, some of specimens were match-cured in the field and other specimens were cured under laboratory conditions. Also at 28 and 56 days, cored specimens were extracted from the slabs with the purpose of comparing information with molded specimens. Different evaluation methods were followed for all the specimens in order to characterize the concrete mixtures.

\subsection{Thesis Organization}

Chapter 1 presents the introduction, the global and present objectives, and a brief description of the work done in the field. Chapter 2 gives a detailed background and presents a literature review. Chapter 3 describes the materials, the mixture proportions, and the types of curing used in this project. Chapter 4 presents the characterization of both fresh and hardened HPC and a durability evaluation of the concrete mixtures. Chapter 5 introduces the maturity method as a technique to estimate the concrete strengths. Chapter 6 presents a detailed airvoid analysis by different methods and a petrographic examination of the concrete mixtures studied. Chapter 7 draws the conclusions from this research and presents recommendations for future work. 


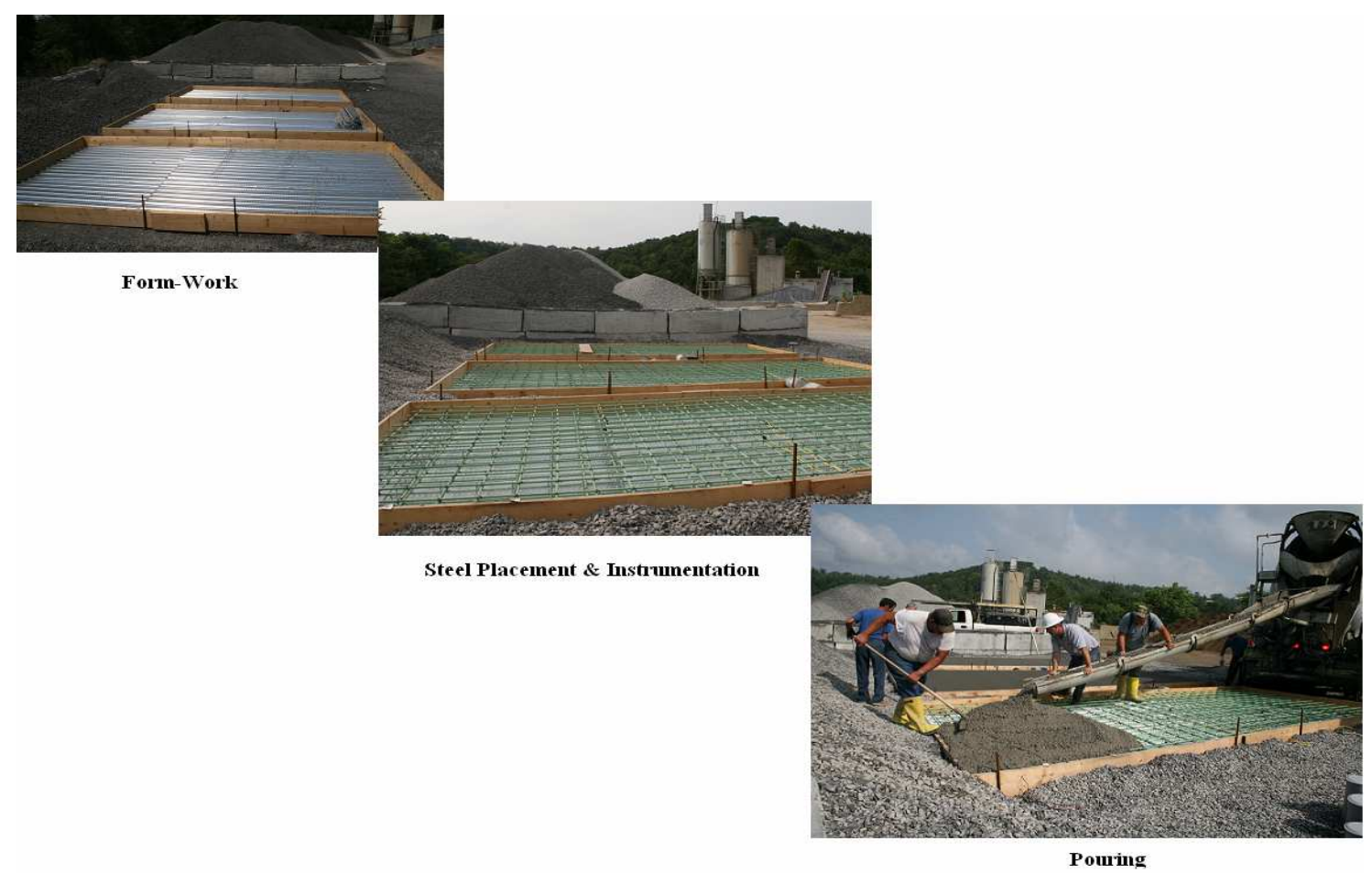

Figure 1-5 Form-work, steel placemen and pouring of the in-place slabs

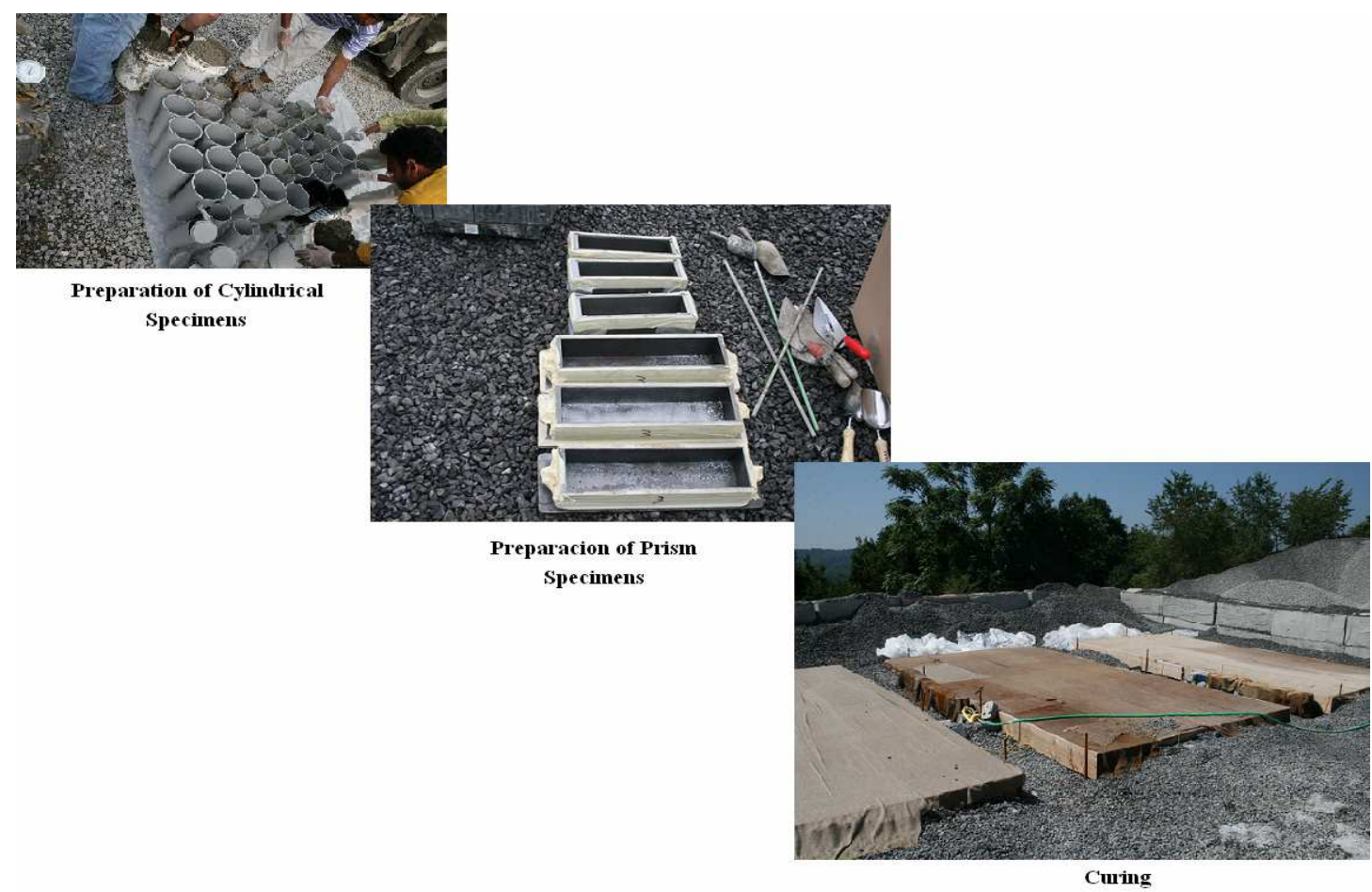

Figure 1-6 Preparation of specimens and curing under wet burlap 

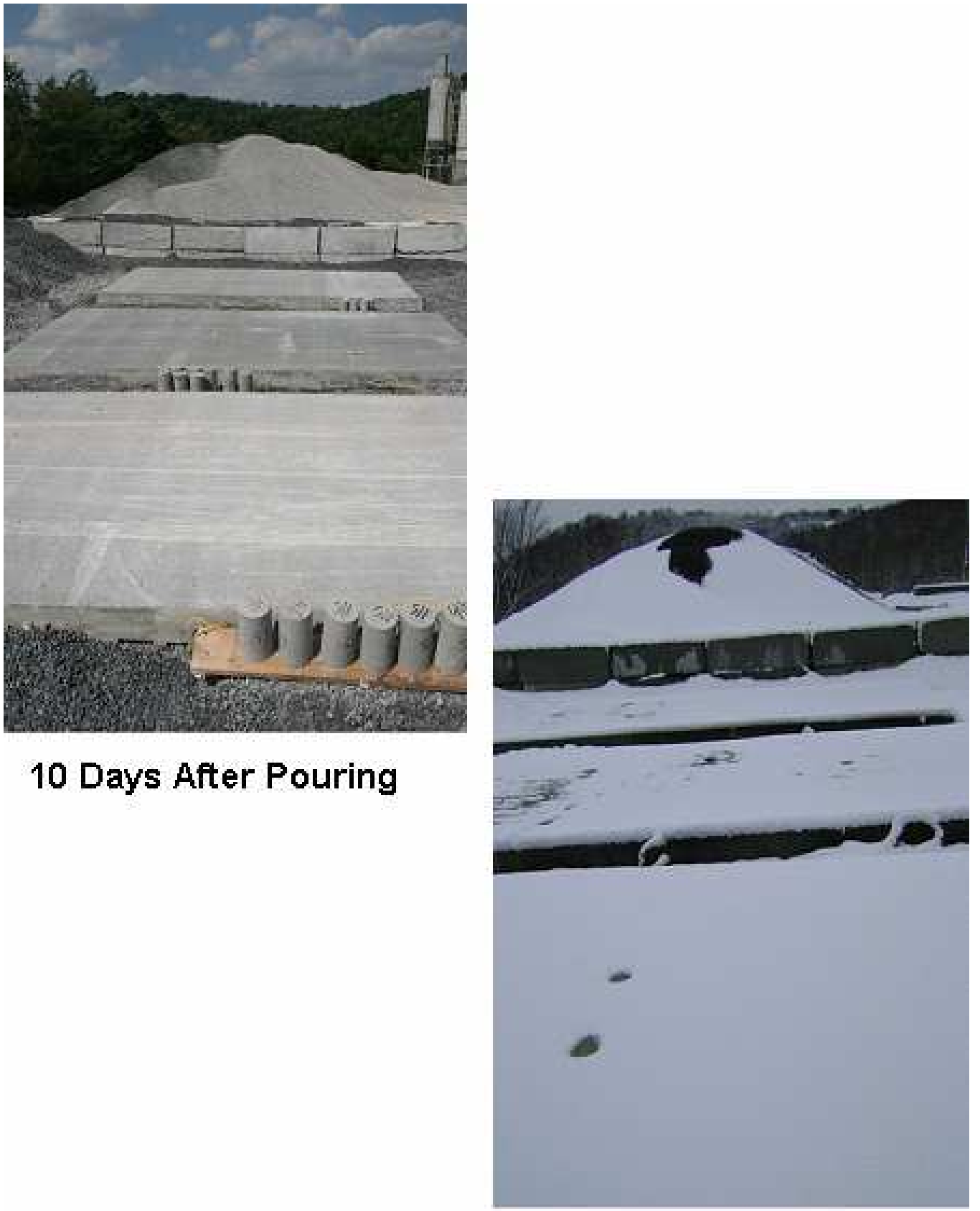

90 Days After Pouring

Figure 1-7 Slabs after 10 days and 90 days of pouring 


\section{CHAPTER 2}

\section{BACKGROUND AND LITERATURE REVEW}

\subsection{High-Performance Concrete}

HPC first appeared as high-strength concrete having some special attributes, however it has undergone several modifications and finally established as a custom-made engineered product with several high-performing attributes. Initially, it was developed and applied for the highrise building construction as a new and innovative material compared to normal strength concrete. But later on it was used in several infrastructure applications including different components of bridges, tunnels, overpass, underground structures, nuclear structures, and many other applications. Two breakthroughs are worth mentioning for the development of HPC: one is the introduction of High range water reducing admixture (HRWRA) to concrete in order to make possible concretes with a low w/cm while maintaining superior workability; and the other is the use of SCM to modify the fresh and hardened properties of concrete and improve the durability significantly..

\subsubsection{Definition}

The definition of HPC continues to change as advances in concrete technology make it easier to achieve increasingly higher strengths and improved properties using conventional construction practices.

The HPC is defined by the American Concrete Institute (ACI) 'as concrete meeting special combination of performance and uniformity requirements that cannot always be achieved routinely using conventional constituents and normal mixing, placing, and curing practices.' A HPC is a concrete in which certain characteristics are developed for a particular application and environment and therefore be customized for a specific purpose. Some examples of characteristics that may be considered critical for an application are: 
- Ease of placement

- Long-term mechanical properties

- Density

- Toughness

- Long life in severe environments

- Early age strength

- Permeability

- Heat of hydration

- Volume stability

Because many characteristics of HPC are interrelated, a change in one characteristic usually results in changes in one or more of the other characteristics. Consequently, if several characteristics have to be taken into account producing a concrete for the intended application, each characteristic must be clearly specified in the contract document of the project.

Strength criteria like compressive strength, modulus of elasticity; volume change criteria like shrinkage and creep; and durability criteria like freezing and thawing, scaling, abrasion and chloride permeability are used in the evaluation of HPC designs.

\subsubsection{Supplementary Cementitious Materials in HPC}

There have been a number of studies focused on HPC mixtures, and the different SCM used, and its effects on concrete performance.

Gong (2006) during his study on different HPC mixtures observed that HPC with SCM presented lower free shrinkage up to 90 days compared to normal concrete. He also concluded that concrete with slag + silica fume, or fly ash + silica fume significantly reduced the early age free shrinkage. In his work mixtures containing metakaolin showed the best performance in terms of free shrinkage. 
Roy et al. (2001) studied the effects of aggressive chemical environments on mortars made with normal portland cement and SCM like silica fume, metakaolin, and fly ash. In their preliminary results they showed that substitution of silica fume, metakaolin, or fly ash increased the chemical resistance of the mortars compared to those made with only portland cement. The increase in chemical resistance was found in the following order (1) silica fume, (2) metakaolin, and (3) fly ash. The compressive strength increased in the following order: (1)fly ash, (2) silica fume, and (3) metakaolin.

Weiss et al. (1998) studied the influence of w/cm, silica fume replacement on cracking potential and strength and permeability of concrete. They concluded that a decrease in w/cm resulted in a significant increase in compressive strength and a reduction in permeability. Also specimens with lower w/cm cracked at an earlier age and exhibited larger cracks openings. The silica fume replacement exhibited very low permeability attributed to pore refinement and densification of the bond between the aggregate and mortar.

Suksawang et al. (2006) studied the effect of pozzolanic materials (or SCM) on the compressive strength and modulus of elasticity of HPC. They concluded that the addition of silica fume increased the early strength of concrete, and the addition of fly ash reduced the early age compressive strength of HPC. They also suggested that the equation from ACI 318 should not be used for calculating the modulus of elasticity for HPC because they did not find a good correlation with experimental results.

Naik et al. (1994) studied the influence of the addition of a class C fly ash on concrete strength and permeability. The concrete mixtures were proportioned to replace cement with class $\mathrm{C}$ fly ash in the range from $0 \%$ to $70 \%$ by weight of cement. They found that at ages up to 28 days, the mixtures with no fly ash attained lower permeability compared to the highvolume fly ash mixtures. They also reported that, in general, the high-volume fly ash mixtures attained lower strengths compared to the normal concrete mixtures.

Ozyildirim (1994) evaluated the strength and the permeability of various combinations of silica fume and slag in concrete. He found that when silica fume was added in small amounts 
(3\% to $5 \%$ ) to concrete with up to $47 \%$ slag replacement, and a $/ \mathrm{cm}$ from 0.40 to 0.45 , economical concretes with very low permeability (353 coulombs at 28 days) and adequate strength (55.6 MPa or $8050 \mathrm{psi}$ ) could be produced.

Cabrera et al. (1997) made a laboratory study on the strength and chloride permeability resistance of fly ash modified and normal cement concretes and mortars. In their study, the concrete was exposed to salt water in order to record diffusion measurement data under two different simulated exposure conditions: (1) an intermittent splashing and (2) capillaryosmosis absorption. They concluded that the unique advantage of fly ash was an enhancement in the concrete workability, and that concrete with $33 \%$ replacement of cement by fly ash gave the same compressive strength as normal concrete at 28 days.

In order to monitor the continuous behavior of concretes containing SCM in a chloride exposure regime, Basheer et al. (2002) studied different concrete mixtures subjected to a cyclic ponding regime with sodium chloride, and then they monitored the change in resistance at different depths. They used normal concrete and concrete mixed with cement and SCM such as slag, silica fume, metakaolin, and fly ash. They concluded that the concrete with the SCM presented a lower chloride penetration, highlighting the superior performance of mixtures with slag + metakaolin.

Li and Ding (2002) studied the physical and mechanical properties of portland cement containing metakaolin or combination of metakaolin and slag including the compatibility between such materials and superplasticizers (or HRWRA). They concluded that the initial and final setting times of cement incorporating $10 \%$ metakaolin were lower than those of portland cement. After studying the effects of incorporation of metakaolin and slag to cement, they concluded that the not only the fluidity of concrete was improved, but also the 28-day compressive strength was enhanced.

Fan (2005) tested HPC developed and fabricated at laboratory scale. In his work, based on his testing samples for freezing and thawing in deicing solutions, he concluded that concrete made with metakaolin presented superior performance in resisting freezing and thawing in 
deicing solutions. The slag + silica fume mixtures exhibited better performance to freezing and thawing than the mixtures containing fly ash + silica fume.

\subsubsection{West Virginia Division of Highways Class H Concrete Specifications}

The WVDOH developed their own specification (601.10.1.2) for Class H concrete used in bridge decks. There are no specifications for HPC in the state of West Virginia, although the Class $\mathrm{H}$ closely resembles HPC mixtures. Class $\mathrm{H}$ concrete specifications are limited in scopes of using different materials as SCM, their percentages, and w/cm. Also it is primarily a prescriptive specification, not performance-based. For Class $\mathrm{H}$ concrete there is no requirements for shrinkage and cracking and also the chloride permeability, strength, slump and other performance requirements need major revisions.

The Class $\mathrm{H}$ concrete specifications are summarized below:

\subsubsection{Materials}

The free moisture content of each aggregate type, at the time of batching, shall not exceed $7 \%$ of the saturated-surface dry weight of the fine or coarse aggregate, or $8 \%$ total for both aggregates. The sources of coarse aggregates shall be approved by WVDOH. The total concrete constituents shall contribute less than $0.10 \%$ water soluble chloride ion by weight of cement.

\subsubsection{Proportioning}

Class $\mathrm{H}$ concrete shall consist of a homogeneous mixture, of cement, fine aggregate, coarse aggregate, silica fume, fly ash or slag, chemical admixtures, and water.

The testing for concrete shall include air content, slump, compressive strength results at 28 days, rapid chloride permeability test (RCPT), and dry shrinkage test. RCPT shall be made on representative samples cured for 28 days in accordance with ASTM C 31, then prepared and tested at an age of 35 to 42 days. The results of this test shall not exceed 750 coulombs as recommended by the WVDOH for Class H Concrete. The 28-day compressive strength of the 
mixture that satisfies the 750 coulomb thresholds shall be used as the basis for acceptance of concrete. For HPC, based on the lab-scale study and preliminary specifications, the recent proposed recommendation was that the RCPT shall not exceed 1000 coulombs at 56 days. Table 2-1 summarizes the WVDOH specifications for Class H concrete.

Table 2-1 WVDOH Specifications for Class H Concrete

\begin{tabular}{l|c}
\hline Specification Item & Values \\
\hline Class of Concrete & $\mathrm{H}$ \\
\hline Max w/cm & 0.4 \\
\hline Entrained air (\%) & $6.5 \pm 0.5$ \\
\hline Max Slump (cm or in) & $18(7)$ \\
\hline RCPT (Coulombs) & $<750$ \\
\hline 28days Compressive Strength (MPa - psi) & $>28(4000)$ \\
\hline
\end{tabular}

\subsection{Overview of Advanced Concrete Materials Development for Bridge Decks in WV}

The potential deterioration of concrete bridge decks is directly related to the durability characteristics of the concrete exposed to environmental and chemical effects in addition to traffic loads. HPC offers favorable durability characteristics in addition to enhanced structural performance, due to high strength and low permeability (Goodspeed et al., 1996).

A large scale project is being undertaken by the West Virginia University researchers and the WVDOH. In this project a total of 24 different concrete mixtures were developed using two types of aggregates (limestone and gravel) and different combinations of slag, fly ash, silica fume, metakaolin, and chemical admixtures. Three different $\mathrm{w} / \mathrm{cm}(0.40,0.35$, and 0.30$)$ were studied for different combinations of SCM. Figure 1-2 presents the flow chart of the mixtures studied.

The WVU researchers performed tests on fresh concretes such as slump and air content, hardened concretes such as compressive strength at different ages, modulus of elasticity, free shrinkage, restrained shrinkage, direct tensile strength, RCPT, chloride diffusion, freezing and thawing in deicing salts, and scaling resistance. 
Some of the significant conclusions from this research were that the charge passed through concrete decreased with the maturity or ageing of HPC, but the rate of change depended on the type of SCM and heating of the permeability cell. From the freezing and thawing testing, the conclusions were that the percentage loss in dynamic modulus of elasticity and mass loss were lowest for metakaolin HPC, compared to other HPC (Davalos et al., 2007).

From the same HPC employed on decks and using West Virginia local aggregates, Ray et al. (2005) evaluated the mechanical properties of the HPC mixtures and found that metakaolin HPC achieved the highest strength, particularly at ages up to 28 days, followed by slag + silica fume HPC, fly ash+ silica fume HPC, and fly ash + slag + silica fume HPC. They also concluded that limestone performed better than gravels in terms of both strength and modulus of elasticity.

\subsection{Rapid Chloride Permeability Test (RCPT) on HPC}

Lane (2005) proposed modifications to improve the consistency of the RCPT test results by using conductivity values obtained from the first 10 minutes of testing. By considering the results for first 10 minutes, the heating problems associated with 6 hours standard test can be eliminated. The heating particularly affects the smaller size specimens, which yields in greater charge passed. Hence, it was suggested that the initial current measurement is more useful to estimate the specimen conductivity. Lane proposed a modification by using the 10 minutes charge multiplied by 36 .

There are some concerns regarding the RCPT test as mentioned in their research by Uchoa et al. (2007). The major concerns are: (1) It measures not only the chloride ions movement but other ions movement including hydroxide, which has greater mobility than chloride ions; (2) High heat is generated due to high voltage applied across the specimens. This leads to higher values for RCPT tests; (3) The mineral admixtures such as silica fume, fly ash, and slag have significant effects on pore solutions that influences the electrical conductivity subsequently affecting the RCPT results. Their study also showed how the early early-stage current can be used to define the chloride permeability for concrete mixed with different admixtures. 


\subsection{Maturity Method on HPC}

This method was first carried out in England by McIntosh (1949), Nurse (1949), and Saul (1951). It is a technique to account for the combined effects of the time and temperature on the strength development of concrete. The hydration of cement is function of the time and the temperature of the hydration; consequently the gain of strength is also controlled by these two parameters. In consequence, the concept of maturity of concrete appears as a function of the product of the curing time and the concrete curing temperature. Proper application of this relatively simple procedure can result in savings by allowing construction operations to be performed safely at the earliest possible time (Carino and Lew, 2001).

Determination of the in-situ strength of concrete is an important step in the quality assurance of an industrial construction project. Usually, cylinder or beam specimens, cast from the same batch of concrete as those used in the construction project, are tested for in-place strength. The maturity method is an alternative to non-destructive evaluation of in-place concrete (Goodrum and Dai, 2004).

\subsubsection{Case Study}

The Dallas High Five was a \$261 million project from the Texas department of Transportation to build a five-level interchange. The existing interchange had a traffic count of 500,000 vehicles per day, making it one of the busiest interchange in the USA. There was an $\$ 11$ million bonus if the project is completed in four years or less what made the TxDOT to specify the use of the concrete maturity method on this project. Since there are many steps in the traditional cylinder testing process that introduce potential errors in cylinder compressive strengths. One of the most important advantages of using maturity method in this project was on the use of pre-cast structural segmental work with maturity logger to detect the maturity as concluded by Director of Construction. By changing to pre-cast segments using maturity, it was possible to indicate that the specified $17 \mathrm{MPa}(2500 \mathrm{psi})$ strength is achieved in 10-12 hours which avoided the mishandling of concrete cylinder leading to wrong conclusions. On this way the project was able to be ahead of schedule getting the bonus offered (http://www.engius.com/). 
The City of Wichita, Kansas, had a paving urban job with a specification of 4 MPa (580 psi) flexural strength within seven days before the pavement is reopened. Overall, the project required $6,116 \mathrm{~m}^{3}\left(8,000 \mathrm{yd}^{3}\right)$ of concrete. The City of Wichita has its own testing lab, so they developed a maturity calibration curve with the same mixtures that were going to be used in the project. Maturity sensors were placed at a depth of $100 \mathrm{~mm}$ (4 in). The data provided by the loggers revealed that strength was being achieved within two to three days, even in cooler weather, which was very fast compared to four to seven days that were expected. The contractors from the project concluded that using maturity method revealed the strength of concrete faster than destructive testing methods (http://www.engius.com/).

Hurricane Katrina slammed into the Mississippi and Louisiana Gulf coast on Monday August 29, 2005 resulting in numerous bridges being damaged or destroyed. The I-10 east bound bridge over the Pascagoula River was badly damaged by two runway barges. The project of reconstruction was awarded for a 31-day contract to repair the bridge with a bid of $\$ 5.4$ million. All work was scheduled on a continuous 24 hours rotation. Construction time was a critical factor on this project, and due to the chlorides associated with the salt water environment, concrete durability was a serious concern as well. Therefore it was imperative that in-situ strength be determined accurately and immediately to allow for timely stripping of forms. The on-site project engineers for MDOT, were in agreement that concrete stripping strength can better be determined by utilizing the maturity method. The mixture design specified by the contractor called for a minimum strength of $17 \mathrm{MPa}$ (2500 psi) in twelve hours. By taking reading of maturity from the concrete in the pier caps and obtaining the strength from calibration curves made to the specified concrete, only 7 to 8 hours were required to reach the specified strength (http://www.engius.com/).

With over 80 million passengers and 700,000 tons of cargo passing through each day, Hartsfield-Jackson Atlanta International Airport is the busiest airport in the world. As part of the current 10 year expansion project, Kiewit Southern Co. used the maturity method to execute a rapid replacement of one of the airport's main runways in under 60 days. If conventional methods were used, the time frame for drilling dowels would have been approximately 45-55 hours after completion of each lane of pavement. However, considering 
the heat generated and trapped in the concrete placement itself, the maturity method indicated that the flexural strength requirement for drilling was met in only 13-15 hours, far ahead the 2-3 days needed to achieve strength in the standard-cured beams. This project originally required 7 beams to be tested for flexural strength for every $153 \mathrm{~m}^{3}$ (200 $\left.\mathrm{yd}^{3}\right)$ of concrete (750 sets or 5250 beams). However, based on early trial successes with the maturity method to manage workflow, the number was reduced to one set per $383 \mathrm{~m}^{3}\left(500 \mathrm{yd}^{3}\right)$, thereby reducing the number of beams by $60 \%$ (http://www.engius.com/).

\subsection{Microscopical Determination of the Air-Void system and Petrographic Examination of Hardened Concrete}

\subsubsection{Air-Void System}

The air-void structure of concrete is a critical parameter for the durability of concrete subjected to freezing and thawing, and to the action and deicing salts. An air-void analysis is the only method available on hardened concrete to evaluate the air-void structure of concrete (Elsen, 2001).

Air-entraining admixtures increase the amount of air in the concrete which is incorporated during the time of mixing. It is expressed as a percentage of the concrete volume. Generally speaking 2 to $8 \%$ of entrained air provides very good durable mixtures without affecting the strength much. The actual amount depends on the maximum size of the aggregates as more paste is required to provide workable concrete with a lower maximum size of coarse aggregates.

Image processing analysis is very powerful tools when morphological information is required to understand the behavior of a material. Image analysis applied to materials used in civil engineering can be divided in three main steps: (1) Image acquisition; (2) Extraction of the pertinent characteristics and image segmentation; and (3) Extension of this information functions, and modeling. It is important to pay special attention to the area of the images studied compared to the structure, their position, and the quantity (Coster and Chermant, 2001). 
Aligizaky and Cady (1999) used the section analysis technique to find the air-void parameters of hardened cement pastes, also compared their results with the standardized point count method, and finally they compared the air-void parameters resulting from applying the lineartraverse method using an image analyzer to the results obtained using the optical microscope. They concluded that the results from the air content calculated by the point count method were close to those from the section analysis method with the values from section analysis method being lower. Also it was shown that the section analysis technique could facilitate airvoid determination because a smaller area could be tested.

Jana (2007) compared different techniques to obtain the air-void parameters of hardened concretes. Some of the techniques compared were the Rapid Air 457, the Flat Bed Scanner, the HF-MAC01 method, the Automatic Concrete Evaluation Method and the Image Analysis Method. He concluded that all methods show good consistency in the results, and that these methods are excellent alternatives to ASTM C 457 for the evaluation of concrete durability.

Chan, et al. (1999) tested the residual compressive strength of HPC after exposure to high temperatures $\left(800^{\circ} \mathrm{C}\right)$. They also measured the variations of the pore structure, including porosity and pore size distribution. They concluded that the residual compressive strength was higher for HPC compared to normal concrete although the rate of strength reduction of HPC was higher than normal concrete after exposure to high temperatures. A model was developed to predict the relationship between porosity and strength of HPC.

A comparative study of the automated method (Image analysis) versus the traditional manual methods (point-count method and linear-transverse method of ASTM C 457) has been published by Ohta (1986), who found a reduction of measurement time of 73-88\% and a reduction of the coefficient of variance of the measurement of $75 \%$ using automated methods.

Elsen (2001) presented the results of a European round robin test of air void analysis on hardened concrete. Out of thirteen laboratories involved in the research, seven used a manual method and six an automated measured system. The specimens tested were of $100 \times 100 \times 20$ $\mathrm{mm}(3.9 \times 3.9 \times 0.8 \mathrm{in})$. They concluded that the automated methods were very fast but could 
be problematic when high amount of porous sand grains were present in the concrete. They also found that using this technique it was not possible to measure the paste content of the sample.

Jakobsen et al, (2006) described the methods and techniques required for automatic air-void analysis using the RapidAir System as well as a data from a round robin study. The RapidAir is an automatic system for analyzing the air void content of hardened concrete. This analysis required polishing of the concrete area of study as well as a contrast enhancement of the surface. This system could analyze the air-void system according to the ASTM C 457 in only 15 minutes or less, by studying a transverse length of $2413 \mathrm{~mm}$ (95 in.). After the testing and the round robin test, the results presented a very good reproducibility and repeatability of the automated system compared with the manual methods described by ASTM C 457.

\subsubsection{Factors affecting the Entrained Air}

The entrained air can be affected by different factors present under field conditions. The materials used in the mixtures can affect the quantity of air that could be entrained. Coarser aggregates allowed a higher entrainment of air to the mixture than fine aggregates. The w/cm plays an important role too because concretes with low w/cm entrain less air than concretes with a high ratios. However, it does not mean that the spacing factor shall change; as due to difference in materials the void sizes gets also modified.

The air is entrained while the concrete is being mixed. That is why the air entrained depends on the mixing type, the rate of mixing, the amount of concrete being mixed, and the time while it is mixed. The air content initially increases with time and then gradually decreases.

Slump and temperature are parameters that can affect the air content of a concrete mixture. Higher initial slump results in higher air content and higher temperature leads to lower air content. Also, vibration and finishing the concrete structure changes the air content of the mixture because coarse bubbles are forced to come out to the concrete surface (Mindess et al. 2003). 


\subsubsection{Petrographic Examination}

A complete petrographic examination is able to determine the type and composition of the aggregates, the nature of the cement paste, and the type of cement. It allows determining the proportions of the coarse and fine aggregates, the cement paste, and the entrapped and entrained air (St John et al., 1998).

A petrographic examination can also determine the disposition and size of calcium hydroxide crystals in the cement paste providing information about the original $\mathrm{w} / \mathrm{cm}$, if the concrete has been placed and cured under normal temperatures. The size, state, and type of remnant clinker particles can provide information about cement type and age. The extent of carbonation can readily be observed and the development of secondary sulfate minerals can indicate sulfate attack.

A petrographic examination can provide the following information (St John et al., 1998):

General information

- Volume proportions of coarse aggregate, fine aggregate, cement paste, and air voids.

- Aggregate grading and shape - whether natural gravel or crush rocks.

- Presence or absence of artificial aggregates and cement replacements. The type, size, shape, and volume proportions of such particulate additions.

- Nature, type, and proportions of air voids.

\section{$\underline{\text { Specific information }}$}

- Rock and mineral types present in coarse and fine aggregates and their relative proportions.

- The grade of weathering of the aggregate particles; whether they are cracked or have interacted with the surrounding paste or have been degraded at the same time as concrete.

- The nature, sizes and state of remaining clinker grains in the cement, features of the cement hydrate gels and the nature, size and disposition of calcium hydroxide crystals in the paste.

- The nature and extent of any carbonation of the cement paste. 
Zhang and Zhang (2005) presented results on the determination of w/cm and cement content of hardened concrete by petrographic and chemical methods for concrete used in tropical environment. They concluded that although the methods are primarily suitable for North America and Europe, the techniques can also be used in tropical countries with good accuracy.

\subsubsection{Determination of Chemical Admixtures}

The chemical admixtures cannot directly be detected by a petrography examination, although in some cases the effects of using an admixture can be observed like the effect of using air entraining admixture. Chemical analyses are required to detect and quantify the presence of chemical admixtures in the concrete.

\subsubsection{Determination of SCM Content and w/cm}

To determine the content of SCM and the $\mathrm{w} / \mathrm{cm}$ is not an easy process because the size and the color of the SCM can vary depending on the source and the grade of hydration when mixed in the concrete. The w/cm determination is function of the curing temperatures of the concrete so it not a easy procedure, since petrography examinations are usually made on old concrete structures with unknown history.

\section{Determination of Fly Ash:}

Particles of fly ash are of about $1 \mu \mathrm{m}$ to $150 \mu \mathrm{m}$, with more than the $50 \%$ of the particles in between 20-30 $\mu \mathrm{m}$, making only the larger un-reacted particles observable by an optical microscope. These fly ash particles are observed as spherical and clear translucent particles. Particle color is very diverse, ranging from colorless to black and frequently being variously yellow, brown, red or grey (St John et al. 1998).

\section{Determination of Slag:}

It is common for slag to form up to the $50 \%$ or more of the binder, so that the recognition of its presence is easy. Concretes made with slag exhibits distinctive dark greenish- blue matrix 
coloration, although exposure to the atmosphere results in the oxidation of the reaction turning the green products to an earth tone or brown-beige.

\section{Determination of Silica Fume:}

Silica fume is an ultra fine powder, with individual particle size from 50 to 100 times finer than cement or fly ash. It comprises of solid spherical glassy particles of amorphous silica. Detecting silica fume in concrete is complicated due to its usually small proportion and its extreme fineness, with almost all of the particles smaller than $25 \mu \mathrm{m}$ to $30 \mu \mathrm{m}$. Also silica fume rapidly consumed in the initial hydration reaction. After a month, it is practically undetectable even using scanning electron microscope.

\section{Determination of Metakaolin:}

In concrete, the use of metakaolin as a cementitious material is usually below $15 \%$. The identification of metakaolin may be difficult unless some unique characteristic is present. Due to the small size of the particles (average particle size of $1.5 \mu \mathrm{m}$ ), it is practically impossible to determine using an optical microscope.

The hydration processes and resultant hydrates from the various cementitious materials are greatly affected by curing, temperature, water content and age. Therefore, no quantitative techniques available such as counting residual cement, fly ash or slag particles are accurate. The degree of hydration can vary greatly between concrete samples under different conditions. Therefore, it is usual practice to use number of qualitative measures and observations to give an estimation of the $w / \mathrm{cm}$ and cementitious materials contents by comparing these observations with observations of concretes with known compositions (Figg, 1989).

\section{Determination of the $\mathrm{w} / \mathrm{cm}$ :}

The procedure followed to determine the w/cm is as follows (Erlin and Bernard, 2000):

- Paste content determination from the air content analysis taking into account any variation in air content to verify that the total volume of water and cementitious materials is close to what was theoretically specified in the mixture design. This will 
confirm that the staring volume of paste is correct and that no excess water or cementitious materials were used.

- Examination of the texture and color of fresh fractured surfaces and comparison to textures of other samples with known water cementitious materials ratios.

- Estimation of the hardness of the paste by making indentations with a needle probe and scratching the surface of the paste.

- Comparison of the percent of residual portland cement particles estimated to be present in a field of view of the thin section to the number of residual particles from thin sections of other similar concretes.

- Examination of the morphology of the calcium hydroxide in the paste both in the thin section and powder mounts.

- Estimation of the $\mathrm{w} / \mathrm{cm}$ of the paste by comparison of all of the above features with concretes examined before.

The review of literature reveals that HPC being an engineered product made with local materials meeting specific performance criteria. Although many studies have been done on various properties of HPC, it is necessary to evaluate and compare the significant properties of HPC to be produced in this project. The difference of materials, construction practice, curing, and environmental conditions are important parameters those will control the final product. The relationships among maturity, strength, permeability, air-void parameters and concrete quality of field-cored, field-mixed match-cured, field-mixed lab-cured, and labproduced concrete shall provide clear guidelines and prediction for future HPC behavior of similar mixtures in local conditions. 


\section{CHAPTER 3}

\section{MATERIALS, MIXTURES PROPORTIONS, AND CONCRETE MAKING}

This chapter describes the materials, mixture proportions, and construction of three test slabs at plant.

\subsection{Materials}

The materials used in this study were selected in consultation with the Advisory Panel members, and the subsequent discussions with local concrete, aggregates, and materials suppliers. The representative aggregates were selected based on the approved list provided by WVDOH, and considering the fact that the materials should be available continuously.

\subsubsection{Cement}

For this study, commercially available Type I portland cement conforming the ASTM C 150 (Standard Specification for Portland Cement) was used. The basic physical properties and compound composition of cement are presented in Table 3-1 and Table 3-2 respectively.

Table 3-1 Basic physical properties of type I portland cement used

\begin{tabular}{c|c|c|c}
\hline \multirow{2}{*}{ Specific Gravity } & \multirow{2}{*}{ Fineness } & \multicolumn{2}{|c}{ Setting time } \\
\cline { 3 - 4 } & & Initial (min.) & Final (min.) \\
\hline 3.15 & $320 \mathrm{~m}^{2} / \mathrm{kg}(1561 \mathrm{ft} / \mathrm{lb})$ & 90 & 260 \\
\hline
\end{tabular}


Table 3-2 Compound composition of Type I portland cement Used

\begin{tabular}{c|c}
\hline Compounds & Percentage by mass \\
\hline Tricalcium Silicate $\left(\mathrm{C}_{3} \mathrm{~S}\right)$ & 49.0 \\
\hline Dicalcium Silicate $\left(\mathrm{C}_{2} \mathrm{~S}\right)$ & 25.0 \\
\hline Tricalcium Aluminate $\left(\mathrm{C}_{3} \mathrm{~F}\right)$ & 12.0 \\
\hline Tetracalcium Aluminoferrite $\left(\mathrm{C}_{4} \mathrm{AF}\right)$ & 8.0 \\
\hline Calcium Sulfate $\left(\mathrm{CSH}_{2}\right)$ & 2.2 \\
\hline Calcium Oxide $(\mathrm{CaO})$ & 0.8 \\
\hline Magnesium Oxide $(\mathrm{MgO})$ & 2.0 \\
\hline Others & 1.0 \\
\hline
\end{tabular}

\subsubsection{Coarse Aggregates}

One type of \#57 graded coarse aggregates provided by Greer Aggregate was used in this study. The aggregates conformed to ASTM C 33 (Standard Specification for Concrete Aggregates). The basic properties are presented in Table 3-3. Table 3-4 shows the sieve analysis for the coarse aggregates used.

Table 3-3 Properties of coarse aggregates

\begin{tabular}{c|c}
\hline Properties & Value \\
\hline Absorption (\%) & 0.53 \\
\hline SSD Specific Gravity & 2.69 \\
\hline Bulk Specific Gravity & 2.68 \\
\hline Apparent Specific Gravity & 2.72 \\
\hline
\end{tabular}


Table 3-4 Sieve analysis for coarse aggregates \# 57

\begin{tabular}{|c|c|c|c|c|c|}
\hline Siev & Size & $\begin{array}{c}\text { Wt. } \\
\text { retained }\end{array}$ & $\begin{array}{l}\text { Amount } \\
\text { Retained }\end{array}$ & $\begin{array}{c}\text { Cumulative } \\
\text { amount } \\
\text { retained }\end{array}$ & $\begin{array}{c}\text { Cumulative } \\
\text { amount } \\
\text { Passing }\end{array}$ \\
\hline & & (gm.) & $(\%)$ & $(\%)$ & $(\%)$ \\
\hline $25 \mathrm{~mm}$ & $1 "$ & 36.30 & 0.88 & 0.88 & 99.12 \\
\hline $19 \mathrm{~mm}$ & $3 / 4 "$ & 626.50 & 15.20 & 16.09 & 83.91 \\
\hline $12.5 \mathrm{~mm}$ & $1 / 2 "$ & 1778.40 & 43.16 & 59.25 & 40.75 \\
\hline $9.5 \mathrm{~mm}$ & $3 / 8 "$ & 1052.90 & 25.55 & 84.80 & 15.20 \\
\hline $4.75 \mathrm{~mm}$ & No. 4 & 587.20 & 14.25 & 99.05 & 0.95 \\
\hline $2.36 \mathrm{~mm}$ & No. 8 & 13.20 & 0.32 & 99.37 & 0.63 \\
\hline $1.18 \mathrm{~mm}$ & No. 16 & 1.70 & 0.04 & 99.41 & 0.59 \\
\hline
\end{tabular}

$\left(1 \mathrm{~mm}=0.039\right.$ in., $\left.1 \mathrm{gm}=2.205 \times 10^{-3} \mathrm{lb}\right)$

\subsubsection{Fine Aggregates}

In this study, one type of fine aggregate conforming to ASTM C 33 (Standard Specification for Concrete Aggregates) was used. The fine aggregates used were natural sand provided by Shelly Materials Co. The basic properties are provided in Table 3-5 and sieve analysis results are presented in Table 3-6.

Table 3-5 Properties of fine aggregates

Source and Basic Properties

\begin{tabular}{c|c}
\hline Facility Source & Arrow Concrete \\
\hline Type & Natural river sand \\
\hline SSD Specific Gravity & 2.61 \\
\hline Bulk Specific Gravity & 2.59 \\
\hline Apparent Specific Gravity & 2.65 \\
\hline Absorption & $1.0 \%$ \\
\hline
\end{tabular}


Table 3-6 Sieve analysis for natural river sand

\begin{tabular}{|c|c|c|c|c|c|}
\hline Siev & Size & $\begin{array}{c}\text { Wt. } \\
\text { retained }\end{array}$ & $\begin{array}{l}\text { Amount } \\
\text { Retained }\end{array}$ & $\begin{array}{c}\text { Cumulative } \\
\text { amount } \\
\text { retained }\end{array}$ & $\begin{array}{c}\text { Cumulative } \\
\text { amount } \\
\text { Passing }\end{array}$ \\
\hline & & (gm.) & (Wt. \%) & $(\%)$ & $(\%)$ \\
\hline $9.5 \mathrm{~mm}$ & $3 / 8 "$ & 0.00 & 0.00 & 0.00 & 100.00 \\
\hline $4.75 \mathrm{~mm}$ & No. 4 & 25.50 & 4.98 & 4.98 & 95.02 \\
\hline $2.36 \mathrm{~mm}$ & No. 8 & 58.30 & 11.39 & 16.37 & 83.63 \\
\hline $1.18 \mathrm{~mm}$ & No. 16 & 55.10 & 10.76 & 27.13 & 72.87 \\
\hline $600 \mu \mathrm{m}$ & No. 30 & 90.80 & 17.74 & 44.87 & 55.13 \\
\hline $300 \mu \mathrm{m}$ & No. 50 & 217.30 & 42.45 & 87.32 & 12.68 \\
\hline $75 \mu \mathrm{m}$ & & 60.30 & 11.78 & 99.10 & 0.90 \\
\hline
\end{tabular}

\subsubsection{Mineral Admixtures}

In this study four types of SCM were used. These are as follows:

\subsubsection{Slag}

Slag is defined as a finely ground glassy granular material made from iron blast-furnace slag when it is rapidly cooled. In this study grade 100 slag conforming to ASTM C 989 (Standard Specification for G.G.B.F Slag for Use in Concrete and Mortars) was used. The basic properties of the slag provided by Essroc Cement Co. are presented in Table 3-7.

\subsubsection{Metakaolin}

Metakaolin is a dehydroxylated form of the clay mineral kaolinite. The particle size of metakaolin is smaller than cement particles, but not as fine as silica fume. Considered to have twice the reactivity of most other pozzolans (or SCM), it is a valuable admixture for concrete applications. For this study commercial metakaolin conforming to ASTM C 618 (Standard Specification for Coal Fly Ash and Raw or Calcined Natural Pozzolan for Use as a Mineral 
Admixture in Concrete) was used. The specific gravity of metakaolin was 2.37 and the material was supplied by WW Natural Resources.

Table 3-7 Basic properties of slag

\begin{tabular}{c|c}
\hline Specific Gravity & 2.88 \\
\hline Specific Surface $\left(\mathrm{m}^{2} / \mathrm{kg}\right)$ & 581 \\
\hline $\mathrm{C}_{3} \mathrm{~S}, \%$ & 48 \\
\hline $\mathrm{C}_{2} \mathrm{~S}, \%$ & 19 \\
\hline $\mathrm{C}_{3} \mathrm{~A}, \%$ & 8 \\
\hline $\mathrm{C}_{4} \mathrm{AF}, \%$ & 7.73 \\
\hline $\mathrm{Na}_{2} \mathrm{O}, \%$ & 0.67 \\
\hline $\mathrm{Appearance}^{\circ}$, & White Powder \\
\hline Odor & No Distinct Odor \\
\hline Physical State & Solid (powder) \\
\hline $\mathrm{pH}$ Value (in water) & 10.5 to 12.7 \\
\hline Solubility in water, $\%$ & Slightly (0.1 to 1.0$)$ \\
\hline Melting Point $\left({ }^{\circ} \mathrm{C}\right)$ & $1300-1350$ \\
\hline$\left(1 \mathrm{~m}{ }^{2} / \mathrm{kg}=703.07\right.$ & in $\left.^{2} / \mathrm{lb},{ }^{\circ} \mathrm{F}=5 / 9 *\left({ }^{\circ} \mathrm{C}-32\right)\right)$
\end{tabular}

\subsubsection{Fly Ash}

Fly Ash is one of the residues generated from combustions of coal. It is finer than cement and consists of glassy-spherical particles. The Class F Fly ash from Headwaters / Hatfield Power station was used in this study which conformed to ASTM C 618. The basic properties of fly ash are presented in Table 3-8.

\subsubsection{Silica Fume}

Silica fume is a by-product of the reduction of high-purity quartz with coke in electric arc furnaces in the production of silicon and ferrosilicon alloys. The silica fume used in this project was type SF 100 conforming to ASTM C 1240 (Standard Specification for used of 
Silica Fume for use as a Mineral Admixture in Hydraulic Cement Concrete, Mortar, and Grout). Silica fume was provided by BASF and its basic properties are described in Table 3-8.

Table 3-8 Basic properties of silica fume and fly ash

\begin{tabular}{c|c|c}
\hline Property & Silica Fume & Fly Ash \\
\hline Specific Gravity & 2.18 & 2.47 \\
\hline Specific Surface $\left(\mathrm{m}^{2} / \mathrm{kg}\right)$ & 21400 & 496 \\
\hline Loss of ignition, \% & 1.64 & 3.00 \\
\hline $\mathrm{SiO}_{2}, \%$ & 100 & 49.34 \\
\hline $\mathrm{Al}_{2} \mathrm{O}_{3}, \%$ & - & 22.73 \\
\hline $\mathrm{CaO}, \%$ & - & 3.09 \\
\hline $\mathrm{MgO}, \%$ & - & 1.06 \\
\hline $\mathrm{SO}_{3}, \%$ & 0.156 & 0.97 \\
\hline $\mathrm{Na}_{2} \mathrm{O}, \%$ & 0.57 & 1.15 \\
\hline $\mathrm{K}_{2} \mathrm{O}, \%$ & - & 1.60 \\
\hline $\mathrm{Fe}_{2} \mathrm{O}_{3}, \%$ & - & 16.01 \\
\hline
\end{tabular}

$\left(1 \mathrm{~m}^{2} / \mathrm{kg}=703.07 \mathrm{in}^{2} / \mathrm{lb}\right)$

\subsubsection{Chemical Admixtures}

Chemical admixtures are natural or manufactured chemicals which are added to the concrete before or during mixing, and are used to give special properties to fresh or hardened concrete. For this study four kinds of chemical admixtures were used as follows:

\subsubsection{Water-Reducing Admixture (WRA)}

Water reducers are used to lower the water content in plastic concrete, to increase the strength and to obtain higher slump without adding extra water to the concrete mixture. In this study Commercial Type D 100 XR water-reducing admixture from BASF conforming to ASTM C 494 (Standard Specification for Chemical Admixtures for Concrete) was used. 


\subsubsection{Air-Entraining Admixture (AEA)}

The AEA produces microscopic air bubbles called entrained air. The entrained air makes the mixture more cohesive, but its primary application is to increase the resistance to freezing and thawing. The commercial air-entraining admixture used in this study conformed to ASTM C 260 (Standard Specification for Air-Entraining Admixtures for Concrete) and it was supplied by BASF.

\subsubsection{High-Range Water Reducing Admixture (HRWRA)}

It is a special class of water-reducing admixture also called superplasticizer. It reduces the water content in a given concrete mixture between 12 to $25 \%$, or even higher. The Rheobuild 1000 HRWRA Type A/F conforming to ASTM C 494 was used in this study which was supplied by BASF.

\subsubsection{Type D Retarder}

Retarders are chemicals that delay the initial setting of concrete by an hour or more. They are often used in hot weather to take care of the rapid setting caused by high temperatures and also for transporting the concrete to a place without causing setting of concrete. In this study, Type D retarder was used with the purpose of simulating a cast-in-place bridge deck.

\subsubsection{Mixing Water}

The mixing water used in this study was tap water from the Morgantown city water supply and it was assumed to have a density of $1000 \mathrm{Kg} / \mathrm{m}^{3}\left(62.43 \mathrm{lb} / \mathrm{ft}^{3}\right)$ for mix design purpose.

\subsection{Mixtures Proportions}

Trial mixtures were developed and evaluated at WVU laboratories using the same and similar group of materials. Out of 24 different mixtures on the preliminary phase of this project, 16 mixtures were made with w/cm of 0.40 . In this study, three most successful concrete mixtures were selected for test slabs. Also considerations were given for the availability of 
materials and feasibility of plant to produce these concrete mixtures at large scale with sufficient trials.

Table 3-9 presents the mixture types and SCM used as percentage of total cementitious materials after adjustments and modifications done at the concrete plant for the field project. Table 3-10 presents the mixture types and SCM used as percentage of total cementitious materials used at WVU laboratory on the previous phase of the project.

Table 3-11 presents the mixture proportions of concrete and basic fresh properties. The ready mix plant was in charge of the mixing procedures and the placement, compacting and finishing was done by experienced local contractors.

Table 3-9 Mixture types and percentage of SCM used in field project

\begin{tabular}{|c|c|c|c|c|c|c|c|}
\hline \multirow[b]{2}{*}{ Slab } & \multirow{2}{*}{$\begin{array}{c}\text { Mixture } \\
\text { Types }\end{array}$} & \multicolumn{4}{|c|}{ SCM Used (\% of total cementitious materials) } & \multirow{2}{*}{$\begin{array}{c}\text { Total } \\
\text { SCM } \\
(\%)\end{array}$} & \multirow{2}{*}{$\begin{array}{c}\text { Cemen } \\
(\%)\end{array}$} \\
\hline & & $\begin{array}{l}\text { Slag } \\
\text { (SL) }\end{array}$ & $\begin{array}{l}\text { Fly Ash } \\
\text { (FA) }\end{array}$ & $\begin{array}{c}\text { Silica } \\
\text { Fume (SF) }\end{array}$ & $\begin{array}{l}\text { Metakaolin } \\
\text { (MK) }\end{array}$ & & \\
\hline 1 & $\mathrm{SL}+\mathrm{MK}$ & 27.9 & 0.0 & 0.0 & 9.0 & 36.9 & 63.1 \\
\hline 2 & $\mathrm{FA}+\mathrm{SF}$ & 0.0 & 20.6 & 4.8 & 0.0 & 25.4 & 74.6 \\
\hline 3 & $\mathrm{SL}+\mathrm{SF}$ & 29.2 & 0.0 & 4.7 & 0.0 & 33.9 & 66.1 \\
\hline
\end{tabular}

Table 3-10 Mixture types and percentage of SCM used in WVU laboratory

\begin{tabular}{|c|c|c|c|c|c|c|c|}
\hline \multirow[b]{2}{*}{ Slab } & \multirow{2}{*}{$\begin{array}{l}\text { Mixture } \\
\text { Types }\end{array}$} & \multicolumn{4}{|c|}{ SCM Used (\% of total cementitious materials) } & \multirow{2}{*}{$\begin{array}{c}\text { Total } \\
\text { SCM } \\
(\%)\end{array}$} & \multirow[b]{2}{*}{$\begin{array}{c}\text { Cement } \\
(\%)\end{array}$} \\
\hline & & $\begin{array}{l}\text { Slag } \\
\text { (SL) } \\
\end{array}$ & $\begin{array}{c}\text { Fly Ash } \\
\text { (FA) }\end{array}$ & $\begin{array}{c}\text { Silica } \\
\text { Fume (SF) } \\
\end{array}$ & $\begin{array}{c}\text { Metakaolin } \\
\text { (MK) }\end{array}$ & & \\
\hline 1 & $*_{\mathrm{MK}}$ & 0.0 & 0.0 & 0.0 & 10.0 & 10.0 & 90.0 \\
\hline 2 & $\mathrm{FA}+\mathrm{SF}$ & 0.0 & 20.0 & 5.0 & 0.0 & 25.0 & 75.0 \\
\hline 3 & $\mathrm{SL}+\mathrm{SF}$ & 30.0 & 0.0 & 5.0 & 0.0 & 35.0 & 65.0 \\
\hline
\end{tabular}

* It is to be noted that in previous lab-scale study, the concrete was made with only metakaolin; however in field- scale study, the slab was made with slag + metakaolin. 
Table 3-11 Mixture proportions of concrete and basic fresh properties

\begin{tabular}{|c|c|c|c|c|c|c|}
\hline & \multicolumn{2}{|c|}{ Slab 1} & \multicolumn{2}{|c|}{ Slab 2} & \multicolumn{2}{|c|}{ Slab 3} \\
\hline Ingredients & $\mathrm{Kg}$ & lb & $\mathrm{Kg}$ & lb & $\mathrm{Kg}$ & Ib \\
\hline Portland Cement & 191.87 & 423.00 & 213.19 & 470.00 & 191.87 & 423.00 \\
\hline Slag & 84.82 & 187.00 & 0.00 & 0.00 & 84.82 & 187.00 \\
\hline Type F Fly Ash & 0.00 & 0.00 & 58.97 & 130.00 & 0.00 & 0.00 \\
\hline Silica Fume & 0.00 & 0.00 & 13.61 & 30.00 & 13.61 & 30.00 \\
\hline Metakaolin & 27.22 & 60.00 & 0.00 & 0.00 & 0.00 & 0.00 \\
\hline Total Cementitious & 303.91 & 670.00 & 285.76 & 630.00 & 290.30 & 640.00 \\
\hline \# 57 Limestone & 793.79 & 1750.00 & 793.79 & 1750.00 & 793.79 & 1750.00 \\
\hline Natural Sand & 508.02 & 1120.00 & 530.70 & 1170.00 & 538.41 & 1187.00 \\
\hline Water & 120.20 & 265.00 & 115.67 & 255.00 & 113.40 & 250.00 \\
\hline Type D Retarder (ml). & 594.43 & 20.10 & 558.94 & 18.90 & 567.81 & 19.20 \\
\hline Air Entraining (ml). & 236.59 & 8.00 & 266.16 & 9.00 & 236.59 & 8.00 \\
\hline HRWR (ml). & 1892.71 & 64.00 & 2218.01 & 75.00 & 1892.71 & 64.00 \\
\hline Total & 1725.92 & 3805.00 & 1725.92 & 3805.00 & 1735.90 & 3827.00 \\
\hline Unit Weight $\left(\mathrm{Kg} / \mathrm{m}^{3}\left(\mathrm{lb} / \mathrm{ft}^{3}\right)\right)$ & 2257.43 & 140.93 & 2270.94 & 140.93 & 2284.07 & 141.74 \\
\hline Water / Cementitious & \multicolumn{2}{|c|}{0.40} & \multicolumn{2}{|c|}{0.40} & \multicolumn{2}{|c|}{0.39} \\
\hline Mortar Fraction (\%) & \multicolumn{2}{|c|}{49.60} & \multicolumn{2}{|c|}{49.40} & \multicolumn{2}{|c|}{49.60} \\
\hline Fine / Total Agg. (\%) & \multicolumn{2}{|c|}{39.40} & \multicolumn{2}{|c|}{40.40} & \multicolumn{2}{|c|}{40.90} \\
\hline Slump (mm (in.)) & 180 & 7.00 & 180 & 7.00 & 180 & 7.00 \\
\hline Air Content (\%) & \multicolumn{2}{|c|}{6.50} & \multicolumn{2}{|c|}{6.50} & \multicolumn{2}{|c|}{7.20} \\
\hline
\end{tabular}

\subsection{Mixing, Placing, and Finishing Concrete}

Because of the sensitivity of HPC to the materials used, it is important that there is a minimum variation in uniformity. Cement uniformity is evaluated in accordance with ATM C 917 (Standard Test Method for Evaluation of Cement Strength Uniformity from a Single Source).

The batching and mixing sequence was done by the ready mixed concrete plant (Arrow Concrete Co.) to ensure thorough dispersion and mixing of all components. Although the concrete was mixed at the project site, it was mixed in a truck and the transportation was simulated by waiting for about 30 minutes in between batching and complete discharge of the concrete at the job site. 
In this project mixing, transporting, and handling of concrete was well coordinated with placing and finishing activities. Concrete could not be discharge faster than it could be spread, struck off, consolidated, and bull floated. Concrete was deposited continuously as close as possible to its final position. Figure 3-1 presents the mixing truck and placing of the concrete in the three different slabs. It was decided that the mixture containing the slag + metakaolin to be slab 1 , the mix with fly ash + silica fume to be slab 2 , and the mix with slag + silica fume to be slab 3 .

During the concrete discharge, the consolidation was done using external vibrators in order to destroy internal friction between aggregate particles. Due to high slump (180 $\mathrm{mm}$ or $7 \mathrm{in}$.) and use of retarder, the consolidation of concrete could easily be done. After adequate consolidation, excess concrete was struck off to bring the top surface of the slab to the proper level. A straight edge was moved across the concrete with a sawing motion and advanced forward a short distance with each movement.

The slabs were bull-floated finished to eliminate high and low spots and embed large aggregate particles after strike off. Bull-floating is a finishing practice to smooth fresh concrete surfaces, it is used after concreted has been placed. Figure 3-2 and Figure 3-3 present leveling and finishing of concrete slabs. 


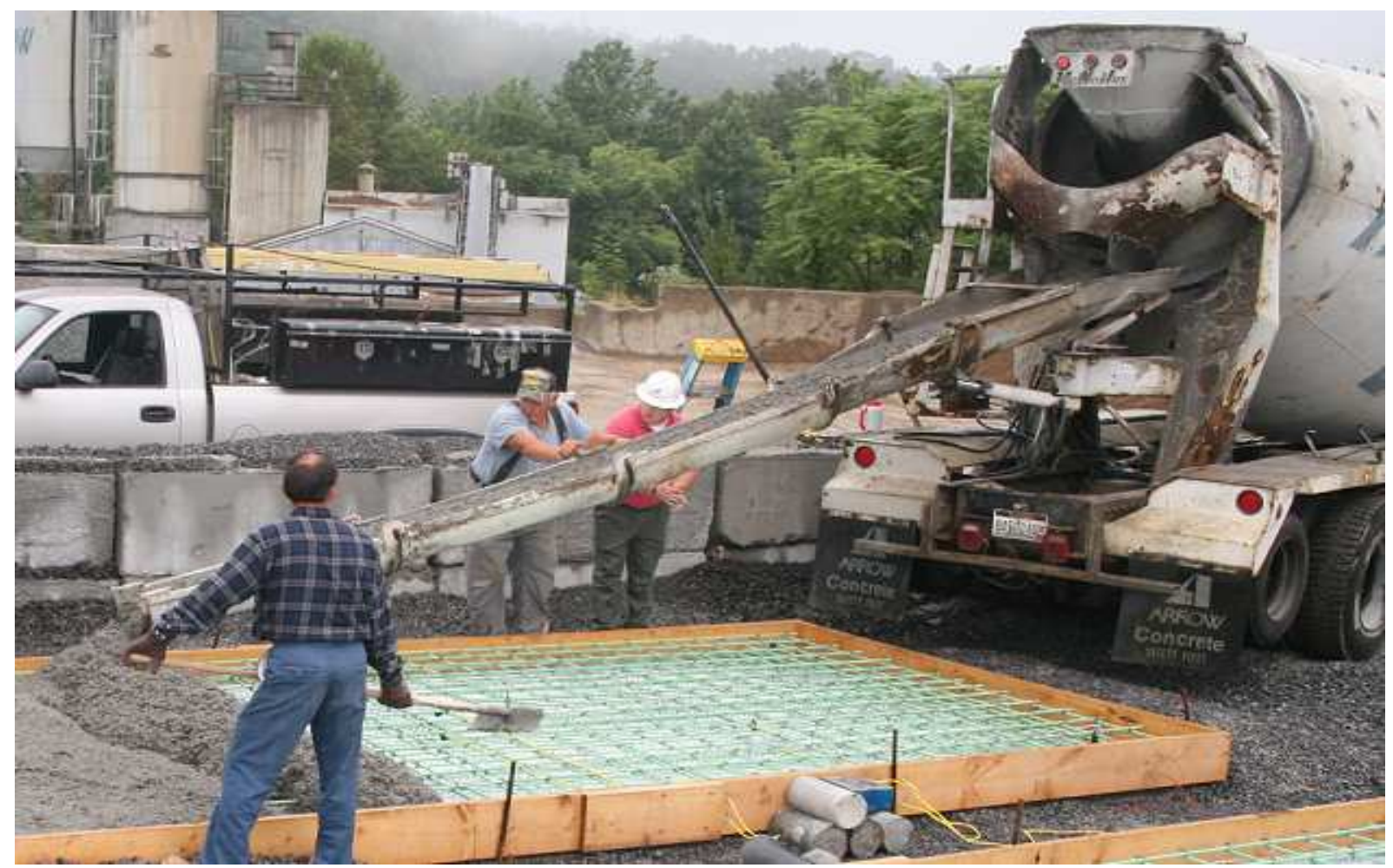

Figure 3-1 Mixing truck, and placing

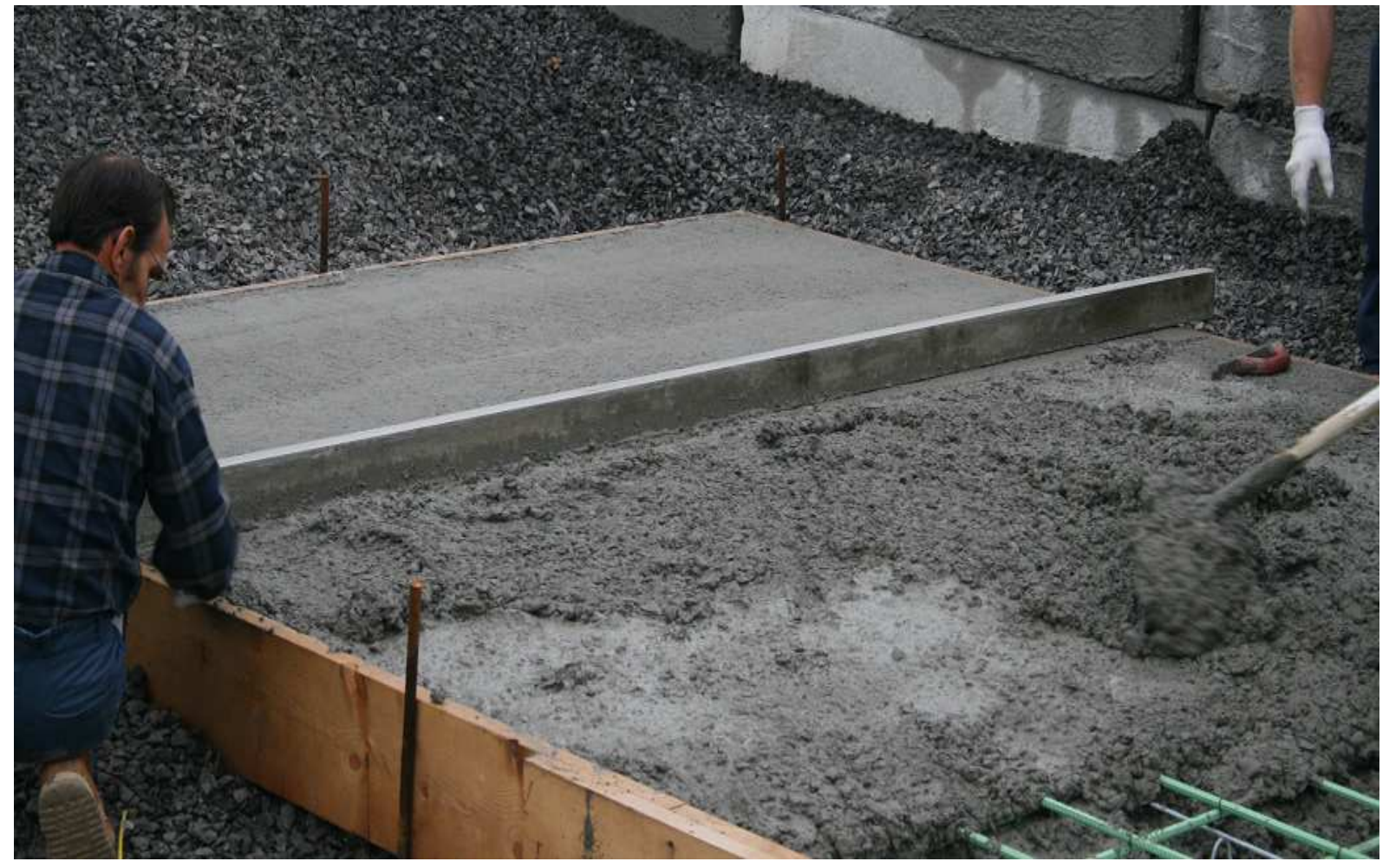

Figure 3-2 Leveling placed concrete 


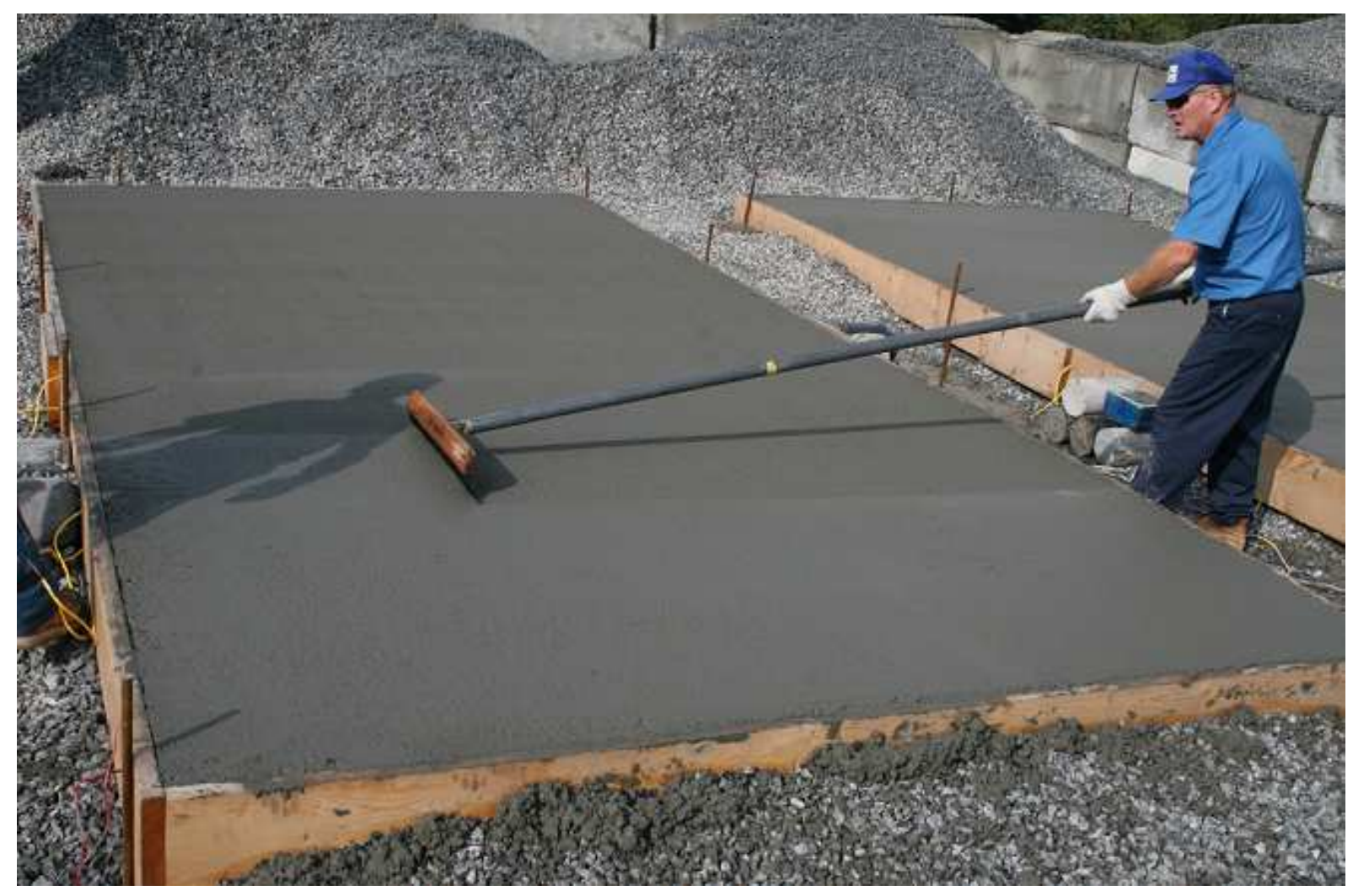

Figure 3-3 Bull-floating

\subsection{Specimens Preparation}

\subsubsection{Casting}

Different types of specimens were cast in order to perform number of tests to the HPC mixtures. All specimens were prepared and cast in place according to relevant ASTM standards. Table 3-12 presents the different type of specimens, their sizes and a short description of how they were prepared. Figure 3-4 presents some of the specimens prepared to be used in different tests. 
Table 3-12 Details of specimen preparation

\begin{tabular}{|c|c|c|}
\hline Specimens & Sizes of Specimens & Casting Description \\
\hline $\begin{array}{c}\text { Compressive } \\
\text { Strength }\end{array}$ & $\begin{array}{c}\text { Cylinder } \\
\mathrm{D}=152.4 \mathrm{~mm}(6 \mathrm{in} .) \\
\mathrm{h}=304.8 \mathrm{~mm}(12 \mathrm{in} .)\end{array}$ & $\begin{array}{l}\text { Fresh concrete was cast in plastic cylindrical } \\
\text { molds in three layers and the finished on the } \\
\text { surface, each layer was compacted by a steel rod }\end{array}$ \\
\hline $\begin{array}{c}\text { Dynamic Modulus of } \\
\text { Elasticity }\end{array}$ & $\begin{array}{c}\text { Cylinder } \\
\mathrm{D}=152.4 \mathrm{~mm}(6 \mathrm{in} .) \\
\mathrm{h}=304.8 \mathrm{~mm}(12 \mathrm{in} .)\end{array}$ & $\begin{array}{l}\text { Fresh concrete was cast in plastic cylindrical } \\
\text { molds in three layers and the finished on the } \\
\text { surface, each layer was compacted by a steel rod }\end{array}$ \\
\hline Free Shrinkage & $\begin{array}{c}\text { Prism } \\
76.2 \times 76.2 \times 285.8 \mathrm{~mm} \\
(3 \times 3 \times 11.25 \mathrm{in} .)\end{array}$ & $\begin{array}{l}\text { Fresh concrete was cast in Metallic prism molds } \\
\text { in two layers and the finished on the surface, } \\
\text { each layer was compacted by a steel rod }\end{array}$ \\
\hline $\begin{array}{c}\text { Freezing and } \\
\text { Thawing }\end{array}$ & $\begin{array}{c}\text { Prism } \\
76.2 \times 101.6 \times 406 \mathrm{~mm} \\
(3 \times 4 \times 16 \text { in. })\end{array}$ & $\begin{array}{l}\text { Fresh concrete was cast in Metallic prism molds } \\
\text { in two layers and the finished on the surface, } \\
\text { each layer was compacted by a steel rod }\end{array}$ \\
\hline RCPT & $\begin{array}{c}\text { Cylinder } \\
\mathrm{D}=101.6 \mathrm{~mm}(4 \mathrm{in} .) \\
\mathrm{h}=203.2 \mathrm{~mm}(8 \mathrm{in} .)\end{array}$ & $\begin{array}{l}\text { Fresh concrete was cast in plastic cylindrical } \\
\text { molds in three layers and the finished on the } \\
\text { surface, each layer was compacted by a steel rod }\end{array}$ \\
\hline
\end{tabular}

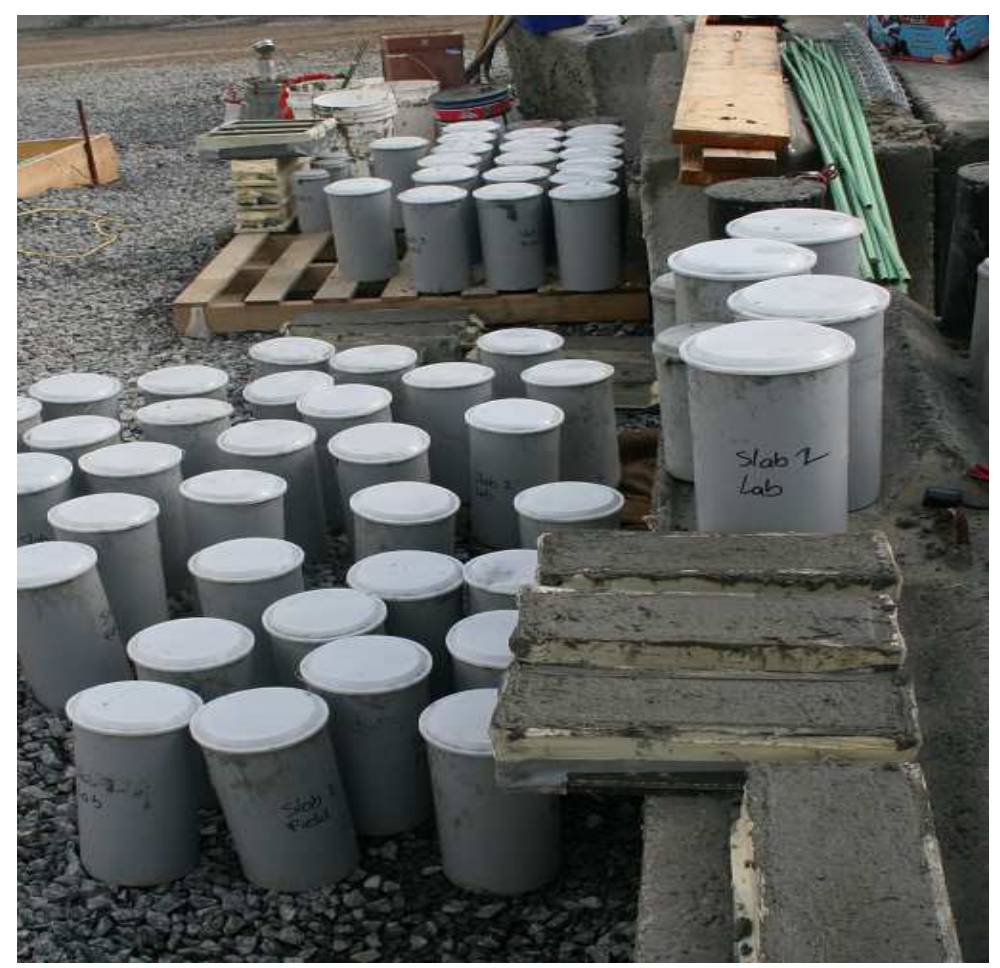

Figure 3-4 Test specimens 


\subsubsection{Curing of Test Slabs and Specimens}

The strength and durability of concrete to a large extent depends on curing. It is important that the concrete surface should be maintained $100 \%$ humid during the entire curing period (up to 10 days) in order to allow the sufficient hydration of cement and control the temperature.

After the initial set and before the final set of concrete, the slabs were covered with watersaturated burlap and protected from loss of moisture by a plastic membrane in order to keep an adequate hydration of the concrete, and also to prevent evaporation. The slabs were kept completely and continuously saturated until 10 days after the pouring following the ASTM C 31 (Standard Practice for Making and Curing Concrete Test Specimens in the Field).

For the specimens prepared with the field mix, two types of curing methods were followed. These are: (1) Match curing in the field and (2) Standard curing in the laboratory. The details are provided below:

\subsubsection{Match Curing (MC) Specimens}

After the initial set and before the final set of concrete, a group of specimens were covered with water saturated burlap and then protected from loss of moisture by a plastic membrane to keep an adequate hydration of the concrete simulating the way the slabs were cured. These specimens were cured along with the slabs in the field for the entire period of study. The specimens under this type of curing are designated as field-mixed match-cured specimens (Field-MC). Figure 3-5 presents the slabs covered with wet burlap and the match specimens next to the concrete slabs in the field. 


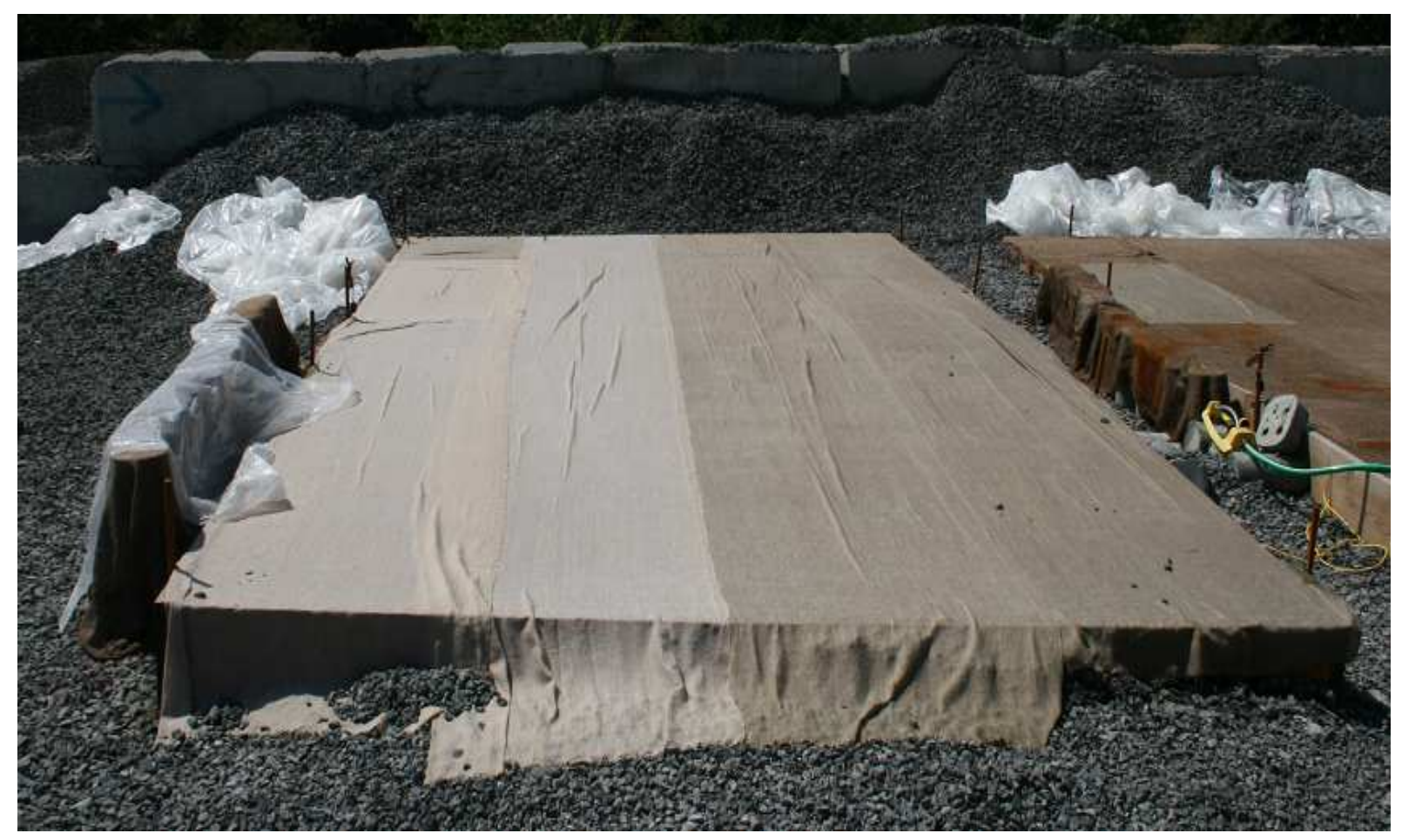

Figure 3-5 Slabs and match-cured specimens

\subsubsection{Standard Curing or laboratory curing (LC) of Specimens}

Similarly, after initial set and before the final set other specimens were cured for 24 hours under wet burlap at ambient temperature in the field and then subsequently were transported in a portable temperature-controlled curing chest to the WVU concrete laboratory. In the lab, the specimens were demolded and immersed in lime saturated water until the day of testing. This curing method followed the ASTM C 192 (Standard Practice for Making and Curing Concrete Test Specimens in the Laboratory). The specimens under this type of curing were designated as field-mixed laboratory-cured specimens (Field-LC). Table 3-13 presents the designations of the specimens followed in this study.

Table 3-13 Specimens type, method of curing and specimens designation

\begin{tabular}{l|c}
\hline \multicolumn{1}{c|}{ Specimens Type } & Specimens Designation \\
\hline Field-mixed Match-Cured & Field-MC \\
\hline Field-mixed Laboratory-Cured & Field-LC \\
\hline Cylinder cored from the Slabs & Field-Core \\
\hline Laboratory mixed Laboratory-Cured & Lab-Mix \\
\hline
\end{tabular}




\section{CHAPTER 4}

\section{FRESH AND HARDENED PROPERTIES OF HPC}

This chapter presents the characterizations of the three different concrete mixtures used for this study. Both fresh and hardened concrete properties were evaluated. Results and analysis are provided in following sections.

\subsection{Plastic Shrinkage}

During the pouring of the slabs, the weather parameters were monitored in order to prevent the plastic shrinkage cracking while the concretes were hardening. The plastic shrinkage occurs on the surface of freshly mixed concrete as soon as it is placed. This cracking occurs when water evaporates from the surface at a rate faster than it can travel to the top surface due to bleeding process, and thus producing shrinkage strain. Due to presence of several restraints within the slabs (from reinforcements, aggregates and longitudinal girders for deck slabs), the tensile stress develops. The concrete at this initial stage does not have enough tensile strength to resist the tensile stress which leads to cracking on the surface of the concrete element. Plastic shrinkage cracks are visible as parallel to each others, sometimes with irregular pattern. This phenomenon is associated with hot-weather concreting, and also with conditions like high air temperature, high concrete temperature, low humidity, and high wind speed.

\subsubsection{Weather-Parameters Monitoring}

The following conditions, singly or collectively, increase evaporation of surface moisture and increase the possibility of plastic shrinkage cracking:

- High air temperature

- High concrete temperature 
- Low humidity

- High wind speed.

In this field project, the above parameters were monitored with a weather station for the first 8 hours after placement of concrete. The intention of this monitoring was to estimate the rate of evaporation of the concrete slabs before they were covered with water saturated burlap and plastic sheets. On Table 4-1, an estimation of the evaporation rate for each slab is shown using an equation from (Uno, 1998).

$$
E=5\left[(T c+18)^{2.5}-\gamma(T a+18)^{2.5}\right] \times(V+4) \times 10^{-6}
$$

Where:

$$
\begin{aligned}
\mathrm{E} & =\text { Evaporation rate, } \mathrm{Kg} / \mathrm{m}^{2} / \text { hour. } \\
\mathrm{Tc} & =\text { Concrete temperature, }{ }^{\circ} \mathrm{C} \\
\mathrm{Ta} & =\text { Air temperature, }{ }^{\circ} \mathrm{C} \\
\gamma & =\text { Relative humidity, } \% / 100 \\
\mathrm{~V} & =\text { Wind velocity, } \mathrm{Km} / \mathrm{hour}
\end{aligned}
$$

Table 4-1 Weather parameters and evaporation rate

\begin{tabular}{c|c|c|c|c|c|c|c|c|c|}
\hline & $\begin{array}{c}\text { Air } \\
\text { Temperature }\end{array}$ & $\begin{array}{c}\text { Relative } \\
\text { Humidity }\end{array}$ & $\begin{array}{c}\text { Wind } \\
\text { Velocity }\end{array}$ & \multicolumn{3}{|c|}{$\begin{array}{c}\text { Concrete } \\
\text { Temperature }\left({ }^{\circ} \mathbf{C}\right)\end{array}$} & \multicolumn{2}{|c|}{$\begin{array}{c}\text { Rate of Evaporation } \\
\left(\mathbf{K g} / \mathbf{m}^{2} / \text { hour) }\right.\end{array}$} \\
\hline Time & oC & $\%$ & mph & $\begin{array}{c}\text { Slab } \\
\mathbf{1}\end{array}$ & $\begin{array}{c}\text { Slab } \\
\mathbf{2}\end{array}$ & $\begin{array}{c}\text { Slab } \\
\mathbf{3}\end{array}$ & $\begin{array}{c}\text { Slab } \\
\mathbf{1}\end{array}$ & $\begin{array}{c}\text { Slab } \\
\mathbf{2}\end{array}$ & $\begin{array}{c}\text { Slab } \\
\mathbf{3}\end{array}$ \\
\hline 7:00 & 20.39 & 100 & 3.48 & - & - & - & - & - & - \\
\hline $8: 00$ & 20.39 & 97 & 3.48 & - & - & 26.86 & - & - & 0.22 \\
\hline 9:00 & 22.50 & 93 & 3.48 & - & 25.50 & 27.00 & - & 0.13 & 0.19 \\
\hline $10: 00$ & 29.78 & 81 & 0.00 & 31.00 & 27.79 & 27.79 & 0.08 & 0.03 & 0.03 \\
\hline $11: 00$ & 31.33 & 76 & 5.78 & 28.21 & 28.50 & 29.79 & 0.10 & 0.12 & 0.19 \\
\hline $12: 00$ & 32.89 & 71 & 3.48 & 28.64 & 29.07 & 33.00 & 0.08 & 0.10 & 0.26 \\
\hline $13: 00$ & 37.00 & 66 & 0.00 & 29.86 & 30.71 & 39.43 & 0.02 & 0.04 & 0.20 \\
\hline $14: 00$ & 40.00 & 62 & 4.60 & 32.79 & 33.29 & 44.86 & 0.14 & 0.17 & 0.88 \\
\hline $15: 00$ & 40.00 & 58 & 0.00 & 38.07 & 38.07 & 47.93 & 0.17 & 0.17 & 0.41 \\
\hline $16: 00$ & 38.00 & 58 & 0.00 & 43.93 & 44.36 & 50.01 & 0.33 & 0.34 & 0.49 \\
\hline $17: 00$ & 45.00 & 58 & 0.00 & 46.93 & 49.29 & 51.71 & 0.31 & 0.38 & 0.45 \\
\hline $18: 00$ & 41.00 & 62 & 0.00 & 48.64 & 51.71 & 52.14 & 0.39 & 0.48 & 0.49 \\
\hline $19: 00$ & 34.00 & 60 & 0.00 & 49.50 & 52.43 & 52.07 & 0.51 & 0.60 & 0.59 \\
\hline $20: 00$ & 25.00 & 66 & 0.00 & 49.64 & 52.14 & 51.36 & 0.59 & 0.66 & 0.64 \\
\hline
\end{tabular}

$\left(1 \mathrm{Kg} / \mathrm{m}^{2} / \mathrm{hour}=0.205 \mathrm{lb} / \mathrm{ft}^{2} / \mathrm{hour},{ }^{\circ} \mathrm{F}=5 / 9^{*}\left({ }^{\circ} \mathrm{C}-32\right)\right)$ 
The evaporation rates calculated did not exceed the threshold values recommended of 0.5 $\mathrm{kg} / \mathrm{m}^{2} /$ hour $\left(0.1 \mathrm{lb} / \mathrm{ft}^{2} /\right.$ hour $)$ per hour for concretes containing SCM during the monitored period. This recommended value is when the surface evaporation and subsequent loss of moisture exceed the rate at which the bleeding water reaches the surfaces, creating negative pressures (PCA; www.cement.org). The evaporation rates threshold values are recommended for concrete structures with no protection. In this project the concrete slabs were protected by covering them with wet burlap and plastic sheets. The slabs were protected against wind, high temperatures and moisture loss.

\subsection{Fresh Concrete Properties}

\subsubsection{Significance of the Test}

Slump and air content are some of the basic fresh properties of concrete, which are essential for evaluation of any concrete. Because of SCM and chemical admixtures these properties are more important for HPC. The specification for WVDOH class $\mathrm{H}$ concrete (WVDOH, 2003) prescribes slump values before and after addition of HRWRA as $102 \mathrm{~mm}$ (4 in.) and $180 \mathrm{~mm}$ (7 in.), respectively. The target entrained air content is specified as $6.5 \pm 1.5 \%$ for HPC.

\subsubsection{Test Standards}

ASTM C192 for making and curing concrete; ASTM C143 for slump; and ASTM C231 for air content by pressure method were followed.

\subsubsection{Results and Discussions}

Due to the addition of SCM and use of low w/cm, the initial slump was $102 \mathrm{~mm}$ (4 in.) before the addition of HRWRA for all three concrete mixtures. However, after the addition of the HRWRA, the slump recommended by the WVDOH was achieved easily $(180 \mathrm{~mm}=7 \mathrm{in}$. slump). The concrete quality was visually cohesive, free from any segregation, and easy to handle and semi-flowing type for all three mixtures. The air content for fresh concrete was of $6.5 \%( \pm 1.5 \%)$ for all the three mixtures. The fresh concrete properties of the concrete placed 
in each slab are presented in Table 3-11. Figure 4-1 presents the apparatus used for evaluating the air content in fresh concrete by the pressure method following ASTM C 231 (Standard Test Method for Air Content of Freshly Mixed Concrete by the Pressure Method).

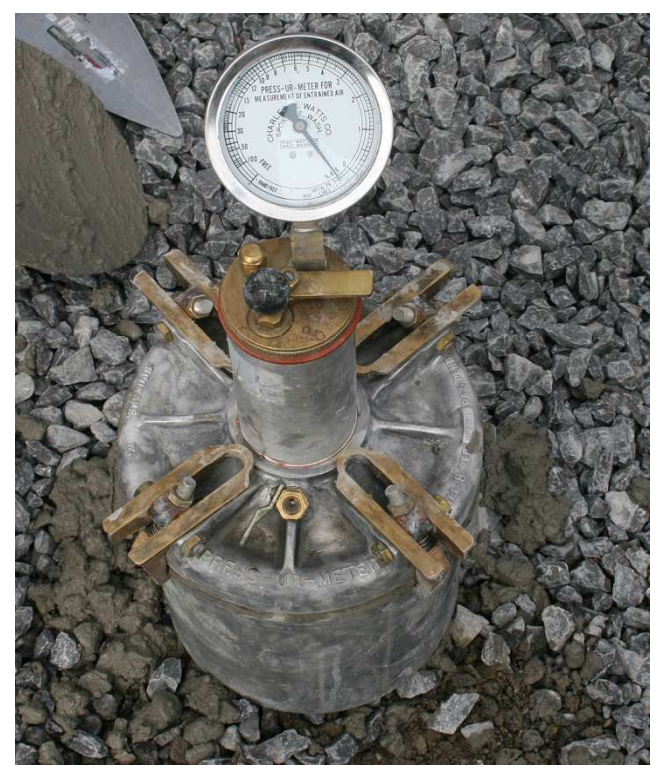

Figure 4-1 Device used for air content test by pressure method

\subsection{Hardened Concrete Properties}

\subsubsection{Compressive Strength}

Compressive strength is the single most important property for the evaluation of concrete mixtures, as all design specifications are based on this parameter.

\subsubsection{Significance of the Test}

Sampling and testing of concrete delivered to a project is important in order to check whether the concrete meets the requirements of the job specification and quality control. For testing the concrete, cylindrical and prisms specimens were cast following the requirements of the ASTM C 31 as mentioned in Chapter 3. For compressive strength, a minimum of 2 to 6 cylinders have been cast for each type of concrete and each age, for every $114.68 \mathrm{~m}^{3}$ (150 $\left.\mathrm{yd}^{2}\right)$ of concrete placed. 
For the specimens cast in field and standard-cured at lab, the resulting strength data is used for acceptance criteria of a specified compressive strength and also for checking adequacy of the mixture proportions and for quality control. However, for the specimens mixed and cured in the field, the data is used for determination of whether the structure is capable of being put in service or not. Also the compressive strength data is used for comparison and acceptance of various in-place methods, for checking adequacy of curing, and to determine the time for formwork removing.

In this project, the compressive strength test was conducted at different ages for match-cured and laboratory-cured specimens, and also for core cylinders drilled from the slabs. Early age strength is a guide for finishing and curing, and later strength is a measure of long-term performance. Values of compressive strength depend on the size and shape of the specimen, batching, mixing procedures, methods of sampling, molding, age, temperature, and moisture conditions during curing.

\subsubsection{Test Standards}

ASTM C 39 for compressive strength of cylindrical concrete specimens, and ASTM C 42 for obtaining and testing drilled cores and sawed beams of concrete were followed in this study.

\subsubsection{Results and Discussions}

The compressive strength development for the concretes placed in slabs 1, 2, and 3 are presented in Table 4-2 (a), (b), (c). Figure 4-3 to Figure 4-6 illustrate a comparison of compressive strength for field-mixed match-cured specimens (Field-MC), field-mixed laboratory-cured specimens (Field-LC), field cores (Field Core) and laboratory mixed and cured samples (Lab-Mix). Figure 4-7 (a), (b) and (c) presents the compressive strength development of each type of specimen tested for the each concrete mixture. From the test results the following observations were made: 
- Slag + silica HPC exhibited the highest compressive strength up to 90 days in all the field specimens tested. This combination of SCM also presented higher early age strength compared to other combinations. This is consistent with the previous research conducted at WVU (Gong, 2006) where a similar concrete was developed and tested in the laboratory, in which he concluded that mixture using slag + silica fume had higher compressive strength compared to the mixture using fly ash + silica fume.

- Field core specimens exhibited the highest compressive strength for 28 and 56 days for all mixtures when compared to the specimens cured in other conditions. The test revealed that when the concrete compressive strength was estimated by laboratorycured and field- cured specimens, it can underestimate the values of real strength of the structural decks. It is important to mention that the compressive strength tested for

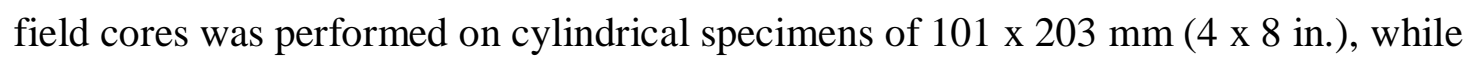
the compressive strength test of Field-MC and Field-LC was performed on 152x300 $\mathrm{mm}(6 \times 12$ in.) cylindrical specimens. The smaller size specimen may be another reason of obtaining higher compressive strength for field core specimens.

- Up to 28 days, the slabs containing slag + metakaolin and fly ash + silica fume exhibited almost the similar compressive strength.

- Among the three mixtures, the lowest compressive strength was shown by the concrete mixture used in slab 1 (slag + metakaolin), though the values are quite high compared to the requirements for HPC by any definition or standard (Table 4-2). The 28 day values for different specimens were between 51.3 MPa (7440 psi) and 59.21 (8585 psi). In a previous study at WVU lab, the concrete mixture using $10 \%$ of metakaolin and $90 \%$ cement, revealed the 28 days compressive strength was 57.10 (8280 psi). The values are comparable. However, at 90 days, the slag +metakaolin mixture used in the test slab had slightly lower strength compared to only-metakaolin mixtures studied by Gong (2006).

- At early ages, the field-mixed laboratory-cured specimens have shown lower compressive strength compared to field-mixed match-cured specimens. But after 28 days, the laboratory-cured specimens exhibited higher strength compared with the ones cured under the field conditions. This was due to the fact that at early age the field temperature was higher than laboratory curing temperature and later it reversed. 
The temperature in turn influenced the maturity and compressive strength accordingly. This phenomenon is explained and presented in more details in chapter 5 where the maturity concept of concrete is introduced.

- The information presented in Figure 4-2 shows that about $60 \%$ of the total compressive strength of HPC is reached during the first 7 days.

- The silica fume replacement caused a higher compressive strength at later ages which can be mainly attributed to the pore refinement and the improvement of the interface bond strength between the aggregate and mortar.

- For 28-day design strength, the WVDOH specifies $28 \mathrm{MPa}$ (4000 psi) for deck concrete which is easily achievable with the use of SCM and low w/cm. The values achieved for HPC in this study and in previous study including all other published data shows that the threshold value of HPC for WVDOH is too low and should be raised.
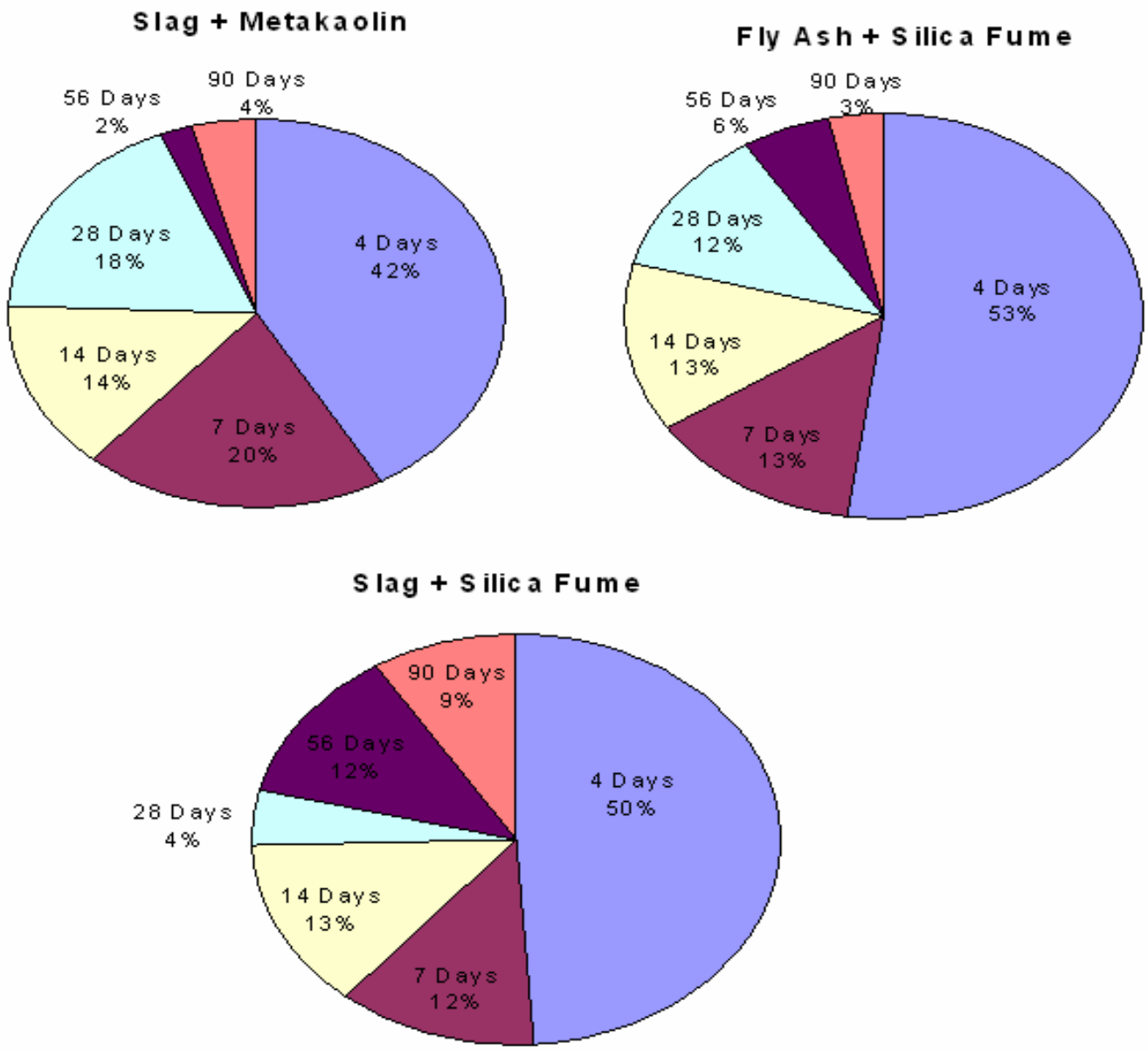

Figure 4-2 Percentage of compressive strength development at every age 
Table 4-2 Compressive strength development (a) Slab 1, (b) Slab 2, (c) Slab 3

\begin{tabular}{c|c|c|c|c}
\hline \multicolumn{5}{|c}{ Slag + Metakaolin } \\
\hline Age & $\begin{array}{c}\text { Field-MC } \\
(\mathbf{M P a})\end{array}$ & $\begin{array}{c}\text { Field-LC } \\
(\mathbf{M P a})\end{array}$ & $\begin{array}{c}\text { Field } \\
\text { Core } \\
(\mathbf{M P a})\end{array}$ & $\begin{array}{c}\text { Lab-Mix* } \\
(\mathbf{M P a})\end{array}$ \\
\hline 4 & 25 & 25 & - & 32 \\
\hline 7 & 38 & 37 & - & 41 \\
\hline 14 & - & 45 & - & 50 \\
\hline 28 & 51 & 56 & 59 & 57 \\
\hline 56 & 51 & 57 & 65 & - \\
\hline 90 & 54 & 59 & - & 67 \\
\hline
\end{tabular}

(a)

\begin{tabular}{c|c|c|c|c}
\hline \multicolumn{5}{c}{ Fly Ash + Silica Fume } \\
\hline Age & $\begin{array}{c}\text { Field-MC } \\
(\mathbf{M P a})\end{array}$ & $\begin{array}{c}\text { Field-LC } \\
(\mathrm{MPa})\end{array}$ & $\begin{array}{c}\text { Field } \\
\text { Core } \\
(\mathrm{MPa})\end{array}$ & $\begin{array}{c}\text { Lab-Mix } \\
(\mathbf{M P a})\end{array}$ \\
\hline 4 & 29 & 31 & - & 27 \\
\hline 7 & 38 & 39 & - & 36 \\
\hline 14 & - & 47 & - & 45 \\
\hline 28 & 52 & 55 & 58 & 52 \\
\hline 56 & 53 & 59 & 65 & - \\
\hline 90 & 56 & 61 & - & 63 \\
\hline
\end{tabular}

(b)

\begin{tabular}{c|c|c|c|c}
\hline \multicolumn{5}{c}{ Slag + Silica Fume } \\
\hline Age & $\begin{array}{c}\text { Field-MC } \\
\text { (MPa) }\end{array}$ & $\begin{array}{c}\text { Field-LC } \\
(\mathbf{M P a})\end{array}$ & $\begin{array}{c}\text { Field } \\
\text { Core } \\
(\mathbf{M P a})\end{array}$ & $\begin{array}{c}\text { Lab-Mix } \\
(\mathbf{M P a})\end{array}$ \\
\hline 4 & 41 & 41 & - & 23 \\
\hline 7 & 51 & 51 & - & 32 \\
\hline 14 & - & 62 & - & 44 \\
\hline 28 & 65 & 66 & 70 & 54 \\
\hline 56 & 66 & 76 & 77 & - \\
\hline 90 & 77 & 83 & - & 66 \\
\hline
\end{tabular}

(c)

$(1 \mathrm{MPa}=145 \mathrm{psi})(*$ Slab 1 Lab-Mix only Metakaolin $)$ 
Field-MC

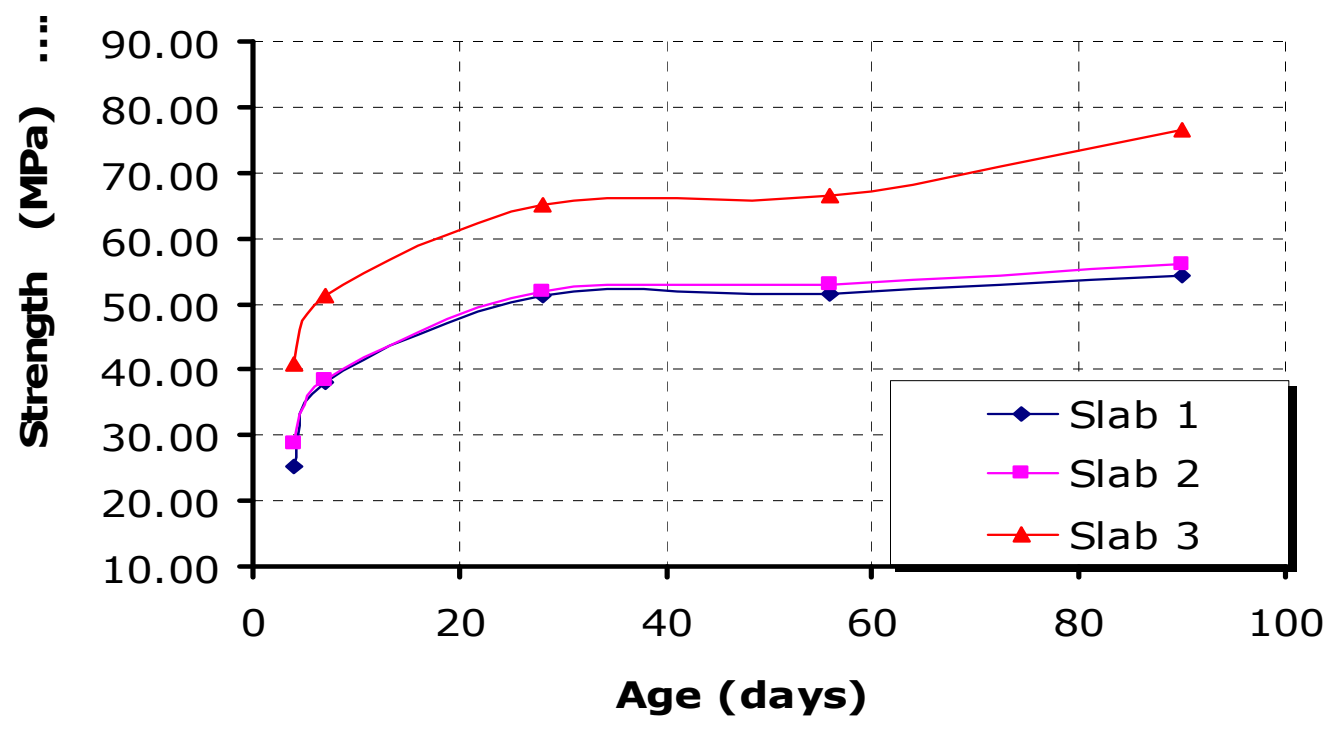

Figure 4-3 Compressive strength comparison for Field-MC specimens up to 90 days

Field-LC

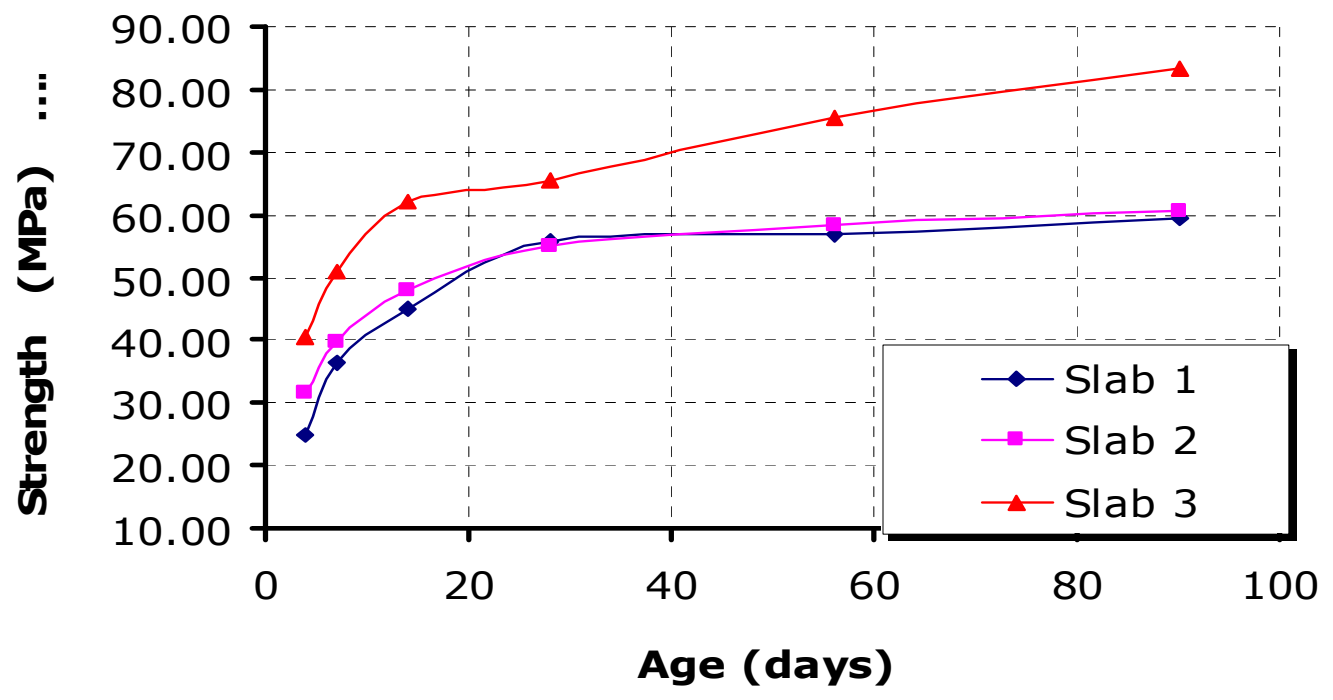

Figure 4-4 Compressive strength comparison for Field-LC specimens up to 90 days 


\section{Field-Core}

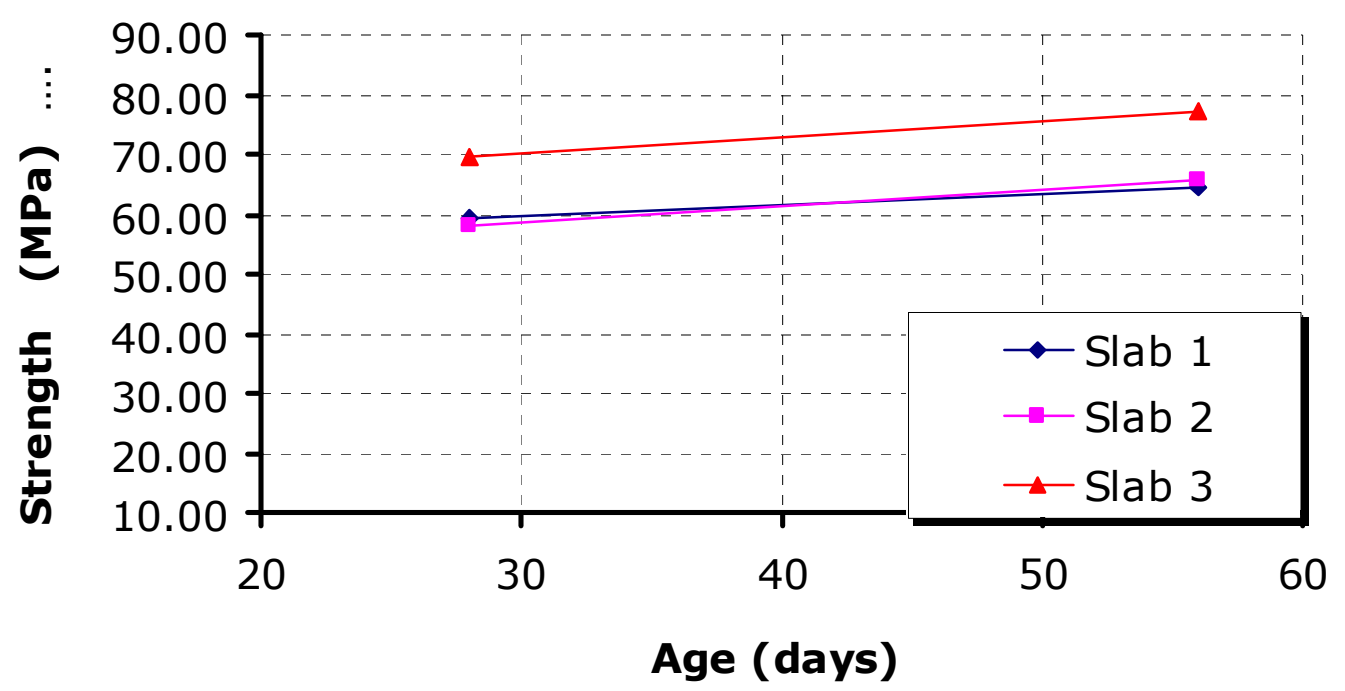

Figure 4-5 Compressive strength comparison for Field-core specimens for 28 and 56 days

\section{Lab-Mix}

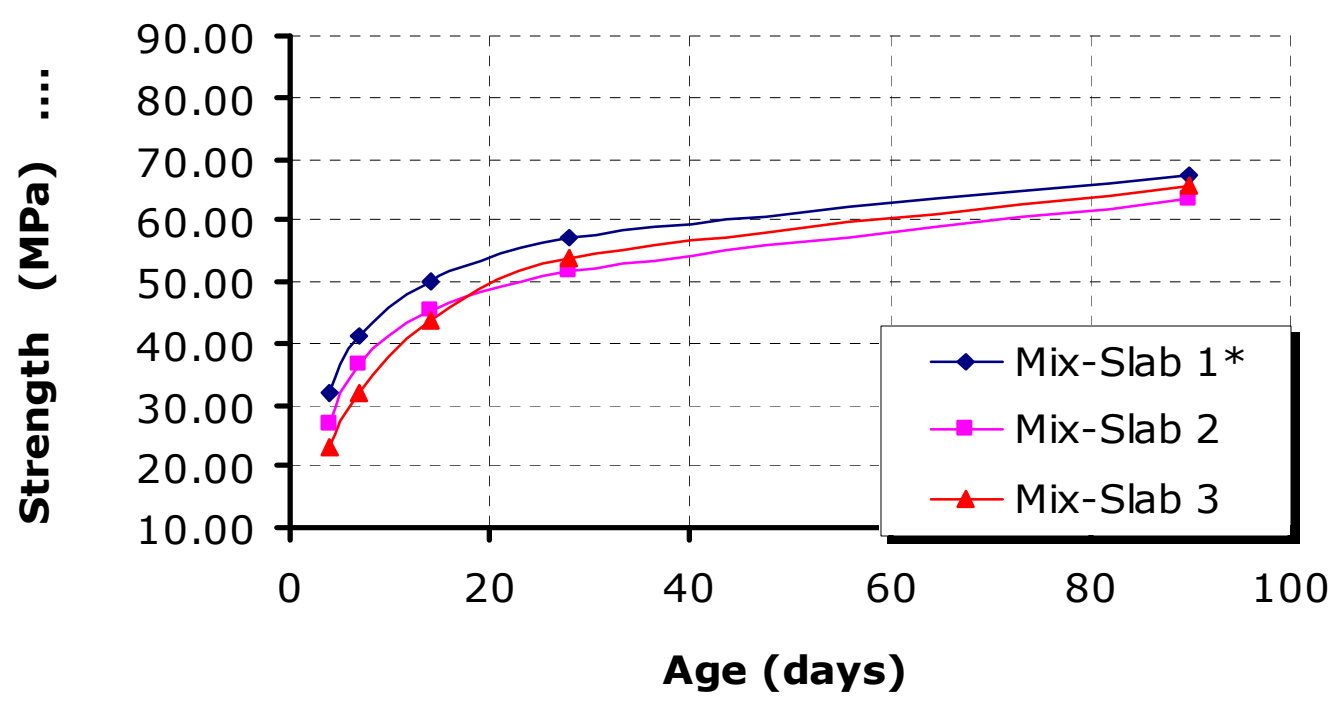

Figure 4-6 Compressive strength comparison for Lab-Mix specimens up to 90 days 


\section{Slag + Metakaolin}

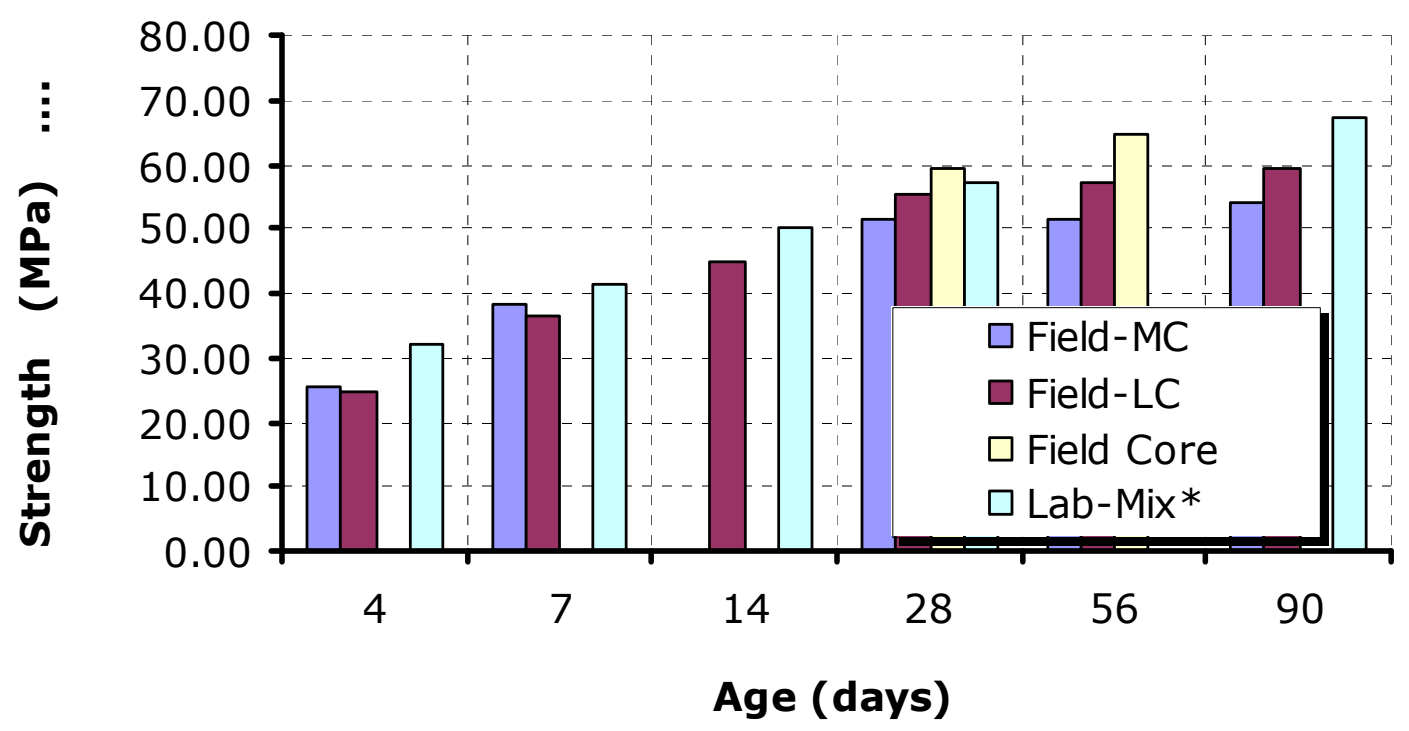

(a)

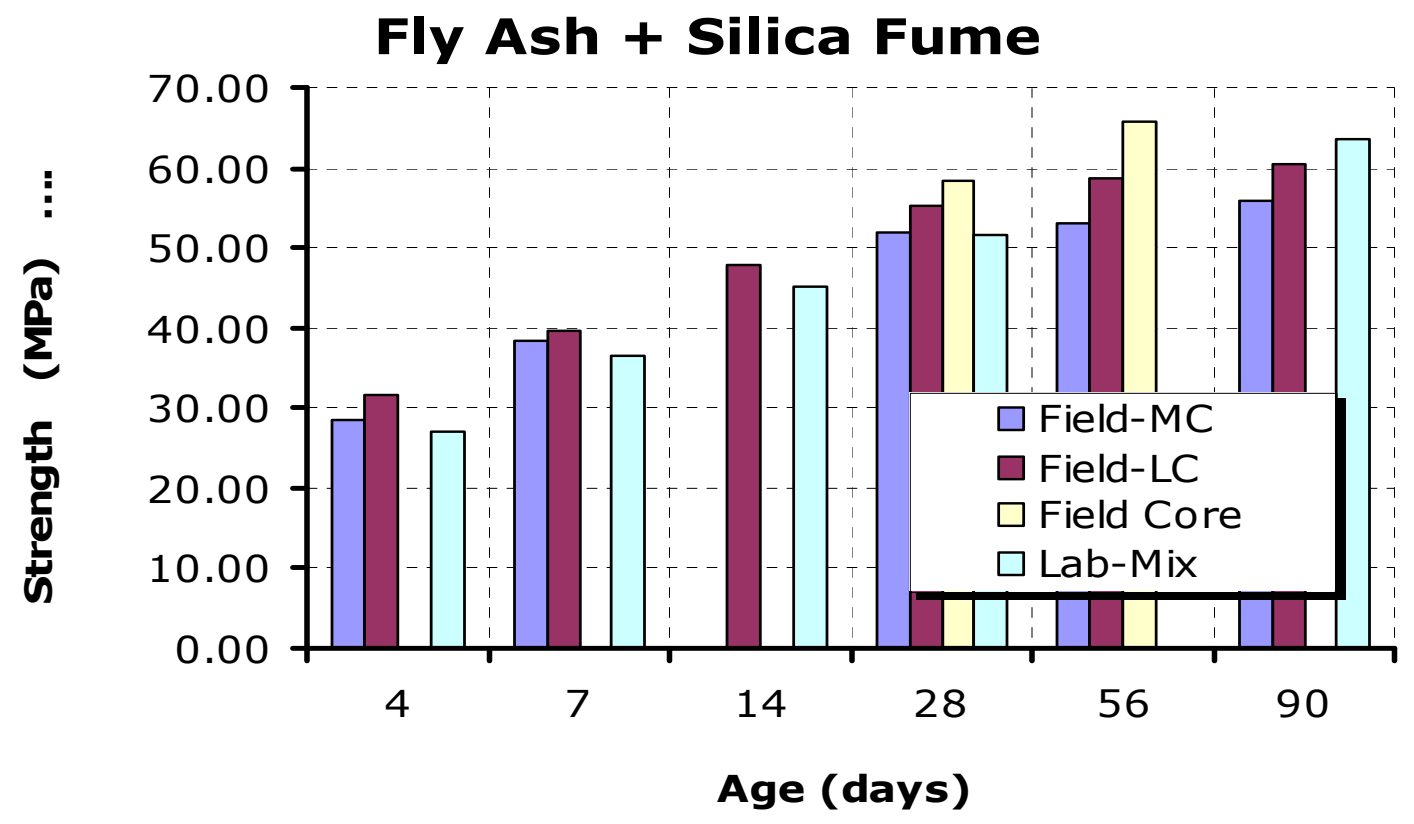

(b) 


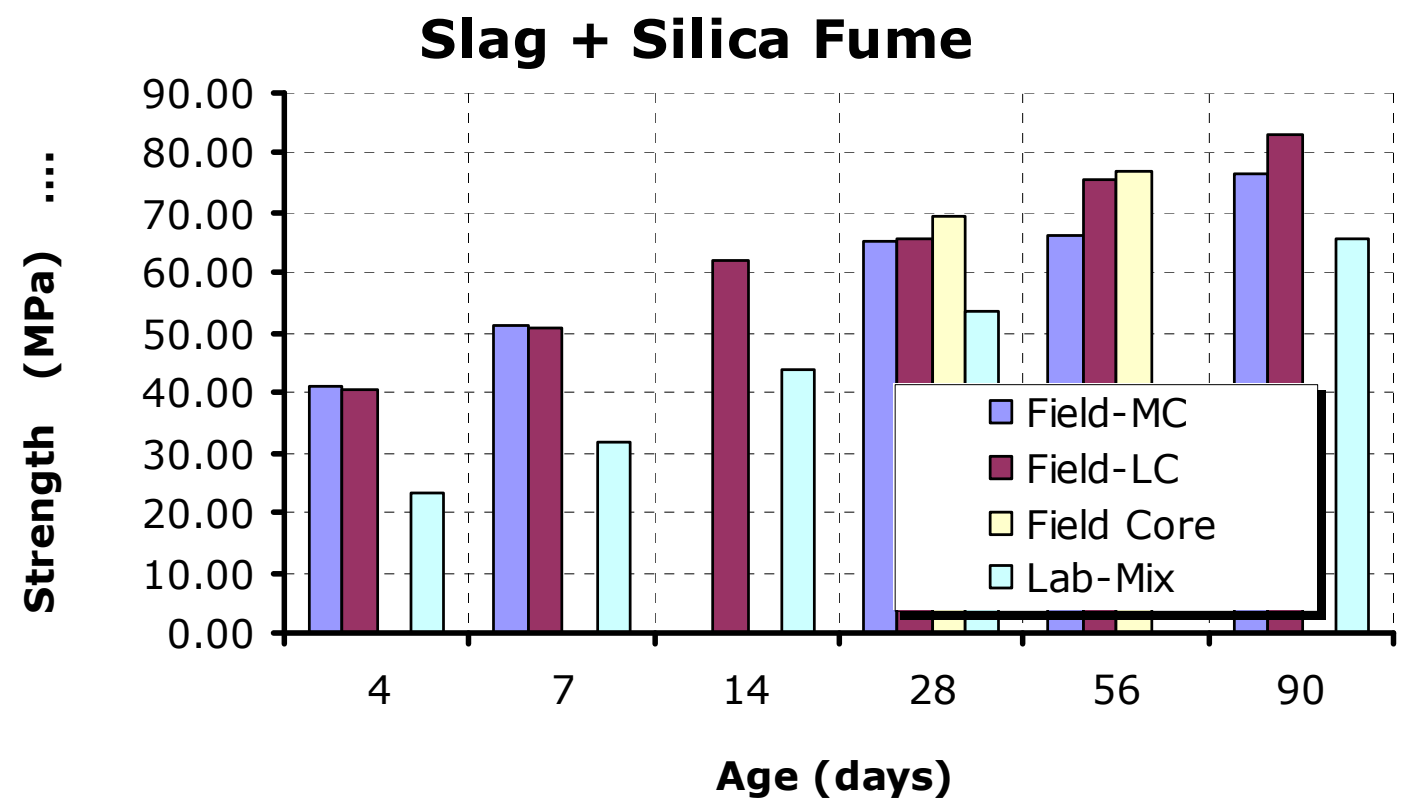

(c)

. (1Mpa=145 psi) (* Lab-mix for Slab 1 for laboratory mixed contains only Metakaolin).

Figure 4-7 Compressive strength development for each type of concrete mixture

(a) Slab 1, (b) Slab 2, (c) Slab 3.

\subsubsection{Dynamic Modulus of Elasticity}

The dynamic modulus of elasticity of concrete is the measure of stiffness of a concrete and used mostly for nondestructive applications and for concrete freezing and thawing evaluations. It is the modulus of elasticity of a test specimen which is computed from physical characteristics of the specimen (size, weight, and shape) and from its fundamental frequency of vibration. The values are usually higher than static modulus of elasticity (secant or chord modulus) and close to initial tangent modulus of elasticity.

\subsubsection{Significance of the Test}

This method covers measurement of the fundamental transverse, longitudinal, and torsional resonant frequencies of concrete prisms and cylinders with the purpose of calculating dynamic Young's modulus of elasticity, the dynamic modulus of rigidity, and the dynamic Poisson's ratio. It is intended for detecting significant changes in the dynamic modulus of 
elasticity of laboratory or field test specimens that are undergoing exposure to weathering or other types of potentially deteriorating influences.

The values for dynamic modulus of elasticity are expected to be greater than the values form the static modulus of elasticity (ASTM C 469), depending on the strength level of the concrete.

For this test, the forced resonance method was followed in which case the specimens were forced to vibrate by an electro-mechanical driving unit. The driving frequency was varied until the measured specimen response reached maximum amplitude obtaining the resonant frequency of the specimen.

\subsubsection{Test Standards}

Dynamic modulus of elasticity was tested per ASTM C 215.

\subsubsection{Calculations}

To calculate the dynamic Young's modulus of elasticity, E, (in Pascal)using cylindrical specimens, the fundamental longitudinal frequency, mass, and dimensions of the specimens were determined and the following equation from ASTM C 215 was used:

DynamicE $=D \times M \times\left(n^{\prime}\right)^{2}$

Where:

$\mathrm{M} \quad=$ Mass of the specimen, $\mathrm{kg}$.

n' = Fundamental longitudinal frequency, Hz.

$\mathrm{D}=5.093 *\left(\frac{L}{d^{2}}\right) \mathrm{N}^{*} \mathrm{~s}^{2}\left(\mathrm{~kg}^{*} \mathrm{~m}^{2}\right)$ for a cylinder $4 *\left(\frac{L}{b^{*} t}\right) \mathrm{N}^{*} \mathrm{~s}^{2}\left(\mathrm{~kg}^{*} \mathrm{~m}^{2}\right)$ for a Prism

$\mathrm{L}=$ Length of specimen, $\mathrm{m}$. 
$\mathrm{d}=$ Diameter of cylinder, $\mathrm{m}$.

$\mathrm{t}, \mathrm{b}=$ Dimensions of cross section of prism, $\mathrm{m}$.

$\mathrm{T}=$ Correction factor that depends on the ratio of the radius of gyration, $(K=\mathrm{d} / 4$ for cylinders and $\mathrm{K}=\mathrm{t} / 3.464$ for prism), to the length of the specimen, $\mathrm{L}$, and Poisson's ratio.

The modulus of elasticity for normal strength concrete and HPC was also calculated using the equation from ACI 363 (1997) and ACI 318 (2001) for strengths of 24 to $83 \mathrm{MPa}$. These values are, however, secant modus of elasticity or chord modulus (experimental correlations).

\section{ACI 636:}

$E c=3.32\left(\sqrt{f^{\prime} c}\right)+6.9$

Where:

Ec = Modulus of elasticity, in GPa

f'c = Compressive strength, in $\mathrm{MPa}$

\section{ACI 318:}

$E c=4.73\left(\sqrt{f^{\prime} c}\right)$

Where:

Ec $=$ Modulus of elasticity, in GPa

f'c = Compressive strength, in $\mathrm{MPa}$

\subsubsection{Results and Discussions}

The dynamic modulus of elasticity for the three different mixtures is presented in Table 4-3. This table includes the tested values for Field-MC and Field-LC and, the estimated values from ACI 363 for 28, 56 and 90 days.

- From the test results it is concluded that the dynamic modulus of elasticity was higher in the laboratory-cured specimens, because these specimens were kept in a controlled environment. 
- Among the mixtures, the highest modulus of elasticity was found to occur for the slag + silica fume HPC which also presented the highest compressive strength.

- The experimental data for 28, 56, and 90 days compressive strength and modulus of elasticity was compared with the empirical relations provided in ACI 318 (2001) and ACI 363 recommendation (1997). It was found that both ACI 318 and ACI 363 offered a very good prediction of the modulus of elasticity even considering the reduction factor to be applied on their estimated values.

- The highest modulus of elasticity was found to occur for the combination of slag + silica fume, in both field and laboratory-mixed concretes.

- The 28 days modulus of elasticity calculated from the laboratory-mixed HPC from the previous phase of the project were of $34 \mathrm{GPa}$ for metakaolin HPC, $33 \mathrm{GPa}$ for fly ash + silica fume HPC, and of $34 \mathrm{GPa}$ for slag + silica fume HPC. These values show a very good correlation to the values obtained from this field project.

Table 4-3 Dynamic modulus of elasticity (a) Slab 1, (b) Slab 2 and (c) Slab 3

\begin{tabular}{c|c|c|c|c}
\hline Slab 1 & Field-MC & Field-LC & ACI 363 & ACI 318 \\
\hline Day & GPa & GPa & GPa & GPa \\
\hline 28 & 37 & 39 & 32 & 35 \\
\hline 56 & 39 & 41 & 32 & 36 \\
\hline 90 & 41 & 38 & 32 & 36 \\
\hline
\end{tabular}

(a)

\begin{tabular}{c|c|c|c|c}
\hline Slab 2 & Field-MC & Field-LC & ACI 363 & ACI 318 \\
\hline Day & GPa & GPa & GPa & GPa \\
\hline 28 & 37 & 32 & 32 & 35 \\
\hline 56 & 38 & 41 & 32 & 36 \\
\hline 90 & 39 & 40 & 33 & 37 \\
\hline
\end{tabular}

(b)

\begin{tabular}{c|c|c|c|c}
\hline Slab 3 & Field-MC & Field-LC & ACI 363 & ACl 318 \\
\hline Day & GPa & GPa & GPa & GPa \\
\hline 28 & 38 & 33 & 34 & 38 \\
\hline 56 & 43 & 45 & 36 & 41 \\
\hline 90 & 43 & - & 37 & 43 \\
\hline
\end{tabular}

(c)

$(1 \mathrm{GPa}=145000 \mathrm{psi})$ 


\subsubsection{Free Shrinkage}

\subsubsection{Significance of the Test}

This test is conducted as a quality control for a concrete mixture, and covers the determination of the length changes that are produced by causes other than externally applied forces, and temperature changes in hardened concrete specimens made in the laboratory and exposed to controlled conditions of temperature and moisture.

Measurement of length change permits assessment of the potential for volumetric expansion or contraction of concrete due to various causes other than applied force and temperature change. This method is useful for comparative evaluation of this potential in different hydraulic concrete mixtures.

\subsubsection{Test Standards}

The length change of hardened hydraulic-cement mortar and concrete (free Shrinkage) was tested by the ASTM C 157. Due to difficulties on casting and testing of some specimens, it was not possible to run all the tests. For all those cases, it was decided to use two of the many empirical relations those have been developed to predict shrinkage of concrete. The ACI 209 describes an equation that is a simple mathematical formula to capture the effects of the different parameters those affect the concrete behavior.

$$
\left(\varepsilon_{s h}\right)_{t}=\frac{t}{\phi+t}\left(\varepsilon_{s h}\right)_{u}
$$

Where:

$(\boldsymbol{E} \mathbf{s h}) \mathbf{t}=$ Shrinkage after $\mathrm{t}$ days of drying

$(\boldsymbol{E s h}) \mathbf{u}=$ Ultimate drying shrinkage $\left(780 \times 10^{\wedge}-6\right.$ recommended by ACI and laboratory mixed HPC at WVU)

$\boldsymbol{\varphi}=$ Empirical constant $=26 \exp [0.0142(\mathrm{v} / \mathrm{s})]=26.11$ for this particular case 


\subsubsection{Results and discussions}

$(\mathcal{E S h})_{7 \text { days }}=165$ microstrain

$\left(\mathcal{E}_{\mathrm{Sh}}\right) 14$ days $=272$ microstrain

$\left(\mathcal{E}_{\text {sh }}\right) 28$ days $=404$ microstrain

$(\mathcal{E}$ sh $) 56$ days $=532$ microstrain

$(\mathcal{E s h}) 90$ days $=605$ microstrain

$\left(\mathcal{E}_{\text {sh }}\right)_{\text {Lab-Mixed }}=605$ microstrain

When the predicted shrinkage for the slabs at 90 days is compared to the shrinkage from the tested specimens from the previous phase of this work and other obtained data considering the mix effects and volume/surface ratio of the field slabs, it may be concluded that the equation presented by the ACI offers a good prediction of shrinkage for in-place structures.

\subsection{Durability Evaluation of Concrete Mixtures}

\subsubsection{Resistance of Concrete to Rapid Freezing and Thawing}

Deterioration of concrete from freezing and thawing actions is common due to presence of saturated hardened cement paste containing high porosity. Mechanisms of attack are well described in published literature and books. When water freezes to ice, it occupies larger volume compared to its liquid state. If there is no extra space available for this enlarged volume, freezing water within pores of pastes may create internal stress within the concrete. Distress to critically saturated concrete from freezing and thawing will commence with the first few freezing and thawing cycles and will continue throughout successive winter seasons resulting in repeated deterioration of concrete. 


\subsubsection{Significance of the Test}

The paste of concrete is porous which makes it vulnerable to damage under repeated cycles of freezing and thawing due to the presence of moisture. For mixtures with w/cm higher than 0.24 , the air entraining admixtures needs to be added to concrete to resist deterioration due to freezing and thawing. To achieve a stable air-void system in HPC, higher quantities of airentraining admixtures are required compared to those incorporated in normal concretes. However, on the other hand due to the low w/ $\mathrm{cm}$ of HPC, there is not much freezable water and therefore lower air contents may prove satisfactory resistance to freeze and thawing provided that the air-void parameters are within the acceptable range. It is always preferable to keep air entrainment minimum, stable, and acceptable range of air-void parameters. The air-void systems of the HPC used in this project are described in details in Chapter 6.

\subsubsection{Test Standards}

Freezing and thawing durability is determined per ASTM C 666 (Standard Test Method for Resistant of Concrete to Rapid Freezing and Thawing). Mass loss is calculated at a given number of cycles of freezing and thawing and durability factor is calculated at end of 300 cycles.

There exist two procedures for freezing and thawing testing: (1) Procedure A requires the specimen to be completely submerged in water at all times while it is subjected to freezing and thawing; and (2) Procedure B requires the specimens to be surrounded by air while freezing but thawed in water. Procedure A was performed in this study subjecting the prism specimens to freezing and thawing cycles. Each cycle consists of freezing to $-18{ }^{\circ} \mathrm{C}\left(0{ }^{\circ} \mathrm{F}\right)$ and then thawing at elevated temperature $+4{ }^{\circ} \mathrm{C}\left(40{ }^{\circ} \mathrm{F}\right)$. Each cycle was completed in 4 hours as shown in Figure 4-8. For procedure A, not less than $25 \%$ of the time was used for thawing. At the end of cooling period, the temperature at the centers of the specimens was -18 $\pm 2{ }^{\circ} \mathrm{C}\left(0 \pm 3{ }^{\circ} \mathrm{F}\right)$ and at the end of heating period the temperature was $4 \pm 2{ }^{\circ} \mathrm{C}\left(40 \pm 3{ }^{\circ} \mathrm{F}\right)$ with no specimen at any time reaching a temperature lower than $-19^{\circ} \mathrm{C}\left(-3^{\circ} \mathrm{F}\right)$ nor higher than $6{ }^{\circ} \mathrm{C}\left(43^{\circ} \mathrm{F}\right)$. All these were verified using thermocouple within few representative specimens. 


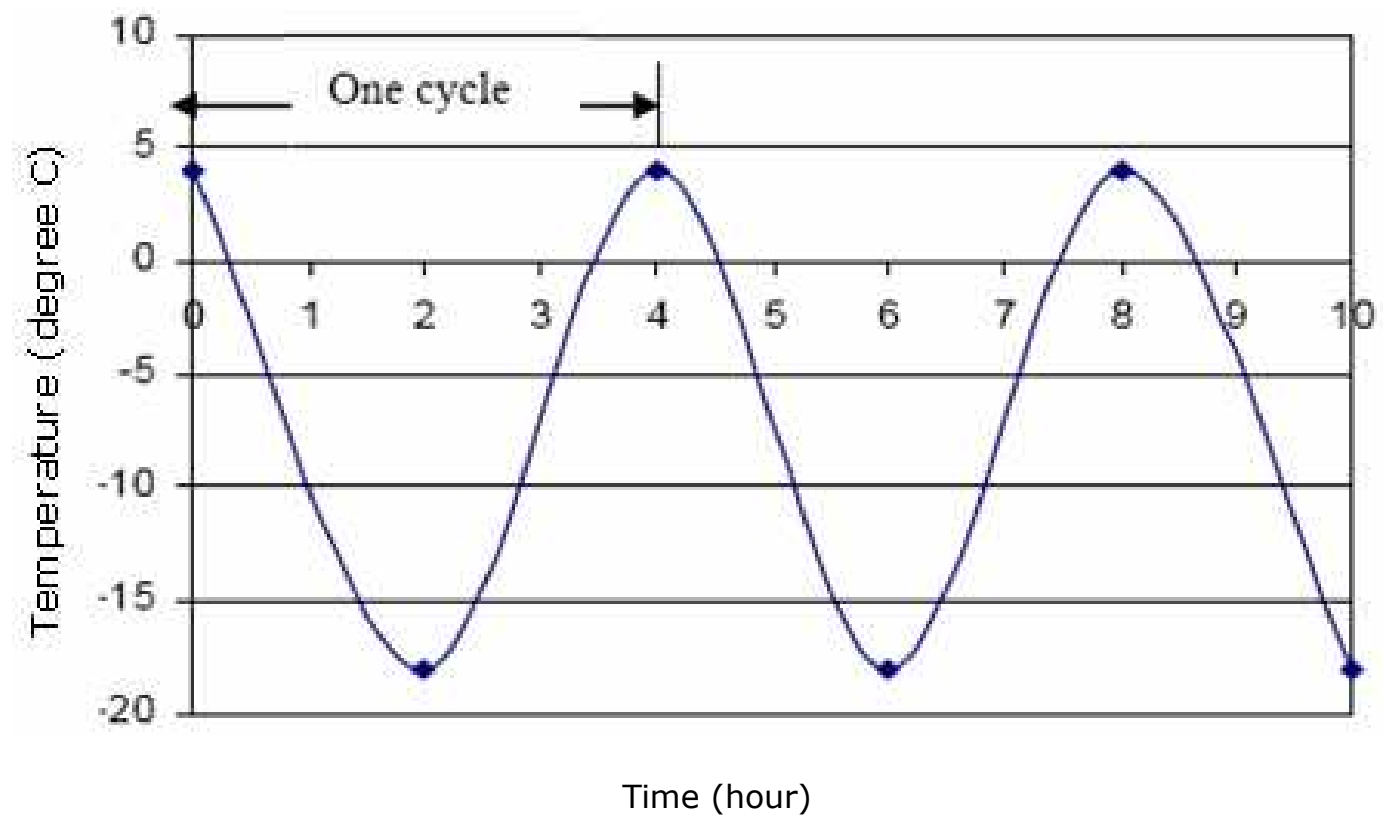

Figure 4-8 Temperature cycles for freezing and thawing test

\subsubsection{Procedure}

- The molded prism specimens were cured for 14 days prior to testing.

- The specimens were placed in the trays containing water and placed in Z-16 environmental chamber programmed with the above freezing and thawing cycles.

- As mentioned above some of the specimens were attached with thermocouples and data loggers for recording the temperature inside the specimen. The average values of temperature recorded was noted and maintained.

- After each of the 30,62, 93, 128, 202, 240, and 300 cycles of freezing and thawing, the specimens were brought to the target thawing temperature and then measured for fundamental transverse frequency and mass loss.

- After every cycle, the water in the container was replaced and the specimens were kept in a different location inside the chamber to achieve uniformity in exposure. 


\subsubsection{Calculations}

The Relative dynamic modulus of elasticity (Pc) was calculated as follows:

$P_{c}=\left(n_{1}^{2} / n^{2}\right) x 100$

Where:

$\mathrm{n} \quad=$ Fundamental transverse frequency at 0 cycles of freezing and thawing.

$\mathrm{n} 1=$ Fundamental transverse frequency after $\mathrm{n}$ cycles of freezing and thawing.

The durability factor (DF) is calculated as follows:

$D F=P N / M$

Where:

$\mathrm{P} \quad=$ Relative dynamic modulus of elasticity at $\mathrm{N}$ cycles, $\%$.

$\mathrm{N} \quad=$ Number of cycles at which $\mathrm{P}$ reaches the specified minimum value for discontinuing the test or the specified number of cycles at which the exposure is to be terminated, whichever is less.

$\mathrm{M} \quad=$ Specified number of cycles at which the exposure is to be terminated.

\subsubsection{Results and Discussions}

Table 4-4 presents the durability factor (DF), the mass loss, and the relative dynamic modulus of elasticity for the three different mixtures for each cycle tested. Among the concretes, the maximum mass loss was reported for mixture with slag + metakaolin HPC, with a $0.45 \%$ loss; and the minimum loss was reported for the mixture made with slag + silica fume with $0.22 \%$ loss.

The relative dynamic modulus over different cycles is presented in Figure 4-9. It is observed that all mixtures presented similar behavior under the freezing and thawing cycles. At end of 300 cycles the durability factor was measured as 96 to $98 \%$ for all three mixtures. The high durability factor is indicative of good resistance of HPC against freezing and thawing cycles. 
Fan (2005) tested HPC mixtures those were very similar to the ones studied in this research, with the difference that those mixtures were developed and fabricated at laboratory scale. In his work he conducted freezing and thawing tests in deicing salt solution (more severe condition). He concluded that concrete made with metakaolin offered superior performance in resisting freezing and thawing in deicing solutions. The slag + silica fume mixtures exhibited better performance to freezing and thawing than the mixtures made with fly ash + silica fume.

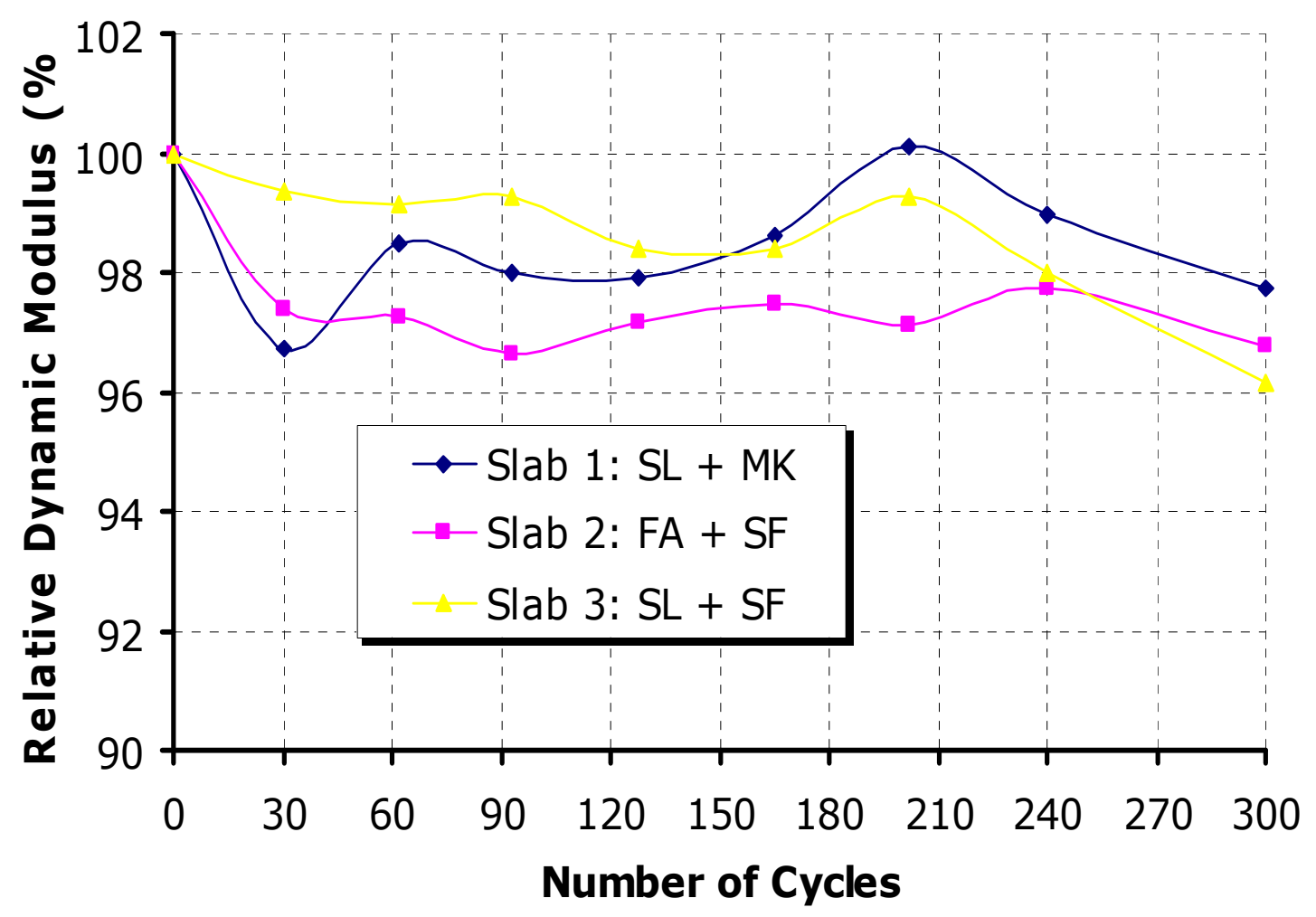

Figure 4-9 Relative dynamic modulus of elasticity versus number of cycles 
Table 4-4 Freezing and thawing test data (a) Slab 1, (b) Slab 2, and (c) Slab 3

\begin{tabular}{|c|c|c|c|c|c|}
\hline \multicolumn{6}{|c|}{ Slag + Metakaolin } \\
\hline Cycles & $\begin{array}{c}\text { Mass } \\
(\mathrm{Kg})\end{array}$ & $\begin{array}{l}\text { Fundamental } \\
\text { Frequency }(\mathrm{HZ})\end{array}$ & $\begin{array}{c}\text { Mass } \\
\text { Loss } \\
(\%)\end{array}$ & Pc (\%) & DF (\%) \\
\hline 0 & 7.45 & 5250 & 0 & 100 & \multirow{8}{*}{97.72} \\
\hline 30 & 7.43 & 5170 & 0.22 & 96.73 & \\
\hline 62 & 7.43 & 5210 & 0.22 & 98.48 & \\
\hline 93 & 7.44 & 5200 & 0.13 & 97.98 & \\
\hline 128 & 7.45 & 5200 & 0.04 & 97.92 & \\
\hline 202 & 7.42 & 5255 & 0.45 & 100.13 & \\
\hline 240 & 7.42 & 5230 & 0.45 & 98.99 & \\
\hline 300 & 7.42 & 5190 & 0.45 & 97.73 & \\
\hline
\end{tabular}

(a)

\begin{tabular}{|c|c|c|c|c|c|}
\hline \multicolumn{6}{|c|}{ Fly ash + Silica fume } \\
\hline Cycles & $\begin{array}{l}\text { Mass } \\
(\mathrm{Kg})\end{array}$ & $\begin{array}{l}\text { Fundamental } \\
\text { Frequency (HZ) }\end{array}$ & $\begin{array}{c}\text { Mass } \\
\text { Loss } \\
(\%)\end{array}$ & Pc (\%) & DF (\%) \\
\hline 0 & 7.28 & 5290 & 0 & 100 & \multirow{8}{*}{96.75} \\
\hline 30 & 7.27 & 5220 & 0.18 & 97.37 & \\
\hline 62 & 7.27 & 5220 & 0.09 & 97.25 & \\
\hline 93 & 7.28 & 5200 & 0 & 96.63 & \\
\hline 128 & 7.27 & 5220 & 0.09 & 97.16 & \\
\hline 202 & 7.26 & 5215 & 0.31 & 97.12 & \\
\hline 240 & 7.26 & 5230 & 0.32 & 97.75 & \\
\hline 300 & 7.26 & 5210 & 0.32 & 96.75 & \\
\hline
\end{tabular}

(b)

\begin{tabular}{|c|c|c|c|c|c|}
\hline \multicolumn{6}{|c|}{ Slag + Silica fume } \\
\hline Cycles & $\begin{array}{l}\text { Mass } \\
(\mathrm{Kg})\end{array}$ & $\begin{array}{l}\text { Fundamental } \\
\text { Frequency }(\mathrm{HZ})\end{array}$ & $\begin{array}{c}\text { Mass } \\
\text { Loss } \\
(\%)\end{array}$ & Pc (\%) & DF (\%) \\
\hline 0 & 7.54 & 5350 & 0 & 100 & \multirow{8}{*}{96.17} \\
\hline 30 & 7.53 & 5330 & 0.18 & 99.38 & \\
\hline 62 & 7.53 & 5325 & 0.18 & 99.13 & \\
\hline 93 & 7.53 & 5330 & 0.18 & 99.25 & \\
\hline 128 & 7.54 & 5310 & 0 & 98.39 & \\
\hline 202 & 7.52 & 5330 & 0.22 & 99.25 & \\
\hline 240 & 7.52 & 5300 & 0.22 & 98.02 & \\
\hline 300 & 7.52 & 5245 & 0.22 & 96.17 & \\
\hline
\end{tabular}

(c)

$(1 \mathrm{Kg}=2.2 \mathrm{Lb})$ 


\subsubsection{Electrical Indication of Concrete's Ability to Resist Chloride Ion Penetration}

In deck slabs, chloride ions diffuse through the concrete from top in the form of de-icing salt solutions. The ingress of the chloride ion takes place through none-steady state diffusion. The mechanisms of chloride transport are combinations of diffusion, absorption, and wicking. The protective passive layer on the surface of embedded steel consisting of gama- $\mathrm{Fe}_{2} \mathrm{O}_{3}$ that tightly adheres and protects the steel is destroyed by the chloride ions and carbonation. As a result the unprotected steel undergoes corrosion in presence of oxygen and moisture. The corrosion of steel due to presence of chloride ions is a major problem for the concrete bridge decks and girders in the North America and many other parts of the world.

\subsubsection{Significance of the Test}

This practice covers the laboratory evaluation of the electrical conductance of concrete samples to provide a rapid indication of their resistance to chloride ion penetration. This test method known as the rapid chloride permeability test (RCPT) is suitable for evaluation of materials and mixture proportions for design purposes and acceptance criteria.

RCPT method consists of monitoring the amount of electrical current passed through $51 \mathrm{~mm}$ (2 in.) thick slices of $102 \mathrm{~mm}$ (4 in.) nominal diameter cores or cylinders during 6-hour period.

The total charge passed (coulombs) in this test method must be used with caution for concrete containing various admixtures. The qualitative assessment of chloride ion penetrability from charge passed can be made from the Table 4-5 (extracted from ASTM C 1202).

Many state DOT or FHWA for the specification purpose recommends RCPT values for 56 days or at later age. Also the RCPT is directly related with the curing procedures followed. Because of these facts, in this project, it was decided to test the concrete mixtures for both cored and field-mixed laboratory-cured specimens at two different ages: 35 days and 60 days. The specimens selected for each type of mixture were: 1) two cylindrical cored specimens 
from different locations in the concrete slabs and 2) two field-mixed laboratory-cured specimens.

Table 4-5 Chloride ion penetrability based on charge passed

\begin{tabular}{c|l}
\hline $\begin{array}{c}\text { Charge Passed } \\
\text { (Coulombs) }\end{array}$ & $\begin{array}{l}\text { Chloride lon } \\
\text { Penetrability }\end{array}$ \\
\hline$>4000$ & High \\
\hline $2000-4000$ & Moderate \\
\hline $1000-2000$ & Low \\
\hline $100-1000$ & Very Low \\
\hline$<100$ & Negligible \\
\hline
\end{tabular}

\subsubsection{Test Standards}

The rapid chloride permeability test of disc specimens cut from laboratory-cured specimens and cored specimens was conducted in accordance with ASTM C 1202 (Standard Test Method for Electrical Indication of Concrete's Ability to Resist Chloride Ion Penetration).

\subsubsection{Procedure}

Conditioning:

- Vigorously a liter or more of tap water was boiled in a large sealable container, and allowed to cool to ambient temperature.

- Since the diameter of the cored specimens was slightly larger than $102 \mathrm{~mm}$ (4 in.), it was needed to grind the specimens until the required diameter was obtained. Then the specimens were placed on a suitable support and coated to ensure complete coating of sides (100\% silicon sealant was used for coating). A 24 hours curing time was allowed for the coating.

- After curing, the specimens were placed in vacuum desiccator. The desiccator was sealed and the vacuum pump started to reduce the internal pressure to lower than 1 $\mathrm{mm}-\mathrm{Hg}$ and then maintained at that level for 3 hours.

- With the vacuum pump still working, sufficient water was drained into a beaker or container to cover and saturate the specimen. 
- The specimens were soaked under water for $18 \pm 2$ hours (Figure 4-10).

Testing Procedure:

- The specimens were removed from the water, and then placed on permeability cells and sealed with $100 \%$ silicone sealant.

- After the silicone has cured for 24 hours, the cell containing the top surface of the specimen was filled with $3.0 \% \mathrm{NaCl}$ solution (This side of the cell was connected to the negative terminal of the power supply). The other side of the cell (which was connected to the positive terminal of the power supply) was filled with $0.3 \mathrm{~N} \mathrm{NaOH}$ solution.

- Finally the power supply was turned on and set to $60.0 \pm 0.1 \mathrm{~V}$ and the readings were taken for every 5 min for the first 60 minutes (1 hour), and the every 30 minutes until 360 minutes (6 hours).

During the test, the temperature of the solution was not allowed to exceed $90{ }^{\circ} \mathrm{C}\left(190{ }^{\circ} \mathrm{F}\right)$ in order to avoid damage to the cell and to avoid boiling of the solution. The apparatus used to run the RCPT test is presented in Figure 4-10.
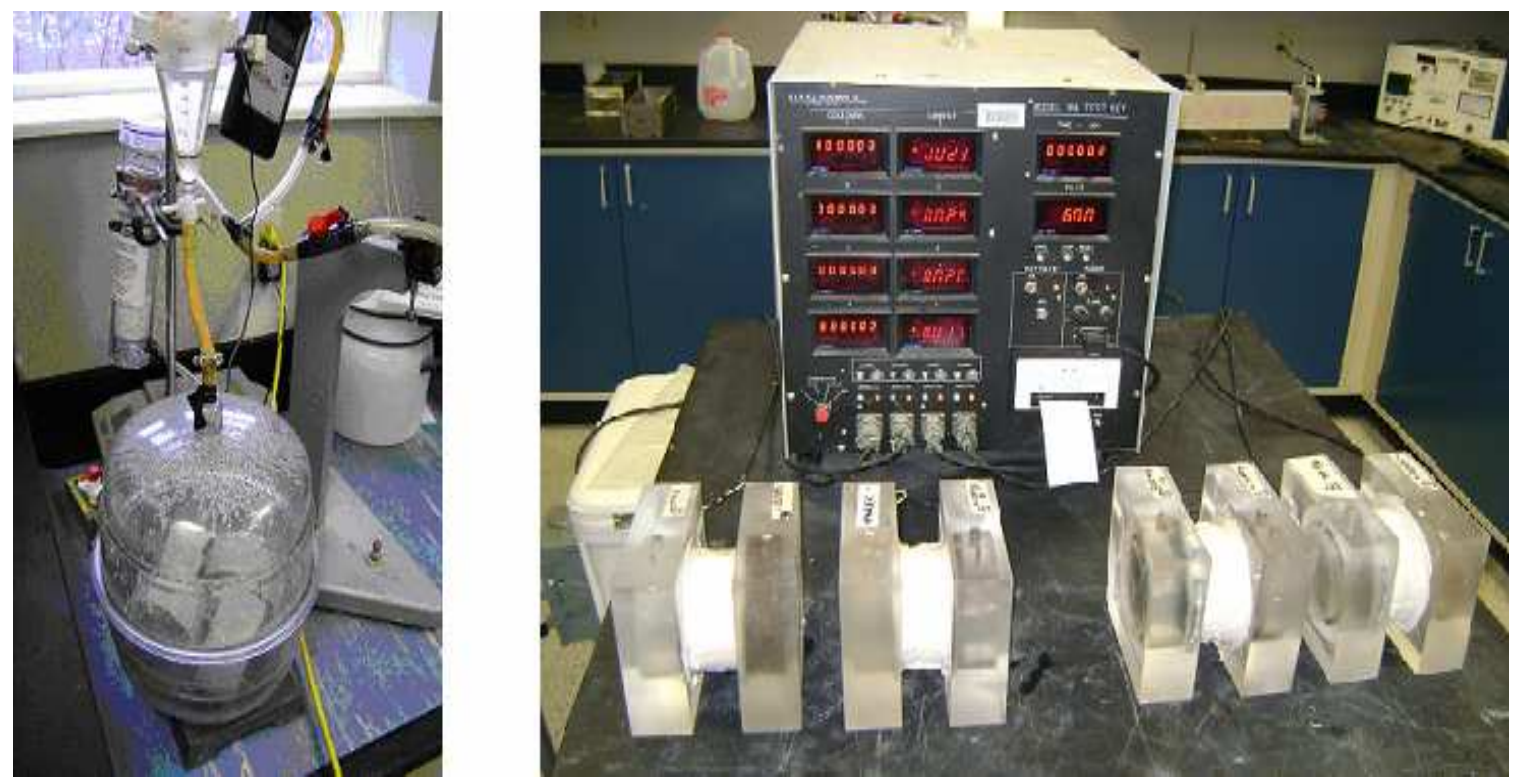

Figure 4-10 Conditioning and testing samples for RCPT 


\subsubsection{Calculations}

To obtain the ampere-seconds or coulombs of charge passed during the 6 hours test period, the area underneath the curve obtained from plotting the current (amperes) versus time (seconds) needs to be integrated. But in this case automatic data processing equipment was used to perform the integration during the test and to display the charge values in coulombs. This total charge passed was a measure of the electrical conductance of the concrete during the period of the test.

\subsubsection{Results and Discussions}

Results show that for the same w/cm, concrete with different SCM presented different charge passed values, as it is evident from Figure 4-14 and Figure 4-15. This was due to the fact that charge passed is dependent on the types of SCM, which affected the pore structure and the chemistry of the pore solutions.

Except slab 3, there was a reduction in the charge passed measured at 60 days compared to the charge passed at 35 days for cored specimens from field indicating sufficient curing and improvement in concrete properties. For slab 3 the values were very close. For field-mixed lab-cured specimens in all cases the 60 days charge was less than 35 days. According to ASTM C 1202 and Table 4-5, the chloride permeability of all three concrete mixtures was rated as 'very low permeability' even after 35 days.

There are some major concerns regarding the RCPT as described as follows (Uchoa et al., 2009):

- The test measures not only the chloride ions movement but other ions movement including hydroxide, which has greater mobility than chloride ions.

- High heat is generated due to high voltage applied across the specimens. This leads to higher values for RCPT tests.

- The mineral admixtures such as silica fume, fly ash, and slag have significant effects on pore solutions that influence the electrical conductivity subsequently affecting the RCPT results. 
Lane (2005) proposed modifications to improve the consistency of the RCPT test results by using conductivity values obtained in the first 10 minutes of testing. This is due to heating problems because of duration of 6 hours for the test. That particularly influences the smaller size specimens which yields in greater charge passed. In our study the concrete specimens at 35 days generated more heat compared to concrete specimens at 60 days. Hence it was suggested that the initial current measurement is more useful to estimate the specimen conductivity. While Lane (2005) proposed a modification of using first 10 minutes, while other researchers suggested using the 30 minutes charge multiplied by 12 to avoid the heating effect. The use of early values also leads to reduce variability of the test results.

From Figure 4-11, through Figure 4-13 is observed that the specimens made at the field and cured in the laboratory had higher charge passed compared to cored specimens from field. This may be due to the fact that the field slabs had different curing conditions compared to lab-cured specimens as well as the field slabs were prepared and consolidated differently from cylindrical specimens.

In Figure 4-14 and Figure 4-15, the blue bars are the tested and predicted charge passed for the field-cured specimens and the yellow bars are the tested and predicted charge passed for laboratory-cured specimens. After comparing the bars, it is observed that the final values did not differ significantly, concluding than the 6-hour test could be replaced by a quick measurement of 10 or 30 minutes and multiplying them with suitable factors.

No general relation was found between charge passed and compressive strength. This is because the two parameters are controlled by different factors. Although both parameters depend of the porosity of the concrete, the charge passed is more related to the connectivity of the pores, movement of both chloride and hydroxyl ions, and aggregate texture. 
Table 4-6 Summary of the charge passed results of all mixtures

\begin{tabular}{l|c|c|c|c|c|c|c}
\hline \multirow{2}{*}{ Slab/ Days } & \multicolumn{2}{|c|}{360 min. } & \multicolumn{2}{c|}{$\mathbf{1 0}$ min. $\mathbf{3 6}$} & \multicolumn{2}{c|}{$\mathbf{3 0}$ min. $\mathbf{1 2}$} & $\mathbf{3 6 0}$ min \\
\cline { 2 - 8 } & Field-Core & Field LC & Field-core & Field LC & Field-Core & Field LC & Lab-Mix \\
\hline S1 35 Days & 689 & 1357 & 594 & 1080 & 606 & 1104 & 1080 \\
\hline S1 60 Days & 546 & 553 & 504 & 486 & 516 & 492 & 913 \\
\hline S2 35 Days & 555 & 753 & 504 & 648 & 522 & 678 & 740 \\
\hline S2 60 Days & 409 & 593 & 396 & 522 & 402 & 528 & 672 \\
\hline S3 35 Days & 365 & 459 & 396 & 450 & 354 & 414 & 520 \\
\hline S3 60 Days & 376 & 419 & 342 & 378 & 360 & 384 & 375 \\
\hline
\end{tabular}


Slab 1: Slag + Metakaolin (35 Days)

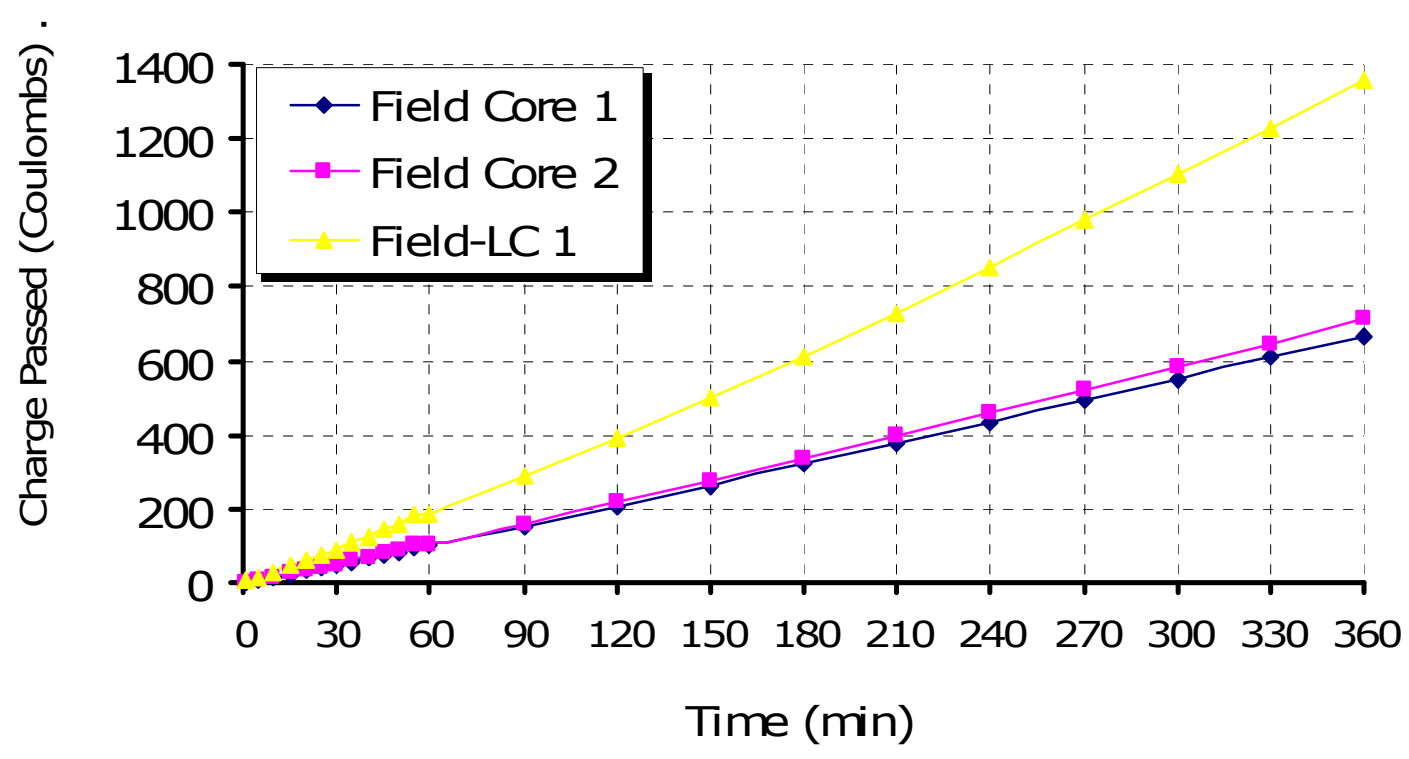

(a)

\section{Slab 1: Slag + Metakaolin (60 Days)}

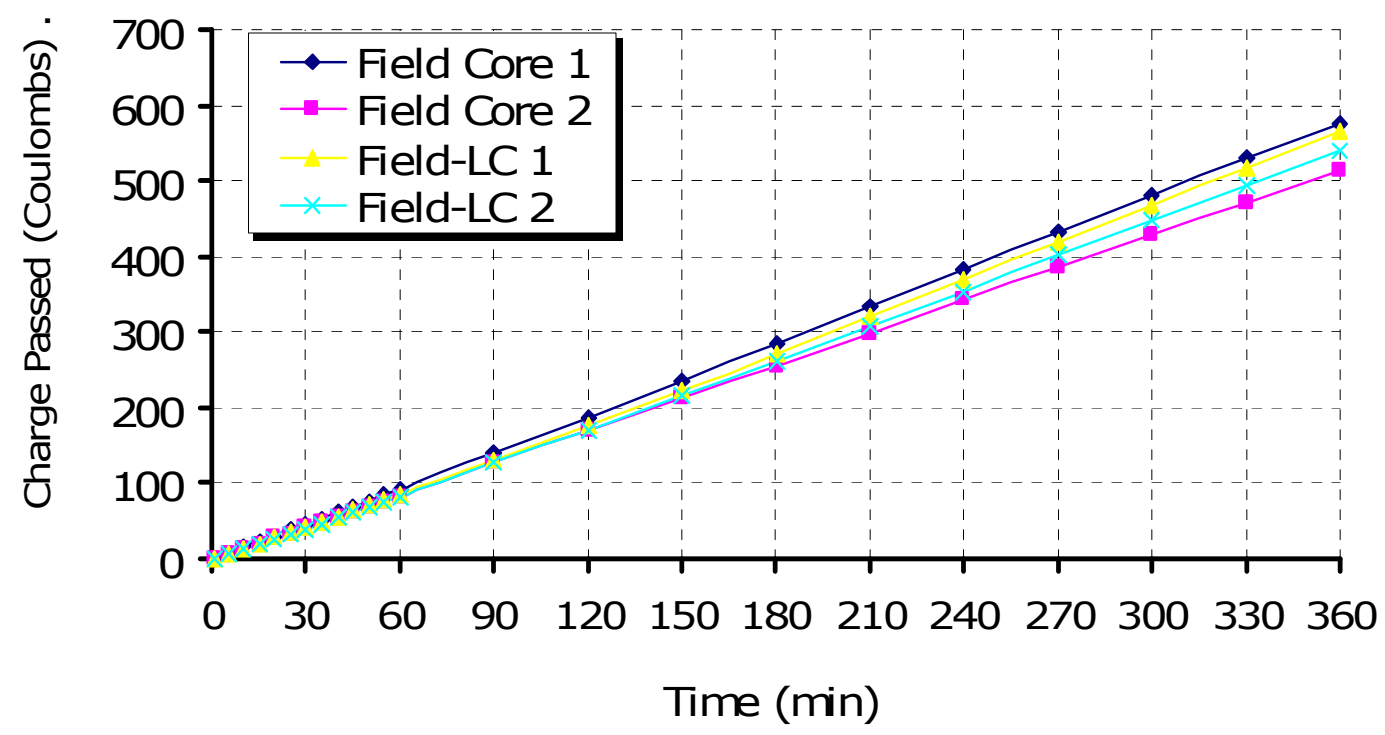

(b)

Figure 4-11 Charge passed versus time (a) Slab 1 at 35 days (b) Slab 1 at 60 days 


\section{Slab 2: Fly Ash+Silica Fume (35 Days)}

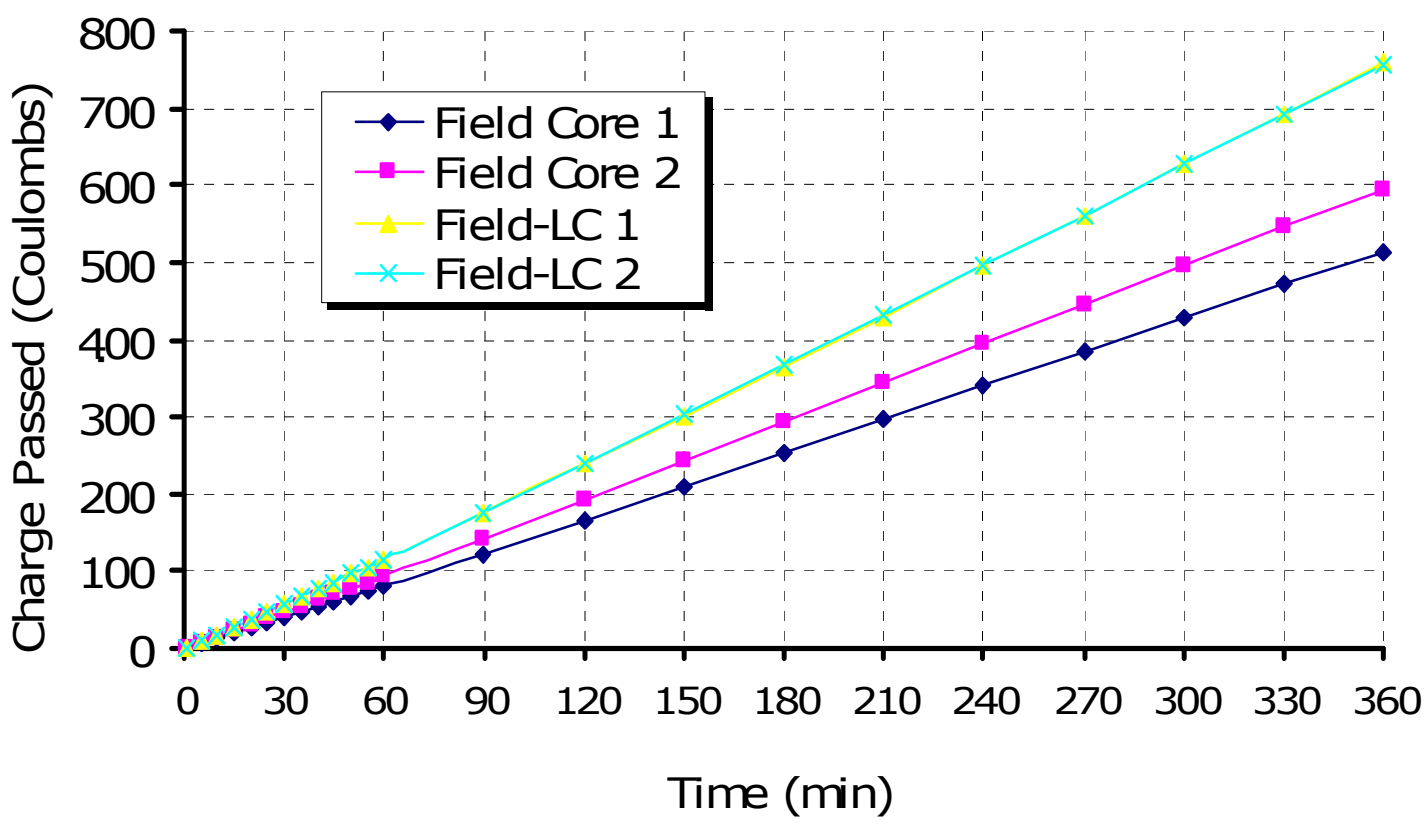

(a)

\section{Slab 2: Fly Ash+Silica Fume (60 Days)}

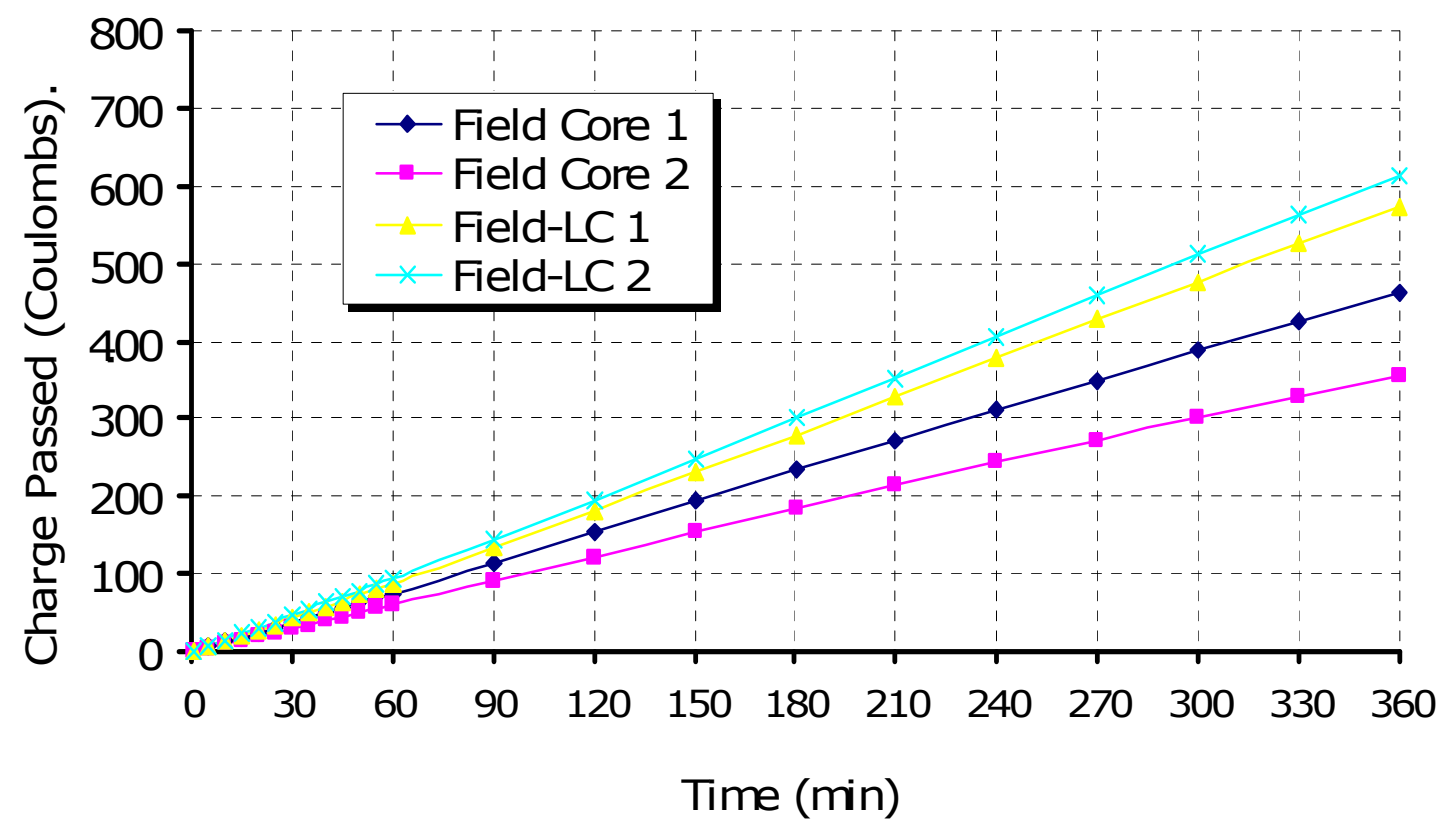

(b)

Figure 4-12 Charge passed versus time (a) Slab 2 at 35 days (b) Slab 2 at 60 days 


\section{Slab 3: Slag +Silica Fume (35 Days)}

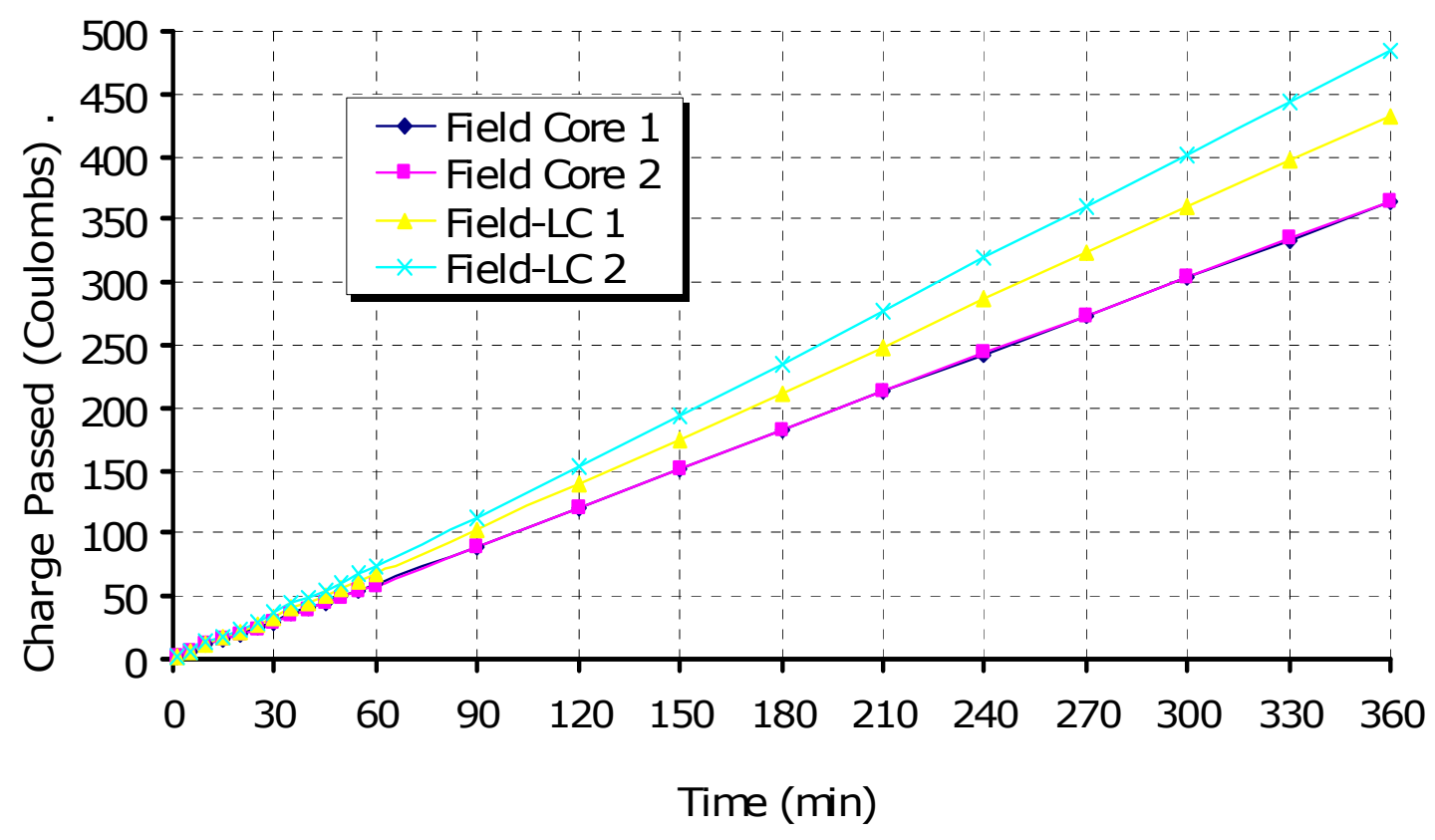

(a)

Slab 3: Slag +Silica Fume (35 Days)

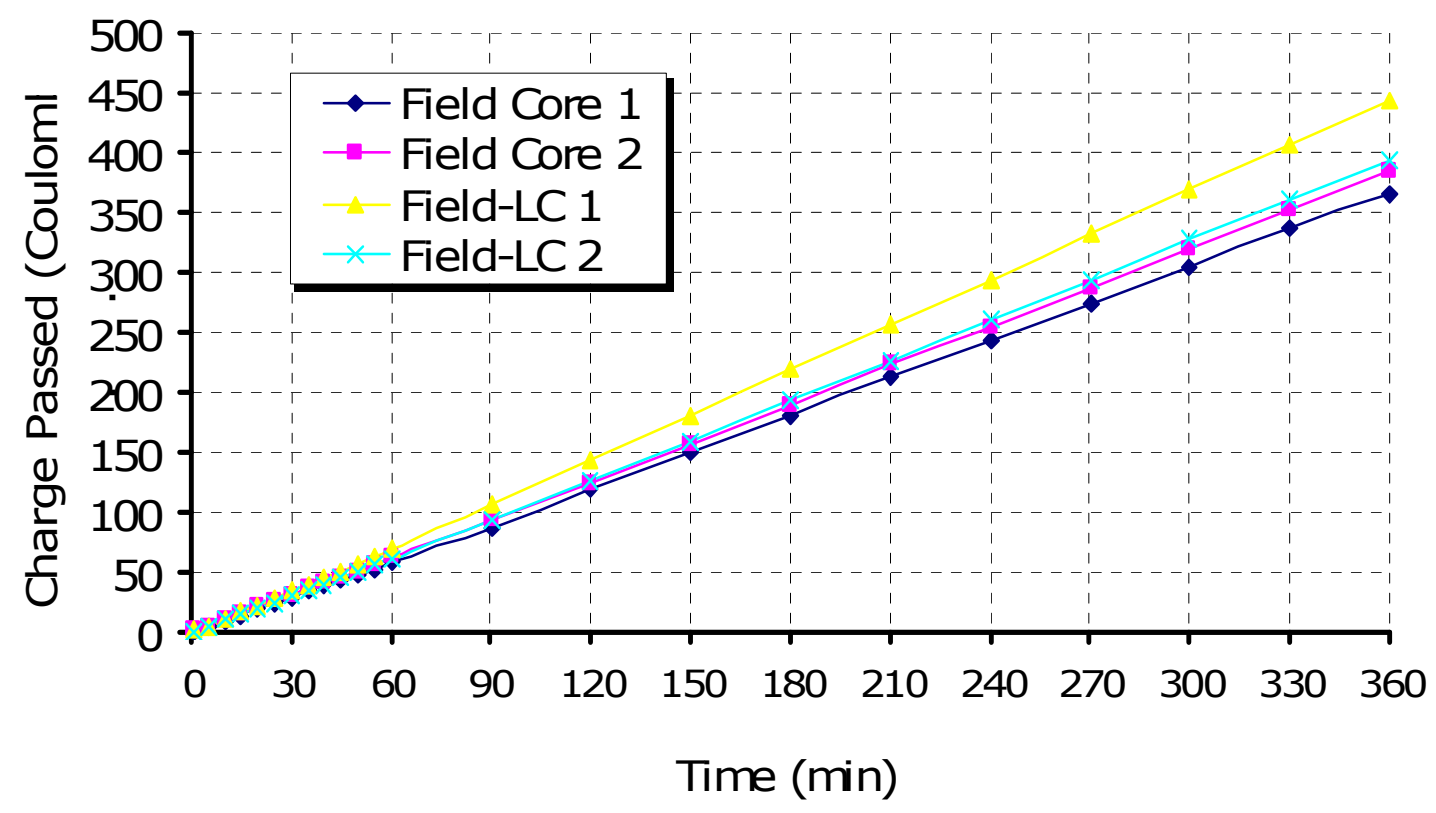

(b)

Figure 4-13 Charge passed versus time (a) Slab 3 at 35 days (b) Slab 3 at 60 days 


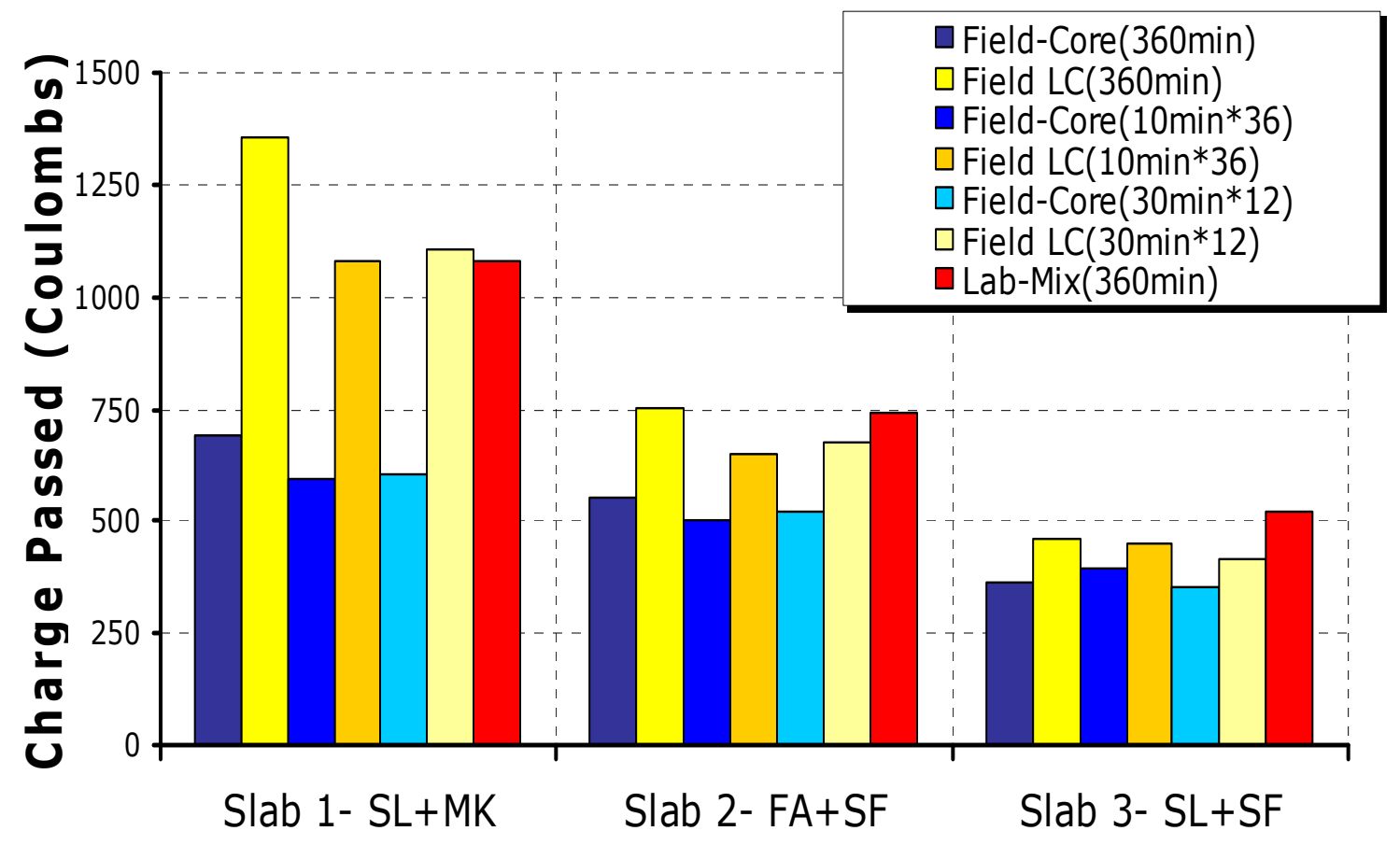

Figure 4-14 Comparison of normal RCPT and suggested extrapolation for 35 Days

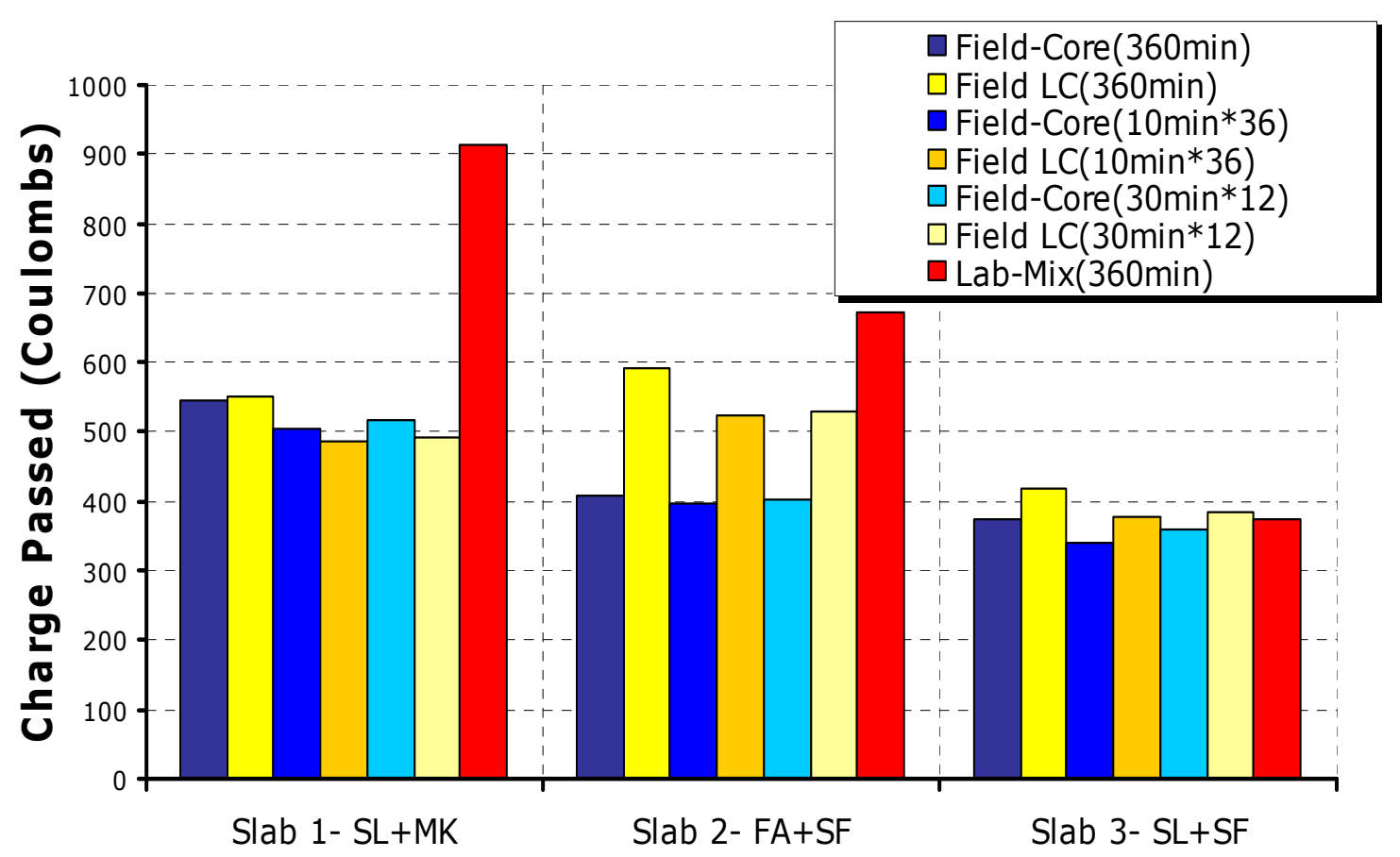

Figure 4-15 Comparison of normal RCPT and Suggested extrapolation for 60 Days 


\section{CHAPTER 5}

\section{ESTIMATION OF CONCRETE STRENGTH BY THE MATURITY METHOD}

The hydration of cement is a function of time and the temperature of the hydration. Consequently the gain of strength is also controlled by these two parameters. In consequence the concept of maturity of concrete appears as a function of the product of the curing time and the concrete curing temperature as it is presented in Figure 5-1.

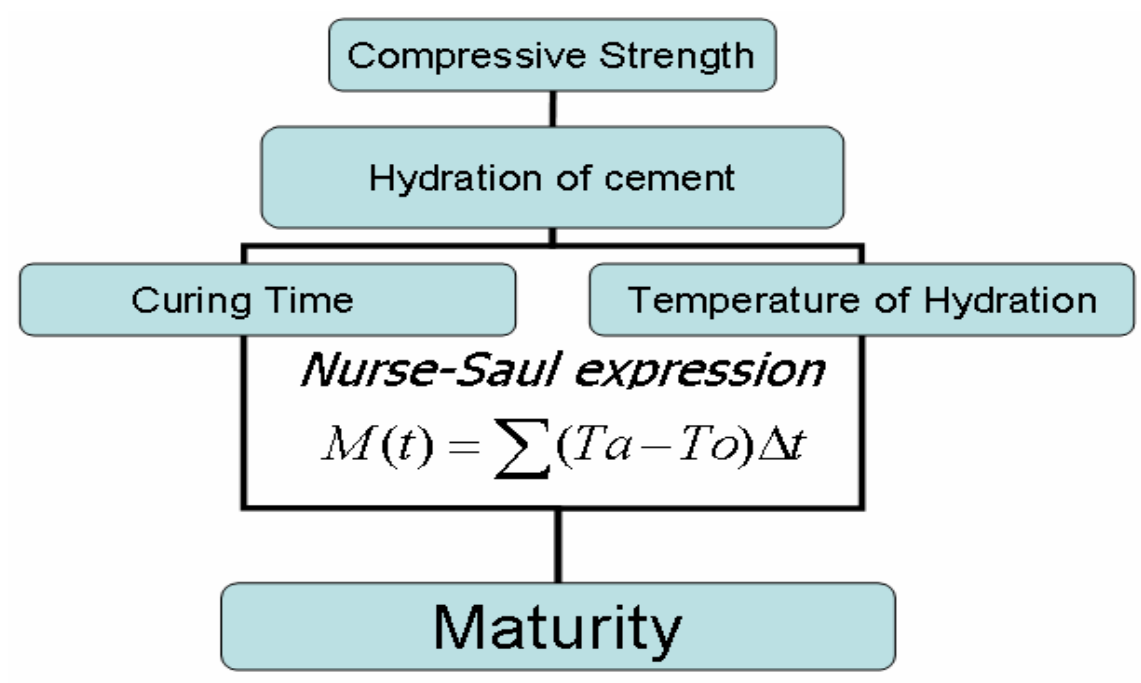

Figure 5-1 Maturity concept

The assumption in this method is that the two concretes with the same maturity present the same compressive strength, even though they have different conditions of exposure. For example, a concrete cured under cold temperatures will take longer time to reach a specific maturity than a concrete cured under hot temperatures. But as soon as the two concrete samples reach the same maturity; these samples will have the same strength even though the individual curing conditions are not the same. This example is shown in Figure 5-2. 

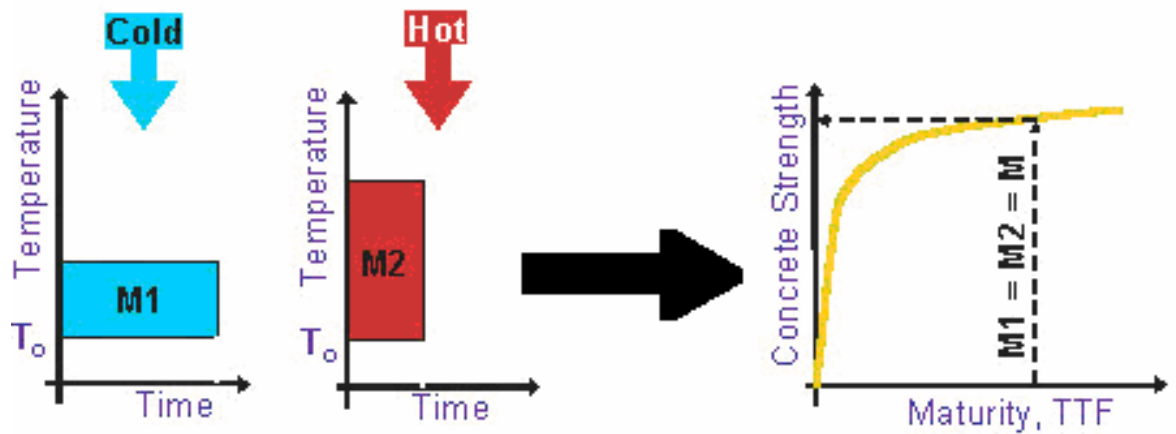

Figure 5-2 Maturity method assumption

\subsection{Significance of the Test}

This test provides a procedure for estimating concrete compressive strength by means of maturity method. This method is a technique for estimating concrete strength based on the assumption that samples of a given concrete mixtures reach equal strength, if they have equal values of a maturity index, which is an indicator of maturity calculated from the temperature history of the cementitious mixture by using a maturity function (ASTM C 1074).

By using this method, the timing for applying external loads in a structure by post-tensioning or live loads can be estimated. Also this provides information on formwork removal time resulting in a faster construction and significant cost savings. Using concrete maturity in combination with, or instead of testing different specimens such as cylinders to measure concrete strength, can improve quality control, because the maturity method is based on data obtained from the real structure and not from test specimens. Like any other testing method, this method has limitations; such as it is important that the concrete must be maintained in a condition that permits the cement hydration and also it does not take into account the effects of early-age concrete temperature on the long-term strength

To obtain accurate values of concrete strength it is important to develop an appropriate maturity function for the particular concrete mixture. The function consists of a mathematical expression that uses the measured temperature history of a cementitious mixture during the 
curing period in order to calculate an index that is indicative of the maturity at the end of that period. In the ASTM C 1074, two functions are described for computing the maturity index from the measured temperature history of the concrete. One is the temperature time factor and the other one uses the equivalent age.

The technology used in this project works with sacrificial data loggers that were attached to the existing reinforcement before the concrete was placed. The loggers contain temperature sensors and memory devices that periodically record the temperature of concrete as it cures. It also calculates the maturity index on the sensor itself using the temperature factor function. Then a reader is used to communicate with and download maturity and temperature data from the loggers. Figure 5-3 presents the way the maturity loggers were attached to the steel reinforcement layers.

For the three mixtures used in this project, a total of 14 maturity loggers were installed in different locations of each slab as it is shown in Figure 5-4. The idea was to take significant readings of the maturity evolution of the complete slab. The recording time interval of these loggers was every 1 hour until 90 days were reached.

The distribution of the maturity loggers followed the recommendations by the Concrete Pavement Technology Program (CPTP). The general location guidelines followed for concrete pavements are presented below:

- Sensors placed at slabs mid-depth are useful for determining the average strength of the slab and the appropriate times for opening to traffic.

- Sensors placed within $25 \mathrm{~mm}$ (1 in.) of the surface can be used to determine the timing of joint sawing operations.

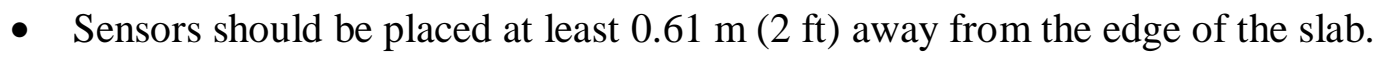

- Sensors should be placed at intervals between 150 and $300 \mathrm{~m}$ (500 and $1000 \mathrm{ft}$ ) along the length of the paving to account for variations in placement time and to provide estimates of optimum joist sawing times in each interval or section. 
- Sensors are often affixed to stakes or rebars that are driven into the base prior to paving operations, allowing the placement of the sensors at the desired depth.

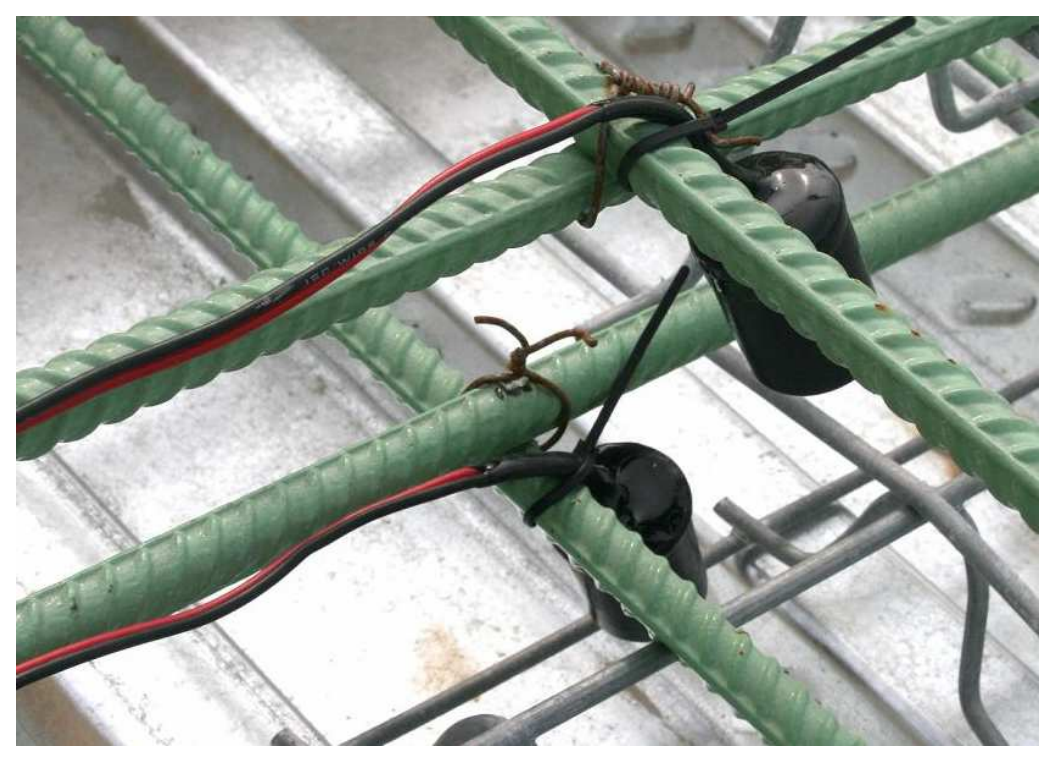

Figure 5-3 Maturity Loggers Attached to the Top and Bottom Steel Reinforcement
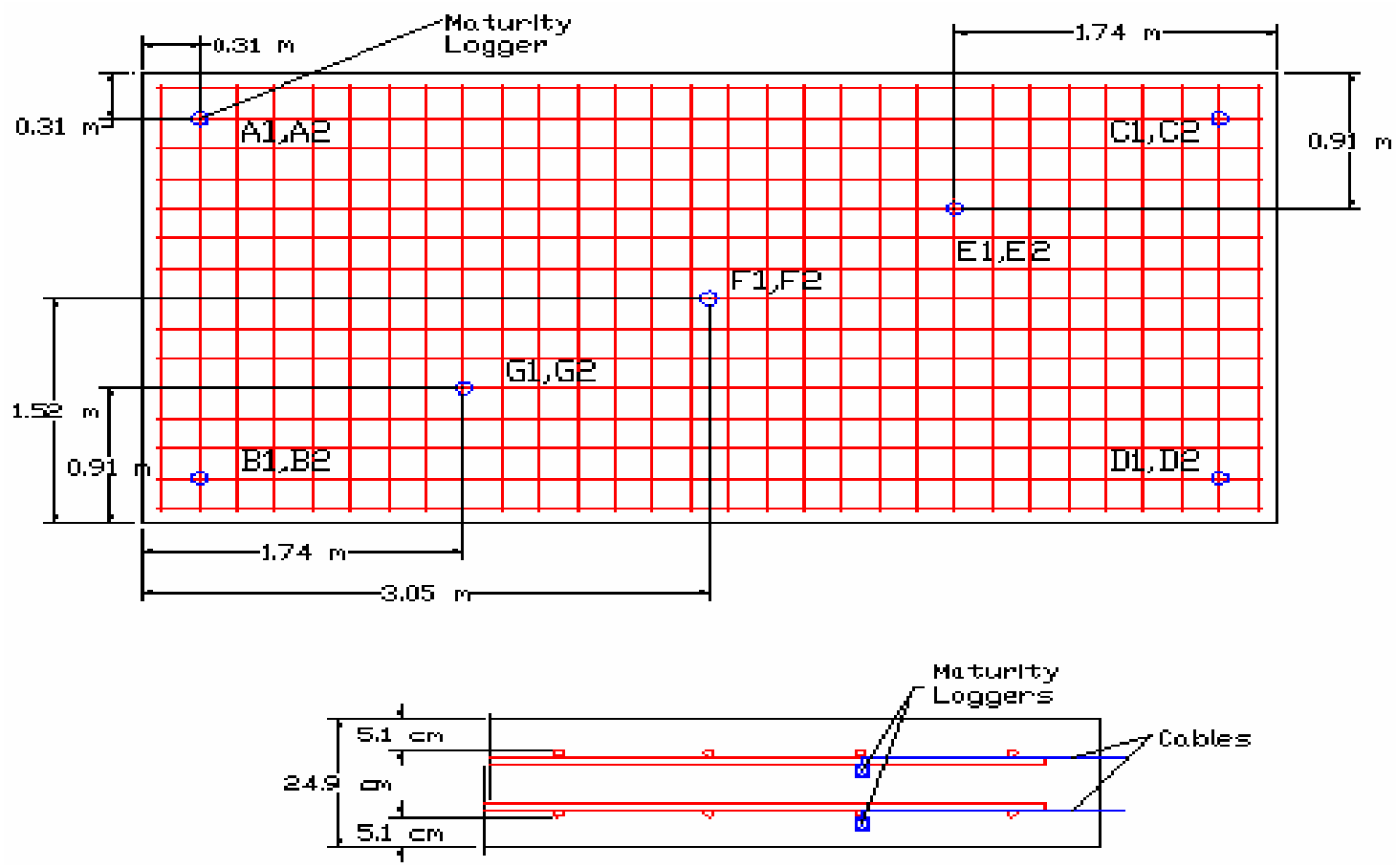

$(1 \mathrm{~m}=3.28 \mathrm{ft}, 1 \mathrm{~mm}=0.039$ in. $)$

Figure 5-4 Distribution of maturity loggers 


\subsection{Test Standards}

The standard ASTM C 1074 (Estimation of concrete strength by maturity method) was followed in this practice.

\subsection{Maturity Function}

A maturity function that offers a good correlation with the strength of concrete is the NurseSaul expression (Crawford, 1997; ACPA, 2002). Due to the type of the maturity loggers and the temperature reader used in this project and because the Nurse-Saul function is more commonly used by various states highways agencies in the United States, it was opted to use this function in this project. The maturity function described in the ASTM C 1074 as temperature-time factor function (Nurse-Saul) is as presented in equation 5-1:

$$
M(t)=\sum(T a-T o) \Delta t
$$

Where:

$\mathrm{M}(\mathrm{t})=$ Temperature-time factor at age $\mathrm{t}$. degree-days or degree-hours.

$\Delta \mathrm{t} \quad=$ Time interval, days or hours.

Ta $=$ Average concrete temperature during time interval, $\Delta \mathrm{t},{ }^{\circ} \mathrm{C}$

To $=$ Temperature subtracted from measure concrete temperature (recommended value 0 $\left.{ }^{\circ} \mathrm{C}=32{ }^{\circ} \mathrm{F}\right)$.

An important variable in equation 5-1 is the datum temperature. It is the temperature below which gain of concrete strength ceases. Therefore, the time periods during which the concrete stays below this datum temperature do not contribute to strength gain. Recommended values for the datum temperature are provided in ASTM C 1074. The datum temperature is affected by parameters such as cement fineness, particle size distribution, w/cm, cement composition, admixtures, and initial temperature. The datum temperatures assumed for this project after recommendations from Engius Inc. (Maturity loggers manufacturer) and discussion with the advisory panel was of $0{ }^{\circ} \mathrm{C}\left(32^{\circ} \mathrm{F}\right)$ for all the concrete mixtures. 
After the maturity function has been selected, following three steps were followed to carry out the maturity method: 1) Development of the maturity calibration curve for the specific mixture; 2) Estimation of the in-situ strength of the concrete using the maturity index calculated from the recorded temperature history; 3) Verification of the strength-maturity relationship.

\subsection{Development of the Maturity Calibration Curve}

Compressive strength is the single most important property for the evaluation of concrete mixtures, as all material and design specifications are based on this parameter. In this work the strength and temperature evolution of concrete were monitored to establish the strengthmaturity relationship of HPC with time which may be used for similar applications in field work.

The strength-maturity relationship was developed in the laboratory using the same concretes those were used in the slabs considering the facts that each maturity calibration curve depends on the characteristics of the specific mixture, material sources, mixture proportions, and mixing equipment. For every alternation of the condition it is required to development of a new calibration curve.

In this project two cylindrical specimens of 152 x $304 \mathrm{~mm}$ (6 x12 in.) were used for each mixture in order to have a laboratory control of the temperature, maturity, and strength of the concrete mixtures at different ages, and then it was possible for the development of a maturity calibration curve and function for each specific HPC used in this project.

To get the temperature and maturity data, a maturity logger was embedded inside the two cylindrical specimens for each mixture. All the specimens were laboratory-cured under the similar conditions to those specimens tested for compressive strengths.

Cylindrical specimens were tested for compressive strengths at 4, 7, 14, 28, 56, and 90 days in accordance with test method ASTM C 39 and the average maturity index was recorded for the 
instrumented specimens at the similar ages. For the development of the maturity calibration curve only the data until 28 days was used following the ASTM 1074.

The plot of average compressive strength vs. average value of the maturity index was the strength-maturity relationship, which could be used for estimating the strength of the concrete mixtures cured under other temperature conditions.
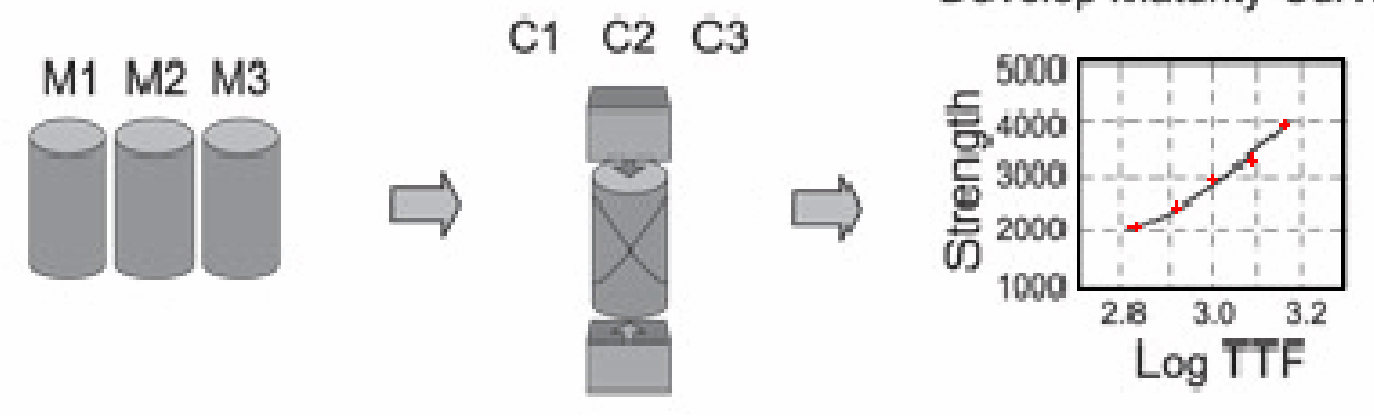

Figure 5-5 Development of maturity calibration curve

\subsection{Estimation of In-Place Strength}

The procedure to estimate the in-place strength of the concrete was as follow:

1. The loggers were located in different places with the intention of having a complete monitoring of the slabs as it is shown in Figure 5-4.

2. The activation of these loggers was done minutes before the concrete was placed.

3. To find the strength at locations of the sensors it was required to read the value of the maturity index from the logger and then used the strength-maturity relationship specified for that concrete mixture.

\subsection{Verification of the Strength-Maturity Relationship}

In order to verify the strength-maturity relationship, some core samples were drilled from locations close to maturity sensors in the concrete slabs. Then the maturity index was 
recorded from the sensors and the cores were tested for compressive strength. Finally, a comparison of the predicted and the tested strength was done in order to check the accuracy of the maturity calibration curves. The predicted values from using the maturity indices from the concrete slabs were also compared to the strength values obtained from the match-cured cylindrical specimens.

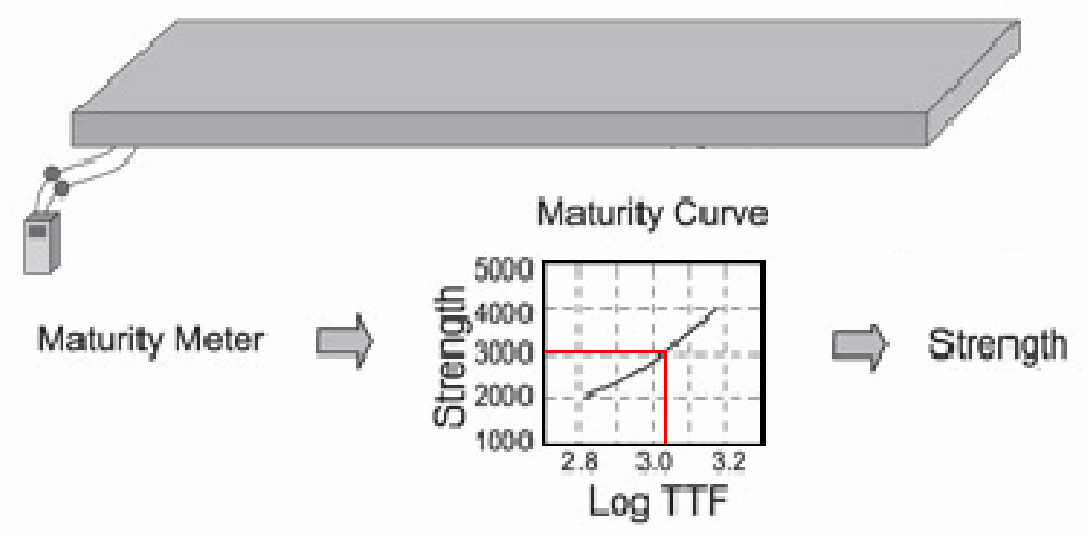

Figure 5-6 Estimation of in-place strength

\subsection{Results and Discussions}

\subsubsection{Strength-Maturity Correlations}

Table 5-2 (a), (b) and (c) present the maturity and compressive strength data used for the correlation curves. The average values for the maturity indices and the compressive strength were calculated and plotted in Figure 5-7 (a), (b) and (c).

The strength-maturity relationship can be written in the form proposed by equation 5-2. Table 5-1 presents the Strength-Maturity equations that were obtained and then used to predict the compressive strength of these three concrete mixtures as function of the maturity index.

$Y=b \times \operatorname{Ln}(x)+a$

Where

Y : Compressive strength 
$\mathrm{x} \quad$ : Maturity index at any time $\mathrm{t}$.

$\mathrm{a}, \mathrm{b}$ : Are functions of the proportions and the materials used in the concrete mixture, (these values have no physical meaning).

The correlation curves were generated according to the Nurse-Saul material function (Equation 5-1). The graphs of the natural logarithms curve adequately fitted the data as shown by the $\mathrm{R}^{2}$ values.

Table 5-1 Strength-maturity equations

\begin{tabular}{l|c|c|c|c}
\hline \multicolumn{1}{c|}{ Concrete mixture } & a & $\mathbf{b}$ & $\mathbf{Y = b}{ }^{*} \operatorname{Ln}(\mathbf{x})+\mathbf{a}$ & $\mathbf{R}^{\mathbf{2}}$ \\
\hline Slag + Metakaolin & -102.23 & 16.41 & $\mathrm{Y}=16.41^{*} \operatorname{Ln}(\mathrm{x})-102.23$ & 0.9843 \\
\hline Fly Ash + Silica Fume & -68.51 & 12.88 & $\mathrm{Y}=12.88{ }^{*} \operatorname{Ln}(\mathrm{x})-68.51$ & 0.9922 \\
\hline Slag + Silica Fume & -68.04 & 14.10 & $\mathrm{Y}=14.10^{*} \operatorname{Ln}(\mathrm{x})-68.04$ & 0.9433 \\
\hline
\end{tabular}

A single correlation curve can be used throughout a project for placement of the same mixture design because each mixture design requires a separate strength-maturity relationship. These relationships can be used as an additional control method to check the adequate strength of a given mixture design.

Periodic validation of the correlation curves and equations using test cylinders with maturity loggers embedded is recommended and also careful quality control is still required when this method is used in order to confirm that each batch is actually prepared using the appropriate design mixture. 
Table 5-2 Maturity and compressive strength data (a) Slab 1, (b) Slab 2 and (c) Slab 3

\begin{tabular}{|c|c|c|c|c|c|c|c|c|}
\hline \multicolumn{9}{|c|}{ Slag + Metakaolin } \\
\hline $\begin{array}{l}\text { Maturity } \\
\text { Level }\end{array}$ & $\begin{array}{c}\text { Specimen } \\
\text { Strength } \\
\text { (MPa) }\end{array}$ & $\begin{array}{c}\text { Average } \\
\text { Strength } \\
\text { (MPa) }\end{array}$ & $\begin{array}{l}\text { Maturity } \\
\text { Elapsed } \\
\text { Time } \\
\text { (hh:mm) }\end{array}$ & $\begin{array}{l}\text { Specimen } \\
\text { Maturity } \\
\text { ('C-Hrs) }\end{array}$ & $\begin{array}{l}\text { Temp } \\
\left({ }^{\circ} \mathrm{C}\right)\end{array}$ & $\begin{array}{l}\text { Average } \\
\text { Maturity } \\
\text { ('C-Hrs) }\end{array}$ & $\begin{array}{c}\text { Average } \\
\text { Temp } \\
\left({ }^{\circ} \mathrm{C}\right)\end{array}$ & $\begin{array}{c}\text { Average } \\
\text { Age } \\
\text { (days) }\end{array}$ \\
\hline \multirow{3}{*}{1} & 20 & \multirow{3}{*}{25} & 102:00 & 2,530 & 23 & \multirow{3}{*}{2,522} & \multirow{3}{*}{23} & \multirow{3}{*}{4} \\
\hline & 26 & & 102:00 & 2,513 & 23 & & & \\
\hline & 29 & & & & & & & \\
\hline \multirow{3}{*}{2} & 32 & \multirow{3}{*}{37} & $170: 00$ & 4,093 & 23 & \multirow{3}{*}{4,085} & \multirow{3}{*}{23} & \multirow{3}{*}{7} \\
\hline & 38 & & 170:00 & 4,076 & 23 & & & \\
\hline & 39 & & & & & & & \\
\hline \multirow{3}{*}{3} & 50 & \multirow{3}{*}{45} & $340: 00$ & 8,049 & 23 & \multirow{3}{*}{8,038} & \multirow{3}{*}{23} & \multirow{3}{*}{14} \\
\hline & 43 & & $340: 00$ & 8,026 & 23 & & & \\
\hline & 41 & & & & & & & \\
\hline \multirow{3}{*}{4} & 55 & \multirow{3}{*}{56} & $672: 00$ & 15,442 & 21 & \multirow{3}{*}{15,431} & \multirow{3}{*}{21} & \multirow{3}{*}{28} \\
\hline & 54 & & 672:00 & 15,420 & 21 & & & \\
\hline & 58 & & & & & & & \\
\hline
\end{tabular}

(a)

\begin{tabular}{|c|c|c|c|c|c|c|c|c|}
\hline \multicolumn{9}{|c|}{ Fly Ash + Silica Fume } \\
\hline $\begin{array}{c}\text { Maturity } \\
\text { Level }\end{array}$ & $\begin{array}{l}\text { Specimen } \\
\text { Strength } \\
\text { (MPa) }\end{array}$ & $\begin{array}{c}\text { Average } \\
\text { Strength } \\
\text { (MPa) }\end{array}$ & $\begin{array}{l}\text { Maturity } \\
\text { Elapsed } \\
\text { Time } \\
\text { (hh:mm) }\end{array}$ & $\begin{array}{l}\text { Specimen } \\
\text { Maturity } \\
\text { ('C-Hrs) }\end{array}$ & $\begin{array}{l}\text { Temp } \\
\left({ }^{\circ} \mathrm{C}\right)\end{array}$ & $\begin{array}{l}\text { Average } \\
\text { Maturity } \\
\text { ('C-Hrs) }\end{array}$ & $\begin{array}{c}\text { Average } \\
\text { Temp } \\
\left({ }^{\circ} \mathrm{C}\right)\end{array}$ & $\begin{array}{c}\text { Average } \\
\text { Age } \\
\text { (days) }\end{array}$ \\
\hline \multirow{3}{*}{1} & 30 & \multirow{3}{*}{32} & $102: 00$ & 2,525 & 23 & \multirow{3}{*}{2,564} & \multirow{3}{*}{23} & \multirow{3}{*}{4} \\
\hline & 30 & & 102:00 & 2,602 & 23 & & & \\
\hline & 35 & & & & & & & \\
\hline \multirow{3}{*}{2} & 34 & \multirow{3}{*}{40} & $170: 00$ & 4,089 & 23 & \multirow{3}{*}{4,128} & \multirow{3}{*}{23} & \multirow{3}{*}{7} \\
\hline & 43 & & $170: 00$ & 4,166 & 23 & & & \\
\hline & 42 & & & & & & & \\
\hline \multirow{3}{*}{3} & 52 & \multirow{3}{*}{48} & $340: 00$ & 8,031 & 23 & \multirow{3}{*}{8,079} & \multirow{3}{*}{23} & \multirow{3}{*}{14} \\
\hline & 43 & & $340: 00$ & 8,126 & 23 & & & \\
\hline & 48 & & & & & & & \\
\hline \multirow{3}{*}{4} & 55 & \multirow{3}{*}{55} & $672: 00$ & 15,416 & 21 & \multirow{3}{*}{15,466} & \multirow{3}{*}{21} & \multirow{3}{*}{28} \\
\hline & 54 & & $672: 00$ & 15,515 & 21 & & & \\
\hline & 56 & & & & & & & \\
\hline
\end{tabular}

(b) 


\begin{tabular}{|c|c|c|c|c|c|c|c|c|}
\hline \multicolumn{9}{|c|}{ Slag + Silica Fume } \\
\hline $\begin{array}{c}\text { Maturity } \\
\text { Level }\end{array}$ & $\begin{array}{l}\text { Specimen } \\
\text { Strength } \\
\text { (MPa) }\end{array}$ & $\begin{array}{c}\text { Average } \\
\text { Strength } \\
\text { (MPa) }\end{array}$ & $\begin{array}{l}\text { Maturity } \\
\text { Elapsed } \\
\text { Time } \\
\text { (hh:mm) }\end{array}$ & $\begin{array}{c}\text { Specimen } \\
\text { Maturity } \\
\text { ('C-Hrs) }\end{array}$ & $\begin{array}{l}\text { Temp } \\
\left({ }^{\circ}\right)\end{array}$ & $\begin{array}{l}\text { Average } \\
\text { Maturity } \\
\left({ }^{\circ} \mathrm{C}-\mathrm{Hrs}\right)\end{array}$ & $\begin{array}{c}\text { Average } \\
\text { Temp } \\
\left({ }^{\circ}\right)\end{array}$ & $\begin{array}{c}\text { Average } \\
\text { Age } \\
\text { (days) }\end{array}$ \\
\hline \multirow[b]{2}{*}{1} & 41 & \multirow[b]{2}{*}{40} & 102:00 & 2,575 & 23 & \multirow[b]{2}{*}{2,585} & \multirow[b]{2}{*}{23} & \multirow[b]{2}{*}{4} \\
\hline & 40 & & 102:00 & 2,595 & 23 & & & \\
\hline \multirow[b]{2}{*}{2} & 48 & \multirow[b]{2}{*}{50} & 170:00 & 4,138 & 23 & \multirow[b]{2}{*}{4,148} & \multirow[b]{2}{*}{23} & \multirow[b]{2}{*}{7} \\
\hline & 53 & & 170:00 & 4,158 & 23 & & & \\
\hline \multirow[b]{2}{*}{3} & 63 & \multirow[b]{2}{*}{62} & $340: 00$ & 8,078 & 23 & \multirow[b]{2}{*}{8,083} & \multirow[b]{2}{*}{23} & \multirow[b]{2}{*}{14} \\
\hline & 60 & & $340: 00$ & 8,088 & 23 & & & \\
\hline \multirow[b]{2}{*}{4} & 68 & \multirow[b]{2}{*}{66} & $672: 00$ & 15,445 & 21 & \multirow[b]{2}{*}{15,431} & \multirow[b]{2}{*}{21} & \multirow[b]{2}{*}{28} \\
\hline & 63 & & $672: 00$ & 15,416 & 21 & & & \\
\hline
\end{tabular}

(c)

$\left(1 \mathrm{MPa}=145 \mathrm{psi},{ }^{\circ} \mathrm{F}=5 / 9 *\left({ }^{\circ} \mathrm{C}-32\right)\right)$

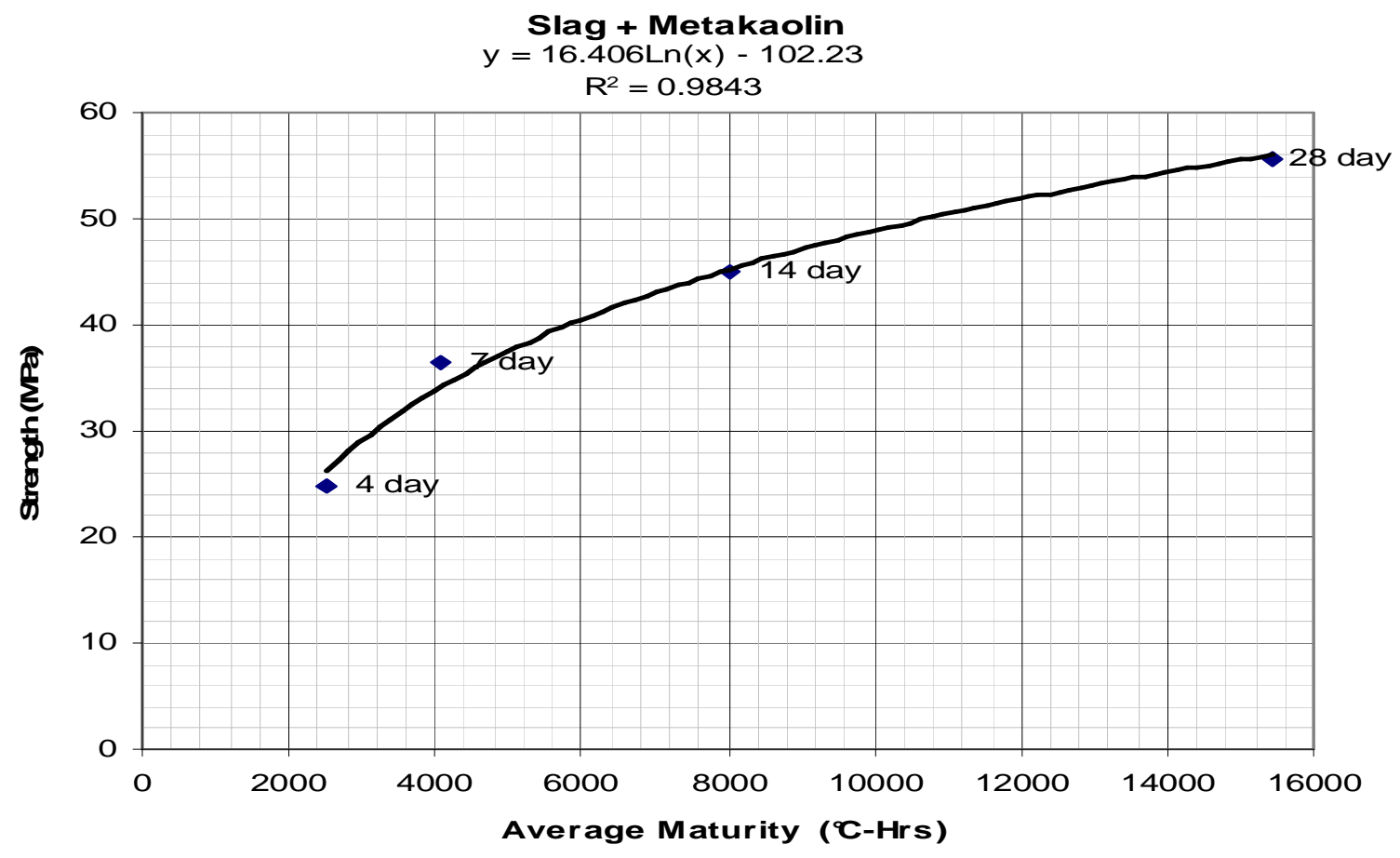

(a) 
Fly Ash + Silica Fume

$y=12.883 \operatorname{Ln}(x)-68.514$

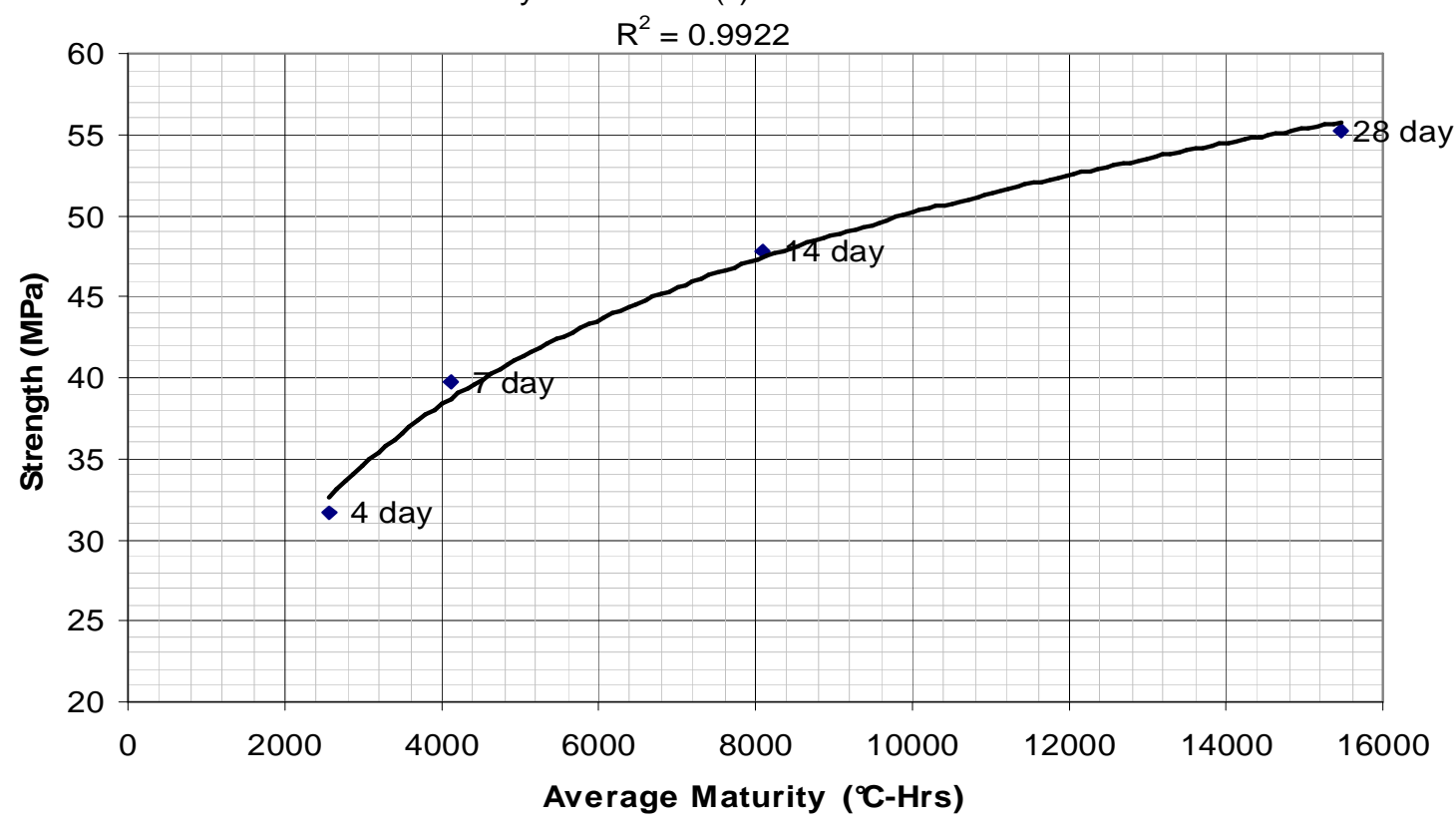

(b)

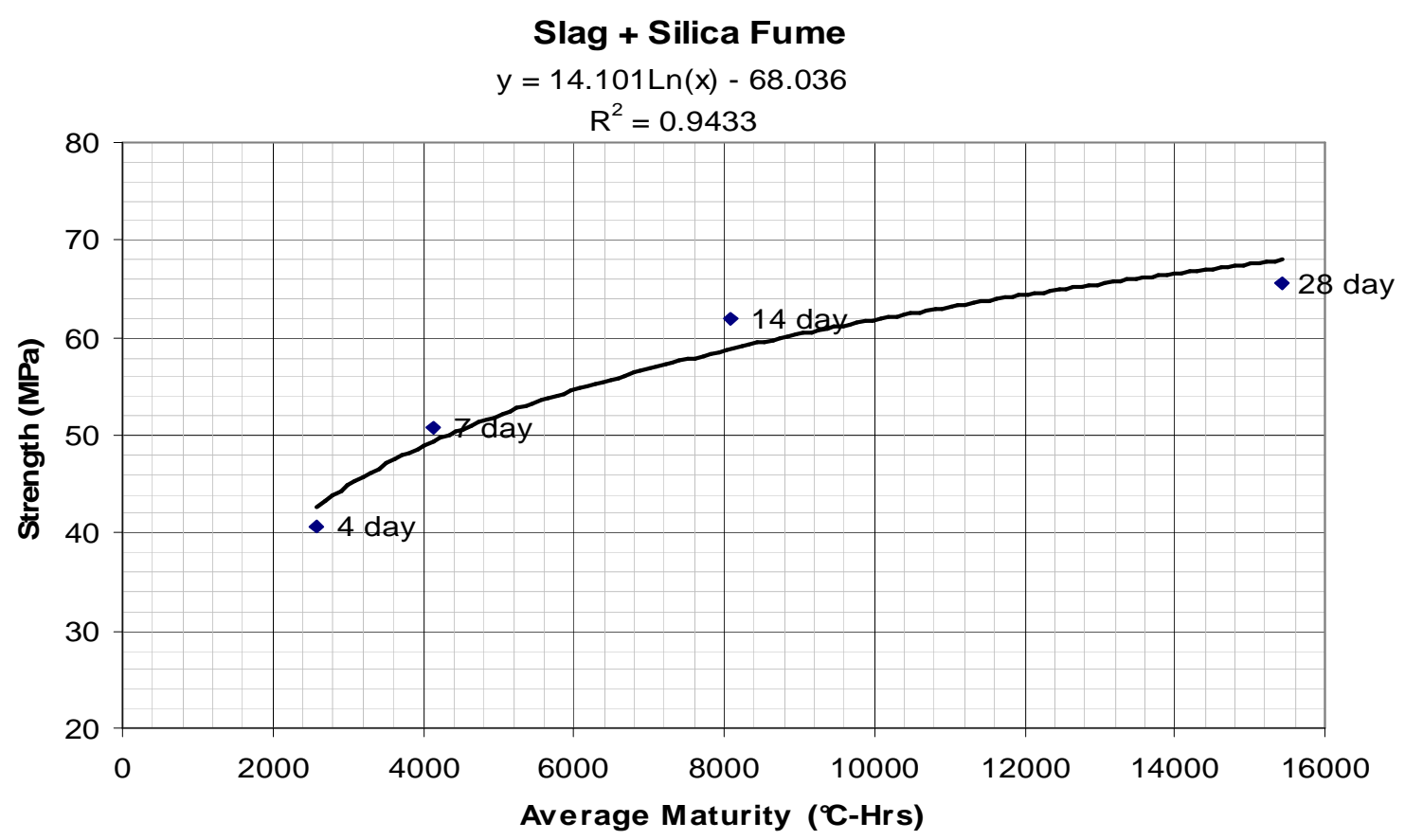

(c)

$\left(1 \mathrm{MPa}=145 \mathrm{psi},{ }^{\circ} \mathrm{F}=5 / 9 *\left({ }^{\circ} \mathrm{C}-32\right)\right)$

Figure 5-7 Strength-maturity relationship curves (a) Slab 1, (b) Slab 2 and (c) Slab 3 


\subsubsection{In-Place Strength and Maturity}

The strength development in a concrete slab is not uniform due to the large area and large volume of the concrete element. Also as concrete gains strength, its temperature varies due to exothermic reaction of hydration. As it was mentioned before the whole area in the slabs was monitored for temperature and maturity using maturity loggers located in two layers at different locations.

After studying the data obtained from the maturity loggers, it was found that higher temperatures were registered by the loggers those were located close to the concrete surface in the interior portions of the slabs. But even when those values were higher, the difference with the others logger was not more than $\pm 4{ }^{\circ} \mathrm{C}\left(8^{\circ} \mathrm{F}\right)$ and the gradient in temperature from the surface to the bottom of the slabs was less than $2^{\circ} \mathrm{C}\left(4^{\circ} \mathrm{F}\right)$.

It is also notable that the temperature reached during the daytime (the peaks) increased after the $10^{\text {th }}$ day curing period. Figure 5-8 through Figure 5-11 clearly shows how the temperature of the concrete slabs was lower than the ambient temperature when they were covered with the wet burlap. But after the wet burlap was removed, the concrete slabs reached higher temperature during the day time compared to the corresponding ambient temperature. 


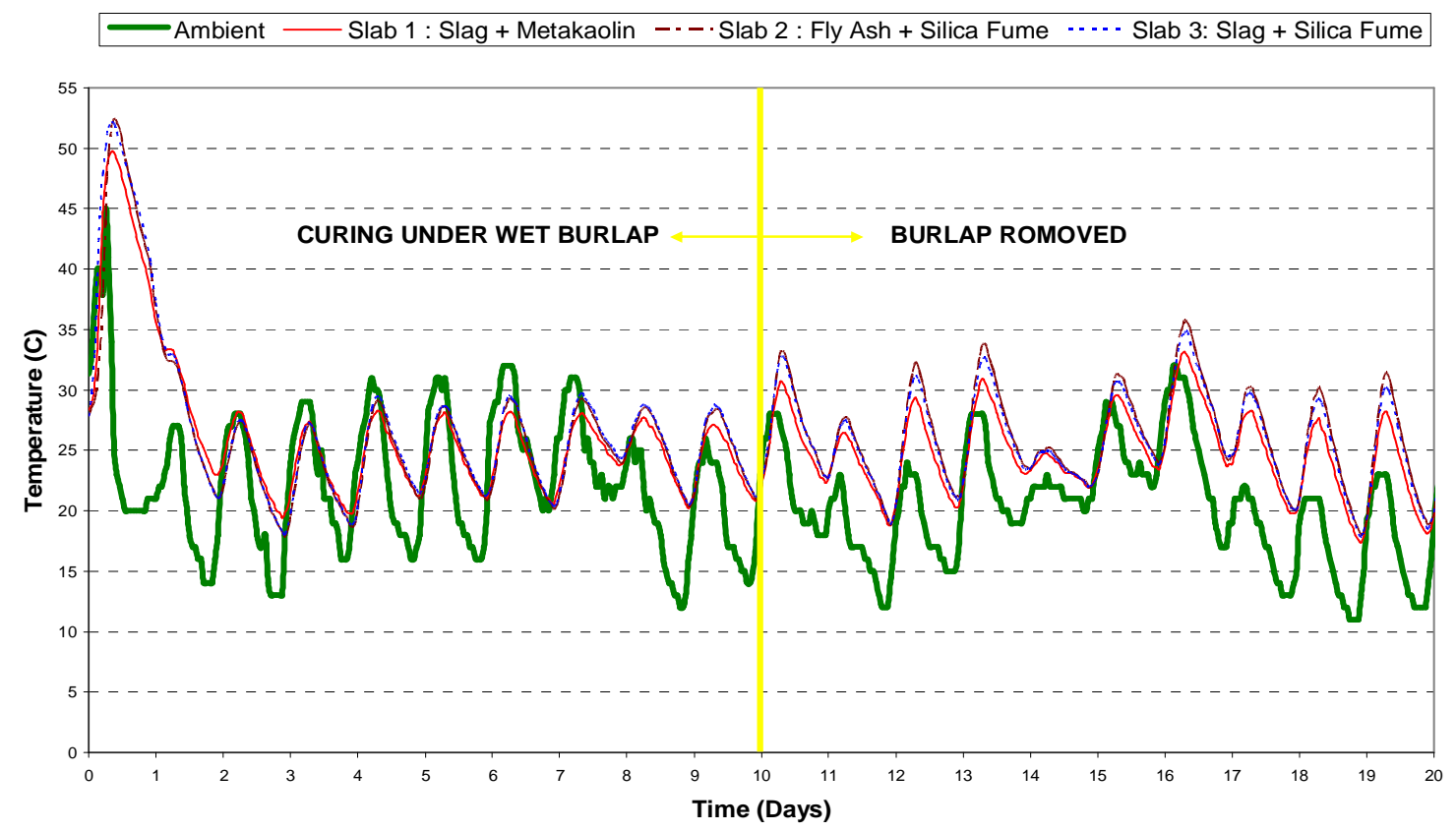

Figure 5-8 Concrete and ambient temperature evolution for 20 Days after Pouring

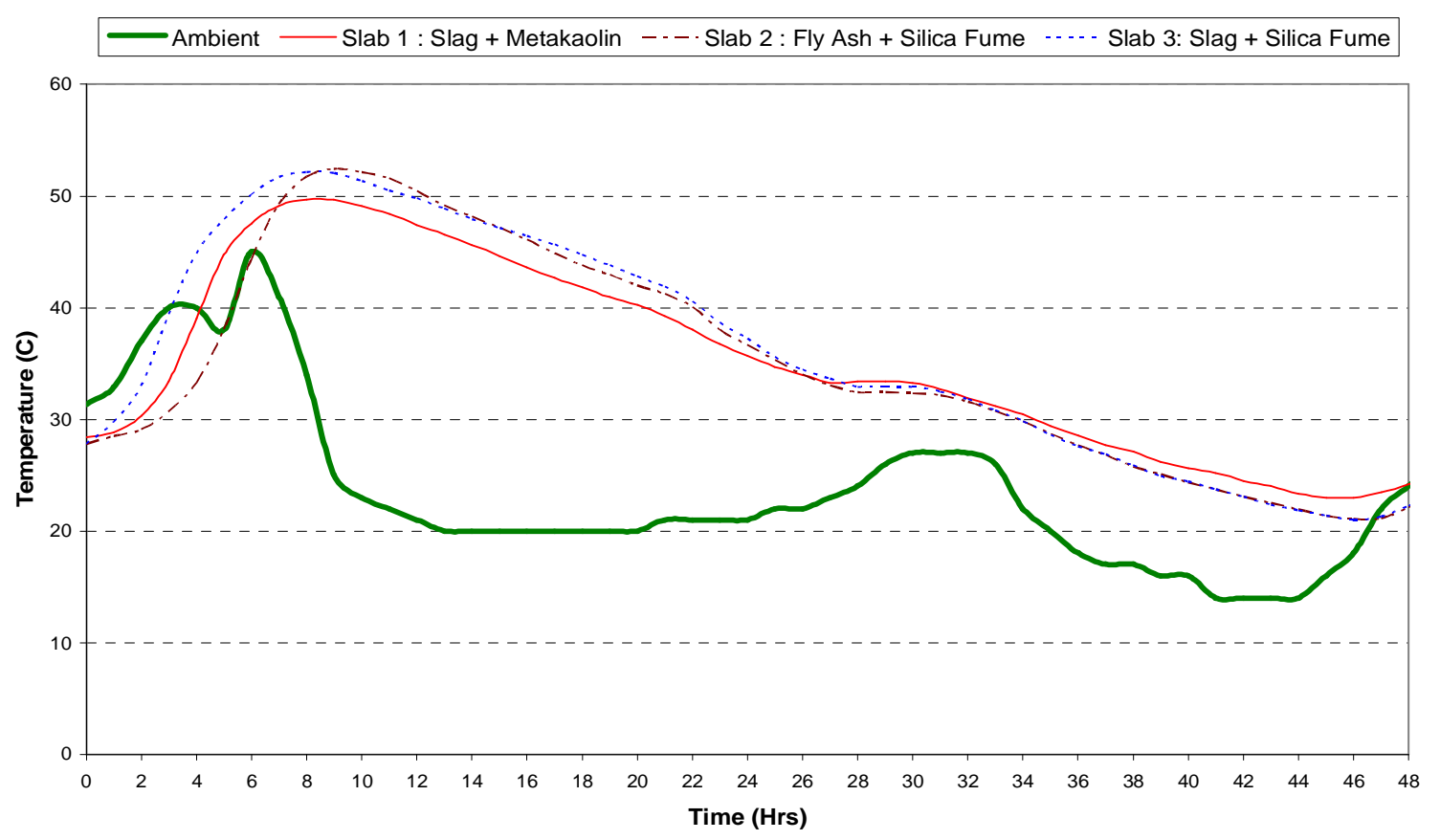

Figure 5-9 Concrete and ambient temperature evolution for the first $\mathbf{4 8}$ hours 


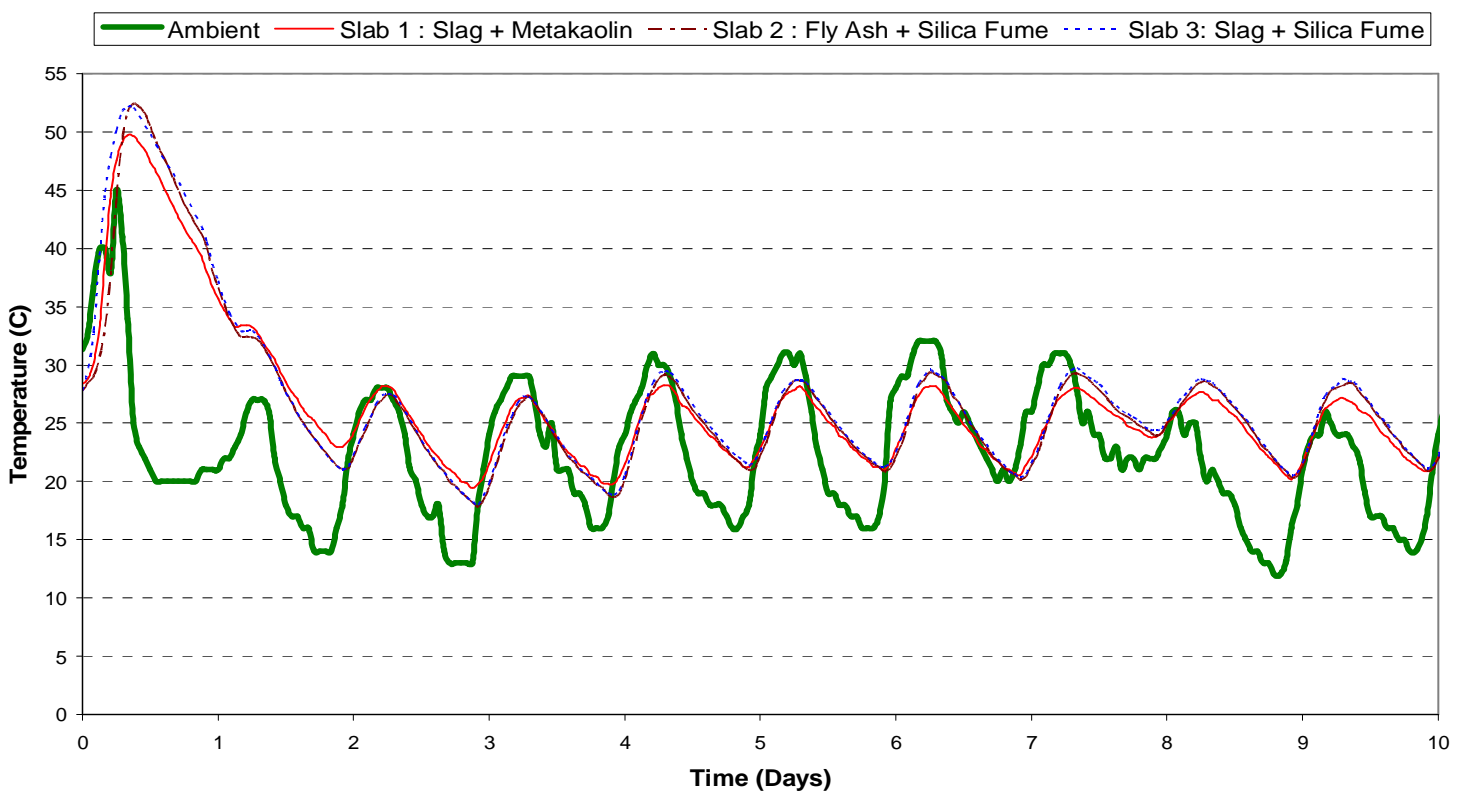

Figure 5-10 Concrete and ambient temperature evolution for the 10 days curing period

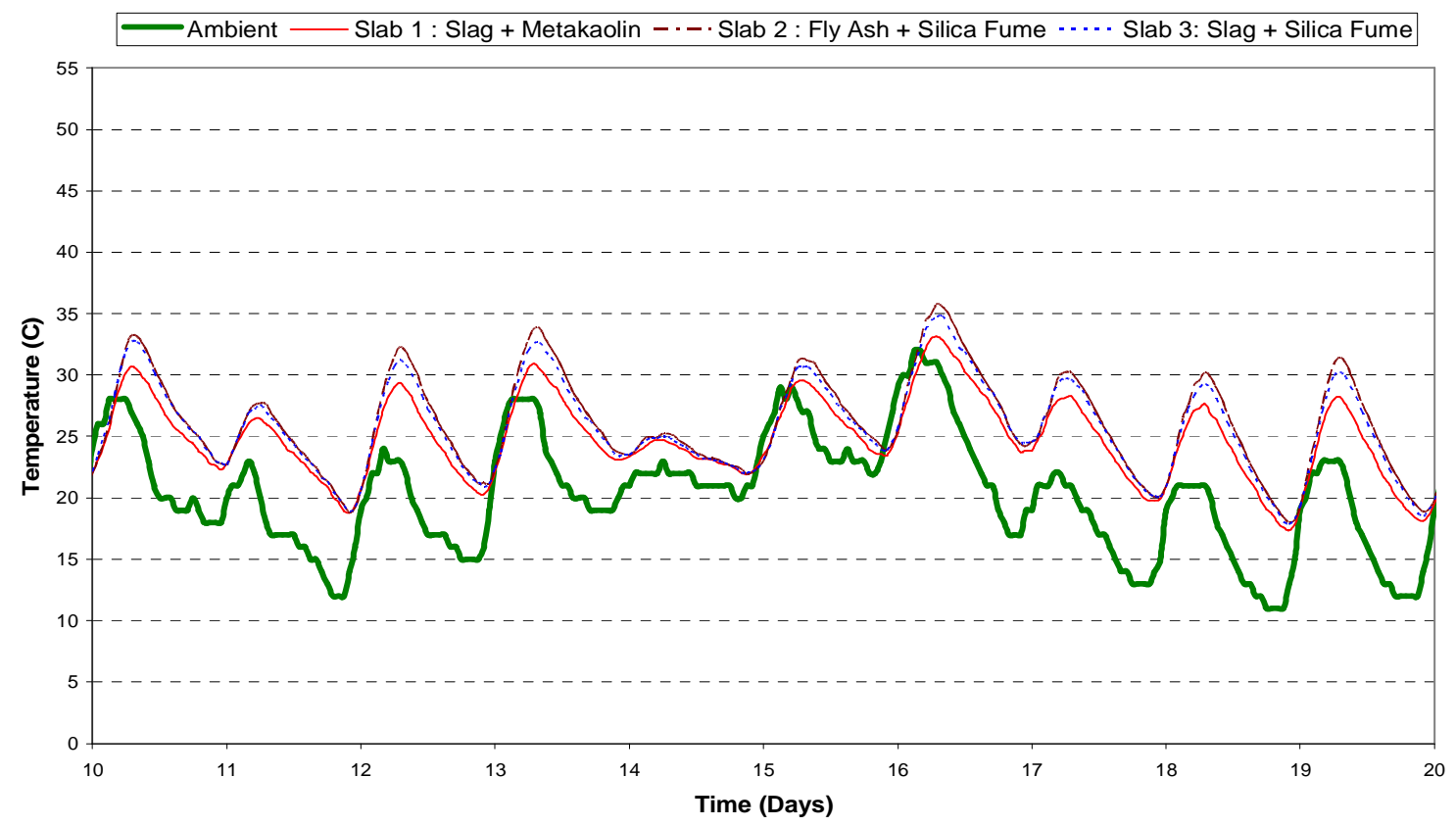

Figure 5-11 Concrete and ambient temperature evolution after burlap was removed

87 
Due to high temperatures in the field during the summer time, the concrete slabs reached higher maturity indices compared to the maturity indices reached by the specimens cured under laboratory conditions. After the second month of pouring, the maturity indices of the specimens cured in the laboratory were higher than the corresponding indices of the concrete slabs. The rate of increase in the maturity index for the laboratory specimens was constant because the temperature in the curing room was controlled and it did not vary much. But for the concrete slabs in the field the rate varied with the ambient temperature. So for in this study as the slabs were poured during the month of August (summer), the rate was higher than the rate of the specimens in the lab. But after the decrease in ambient temperature during the fall, the rate decreased. Figure 5-12 presents how the average temperature in the concrete slabs decreased with time while the temperature of the specimens in the laboratory did not showed any major changes. The rate changes can be observed in Figure 5-13.

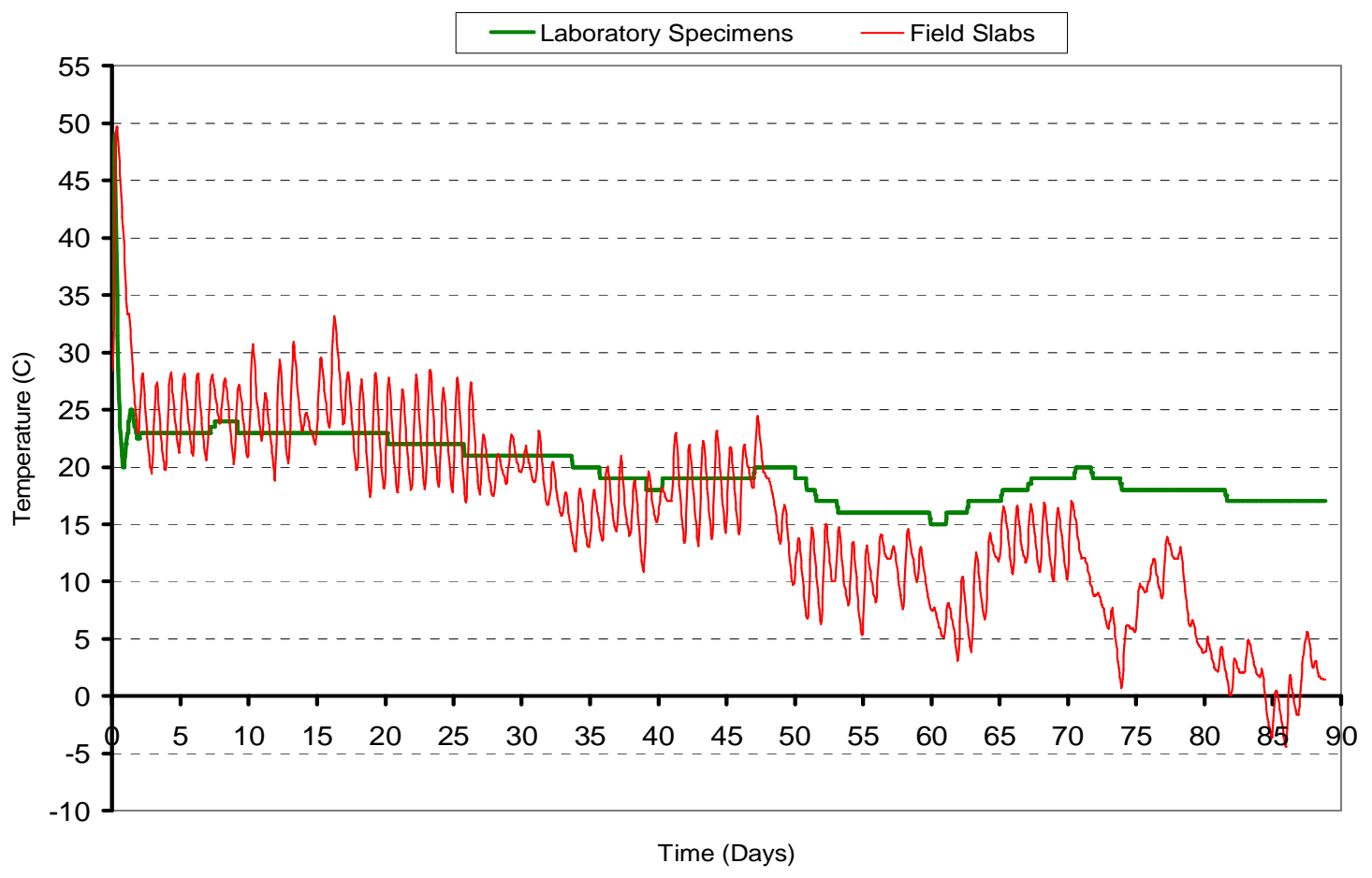

Figure 5-12 Laboratory and field temperature comparison 


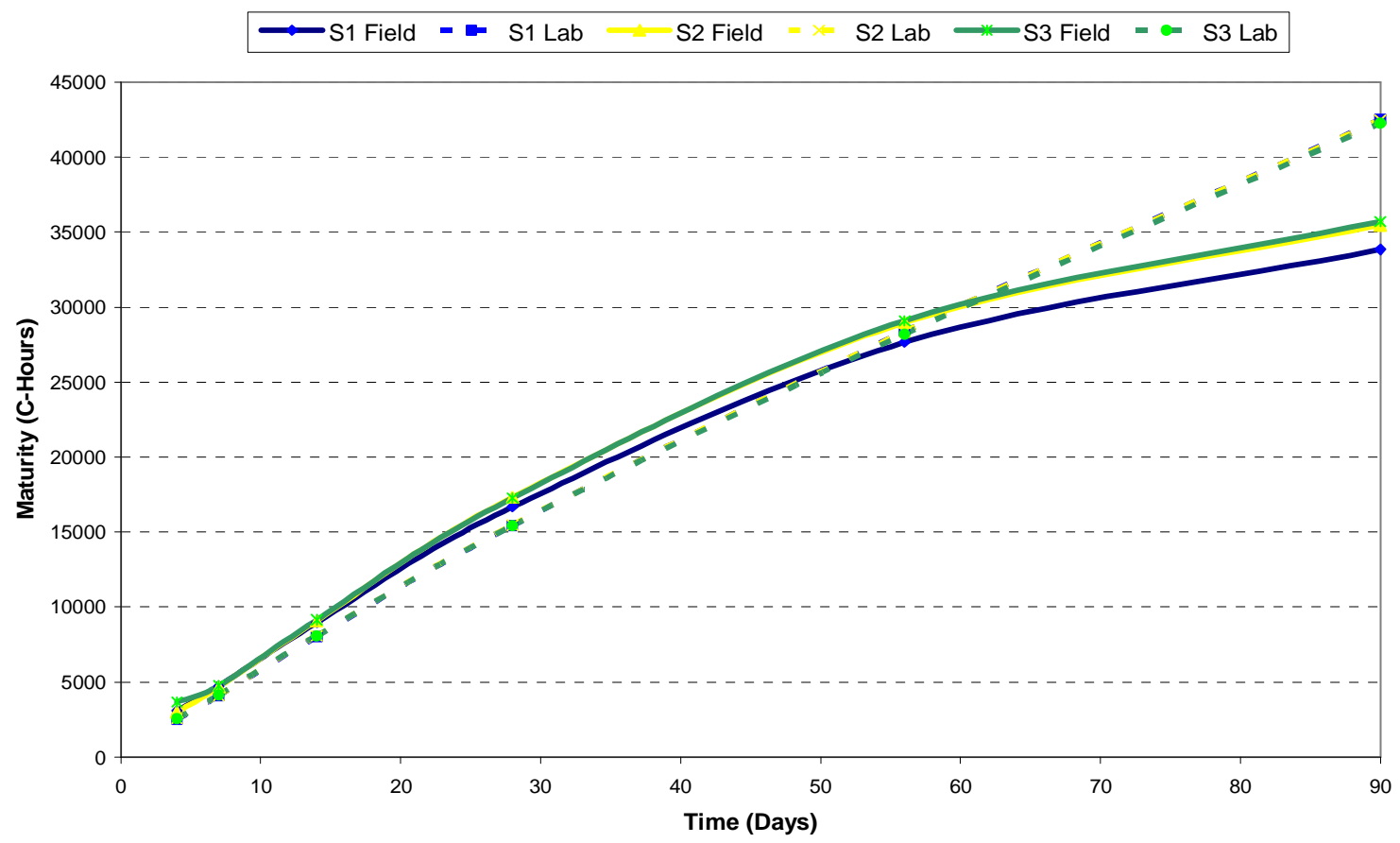

Figure 5-13 Maturity development of concrete slabs and lab-cured specimens

\subsubsection{Verification of Predicted Values}

To check the accuracy of these strength-maturity curves, cylindrical cores were drilled from the concrete slabs at 28 and 56 days and tested for compressive strength.

- For the concrete mixture used in the slab 1 (slag + metakaolin), the predicted and the measured compressive strengths for 28 days were $57 \mathrm{MPa}$ (8270 psi) and $59 \mathrm{MPa}$ (8560 psi), respectively. For 56 days, the predicted strength was $65 \mathrm{MPa}$ (9430 psi) and the measured strength was $66 \mathrm{MPa}(9570 \mathrm{psi})$.

- For the concrete mixture used in the slab 2 (fly ash + silica fume), the predicted and measured compressive strengths for 28 days were $57 \mathrm{MPa}(8270 \mathrm{psi})$ and $58 \mathrm{MPa}$ (8410 psi), respectively. For 56 days, the predicted strength was of $64 \mathrm{MPa}$ (9280 psi) and the measured strength was of $66 \mathrm{MPa}(9570 \mathrm{psi})$. 
- For the concrete mixture used in the slab 3 (slag + silica fume), the 28-day strength was $70 \mathrm{MPa}$ (10150 psi) for both predicted and measured strength; and for 56 days both the predicted and measured values were of $77 \mathrm{MPa}$ (11170 psi).

All The values were compared and observed in Figure 5-14.

From the results presented above it is concluded that the correlation curves and equations obtained from the laboratory testing were accurate and could be used to make a good prediction of the compressive strength for this specific concrete mixtures

For future work, it is recommended to create new correlation curves for these concrete mixtures with more data at early ages, because in this project due to some difficulties in transporting the specimens from the field to the laboratory it was not possible to test the compressive strength of the concrete mixtures before the $4^{\text {th }}$ day.

Slag + Metakaolin

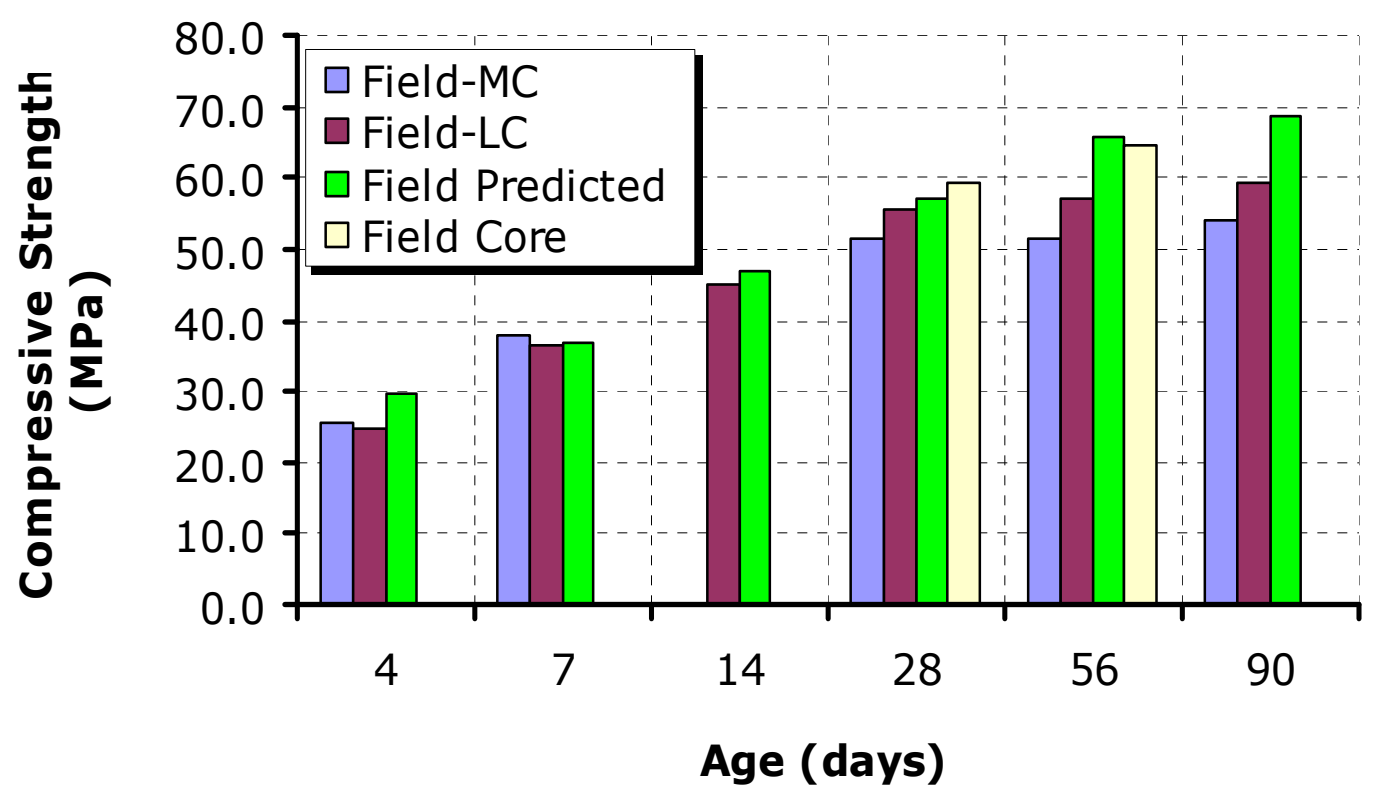

(a) 
Fly Ash + Silica Fume

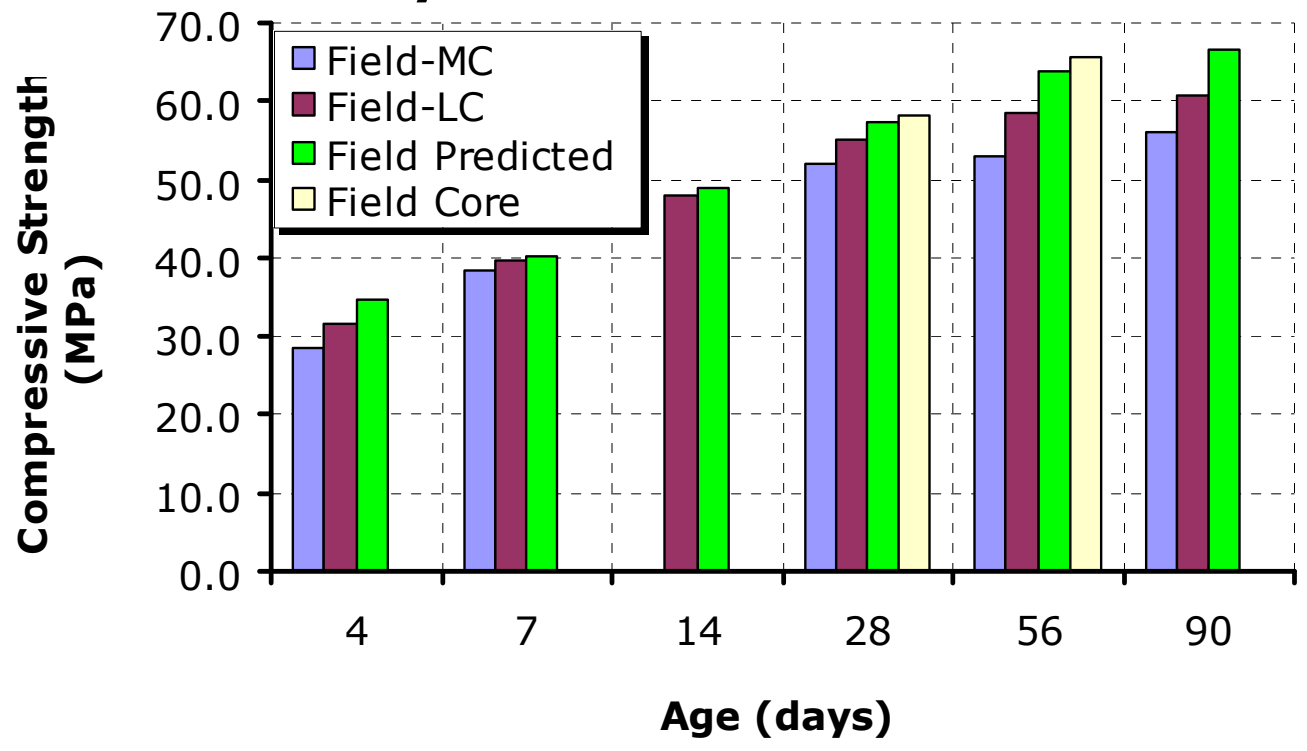

(b)

\section{Slag + Silica Fume}

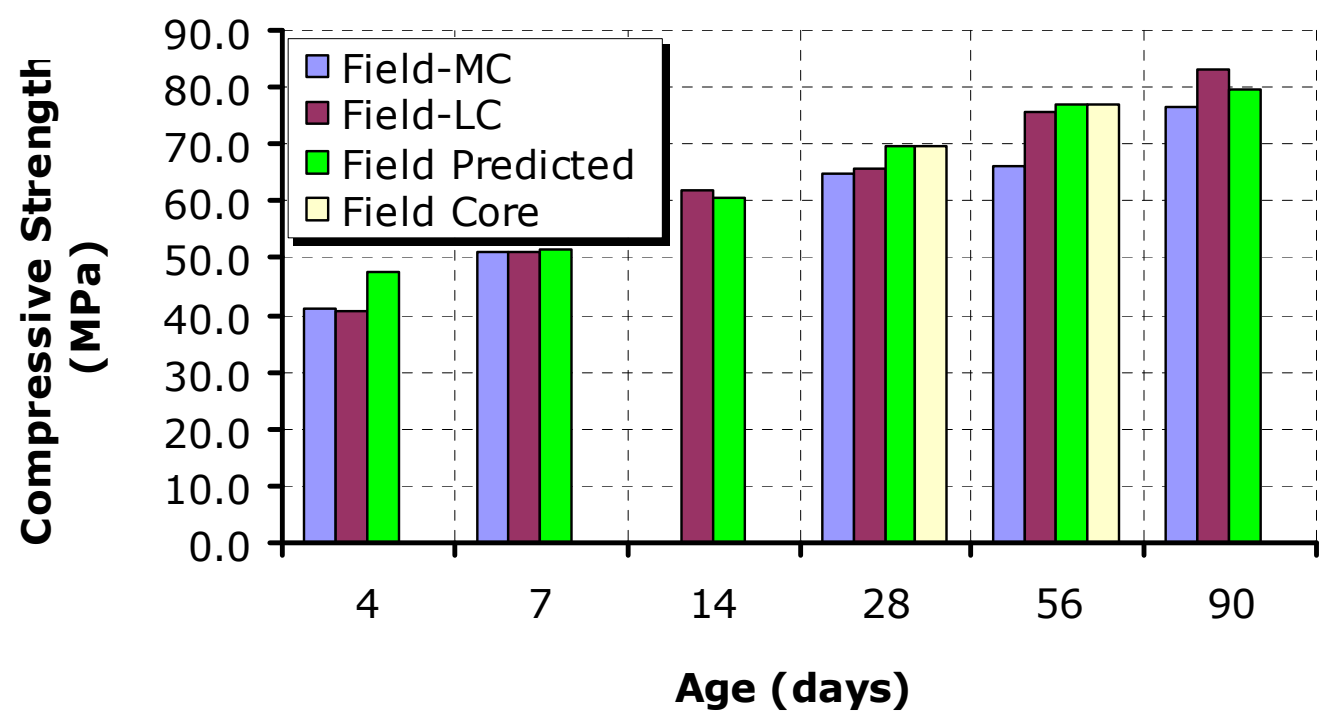

(c)

Figure 5-14 Tested and predicted compressive strength (a) Slab 1, (b) Slab 2, and (c) Slab 3 


\section{CHAPTER 6}

\section{DETAILED AIR-VOID ANALYSIS AND PETROGRAPHIC EXAMINATIONS OF CONCRETE CORE SAMPLES}

This chapter presents the results of petrographic examinations of three concrete cores and hardened air content determinations of nine concrete cores by different techniques. All the cores were taken from the concrete slabs cast as part of this research project.

\subsection{Microscopical determination of the Air-Void System Parameters in hardened HPC}

A cubic meter of concrete has millions of air bubbles creating an air-void system that provides concrete engineers with insight into concrete properties such as compressive strength and resistance to deterioration, which is very important for the evaluation of freezing and thawing performance. An appropriate air-void system ensures a good distribution of the bubbles protecting the whole paste volume. An air bubble also called a air-void, is a space enclosed by the cement paste that was filled with air or other gas prior the setting of the paste, these voids are usually larger than few micrometers in diameter. Usually, when the diameter of the bubble is from 0.05 to $1.0 \mathrm{~mm}$ ( 0.002 to $0.04 \mathrm{in}$.), it is called an entrained air-void and when it is from 1.0 to $1.25 \mathrm{~mm}$ (0.04 to $0.05 \mathrm{in}$.), it is termed as entrapped air-void. The percentage of the total volume of air-void occupied in a given volume of concrete is known as air content (Mindess et al., 2003).

There are three critical parameters that have to be measured to have a good definition of the air-void system in the concrete (ASTM C 457). All three target values should be achieved when a good air-entrained concrete is desired ensuring a good distribution of the air bubbles protecting the paste volume 
The air-void parameters those are usually measured are described below:

- The first and most commonly used parameter is the spacing factor defined by the ASTM C 457 as the maximum distance in the cement past from the periphery of an air-void. This value should be in the range between 0.1 to $0.2 \mathrm{~mm}(0.004$ to $0.008 \mathrm{in}$.) to ensure adequate freeze-thaw protection.

- The second parameter is the void frequency defined by the ASTM C 457 as the number of air-voids intercepted by a transverse line divided by the length of that line. The frequency should be in the range between 0.3-0.6 1/mm. (8-16 1/in.).

- The third parameter is the specific surface area defined by the ASTM C 457 as the surface area of the void divided by the volume. This area should be in the range between 24 to $43 \mathrm{~mm}^{2} / \mathrm{mm}^{3}$ (600 to $1100 \mathrm{in}^{2} / \mathrm{in}^{3}$ ).

\subsubsection{Significance of the Test}

Obtaining the air-void parameters using the methods described in the ASTM C 457 is time consuming and requires an experienced person to do them. A method is proposed here which is based on section-analysis method considering the cross section instead of line as usually followed by ASTM C 457. The section analysis method can be done relatively quickly with the help of a digital camera, a microscope, and using image analyzer software.

The main objectives of this study were:

- To propose and use the section-analysis method to obtain the air-void system of hardened concrete.

- To compare the data using the section-analysis method with results obtained by modified point count method per ASTM C 457.

- To find the air-void distribution for the section analyzed.

- To make a final comparison of the data using a technique similar to the lineartransverse method for comparison purpose. 


\subsubsection{Test Standards}

The data required for the calculation of the air-void parameters can be obtained by three different methods such as the point-count method, the linear-transverse method, and the section analysis method (proposed here). The ASTM C 457 has standardized two of them: (1) the linear-traverse method and (2) the modified point-count method.

By using a stereoscopic microscope, the linear-transverse method determines the volumetric composition of the concrete by summing the transverse distance across a given component along a series of regularly spaced lines. The modified point-count method uses the frequency of areas of a given component coinciding with a regular grid system of points. The section analysis method measures areas of circles and areas with irregular shapes, which is very difficult to measure only with a stereoscopic microscope. The section analysis method therefore is used with the help of image analyzers like Image-Pro to determine air content, airvoid size distribution, and paste content on hardened concrete samples.

\subsubsection{Sample Preparation}

For the evaluation of the air-void system of the three different mixtures studied in this project, two core samples of $101.6 \mathrm{~mm}$ (4 in.) were drilled from each concrete slab and sent to a laboratory and one more sample drilled from the slabs was analyzed at WVU laboratory, with the idea of comparing different methods and comparing the air content at different locations of the slabs. The specimens studied were conditioned following the procedures described in ASTM C 457.

At the age of 28-day concrete slabs, the samples were obtained from field by coring cylinders at different locations of the slabs. Then the area of study was obtained by sawing the cored samples perpendicular to the finished surface using a water-cooled saw with a diamond blade. ASTM C 457 requires a minimum area of $7700 \mathrm{~mm}^{2}\left(12 \mathrm{in}^{2}\right)$ for nominal maximum size of aggregate of $25 \mathrm{~mm}$ ( $1 \mathrm{in}$.). After the specimens were cut, the sections decided to be analyzed were grinded and polished using successively finer abrasives until they were suitable for microscopical observation. In case of the specimens prepared at WVU, the series used were 
No. $80,220,600$, and 1200 and then $3 \mu \mathrm{m}$ and $0.3 \mu \mathrm{m}$ aluminum oxide. Finally the specimens were cleaned with an ultrasonic cleaner and the specimens were dried in an oven until all water contained in the concrete was evaporated.

Before starting the actual study it is important to know whether the preparation of the sample was adequate. In this study the samples were accepted after observing an excellent reflection of a distant light when viewed at a low incident angle. Figure 6-1 presents the sections those were obtained from a cored cylinder. The sections labeled as 2 and 3 were used for the microscopical analysis. Figure 6-2 presents the condition of the specimens after sawing, cutting and grinding.

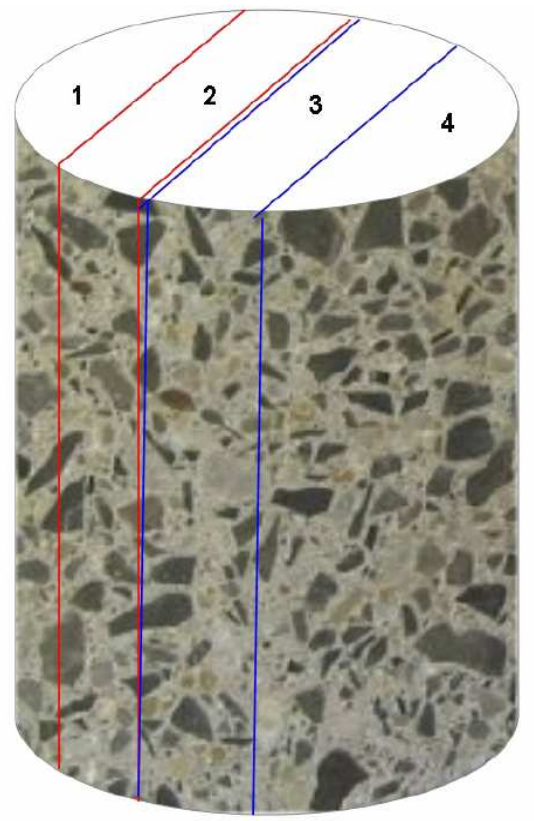

Figure 6-1 Concrete sections used for microscopical analysis 


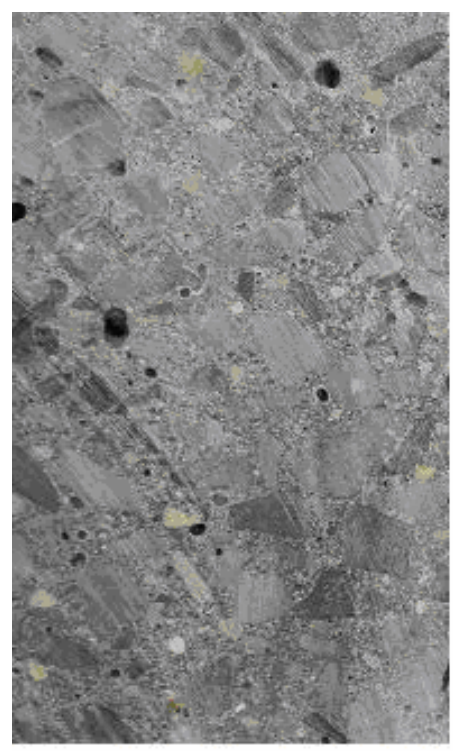

Sawed

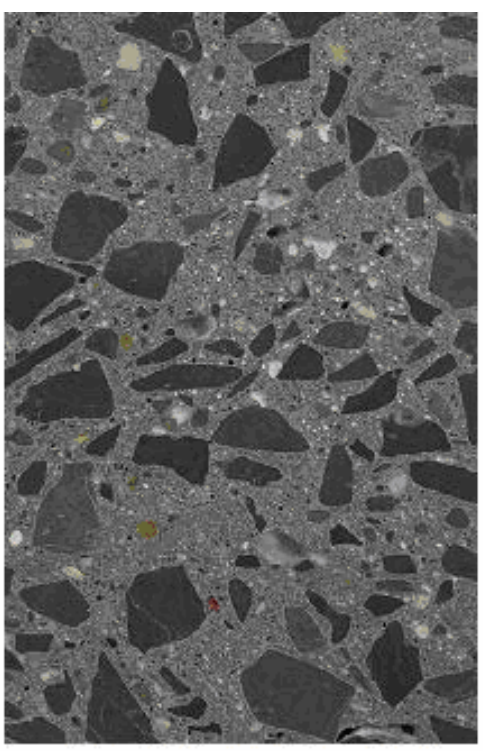

Grinded

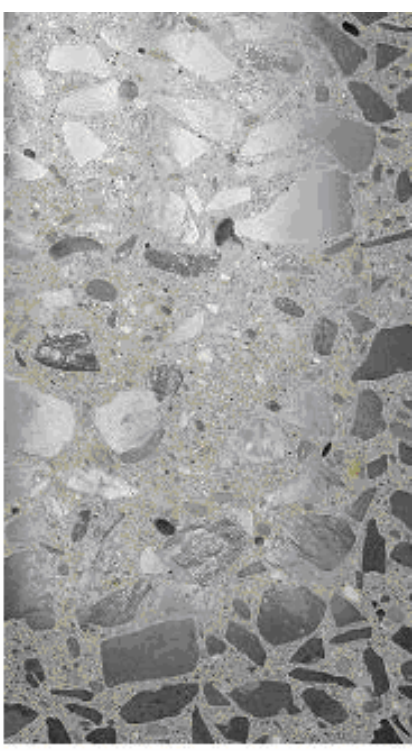

Polished

Figure 6-2 Concrete specimens after sawing, grinding and polishing

\subsubsection{Testing Procedure}

\subsubsection{Modified Point Count Method}

This test method followed the procedures and requirements prescribed in the ASTM C 457, using a magnification of 90x and conducted in a high quality laboratory.

\subsubsection{Section Analysis Method}

In this method the analysis was done in a different set of samples than those were used for the point count method. About 80 pictures of approximately $2 \mathrm{~mm}^{2}\left(0.0031 \mathrm{in}^{2}\right)$ using a magnification of $51 \mathrm{x}$ were studied covering a total area of about $150 \mathrm{~mm}^{2}\left(0.2325 \mathrm{in}^{2}\right)$. The pictures were taken by moving the specimen parallel to its initial position in such a way that the area photographed in each picture was never repeated. The equipment used for this procedure is presented in Figure 6-3.

The prepared area of study was divided in 4 different sections: the first section was from 50 $\mathrm{mm}(2 \mathrm{in}$.) from the top of the finished surface of the concrete to $75 \mathrm{~mm}(3 \mathrm{in}$.$) , the second$ 
section was from 75 to $100 \mathrm{~mm}$ ( 3 to 4 in.), the third section was from 100 to $125 \mathrm{~mm}$ (4 to 5 in.), and the last section was from 125 to $150 \mathrm{~mm}$ (5 to 6 in.). From each section, 20 pictures were taken and then analyzed.

The procedure followed for the picture acquisition was:

- First the specimens were divided in the different sections using a marker to delimit the areas.

- Then the specimens were placed on a horizontal surface with 5 x $5 \mathrm{~mm}(0.2 \times 0.2 \mathrm{in}$. $)$ grid lines used to delimitate the position of the specimen at the moment of taking the pictures, and thus preventing the repetition of areas.

- Two spotlight microscope lamps were used to provide illumination at low and variable incident angle to the surface, in order to demarcate the air-voids by a shadow.

- Pictures were taken using a magnification of $51 \mathrm{x}$ with the help of a digital camera attached to the microscope.

- Finally, each picture was analyzed separately using image analysis software. The software used in this study was Image-Pro (version 5.0), which was used to measure areas with different shapes.

When the images were analyzed in the computer, the air-voids were identified as being nearly circular shapes demarcated by shadows as it is shown in Figure 6-4. The data obtained from each picture was: the area of the air-voids; the number of voids; and the total area covered by the aggregates. 


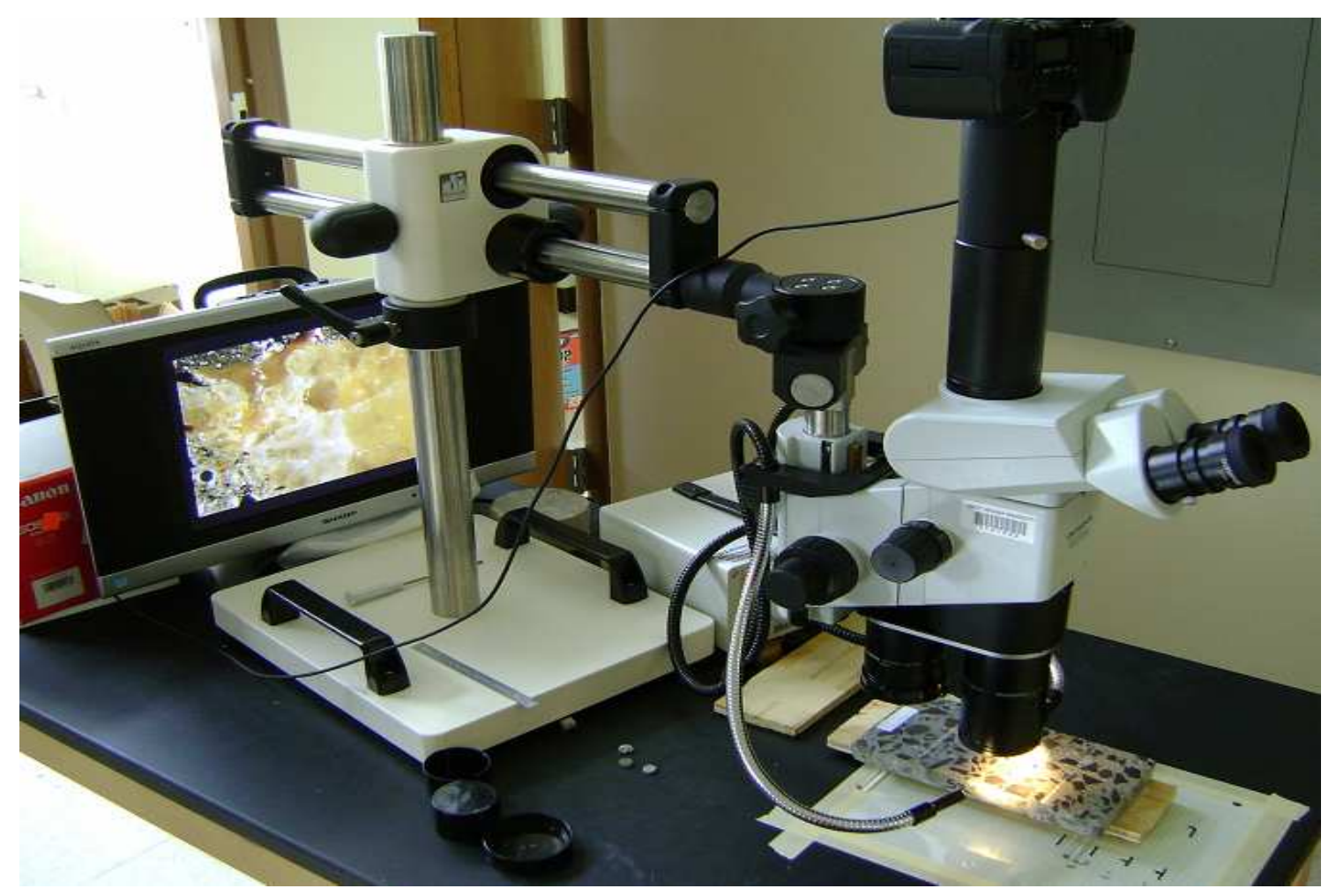

Figure 6-3 Stereomicroscope and digital camera

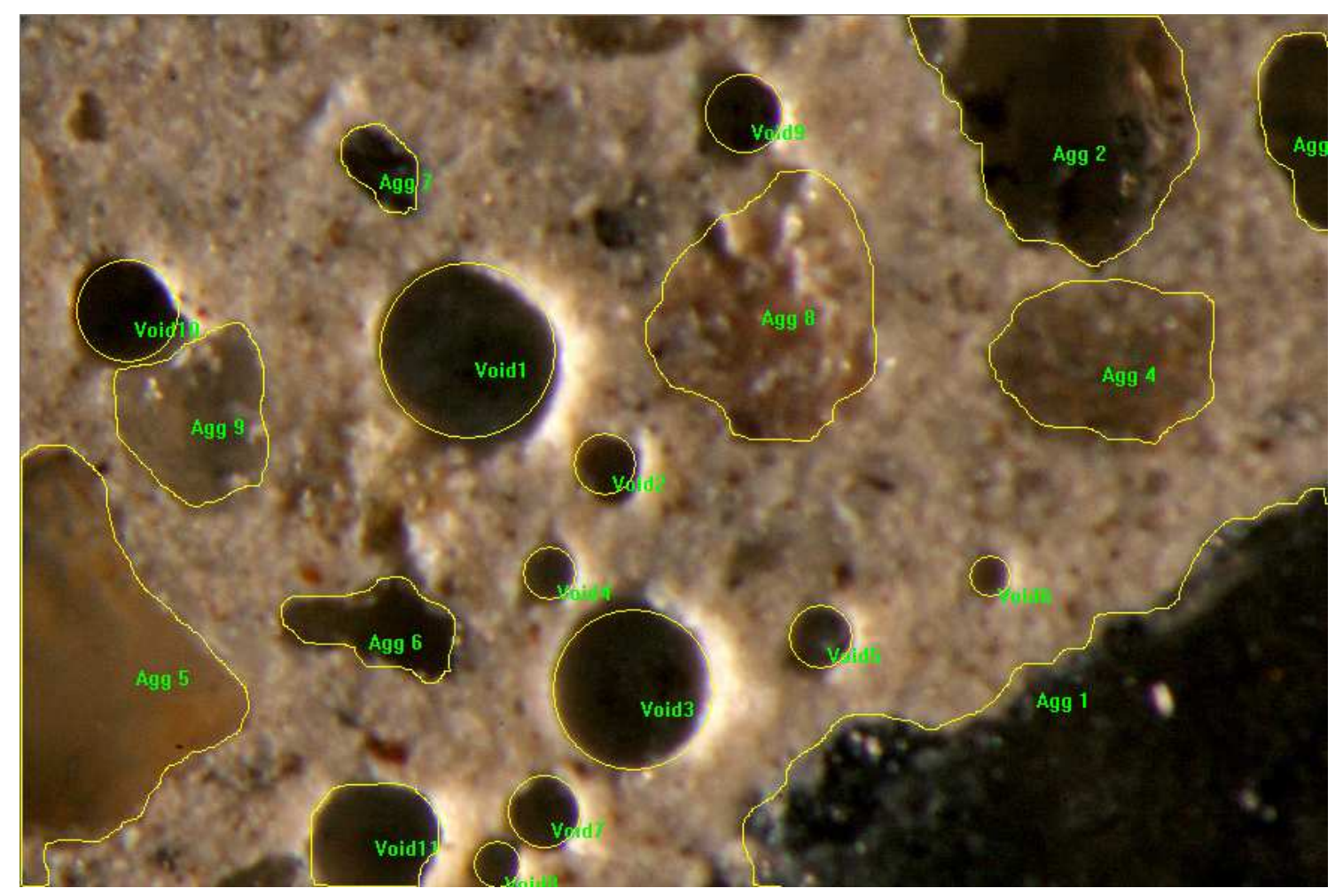

Figure 6-4 Image analyzed using Image-Pro (Area $2.0 \mathrm{~mm}^{2}$ ) 


\subsection{Calculation}

With the data obtained from the image analyzer software, the air-void parameters were obtained using the following equations proposed by the ASTM C 457:

Measured data:

- $\quad \mathrm{Aa}=$ Total area of air-voids in section $\left(\mathrm{mm}^{2}\right)$

- $\quad$ Ap $=$ Total area covered by paste $\left(\mathrm{mm}^{2}\right)$

- $\quad$ At $=$ Total area scanned on the surface $\left(\mathrm{mm}^{2}\right)$

Air Content (A), in \%

$A=\frac{A a}{A t} x 100$

$\underline{\text { Void Frequency (n), in voids } / \mathrm{mm}^{2}}$

$n=\frac{N}{A t}$

Average Diameter (d), in mm

$d=\sqrt{\frac{A a / N \times 4}{\Pi}}$

Specific surface $(\alpha)$, in $\mathrm{mm}^{2} / \mathrm{mm}^{3}$

$\alpha=\frac{4}{d}$

$\underline{\text { Paste content (p), in \% }}$

$p=\frac{A p}{A t} x 100$ 
Spacing factor $(\mathrm{L})$

- If $\mathrm{p} / \mathrm{A} \leq 4.342$

$L=\frac{A p}{4 N}$

- If $\mathrm{p} / \mathrm{A}>4.342$

$L=\frac{3}{\alpha}\left[1.4 \times(1+p / A)^{1.3}-1\right]$

\subsubsection{Modified Linear Transverse Method}

In order to compare and validate the data obtained from the section analysis method, it was decided to perform an approximation to the linear transverse method described in the standards. Following procedures were followed for this method.

For each picture obtained for the section analysis method, a diagonal line was traced measuring its total length, the total number of air-voids intersected, the length through air, and the length through paste and aggregates. It was an approximation to what is usually followed in the standardized method. The data obtained can only be used for comparison purposes because the total length analyzed was lower when compared to the length described in the standard. The calculation of the air-void parameters was done using the equations presented in the ASTM C 457. Figure 6-5 presents how the length of voids, paste and aggregates were measured by tracing a diagonal line. 


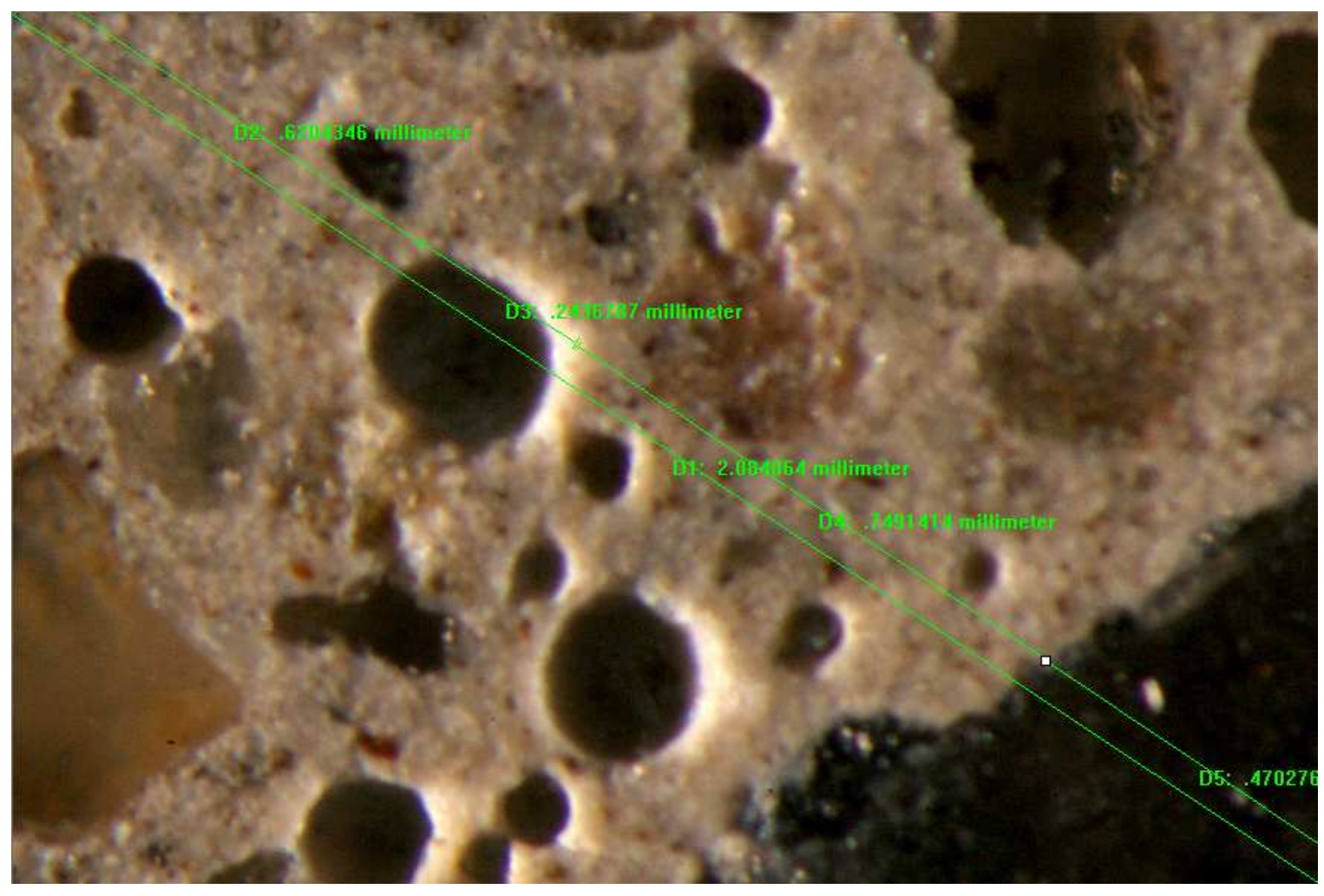

Figure 6-5 Image analyzed with Image-Pro by the modified linear-transverse method

\subsubsection{Results and Discussions}

The results of air content, specific surface, void spacing factor, void frequency, and paste content for the three slabs investigated are furnished in Table 6-1, Table 6-2 and Table 6-3. The results from all three different methods described above are presented.

\subsubsection{Results for the Modified Point-Count Method}

The conclusion from the reported data by the testing laboratory was that the air in all of the cores occurred mainly as numerous fine and small spherical voids characteristics of entrained air-voids. There were no clusters or collections of air-voids and the air-voids were well dispersed providing a good air-void system for the concrete slabs.

It was observed that varying amounts of non spherical void characteristic of entrapped air were present in all of the cores studied. Some larger size entrapped air-voids reduced the 
specific surface of the air-voids. This was found for all of the cores; however most prominent for cores from slab 1 .

The results furnished in Table 6-1 were compared with ASTM C 457 and it was found that the different HPC mixtures used for the slabs had adequate freeze-thaw protection.

Table 6-1 Air-void parameters determined by the point-count method

\begin{tabular}{c|c|c|c|c|c|c}
\hline Slab & Core I.D. & $\begin{array}{c}\text { Air } \\
\text { content } \\
(\%)\end{array}$ & $\begin{array}{c}\text { Specific } \\
\text { Surface } \\
\mathbf{m m}^{2} / \mathbf{m m}^{3} \\
\left.\mathbf{( i n}^{2} / \mathbf{i n}^{3}\right)\end{array}$ & $\begin{array}{c}\text { Void Spacing } \\
\text { Factor } \\
\mathbf{m m}(\mathbf{i n} .)\end{array}$ & $\begin{array}{c}\text { Void } \\
\text { Frequency } \\
\text { Void/mm } \\
\text { (Void/in.) }\end{array}$ & $\begin{array}{c}\text { Paste } \\
\text { Content } \\
(\%)\end{array}$ \\
\hline \multirow{2}{*}{ Slab 1 } & S1-8 & 7.2 & $23.4(595)$ & $0.178(0.007)$ & $0.425(10.8)$ & 28.5 \\
\cline { 2 - 7 } & S1-9 & 6.9 & $21.7(550)$ & $0.178(0.007)$ & $0.374(9.5)$ & 27.2 \\
\hline \multirow{2}{*}{ Slab 2 } & S2-5 & 7.3 & $32.1(815)$ & $0.1016(0.004)$ & $0.583(14.8)$ & 25 \\
\cline { 2 - 7 } & S2-10 & 9.0 & $23.8(604)$ & $0.127(0.005)$ & $0.535(13.6)$ & 14.9 \\
\hline \multirow{2}{*}{ Slab 3 } & S3-5 & 8.2 & $22.8(580)$ & $0.1524(0.006)$ & $0.469(11.9)$ & 27.5 \\
\cline { 2 - 7 } & S3-8 & 7.6 & $23.9(609)$ & $0.1524(0.006)$ & $0.457(11.6)$ & 28.4 \\
\hline
\end{tabular}

\subsubsection{Results for Section Analysis Method}

\subsection{Air-Void Parameters}

The results of the air-void parameters obtained using the section analysis method for the three different HPC studied are compiled in in Table 6-2. The parameters from section analysis method were similar to those found in the modified point count method except those of the void frequency. In the standard, the void frequency is defined as the number of air-voids intercepted by a traverse line divided by the length of that line, which is expressed in number of air-voids per unit of length. But when the measurements are taken on areas instead of lines, the frequency obtained is the number of void present in one unit of area, which made the 
difference of values. The measurements based on the areas are more accurate as it reveals the two-dimensional air-void character of concrete surface.

Also when the values obtained using the section analysis method was compared with the standard methods, the differences were not significant as it evident from the Figure 6-11. The results show that the air content calculated by the point count method (Standard method) agreed well with the air content determined using the section-analysis method. The differences in the values were due to use of different cored specimens as can be observed in Table 6-2.

The largest differences were observed in the paste content and the spacing factor those are the function of the paste-air ratio (p/A). These differences were due to the difficulty of differentiating the fine aggregates from the cement paste in some pictures. Though the voids could easily be recognized due to their circular shape and also because they appeared black in the pictures due to the light orientation, in some cases it was difficult to recognize and measure the aggregates due to its obscuring appearance.

The section analysis method facilitated the rapid air-void determination as smaller areas could be tested. Also if a small area is covered, it may not be representative of the total concrete volume and also on the other hand a very large area shall take longer time. To check whether the areas studied in this work were representative and adequate, the air content values were compared with the standardized point count method by plotting a graph of cumulative analyzed area versus air content for each concrete mixture (Figure 6-6). Figure 6-6 shows that the area of $150 \mathrm{~mm}^{2}$ was adequate to represent the concrete samples for the evaluations of air content. 
Table 6-2 Air-void parameters determined by the section-analysis method

\begin{tabular}{c|c|c|c|c|c|c}
\hline Slab & $\begin{array}{c}\text { Core } \\
\text { I.D. }\end{array}$ & $\begin{array}{c}\text { Air } \\
\text { content } \\
\text { (\%) }\end{array}$ & $\begin{array}{c}\text { Specific } \\
\text { Surface } \\
\mathbf{m m}^{2} / \mathbf{m m}^{3} \\
\text { (in²/in }^{3}\end{array}$ & $\begin{array}{c}\text { Void Spacing } \\
\text { Factor } \\
\mathbf{m m}(\mathbf{i n} .)\end{array}$ & $\begin{array}{c}\text { Void } \\
\text { Frequency } \\
\text { Void/mm² } \\
\text { (Void/in') }\end{array}$ & $\begin{array}{c}\text { Paste } \\
\text { Content } \\
\text { (\%) }\end{array}$ \\
\hline S1 & S1-10 & 6.8 & $21.2(538)$ & $0.206(0.008)$ & $2.4(1587)$ & 30.121 \\
\hline S2 & S2-9 & 8.3 & $22.5(573)$ & $0.196(0.007)$ & $3.3(2178)$ & 37.801 \\
\hline S3 & S3-9 & 7.3 & $20.7(526)$ & $0.212(0.008)$ & $2.4(1609)$ & 32.62 \\
\hline
\end{tabular}

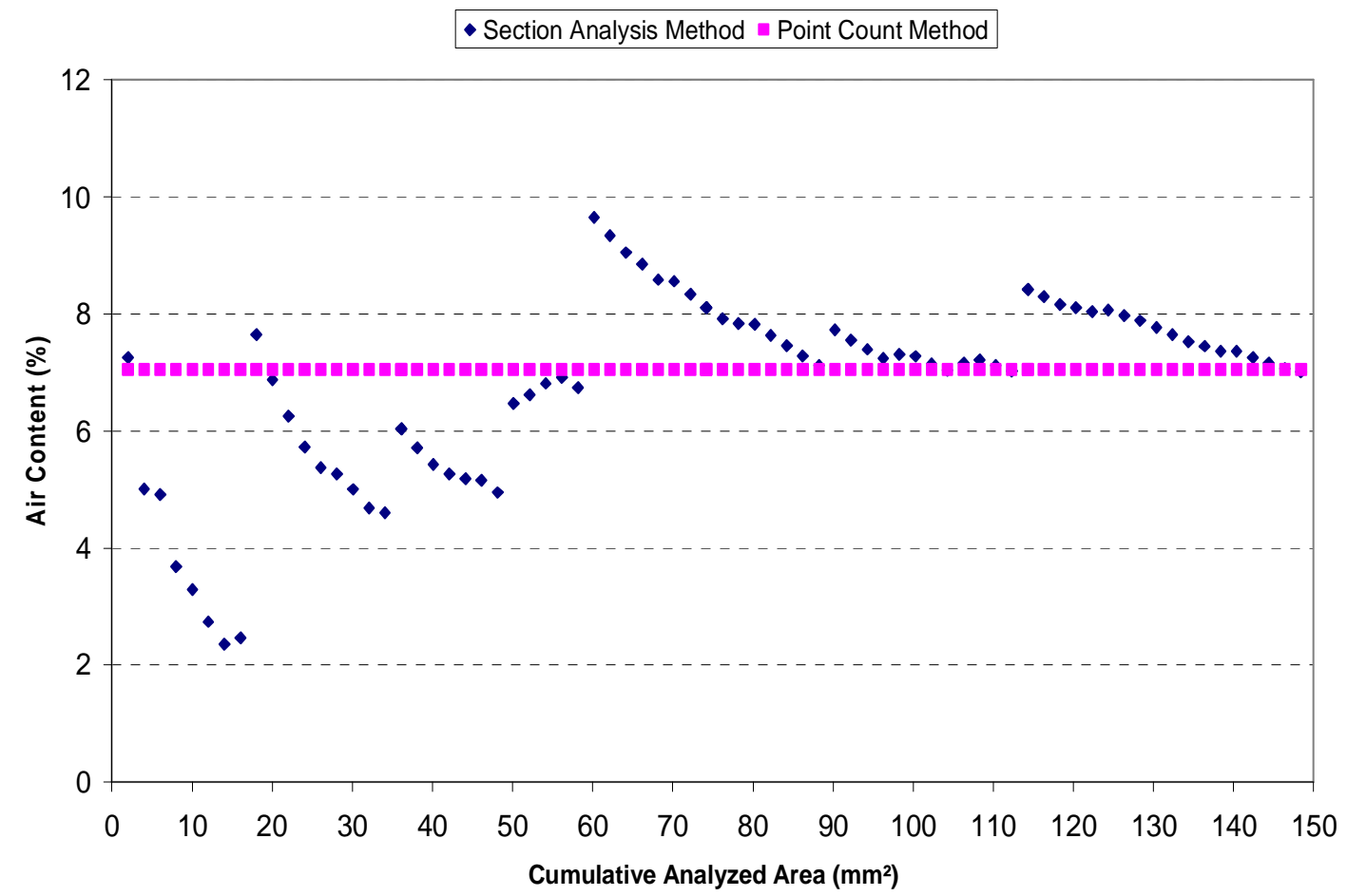

(a) 


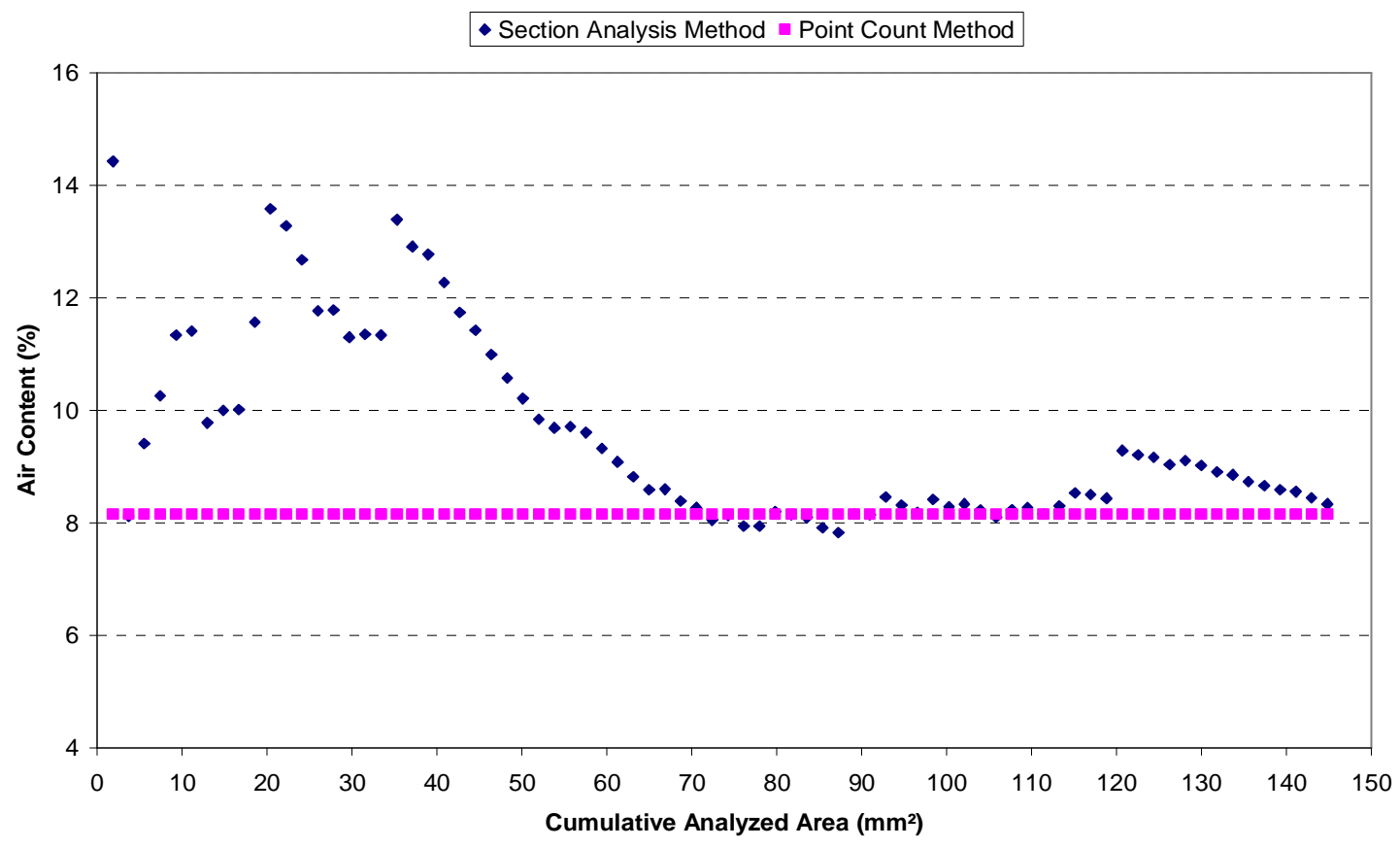

(b)

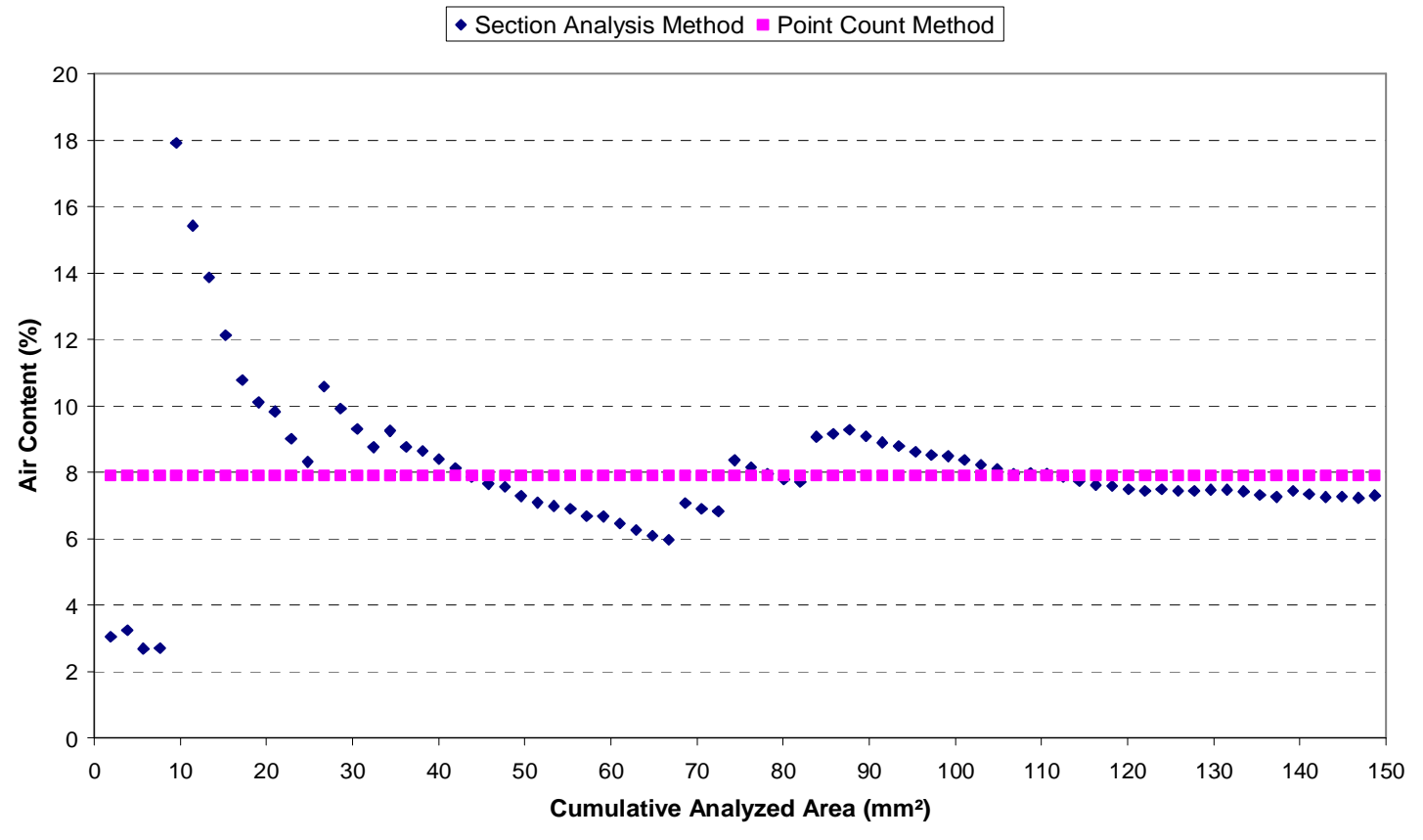

(c)

Figure 6-6 Air content from the cumulative analyzed area 


\subsection{Air-Void Size Distribution}

One of the major advantages of the section analysis method over the point-count method is that it can estimate the air-void size distribution. The cumulative frequency distribution presented in Figure 6-7 shows that small and fine spherical voids characterizes entrained air and relatively lesser amounts of non-spherical coarse voids are the characteristic of entrapped air.

Elsen, (2001) suggested a physical parameter called the Micro Air Content which is defined as the contents of air-voids of size $0.3 \mathrm{~mm}(0.012$ in.) diameter or less. In this study, all the three slabs had about $95 \%$ 'micro air content' as defined above.

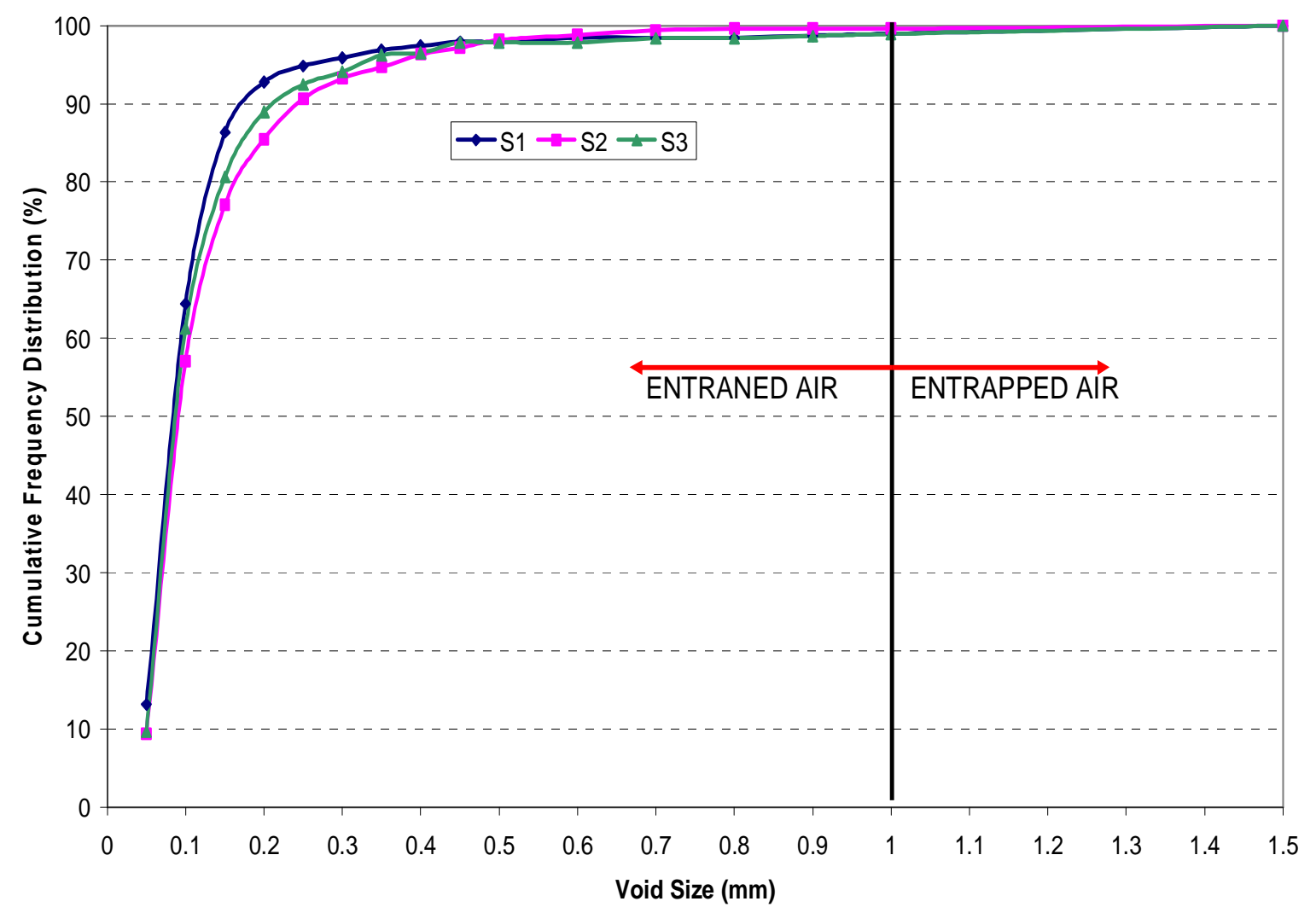

Figure 6-7 Air-void size distribution 


\subsubsection{Results for Modified Linear Transverse Method}

In the approximate linear-transverse method in this studied, the total length studied was 160 mm compared to $2413 \mathrm{~mm}$ required by the standard. It was found that in spite of the studied length being substantially lower than the required length, from Table 6-3 and from Figure 6-8 through Figure 6-11 it can be concluded that the air-void parameters obtained by this approximate method were not much different from the values obtained by the standardized method.

Due to the smaller length covered in the air-void parameters it was observed that the total air content was overestimated, but still close to the standard value. It was also evident that the values were similar to point count method where the highest air content was obtained for the specimens in slab 2, followed by slab 3, and slab 1.

From the above study it is evident that this approximate method still can be used when an approximate value is desired as it is easier and faster to measure voids, aggregates, and paste from image collected directly from a stereoscopic microscope, and can be run parallel to the section analysis method as proposed above.

Table 6-3 Air-void parameters determined by the modified linear-transverse method

\begin{tabular}{c|c|c|c|c|c|c}
\hline Slab & $\begin{array}{c}\text { Core } \\
\text { I.D. }\end{array}$ & $\begin{array}{c}\text { Air } \\
\text { content } \\
(\%)\end{array}$ & $\begin{array}{c}\text { Specific } \\
\text { Surface } \\
\mathbf{m m}^{2} / \mathbf{m m}^{3} \\
\left.\text { (in }^{2} / \mathbf{i n}^{3}\right)\end{array}$ & $\begin{array}{c}\text { Void } \\
\text { Spacing } \\
\text { Factor } \\
\mathbf{m m}(\mathbf{i n} .)\end{array}$ & $\begin{array}{c}\text { Void } \\
\text { Frequency } \\
\text { Void/mm } \\
\text { (Void/in.) }\end{array}$ & $\begin{array}{c}\text { Paste } \\
\text { Content } \\
(\%)\end{array}$ \\
\hline S1 & S1-10 & 7.6 & $13.6(345)$ & $\begin{array}{c}0.894 \\
(0.0351)\end{array}$ & $0.258(6.5)$ & 31.4 \\
\hline S2 & S2-9 & 9.9 & $16.8(427)$ & $\begin{array}{c}0.544 \\
(0.0214)\end{array}$ & $\begin{array}{c}0.415 \\
(10.5)\end{array}$ & 34.5 \\
\hline S3 & S3-9 & 8.3 & $14.9(380)$ & $\begin{array}{c}0.740 \\
(0.0291)\end{array}$ & $0.310(7.9)$ & 29.2 \\
\hline
\end{tabular}




\section{$\square$ Point-Count $1 \square$ Point-Count $2 \square$ Section-Analysis $\square$ Linear-Transverse}

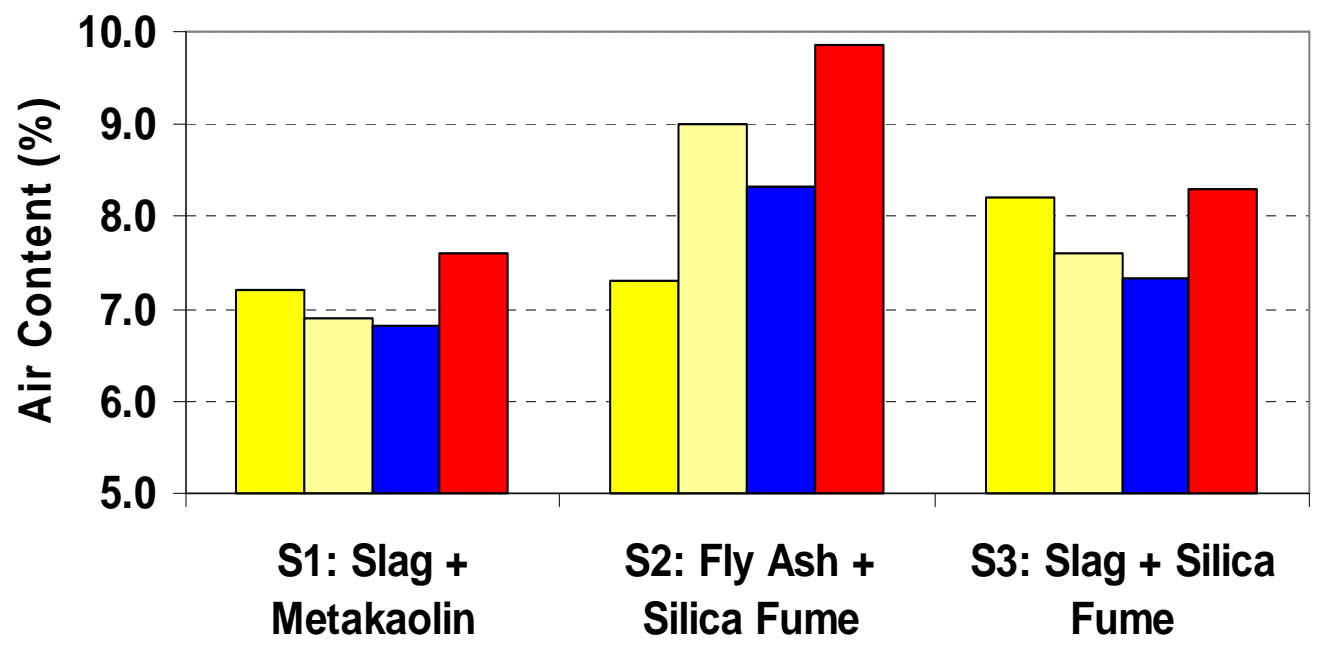

Figure 6-8 Air content by different methods

\section{$\square$ Point-Count $1 \square$ Point-Count $2 \square$ Section-Analysis $\square$ Linear-Transverse}

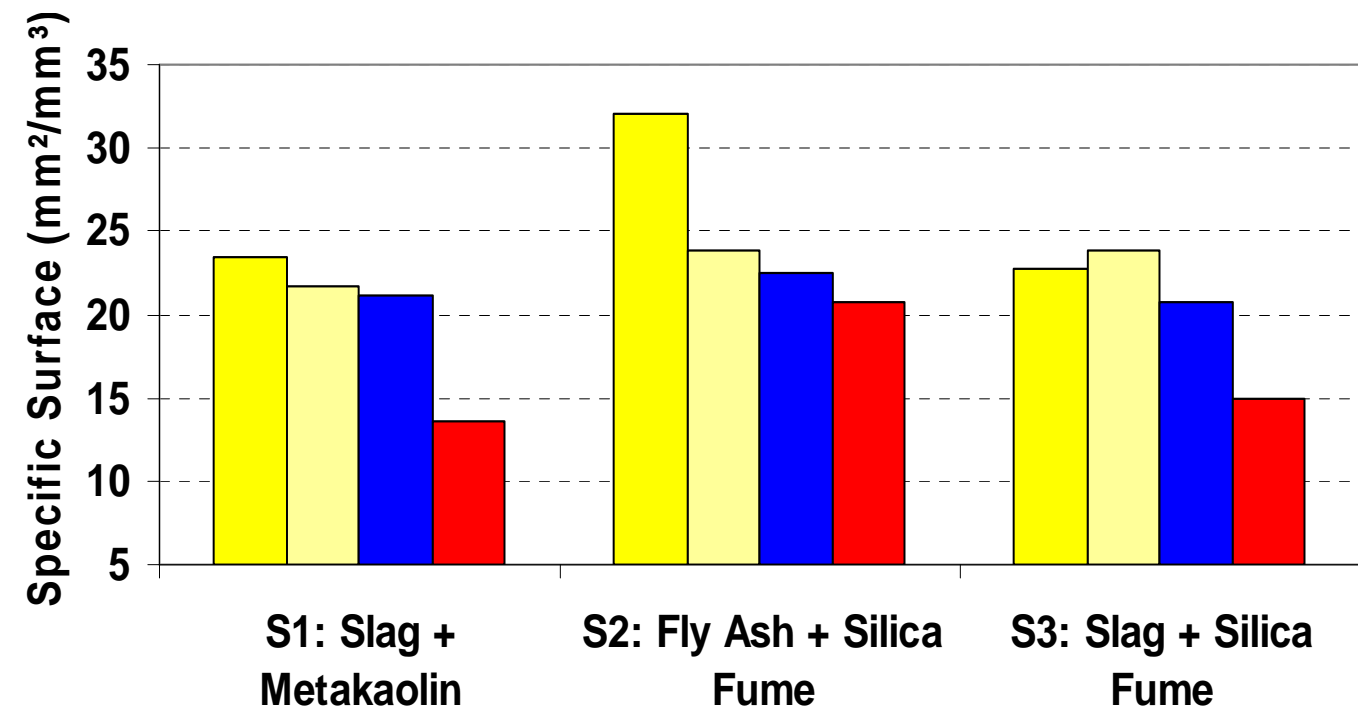

Figure 6-9 Specific surface by different methods 


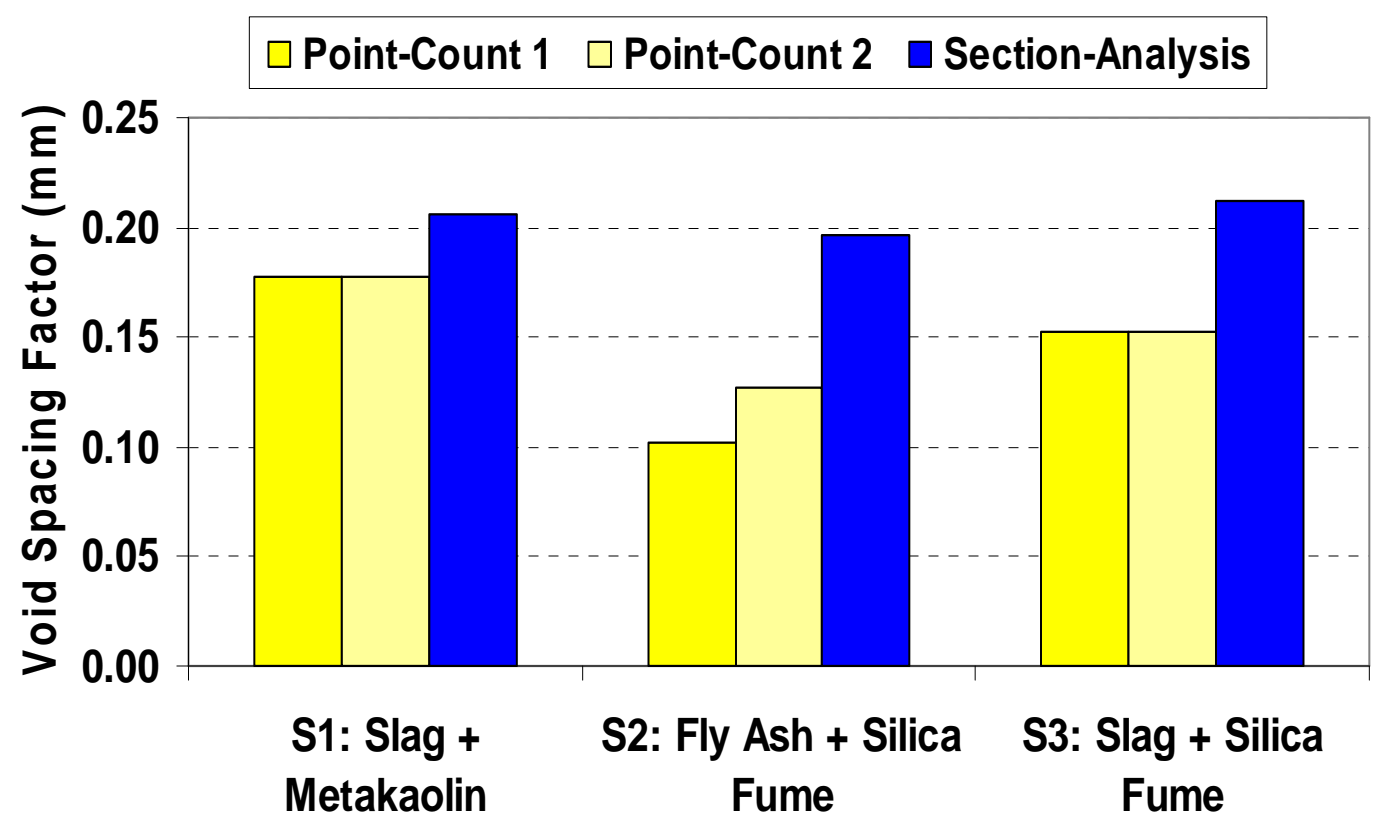

Figure 6-10 Void spacing factor by different methods

\section{$\square$ Point-Count $1 \square$ Point-Count $2 \square$ Section-Analysis $\square$ Linear-Transverse}

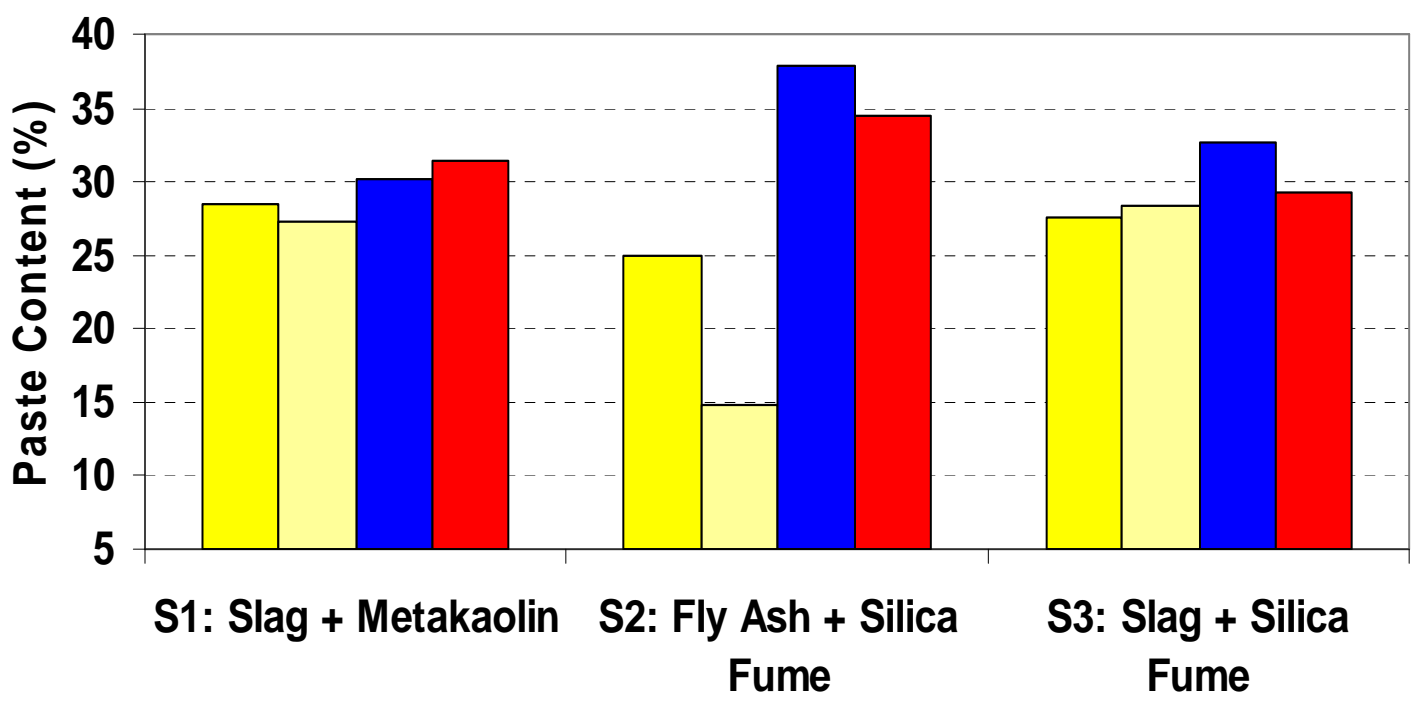

Figure 6-11 Paste content by different methods 


\subsection{Petrographic Examinations on HPC}

\subsubsection{Significance of the Test}

Petrography is the microscopic study of rocks, minerals or man-made materials like concrete. It is a very important tool for investigating the composition, microstructure, relative proportions of variety of natural and synthetic materials. When it is used alone, or in combination with other investigative techniques, it can be of remarkable value in many areas of the minerals and construction industries. The objectives of conducting a petrographic analysis in this project were:

- Determination of the cause of inferior quality, distress, or deterioration of concrete if present.

- Determination of the probable future performance of the concrete.

- Determination whether the concrete was or was not as specified.

- Description of the cementitious matrix, including qualitative determination of the kind of hydraulic binder used, degree of hydration, degree of carbonation if present, presence of mineral admixtures, adequacy of consolidation and w/cm.

\subsubsection{Test Standards}

The prepared samples were tested per ASTM C 856. The samples used were from the same source and similar to those were prepared for the air content measured by the modified pointcount method. The samples examined were the standard size thin section made from mid depth in each core sample that required a petrographic microscope (polarizing microscope with a rotating stage) at magnifications up to $400 \mathrm{x}$. After collections of the cores and sampling the tests were conducted in a high quality petrography laboratory of a materials consultant.

In addition, some broken portions left from the unprepared sections from the cores were studied to provide an examination of the fresh fracture surface. 


\subsubsection{Results and Discussions}

\subsubsection{Coarse and Fine Aggregates}

The coarse aggregates observed were dense, dark gray, and dark brown-gray crushed limestone with a nominal maximum size of $25 \mathrm{~mm}$ ( $1 \mathrm{in}$.). There were no indications of any reactions between the aggregate and the paste due to the early evaluation of the samples. The aggregates were well graded and uniformly dispersed. Some aggregate particles presented fractures, but these fractures did not extend into the contiguous paste. The fractures in the coarse aggregate particles were present prior to the use of the aggregate in the concrete. Fine aggregate was natural sand that contained mostly quartz with minor to trace amounts of feldspar, sandstone, quartzite, mica, granites, and chert.

\subsubsection{Paste}

\subsection{Slab 1 (Slag + Metakaolin)}

Paste was hard and firm. It was variable on a micro scale and mainly medium beige-gray with small areas of medium green gray within the matrix. Above a depth of $6.4 \mathrm{~mm}(0.25 \mathrm{in}$.), the paste was uniform medium beige-gray. Below a depth of $6.4 \mathrm{~mm}(0.25 \mathrm{in}$.), the paste was mainly medium beige-gray with small areas of medium green gray distributed throughout with a more prominent presence near coarse aggregate particles. The green color was the indication of the presence of slag. The green color was a consequence of components of the slag reacting with certain hydrated products of the portland cement. The reaction products oxidized when exposed to the atmosphere turning the green products to an earth tone or brown-beige. Fresh fracture surfaces had textures that were semi-conchoidal. In addition to the presence of slag, powder mounts of the paste revealed the presence of a trace amount of fly ash particles as shown in Figure 6-12.

Hydration of the cement was advanced; relict and residual portland cement particles were abundant. Partially hydrated cement and slag particles with prominent hydration rims were present. In Figure 6-13 are presented two views of a portion of the thin section from slab 1. The calcium hydroxide component of the cement hydration products occurred mainly as 
moderately sized units. Rarely a larger deposit of calcium hydroxide occurred at an aggregate socket. These features are shown in Figure 6-13.

Air was present mainly as small, spherical voids characteristic of entrained air-voids and as lesser amounts of coarse spherical and non spherical voids characteristic of entrapped air. The air-voids were clean, shiny and essentially free of secondary deposits.

Compositional and textural features of the paste are indicative of a cementitious material content estimated to be moderately high (e.g. equivalent on a volume basis to $7^{1} / 2$ bags of portland cement) and a w/cm that was estimated to be low (e.g. 0.38 to 0.40 ). The estimates of total cementitious materials content and w/cm were consistent with the mixture design.

\subsection{Slab 2 (Fly Ash + Silica Fume)}

Paste was hard, firm and uniformly medium dark gray. Fresh fracture surfaces induced in paste in the laboratory presented textures that were semi-conchoidal. Hydration of the cement was advanced; residual particles were abundant. The calcium hydroxide component of the cement hydration products occurred as moderate units as shown in Figure 6-14. Spherical particles of fly ash were present throughout the paste as shown in the views of the thin section in Figure 6-14. Fly ash appeared mainly as opaque, dark brown and translucent yellow to brown spherical particles and minor to trace amounts of opaque, non spherical particles.

Air-voids were present mainly as small and fine spherical voids those are characteristic of entrained air-voids and lesser amounts of non spherical voids those are characteristic of entrapped air. There were several interconnected non spherical voids characteristics of improper consolidation, but this is limited to the location from which the core was collected.

Compositional and textural features of the paste were indicative of a cementitious materials content estimated to be moderately high (e.g. equivalent on a volume basis to 7 bags per cubic yard) and a w/cm estimated to be low (e.g. 0.36 to 0.38 ). The estimates of total cementitious materials content and w/cm are consistent with the concrete mixture design. 


\subsection{Slab 3 (Slag + Silica Fume)}

Paste was hard, firm, and uniformly medium dark gray with an olive-green tint. Fresh fracture surfaces induced in paste were semi-conchoidal. As discussed previously, a green color was a consequence of components of the slag reacting with certain hydration products of the portland cement. Exposure to the atmosphere resulted in the oxidation of the reaction products turning the green products to an earth tone or brown-beige.

The hydration of the paste was advanced; residual portland cement and slag particles, some with hydration rims were present as shown in the views of the thin section in Figure 6-15 and Figure 6-16. The calcium hydroxide component of the cement hydration products occurred mainly as moderately sized units.

Air in the studied core was present mainly as small and fine spherical voids characteristic of entrained air-voids and lesser amounts of non-spherical coarse voids characteristic of entrapped air. At a depth of $76 \mathrm{~mm}$ (3 in.) in the core, there were several interconnected coarse non spherical voids characteristic of honeycombs resulting from poor consolidation on the area of the slab from where this core was dilled. These voids are shown in Figure 6-17 on a horizontal saw cut made in the in the core to expose the voids more clearly. All of the voids were clean and essentially free of secondary deposits.

Compositional and textural features of the paste were indicative of a cementitious material content estimated to be moderately high (e.g. equivalent on a volume basis to 7 bags of portland cement) and a w/cm that is estimated to be low (e.g. 0.37 to 0.38 ). The estimates of total cementitious materials content and w/cm are consistent with the concrete mixture design.

\subsubsection{Carbonation}

The depth of carbonation of the top surface of the core from slab 1 varied from 0 to $0.79 \mathrm{~mm}$ ( 0 to 0.031 in.). In the core from slab 2 , the depth of carbonation of the top surface varied from to 0.40 to $0.79 \mathrm{~mm}(0.016$ to $0.031 \mathrm{in}$.), and in the core from slab 3 it varied from 0 to 
$0.4 \mathrm{~mm}$ (0 to $0.016 \mathrm{in}$.). All the depth of carbonation were insignificant up to the time of testing.

\subsubsection{Cracks}

One crack was present in the core analyzed from slab 3. The tight and fine crack was extended from the surface of the core to a depth of $3.18 \mathrm{~mm}(0.13 \mathrm{in}$.) where it terminated at a non spherical void located just below the surface.

\subsubsection{Secondary Deposits}

A thin layer of calcite rarely lined one or two voids, but as stated previously, voids in the cores were essentially free of secondary deposits.

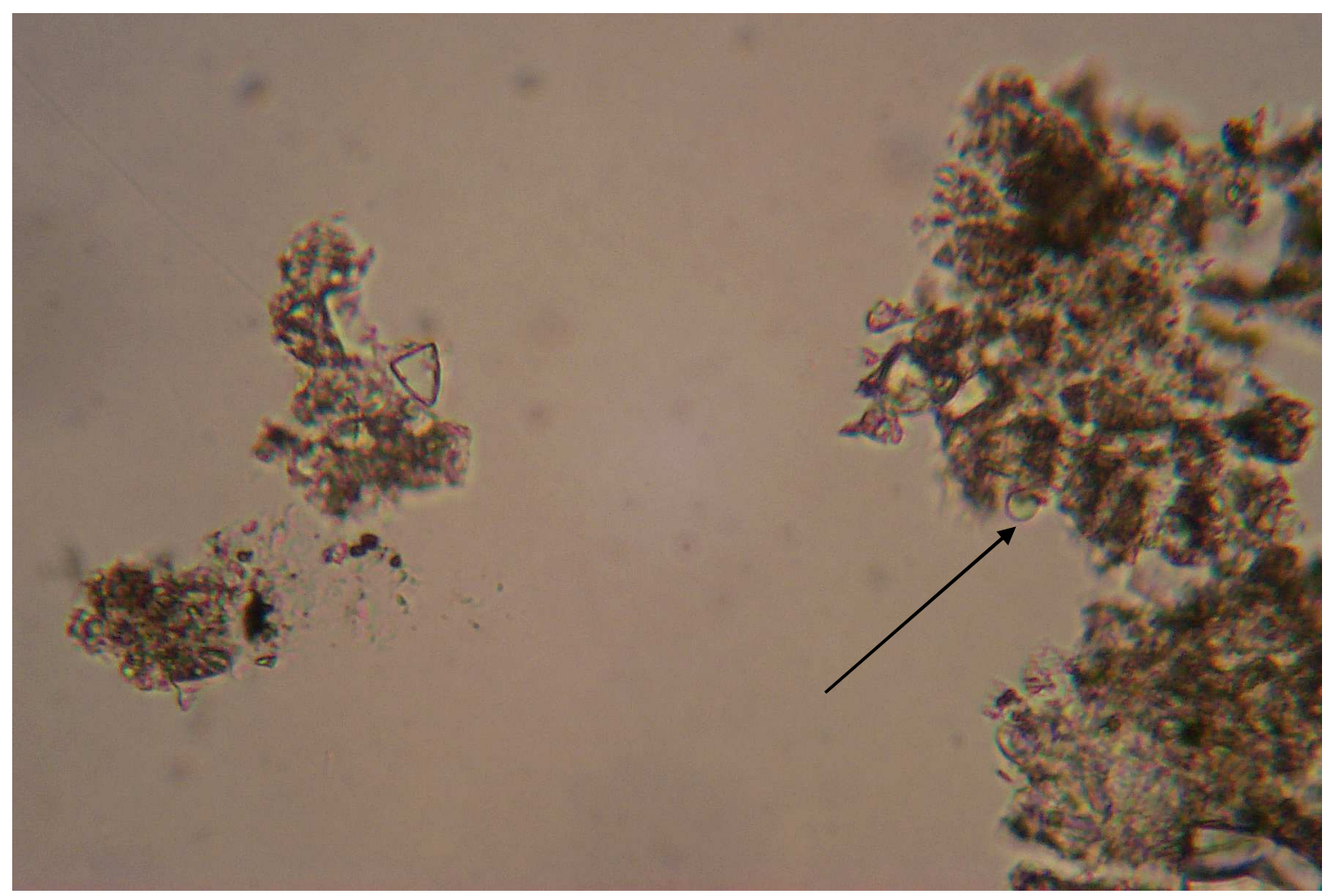

Figure 6-12 View of a powder mount from the paste from slab 1

The figure presents a single fly ash particle (arrow). Magnification is 200X and the width of the field is approximately $0.03175 \mathrm{~mm}(0.00125 \mathrm{in}$.) 


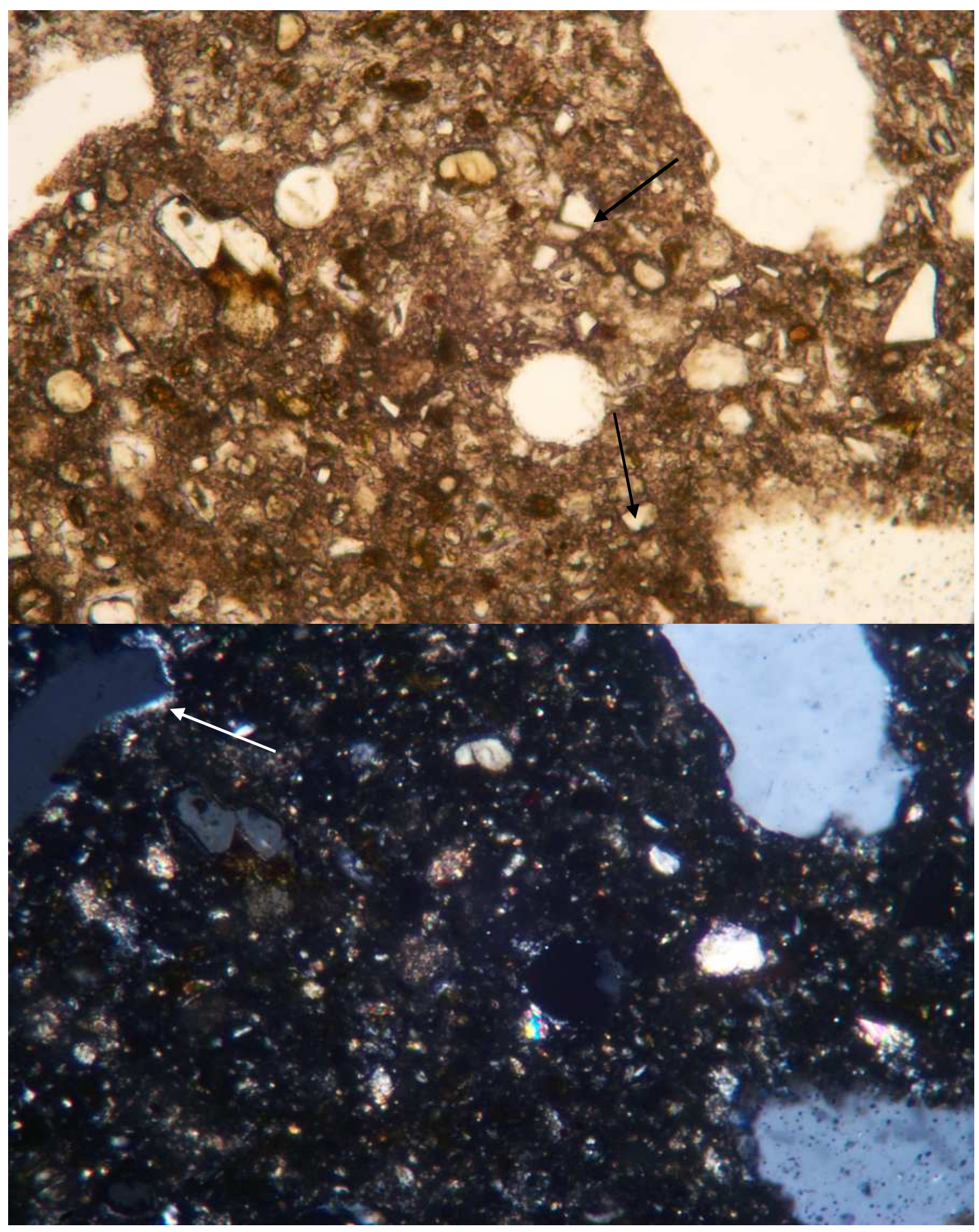

Figure 6-13 Views of portions of the thin section from slab 1 at 100x

The top in plane polarized light and the bottom with crossed polars (With of the field of view $0.365 \mathrm{~mm}(0.025 \mathrm{in}$.)). Two residual slag particles are indicated by the arrows. The calcium hydroxide is a small bright birefrigent areas distributed throughout in the bottom view and the aggregate socket (arrow). 


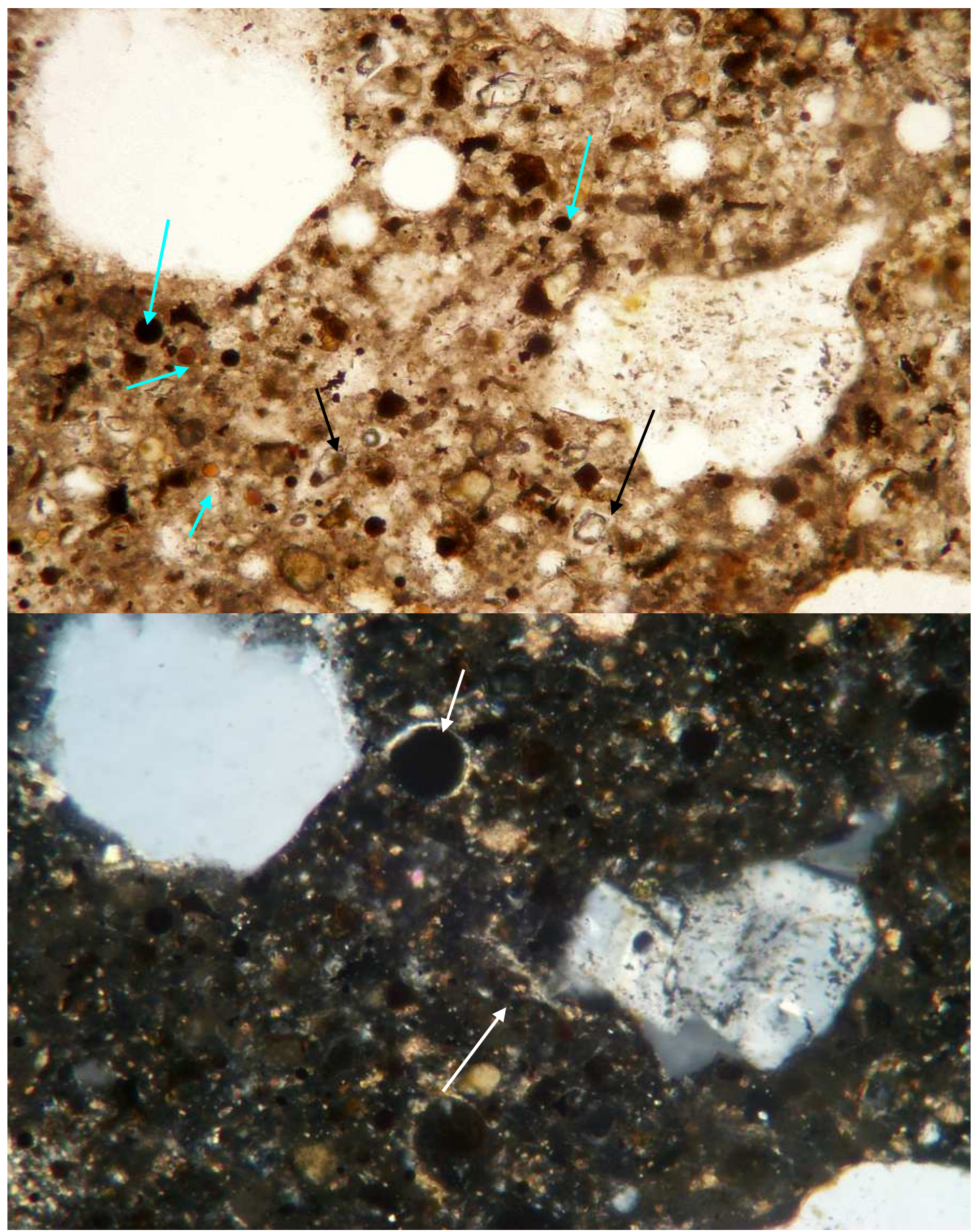

Figure 6-14 Views of the thin section from slab 2 at 100x

Residual portland cement particles are indicated with black arrows and fly ash with blue arrows in the upper view under plane polarized light. Calcium hydroxide at air-voids and aggregate sockets is indicated by white arrows in the bottom view under crossed polars. 


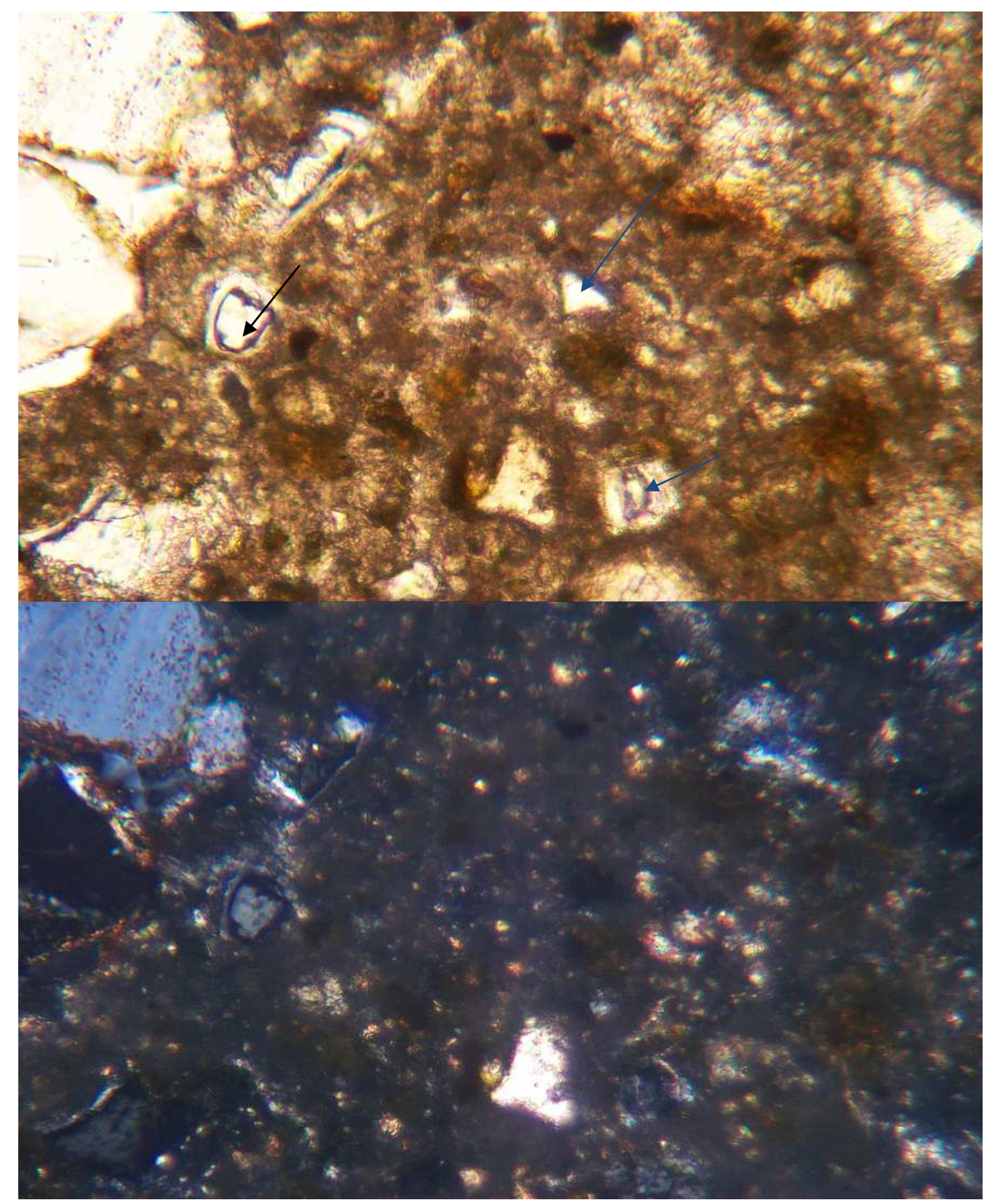

Figure 6-15 Views of portions of the thin section slab 3

In plane polarized light (top) and crossed polars (bottom), at a magnification of 200x. Residual slag particles are indicated by the blue arrows and portland cement particles by the black arrows. The calcium hydroxide is the small bright birefrigent areas distributed throughout in the bottom view 


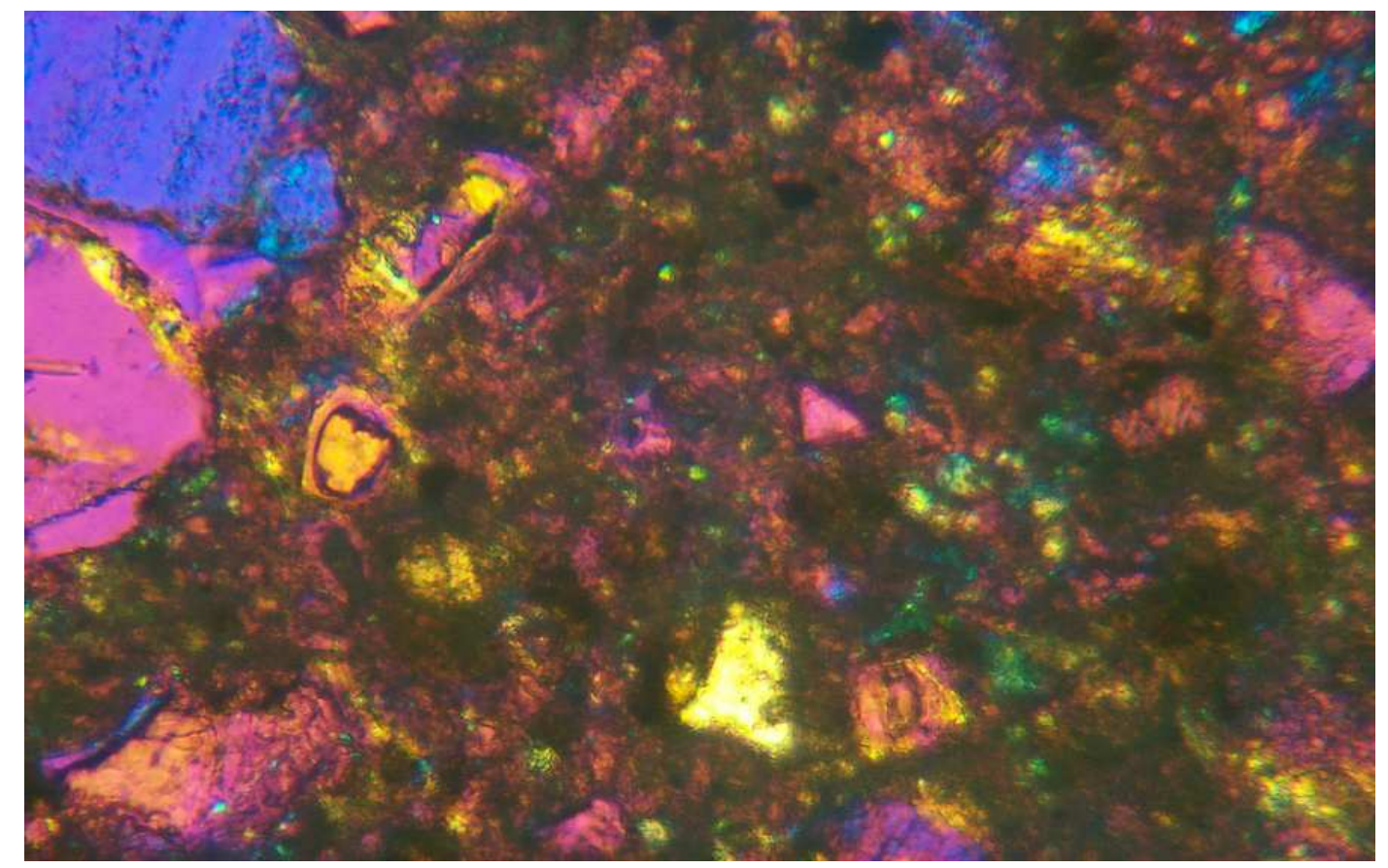

Figure 6-16 Views of portions of the thin section slab 3 (gypsum plate)

Some of the residual cement and slag particles are more visible in the view presented in Figure 6-16

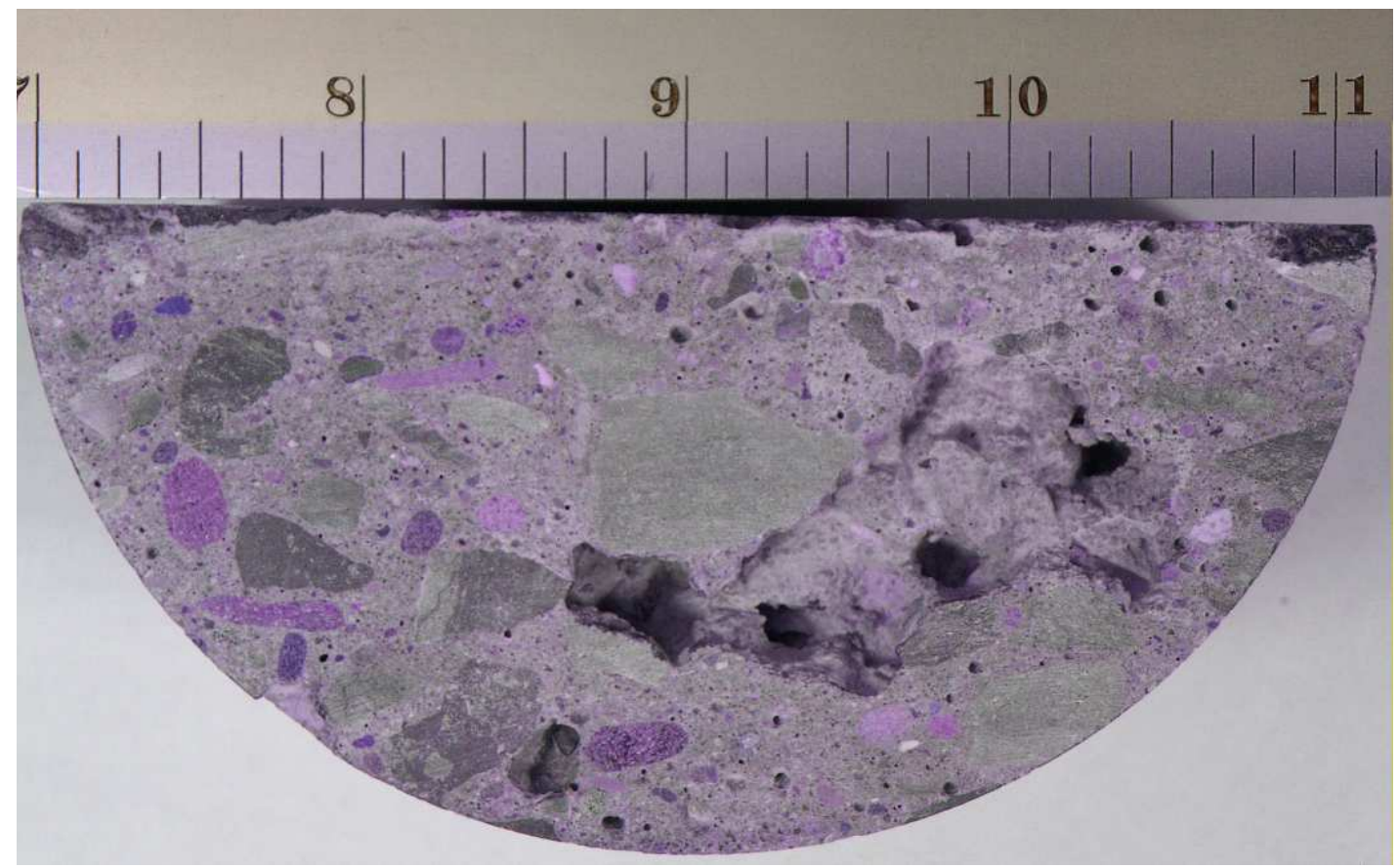

Figure 6-17 View of numerous consolidation voids in Core from Slab 3 


\section{CHAPTER 7}

\section{CONCLUSIONS AND RECOMMENDATIONS FOR FUTURE WORK}

Based on the study of implementing three plant scale mixtures in the field, this chapter draws conclusions on the construction procedures, monitoring and evaluations of fresh and hardened concrete properties, temperature and maturity, microscopical examinations, and petrographic analysis of the test slabs. It will also assign the grading for the HPC developed in the plant. Recommendations for future work is also provided

\subsection{Conclusions}

The conclusions for every test and examination made are included in the correspondent section, but some of the main conclusions are presented as follows:

\subsubsection{Fresh Concrete Properties}

- Proper addition of HRWRA seemed to be very important. In this project, HRWRA was added to obtain a good workability of the HPC mixtures and the desired slump.

- By protecting the slabs with wet burlap and plastic sheets immediately after pouring, it was possible to completely prevent drying shrinkage cracking.

- The evaporation rates calculated did not exceed the threshold values recommended of $0.5 \mathrm{~kg} / \mathrm{m}^{2} /$ hour $\left(0.1 \mathrm{lb} / \mathrm{ft}^{2} /\right.$ hour $)$ per hour for concretes containing SCM during the monitored period.

- Because of the use of large quantity of SCM and a low w/cm of 0.4, the initial slump for all mixtures were $100 \mathrm{~mm}$ (4 in.) before the addition of HRWRA. But after the addition of the HRWRA, the slump parameters established by the WVDOH could be achieved $(180 \mathrm{~mm}=7 \mathrm{in})$. 
- The air content of the fresh concrete mixtures was found to be $6.5 \%( \pm 1.5 \%)$ for the three different mixtures.

\subsubsection{Hardened Concrete Properties}

- The compressive strength of the different mixtures studied was adequately high.

- Slag + silica fume HPC exhibited the highest compressive strength for each of the age tested.

- Slag + silica fume exhibited higher early age strength compared to other combinations of SCM used in this study.

- Field-cored samples exhibited higher compressive strength compared to field-mixed match-cured specimens, field-mixed lab-cured specimens, and laboratory mixed specimens.

- The compressive strength increase was consistent with maturity index irrespective of type of mixture and curing conditions

- Up to 60 days, the compressive strength of field-mixed match-cured specimens were higher than field-mixed lab-cured specimens due to higher ambient temperature but at later ages the trend reversed.

- There exist definite correlations between compressive strength and paste volume for all the mixtures. Compressive strength was higher for the concretes made with higher paste volume. This was true for all curing conditions.

- HPC containing silica fume exhibited higher compressive strength at later ages which can be attributed to the pore refinement and the improved bond strength between the aggregate and mortar. Though the bond strength was not measured the petrography of core samples partially revealed the fact.

- For all mixtures about $60 \%$ of the compressive strength was found to reach at 7 days after pouring.

- The minimum 28-day compressive strength requirements for Class $\mathrm{H}$ concrete by WVDOH is $28 \mathrm{MPa}$ (4000 psi). This is achieved almost within 7 days due to use of $\mathrm{SCM}$ and low w/cm. The value is also lower compared to those prescribed by FHWA 
or other state. The previous research on lab-scale and current research at plant scale show that the minimum strength criteria may be increased to make it more realistic.

- When the predicted shrinkage for the slabs at 90 days is compared with the shrinkage data obtained from the laboratory specimens tested on the previous phase of this project, it may be concluded that equation presented by the ACI offers a good prediction of shrinkage for in-place concrete structures.

- There was not much difference of dynamic modulus of elasticity values for lab-cured and match-cured specimens. The dynamic modulus of elasticity was primarily measured to monitor the concrete quality over time as it is based on the same set of specimens. All the values were higher than predicted static modulus of elasticity by ACI 363 and ACI 318 as expected.

- Freezing and thawing resistance of HPC containing slag + silica fume was best among all mixtures; however the HPC containing fly ash + silica fume and slag + metakaolin exhibited very good resistance too.

- All the mass loss after 300 cycles of freezing and thawing was below $0.5 \%$ which is insignificantly low.

- It was observed that durability factor (after 300 cycles) for all three mixtures were above $96 \%$, indicating a high resistance to freezing and thawing for all mixtures.

- The RCPT values indicate that for the same $\mathrm{w} / \mathrm{cm}$, concretes with different SCM presented different charge passed values.

- The maturity of the concrete was well related to the charge passed through concrete. More was the maturity of concrete, less was the charge passed.

- The slag + silica fume HPC had the lowest chloride permeability and the slag + metakaolin HPC showed the highest permeability, but all the values were in the range of "Very Low permeability" per ASTM C 1202 or AASHTO T 277

- Although all the RCPT values of concrete under different curing conditions were in the range of either "low" or "very low" category per ASTM C 1202 or AASHTO T 277 , the RCPT values obtained from field cores were found to have lower chloride permeability compared to field-mixed lab-cured specimens. This was primarily due to difference in curing temperature at lab and field. 
- All the HPC produced satisfied the FHWA strength, modulus of elasticity, RCPT, and durability (freezing and thawing) criteria; however each of the criteria satisfied different grades as assigned by FHWA.

\subsubsection{Maturity of HPC}

- Strength-maturity curves were developed for each concrete mixture in order to have a relationship that will allow the prediction of compressive strength.

- For each slab, higher temperature was found to occur compared to interior of the slab.

- Continuous curing of the slabs under wet burlap protected the concrete from the high ambient temperature during curing period. Therefore the curing not only helped to continue the hydration process but also controlled the undesirable temperature rise.

- Due to higher temperatures in the field compared with the laboratory, the field matchcured specimens reached higher maturity at early ages than field lab-cured specimens.

- Predicted values using the strength-maturity relationship were obtained for 28 and 56 days and then compared with real values from field cores tested. It was found that the prediction was very accurate, indicating that the relationships were well established for each HPC studied.

- The compressive strength values predicted from the average maturity index from each slab were very close to the values obtained from testing the drilled cores for compressive strength.

\subsubsection{Microscopical Examination of HPC}

\subsubsection{Air-Void Analysis}

- The air-void systems of all three different HPC slabs satisfied the requirements by ASTM C 457 for air-void parameter, concluding that the slabs were well protected to freezing and thawing. Also the high durability factor (above 96\%) for all three slabs support this observation

- In some locations of cored samples, there were some interconnected non-spherical voids found in cored samples collected from some locations. This is characteristics of 
a difficulty in consolidation in those locations. However, looking at the entire slabs, the number is insignificant and common for field work. The purpose of mentioning here is to highlight the fact that air-void parameter study can also reveal additional information.

- The highest air content and lowest paste content were found to occur for cores from slab 2 compared to the cores from slab 1 and 3.

- From the data obtained it may be concluded that finer the SCM used in the concrete mixture, larger was the void frequency and the specific surface with smaller the void spacing factor.

- The section analysis method proposed in this work was an efficient approach for finding the air-void parameters of hardened concrete. It was comparable to the standard methods, but quicker and easier to conduct using image analysis.

- The section analysis method facilitated the air-void determination more precisely because smaller areas could be studied compared to the standard methods.

- The determination of the air-void size distribution obtained by the section analysis method revealed that $95 \%$ of the air-voids were entrained air-voids (which is difficult to be determined by standard methods).

\subsubsection{Petrographic Examinations}

- The petrographic examination confirmed that coarse and fine aggregates, w/cm, and cementitious materials contents were consistent with the original mixture design.

- The petrographic examination revealed that the aggregates were well dispersed throughout the concrete matrix.

- The hydration of the concrete paste at 28 days was advanced and the calcium hydroxide components of the cement hydration products occurred mainly as moderate sized units.

- Some difficulty in consolidation in few locations was detected from core samples with slab 3, however compared with the size of slab it was insignificant and also normal phenomena for the field work. 
- The carbonation depth of the slabs was very low at the age of 28 days. The carbonation depth at later age may reveal more useful information.

- There were no significant cracks observed in the cores studied at 28 days.

- The petrographic examination confirmed that the air-voids were present mainly as small and fine spherical voids characteristic of entrained air-voids and lesser amounts of non spherical voids characteristic of entrapped air.

- Cementitious material contents were estimated to be consistent with the mixture designs; however components such as metakaolin and silica fume are too fine to be identified.

- The fly ash content of slab 2 was estimated to be 20 percent. Slag was present in the cores from slabs 1 and 3, and it was estimated to represent 25 to 30 percent by weight of total cementitious materials content.

- Petrography examination identified the presence of unreacted cement, slag + fly ash particles, which is common. The magnification, however, could not determine silica fume and metakaolin (for which SEM is recommended).

- All of the cores studied were adequately air entrained and was made using similar crushed calcareous stone (limestone) coarse aggregate and siliceous natural sand fine aggregate.

\subsubsection{FHWA Grades of Performance Characteristics for HPC}

Using the grades of performance characteristics for HPC as proposed by the FHWA, the different concrete mixtures used in this project and the similar mixtures used on the previous phase of this project was graded as follows (Grade 3 is considered as highest and Grade 1 the lowest):

Table 7-1 FHWA performance grades for the field-mixed HPC

\begin{tabular}{c|c|c|c}
\hline Performance Characteristics & SL+MK & FA+SF & SL+SF \\
\hline Compressive Strength (28 days) & 2 & 2 & 2 \\
\hline Modulus of Elasticity (28 days) & 1 & 1 & 1 \\
\hline Freeze/Thaw Durability & 2 & 2 & 2 \\
\hline Chloride Permeability (60 days) & 3 & 3 & 3 \\
\hline Shrinkage (90 days) & 2 & 2 & 2 \\
\hline
\end{tabular}


Table 7-2 FHWA performance grades for the laboratory mixed HPC

\begin{tabular}{l|c|c|c}
\hline Performance Characteristics & MK & FA+SF & SL+SF \\
\hline Compressive Strength (28 days) & 2 & 1 & 1 \\
\hline Modulus of Elasticity (28 days) & 1 & 1 & 1 \\
\hline Freeze/Thaw Durability & - & - & - \\
\hline Chloride Permeability (60 days) & 2 & 3 & 3 \\
\hline Shrinkage (90 days) & 2 & 2 & 2 \\
\hline
\end{tabular}

\subsection{Future Work Recommendations}

Arrangements will be made with collaborators regarding the final mixture design and feasibility of producing different mixtures in other two ready-mix concrete plants. The mixtures to be considered: slag + silica fume, fly ash + silica fume, fly ash + metakaolin, and slag + metakaolin. Through discussions with two representative plants (Boxley in southern WV; and Potomac Construction Industry in Martinsburg, WV) some strategies will be developed for production and delivery of the samples either to WVU or to nearest testing laboratories. It is likely that most of the tests other than compressive strength will be performed at WVU laboratories. The location of the three different ready-mix concrete plants selected can be observed in Figure 7-1.

Interim specifications will be developed for making final plan for full-scale demonstration projects. However based on the current information, tentative plan for full-scale project can be made. Full-scale HPC Bridge decks needs to be built, evaluated, and monitored to develop final specifications and guidelines for the state of West Virginia. It is recommended to study same HPC mixture in two different location of the state and two different HPC in each location of the state. Two-lane and single or two span bridges may be built in Northern and Southern part of West Virginia to achieve the goal. An experimental (single span and smaller) bridge is also recommended to be tested to study the effects of corrosion inhibitor and shrinkage reducing admixtures. 
As future work, it is recommended to develop new strength-maturity correlation curves for the studied concrete mixtures. This could be done to correlate the accuracy of the curves presented in this study and to include more values for early age compressive strength.

Long term health monitoring of effects of deicing salts on abrasions of deck surface, diffusion of chloride ions, carbonation, reinforcement corrosions, and cracking can be undertaken with NDE or built-in sensing technology in order to predict the life-cycle of the HPC decks.

\section{WEST VIRGINIA}

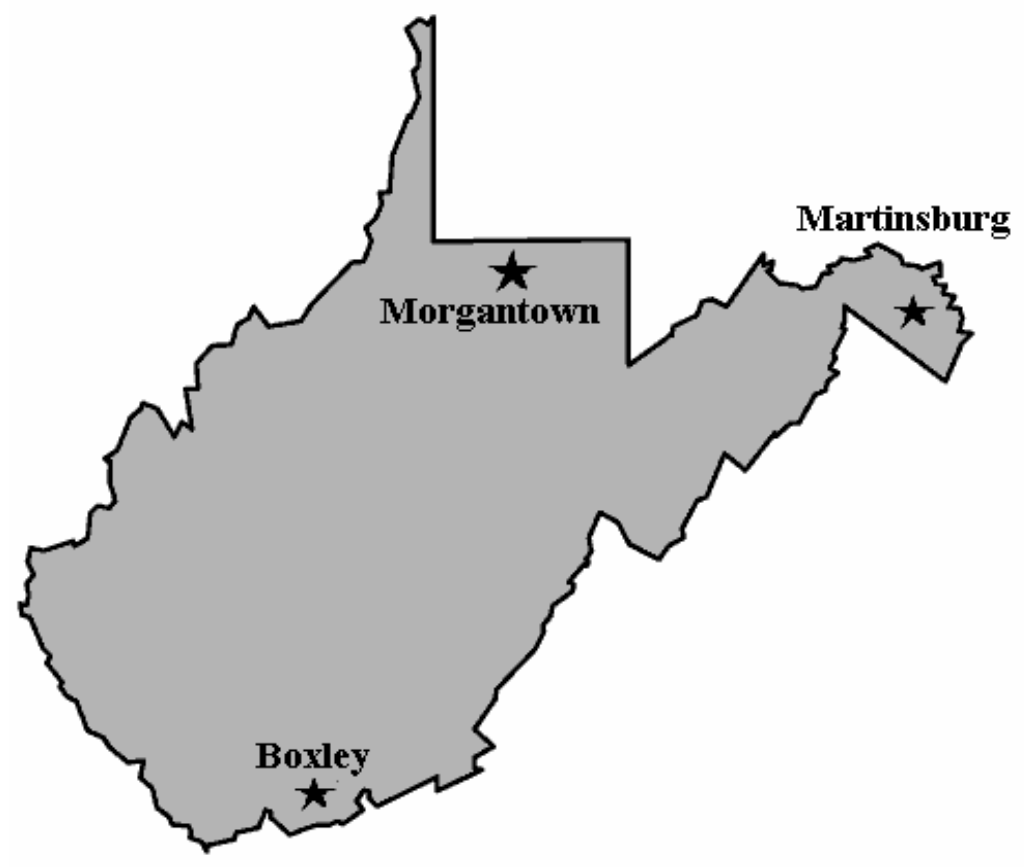

Figure 7-1 Concrete Plants Location 


\section{BIBLIOGRAPHY}

Aligizaki, K. K.; and Philip D. C., "Air content and size distribution of air voids in hardened cement pastes using the section-analysis method," Cement and concrete research, Vol.29 (1999), pp: 273-80.

American Concrete Pavement Association. "Maturity Testing of Concrete Pavements: Applications and Benefits,” IS257P. ACPA, Skokie, IL (2002).

American Concrete Institute. "Concrete: A Century of Innovation," American Concrete Institute, http://www.concrete.org/ staffreport/concrete.html (accessed June 21, 2008).

ASTM C 31, "Standard Practice for Making and Curing Concrete Test Specimens in the Field," ASTM International, West Conshohocken, PA., (2006).

ASTM C 33, "Standard Specification for Concrete Aggregates," ASTM International, West Conshohocken, PA., (2003).

ASTM C 39, "Standard Test Method for Compressive Strength of Cylindrical Concrete Specimens," ASTM International, West Conshohocken, PA., (2005).

ASTM C 42, "Standard Test Method for Obtaining and Testing Drilled Cores and Sawed beams of Concrete," ASTM International, West Conshohocken, PA., (2004).

ASTM C 94, "Standard Specifications for Ready-Mixed Concrete," ASTM International, West Conshohocken, PA., (2007).

ASTM C 143, "Standard Test Method for Slump of Hydraulic-Cement Concrete," ASTM International, West Conshohocken, PA., (2005).

ASTM C 150, "Standard Specification for Portland cement," ASTM International, West Conshohocken, PA., (2007).

ASTM C 157, "Standard Test Method for Length Change of Hardened Hydraulic-Cement Mortar and Concrete," ASTM International, West Conshohocken, PA., (2006).

ASTM C 192, "Standard Practice for Making and Curing Concrete Test Specimens in the Laboratory" ASTM International, West Conshohocken, PA., (2006).

ASTM C 215, "Standard Test Method for Fundamental Transverse, Longitudinal, and Torsional Resonant Frequencies of Concrete Specimens," ASTM International, West Conshohocken, PA., (2002). 
ASTM C 260, "Standard Specification for Air-Entraining Admixtures for Concrete," ASTM International, West Conshohocken, PA., (2006).

ASTM C 457, "Standard Test Method for Microscopical Determination of Parameters of the Air-Void System in Hardened Concrete," ASTM International, West Conshohocken, PA., (2006).

ASTM C 469, "Standard Test Method for Static Modulus of Elasticity and Poisson's Ratio of Concrete in Compression," ASTM International, West Conshohocken, PA., (2002).

ASTM C 494, "Standard Specification for Chemical Admixtures for Concrete," ASTM International, West Conshohocken, PA., (2005).

ASTM C 618, "Standard Specification for Coal Fly Ash and Raw or Calcined Natural Pozzolan for Use as a Mineral Admixture in Concrete," ASTM International, West Conshohocken, PA., (2005).

ASTM C 666, "Standard Test Method to Rapid Freezing and Thawing," ASTM International, West Conshohocken, PA., (2003).

ASTM C 856, "Standard Practice for Petrographic Examination of Hardened Concrete," ASTM International, West Conshohocken, PA., (2004).

ASTM C 989, "Standard Specification for G.G.B.F Slag for Use in Concrete and Mortars," ASTM International, West Conshohocken, PA., (2006).

ASTM C 1074, "Estimation of concrete strength by maturity method," ASTM International, West Conshohocken, PA., (2004).

ASTM C 1202, "Standard Test Method for Electrical Indication of Concrete's Ability to Resist Chloride Ion Penetration," ASTM International, West Conshohocken, PA., (2005).

ASTM C 1240, "Standard Specification for used of Silica Fume for use as a Mineral Admixture in Hydraulic Cement Concrete, Mortar, and Grout," ASTM International, West Conshohocken, PA., (2005).

Basheer, P. M.; Gilleece, P. R.; Long, A.E; and Mc Carter, W.J., "Monitoring electrical resistance of concretes containing alternative cementitious materials to assess their resistance to chloride penetration," Cement \& Concrete Composites, Vol. 24 (2002), pp: 437-49.

Bhattacharya, Arka., "Effects of Aggregate Grading and Admixtures/Fillers on Fresh and Hardened Properties of Self-Consolidating Concrete." M.S. Thesis, West Virginia University, Morgantown, WV.,(2008). 
Cabrera, J. G.; Woolley, G. R.; and Hassan, K. E., "The uses of fly ash to improve the chloride resistance of cement mortars." Waste Materials in Construction: Putting Theory into Practice (1997), pp: 387-400.

Carino, N. J.; and Lew, H. S., "The maturity method: From Theory to Application." National Institute of Standards and Technology (2001).

Chan, Y. N.; Luo, X.; and Sun, W., "Compressive strength and pore structure of highperformance concrete after exposure to high temperature up to $800 \mathrm{C}$." Cement and Concrete Research, Vol. 30, (2000), pp: 247-51.

Chatterjee, A., "Shrinkage and Strength Characterization of Concrete Containing Supplementary Cementitious Materials," M.S. Thesis, West Virginia University, Morgantown, WV., (2004).

Coster, M; and Chermant, J., "Image analysis and mathematical morpholigy for civil engineering materials," Cement and Concrete Composites, Vol. 23 (2001), pp: 133-51.

Crawford, G. "Guide to Nondestructive Testing of Concrete," FHWA-SA-97-105. Federal Highway Administration, Washington, DC (1997).

Davalos, J. F.; Ray, I; Sothen, J.E.; Baiely, G. L.; and Shook, J. D., "Overview of advanced concrete materials development for bridge decks of West Virginia," The First International Conference on Recent Advances in Concrete Technology, Washington D.C., September 1921 (2007), pp: 583-597.

Demir, F., "A new way of prediction elastic modulus of normal and high strength concretefuzzay logic." Cement and Concrete Research, Vol. 35, (2005), pp: 1531-38.

Elsen, J., "Automated air void analysis on hardened concrete Results of a European intercomparison testing program." Cement and Concrete Research, Vol. 31, (2001), pp: 102731.

Engius: constructive intelligence. "Intellirock Case Study", http://www.engius.com /publications/casestudies.html (accessed December 4, 2008).

Erlin, B., "Water-Cement ratio." Concrete international (2000), pp: 7-9.

Erlin, B., "Other Viewpoint of Petrographic Reports ." Concrete Construction Magazine Feb. (2000), pp: 21-27.

Fan, D., "Durability Studies of High Performance Concrete Used for Bridge Decks," M.S Thesis, West Virginia University; Morgantown, WV. (2005).

Figgs, J. W., "Analysis of hardened concrete - a guide to test, procedures and interpretation of results," The concrete society, Vol. 32, London, UK. (1989). 
Gong, Z., "Cracking Studies of High-Performance Concrete for Bridge Decks," PhD Thesis, West Virginia University; Morgantown, WV., (2006).

Goodrum, P; and Dai, J., "The use of the concrete maturity method in construction of industrial facilities: A case of study" University of Kentucky, (2004).

Goodspeed, C. H.; Vanikar, S.; and Cook, R., "High-Performance concrete defined for highway structures," Concrete International, Vol. 18 (1996), pp: 62-67.

Jana, D., "A routine test on measurements of air void parameters in hardened concrete by various automated image analyses and ASTM C 457 methods," Paper presented at the $29^{\text {th }}$ ICMA conference. Quebec City, Canada., (2007).

Kosmatka, S. H.; Kerkhoff, B.; and Panarese, W. C., "Design and Control of Concrete Mixtures," 14th ed. Skokie, IL: PCA, (2006).

Lane, S., "Supplanting the rapid chloride permeability test with a quick measurement of concrete conductivity - Final Report," Virginia Transportation Research Council, Charlottesville, VA. (2005).

Li, Z.; and Ding, Z., "Property improvement of Portland cement by incorporating with metakaolin and slag," Cement and Concrete Research, Vol. 33 (2002), pp: 579-84.

Liu, J. J.; and Kahn M. S., "Comparison of Known and Determined Water-Cement Ratios Using Petrography," American Concrete Institute (2000), pp: 11-25.

McIntosh, J., "Electrical Curing of Concrete." Magazine of Concrete Research, Vol. 1, No. 1 (1949), pp: 21-28.

Mehta, P. K.; and Monteiro, P.J., "Concrete: Structure, Properties, and Materials," 2nd ed. Englewood Cliffs, NJ: Prentice Hall Inc, (1993).

Mindess, S.; Young, J. F.; and Darwin D., “Concrete,” Vol. 1, 2nd ed. Upper Saddle River, NJ: Prentice Hall, (2003).

Naik, T. R.; Singh S. S.; and Hassain M. M., "Permeability of concrete containing large amount of Fly Ash." Cement and Concrete Research, Vol. 24, (1994), pp:913-22.

Neville, A. M., "Properties of Concrete", Fourth Edition, Addison Wesley Longman Limited, Harlow, England, (1996).

Nurse, R., "Steam Curing of Concrete," Magazine of Concrete Research, Vol. 1 No. 2 (1949), pp:79-88. 
Ozyildirim, C., "Laboratory investigation of low-permeability concretes containing Slag and Silica Fume," ACI Materials Journal, Vol. 91 (1994), pp: 197-203.

Park, S.; Kim, H.; Morales, A.; and Ko, S., "Air-void Analysis System of Polished Concrete Using Image Processing." Journal of Applied Computer Science, pp: 1-7.

Ray, I.; Davalos J. F.; and Fan, D., "Combined freeze-thaw and deicing salt tests for highperformance concrete," The First International Conference on Recent Advances in Concrete Technology, Washington D.C., September 19-21 (2007), pp 241-252.

Ray, I.; Davalos J. F.; Gong, Z.; and Chatterjee, A., "Seven International Symposium on the Utilization of High-strength/High-Performance Concrete," Michigan: American Concrete Institute, Vol. 2 (2005), pp: 903-916

Ray, I.; Davalos, J. F., and Morris, J., "Shrinkage and Cracking Evaluations of HighPerformance Concrete for Bridge Decks in West Virginia," Proceedings of the International Conference on Civil Engineering in the New Millennium, Opportunities and Challenges, India, Vol. II, (2007), pp: 1091-98.

Roy, D. M., Arjunan P.; and Silsbee M. R., "Effects of silica fume, metakaolin, and lowcalcium fly ash on chemical resistance of concrete," Cement and Concrete Research, Vol. 31 (2001), pp: 1809-13.

Saul, A. "Electrical Curing of Concrete," Magazine of Concrete Research, Vol. 2, No. 6 (1951), pp: 127-40.

Shi, C.; Stegemann J. A.; and Caldwell R. J., "Effect of supplementary cementing materials on the specific conductivity of pore solution and its implications on the rapid chloride permeability test (AASHTO T227 and ASTM C1202)." ACI Material Journal, Vol. 95, (1998), pp: 389-93.

Smith, K., "Implementation of a Total Environmental Management for Paving (TEMP) System." Www.fhwa.dot.gov U.S Department of transportation. 22 Oct. (2008) http://www.fhwa.dot.gov/pavement/pccp/pubs/06004/index.cfm

St John, D. A.; Poole, A.B..; and Sims, I., "Concrete Petrography- A handbook of investigative techniques", Arnold (a member of the Hodder Headline Group), London and copublished by John Wiley \& Sons Inc, New York and Toronto (1998).

Suksawang, N; Nassif, H.H.; and Tanchan P., "Comparison of Elastic Modulus Equations for High-Performance Concrete (HPC) with Pozzolanic Materials." International conference on pozzolan, concrete and geopolymer, Khon Kaen, Thailand (2006), pp: 237-46.

Uchoa, S. B.; Ray I.; Davalos J. F., and Tonholo J., "Comparative Studies of Chloride Permeability, Conductivity, and Salt-Ponding Tests of Concrete Containing Different 
Admixtures", International Journal of Modelling, Identification and Control (IJMIC), Special Issue: Modelling, Monitoring and Control of Durability of Concrete Structures (in press) (2009).

Uno, P. J., "Plastic Shrinkage Cracking and Evaporation Formulas." ACI Materials, Vol. 95, (1998), pp: 365-75.

Wazczuk, C. M.; and Juliano, M. L., "Application of HPC in a New Hampshire Bridge." Concrete international, Vol 21, No 2 (1999), pp: 61-62.

Weiss, W. J; Schiebl, A; Yang, W; and Shah, S. P., "Shrinkage Cracking Potential, Permeability, and Strength for HPC: Influence of W/C, Silica Fume, Latex, and Shrinkage Reducing Admixtures." International Symposium on High-Performance and Reactive Powder Concretes. Sherbrooke, Canada (1998), pp: 349-64.

West Virginia Department of Transportation, www.wvdot.com, (accessed November 11, 2008).

Zhang, W., "Exploratory Study on High Performance Concrete for Bridge Decks in West Virginia," M.S. Thesis, West Virginia University, Morgantown, WV, (2001). 


\section{APPENDIX A}

1. Compressive strength data for Field-MC and Field LC ( $1 \mathrm{MPa}=145 \mathrm{psi} ; 1 \mathrm{lb}=0.45 \mathrm{~kg})$

\begin{tabular}{|c|c|c|c|c|c|c|c|}
\hline \multirow[b]{2}{*}{$\begin{array}{c}\text { Age } \\
\text { (Days) }\end{array}$} & \multirow[b]{2}{*}{ Slab } & \multicolumn{3}{|c|}{ Match-Cured Specimens } & \multicolumn{3}{|c|}{ Laboratory-Cured Specimens } \\
\hline & & $\begin{array}{l}\text { Field } \\
\text { (Lbs) }\end{array}$ & $\begin{array}{l}\text { Strength } \\
\text { (psi) }\end{array}$ & $\begin{array}{c}\text { Strength } \\
\text { (MPa) }\end{array}$ & $\begin{array}{l}\text { Lab } \\
\text { (Lbs) }\end{array}$ & $\begin{array}{l}\text { Strength } \\
\text { (psi) }\end{array}$ & $\begin{array}{c}\text { Strength } \\
\text { (MPa) }\end{array}$ \\
\hline \multirow{8}{*}{4} & \multirow{3}{*}{ S1 } & 97000 & 3430.67 & 23.65 & 80500 & 2847.10 & 19.63 \\
\hline & & 99000 & 3501.40 & 24.14 & 106000 & 3748.97 & 25.85 \\
\hline & & 116000 & 4102.65 & 28.29 & 117500 & 4155.70 & 28.65 \\
\hline & \multirow{3}{*}{$\mathrm{S} 2$} & 102000 & 3607.50 & 24.87 & 125000 & 4420.96 & 30.48 \\
\hline & & 122000 & 4314.86 & 29.75 & 121000 & 4279.49 & 29.51 \\
\hline & & 127000 & 4491.70 & 30.97 & 144000 & 5092.95 & 35.11 \\
\hline & \multirow{2}{*}{ S3 } & 167000 & 5906.40 & 40.72 & 170000 & 6012.51 & 41.45 \\
\hline & & 169000 & 5977.14 & 41.21 & 163000 & 5764.93 & 39.75 \\
\hline \multirow{8}{*}{7} & \multirow{3}{*}{ S1 } & 168000 & 5941.77 & 40.97 & 133000 & 4703.90 & 32.43 \\
\hline & & 168000 & 5941.77 & 40.97 & 156000 & 5517.36 & 38.04 \\
\hline & & 132000 & 4668.53 & 32.19 & 160000 & 5658.83 & 39.02 \\
\hline & \multirow{3}{*}{$\mathrm{S} 2$} & 156000 & 5517.36 & 38.04 & 140000 & 4951.48 & 34.14 \\
\hline & & 153000 & 5411.26 & 37.31 & 176000 & 6224.71 & 42.92 \\
\hline & & 162000 & 5729.56 & 39.50 & 173000 & 6118.61 & 42.19 \\
\hline & \multirow{2}{*}{ S3 } & 200000 & 7073.54 & 48.77 & 199000 & 7038.17 & 48.53 \\
\hline & & 220000 & 7780.89 & 53.65 & 218000 & 7710.15 & 53.16 \\
\hline \multirow{8}{*}{14} & \multirow{3}{*}{ S1 } & - & - & - & 206000 & 7285.74 & 50.23 \\
\hline & & - & - & - & 177000 & 6260.08 & 43.16 \\
\hline & & - & - & - & 170000 & 6012.51 & 41.45 \\
\hline & \multirow{3}{*}{$\mathrm{S} 2$} & - & - & - & 215000 & 7604.05 & 52.43 \\
\hline & & - & - & - & 178000 & 6295.45 & 43.41 \\
\hline & & - & - & - & 196000 & 6932.07 & 47.79 \\
\hline & \multirow{2}{*}{ S3 } & - & - & - & 260000 & 9195.60 & 63.40 \\
\hline & & - & - & - & 248000 & 8771.19 & 60.48 \\
\hline
\end{tabular}




\begin{tabular}{|c|c|c|c|c|c|c|c|}
\hline \multirow{2}{*}{$\begin{array}{c}\text { Age } \\
\text { (Days) }\end{array}$} & \multirow[b]{2}{*}{ Slab } & \multicolumn{3}{|c|}{ Match-Cured Specimens } & \multicolumn{3}{|c|}{ Laboratory-Cured Specimens } \\
\hline & & $\begin{array}{l}\text { Field } \\
\text { (Lbs) }\end{array}$ & $\begin{array}{l}\text { Strength } \\
\text { (psi) }\end{array}$ & $\begin{array}{c}\text { Strength } \\
\text { (MPa) }\end{array}$ & $\begin{array}{l}\text { Lab } \\
\text { (Lbs) }\end{array}$ & $\begin{array}{l}\text { Strength } \\
\text { (psi) }\end{array}$ & $\begin{array}{c}\text { Strength } \\
\text { (MPa) }\end{array}$ \\
\hline \multirow{8}{*}{28} & \multirow{3}{*}{ S1 } & 190000 & 6719.86 & 46.33 & 226000 & 7993.10 & 55.11 \\
\hline & & 221000 & 7816.26 & 53.89 & 220000 & 7780.89 & 53.65 \\
\hline & & 220000 & 7780.89 & 53.65 & 238000 & 8417.51 & 58.04 \\
\hline & \multirow{3}{*}{ S2 } & 237000 & 8382.14 & 57.79 & 227000 & 8028.46 & 55.35 \\
\hline & & 195000 & 6896.70 & 47.55 & 223000 & 7886.99 & 54.38 \\
\hline & & 208000 & 7356.48 & 50.72 & 229000 & 8099.20 & 55.84 \\
\hline & \multirow{2}{*}{ S3 } & 255000 & 9018.76 & 62.18 & 278000 & 9832.22 & 67.79 \\
\hline & & 279000 & 9867.58 & 68.03 & 260000 & 9195.60 & 63.40 \\
\hline \multirow{8}{*}{56} & \multirow{3}{*}{ S1 } & 200000 & 7073.54 & 48.77 & 230000 & 8134.57 & 56.09 \\
\hline & & 210000 & 7427.21 & 51.21 & 231000 & 8169.93 & 56.33 \\
\hline & & 225000 & 7957.73 & 54.87 & 240000 & 8488.24 & 58.52 \\
\hline & \multirow{3}{*}{ S2 } & 222000 & 7851.63 & 54.14 & 238000 & 8417.51 & 58.04 \\
\hline & & 221000 & 7816.26 & 53.89 & 246000 & 8700.45 & 59.99 \\
\hline & & 210000 & 7427.21 & 51.21 & 236000 & 8346.77 & 57.55 \\
\hline & \multirow{2}{*}{ S3 } & 274000 & 9690.74 & 66.82 & 138000 & 10981.67 & 75.72 \\
\hline & & 270000 & 9549.27 & 65.84 & 310000 & 10963.98 & 75.59 \\
\hline \multirow{8}{*}{90} & \multirow{3}{*}{ S1 } & 223000 & 7886.99 & 54.38 & 250000 & 8841.92 & 60.96 \\
\hline & & 224000 & 7922.36 & 54.62 & 241000 & 8523.61 & 58.77 \\
\hline & & 220000 & 7780.89 & 53.65 & 240000 & 8488.24 & 58.52 \\
\hline & \multirow{3}{*}{ S2 } & 230000 & 8134.57 & 56.09 & 245000 & 8665.08 & 59.74 \\
\hline & & 225000 & 7957.73 & 54.87 & 250000 & 8841.92 & 60.96 \\
\hline & & 234000 & 8276.04 & 57.06 & 250000 & 8841.92 & 60.96 \\
\hline & \multirow{2}{*}{ S3 } & 308000 & 10893.25 & 75.11 & 150000 & 11936.59 & 82.30 \\
\hline & & 320000 & 11317.66 & 78.03 & 153000 & 12175.32 & 83.95 \\
\hline
\end{tabular}




\section{APPENDIX B}

1. Mass, Longitudinal frequency and dynamic modulus of elasticity measured and calculated for freezing and thawing $(1 \mathrm{Kg}=2.2 \mathrm{lb})$.

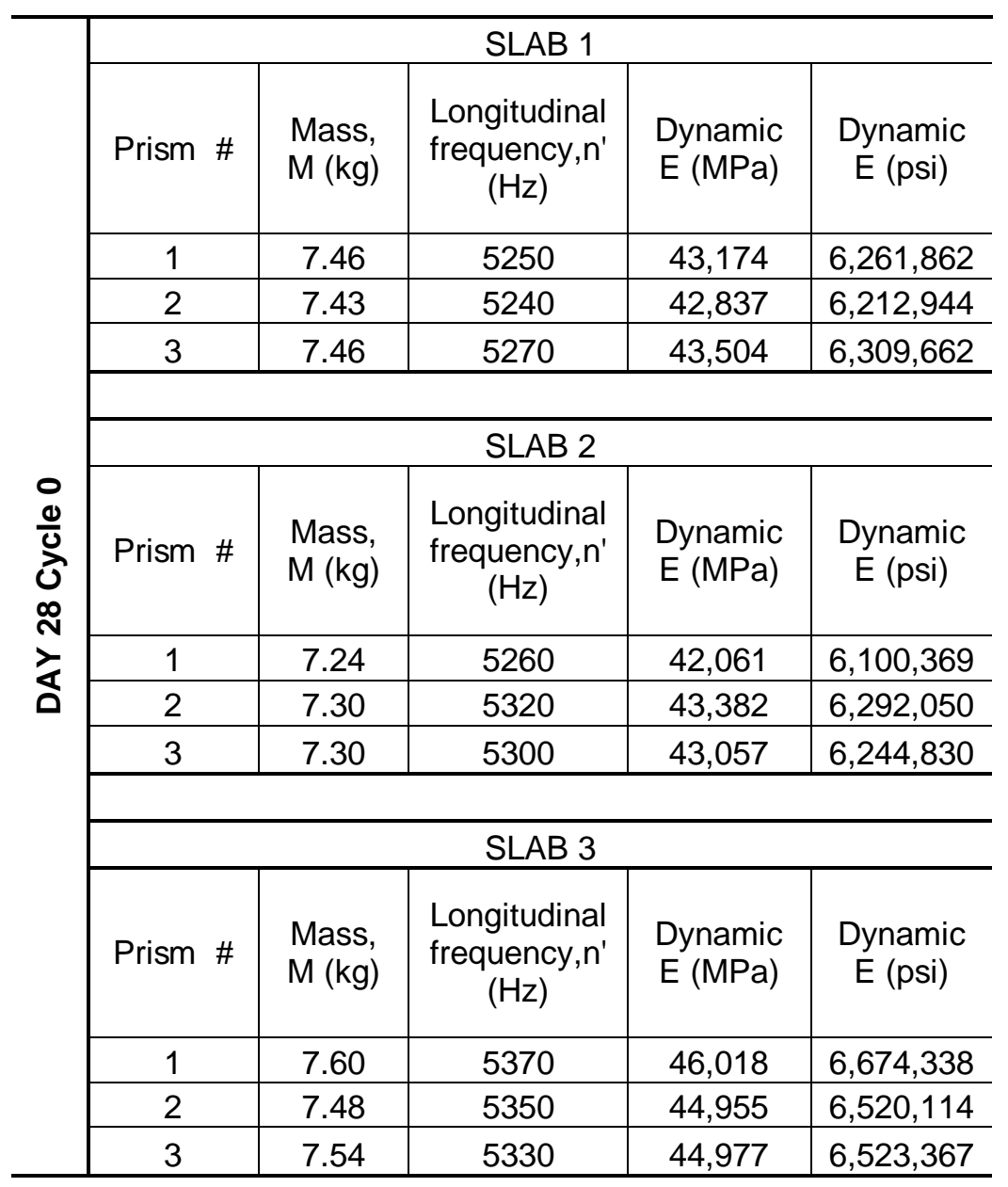




\begin{tabular}{|c|c|c|c|c|c|}
\hline & \multicolumn{5}{|c|}{ SLAB 1} \\
\hline & Prism \# & $\begin{array}{l}\text { Mass, } \\
\text { M (kg) }\end{array}$ & $\begin{array}{l}\text { Longitudinal } \\
\text { frequency,n' } \\
(\mathrm{Hz})\end{array}$ & $\begin{array}{l}\text { Dynamic } \\
\text { E (MPa) }\end{array}$ & $\begin{array}{l}\text { Dynamic } \\
\text { E (psi) }\end{array}$ \\
\hline \multirow{13}{*}{$\begin{array}{l}10 \\
0 \\
0 \\
0 \\
0 \\
0 \\
0 \\
0 \\
⿱ 亠 乂 \\
0\end{array}$} & 1 & 7.44 & 5240 & 42,894 & $6,221,306$ \\
\hline & 2 & 7.40 & 5210 & 42,177 & $6,117,207$ \\
\hline & 3 & 7.44 & 5200 & 42,242 & $6,126,686$ \\
\hline & \multicolumn{5}{|c|}{ SLAB 2} \\
\hline & Prism \# & $\begin{array}{l}\text { Mass, } \\
\text { M (kg) }\end{array}$ & $\begin{array}{l}\text { Longitudinal } \\
\text { frequency, } n^{\prime} \\
\qquad(\mathrm{Hz})\end{array}$ & $\begin{array}{l}\text { Dynamic } \\
\mathrm{E}(\mathrm{MPa})\end{array}$ & $\begin{array}{c}\text { Dynamic } \\
\text { E (psi) }\end{array}$ \\
\hline & 1 & 7.22 & 5189 & 40,820 & $5,920,393$ \\
\hline & 2 & 7.28 & 5280 & 42,615 & $6,180,808$ \\
\hline & 3 & 7.28 & 5210 & 41,493 & $6,018,009$ \\
\hline & \multicolumn{5}{|c|}{ SLAB 3} \\
\hline & Prism \# & $\begin{array}{l}\text { Mass, } \\
\text { M (kg) }\end{array}$ & $\begin{array}{l}\text { Longitudinal } \\
\text { frequency, } n^{\prime} \\
\qquad(\mathrm{Hz})\end{array}$ & $\begin{array}{l}\text { Dynamic } \\
\text { E (MPa) }\end{array}$ & $\begin{array}{c}\text { Dynamic } \\
\text { E (psi) }\end{array}$ \\
\hline & 1 & 7.60 & 5300 & 44,826 & $6,501,467$ \\
\hline & 2 & 7.48 & 5330 & 44,619 & $6,471,457$ \\
\hline & 3 & 7.54 & 5290 & 44,304 & $6,425,822$ \\
\hline
\end{tabular}




\begin{tabular}{|c|c|c|c|c|c|}
\hline \multirow{15}{*}{ 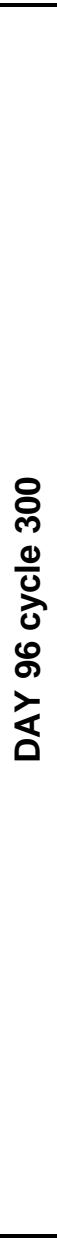 } & \multicolumn{5}{|c|}{ SLAB 1} \\
\hline & $\begin{array}{l}\text { Prism } \\
\quad \#\end{array}$ & $\begin{array}{l}\text { Mass, } \\
\text { M (kg) }\end{array}$ & $\begin{array}{l}\text { Longitudinal } \\
\text { frequency,n' } \\
(\mathrm{Hz})\end{array}$ & $\begin{array}{l}\text { Dynamic } \\
\text { E (MPa) }\end{array}$ & $\begin{array}{c}\text { Dynamic } \\
\text { E (psi) }\end{array}$ \\
\hline & 1 & 7.44 & 5200 & 42,236 & $6,125,761$ \\
\hline & 2 & 7.37 & 5190 & 41,689 & $6,046,410$ \\
\hline & 3 & 7.44 & 5190 & 42,073 & $6,102,223$ \\
\hline & \multicolumn{5}{|c|}{ SLAB 2} \\
\hline & $\begin{array}{c}\text { Prism } \\
\quad \#\end{array}$ & $\begin{array}{l}\text { Mass, } \\
\text { M (kg) }\end{array}$ & $\begin{array}{l}\text { Longitudinal } \\
\text { frequency, n' } \\
(\mathrm{Hz})\end{array}$ & $\begin{array}{l}\text { Dynamic } \\
\mathrm{E}(\mathrm{MPa})\end{array}$ & $\begin{array}{c}\text { Dynamic } \\
\text { E (psi) }\end{array}$ \\
\hline & 1 & 7.21 & 5200 & 40,936 & $5,937,286$ \\
\hline & 2 & 7.28 & 5230 & 41,812 & $6,064,302$ \\
\hline & 3 & 7.28 & 5190 & 41,175 & $5,971,992$ \\
\hline & \multicolumn{5}{|c|}{ SLAB 3} \\
\hline & $\begin{array}{c}\text { Prism } \\
\#\end{array}$ & $\begin{array}{l}\text { Mass, } \\
\text { M (kg) }\end{array}$ & $\begin{array}{l}\text { Longitudinal } \\
\text { frequency, n' } \\
(\mathrm{Hz})\end{array}$ & $\begin{array}{l}\text { Dynamic } \\
\text { E (MPa) }\end{array}$ & $\begin{array}{c}\text { Dynamic } \\
\text { E (psi) }\end{array}$ \\
\hline & 1 & 7.60 & 5290 & 44,657 & $6,476,956$ \\
\hline & 2 & 7.46 & 5250 & 43,174 & $6,261,862$ \\
\hline & 3 & 7.51 & 5200 & 42,639 & $6,184,330$ \\
\hline
\end{tabular}




\section{APPENDIX C}

1. RCPT data for three different mixtures at 35 days.

\begin{tabular}{c|c|c|c|c|c|c|c|c}
\hline \multicolumn{9}{c}{ Slab 1: Slag + Metakaolin (35 Days) } \\
\hline \multirow{2}{*}{$\begin{array}{c}\text { Time } \\
(\mathbf{m i n})\end{array}$} & \multicolumn{2}{|c|}{ Field Core 1 } & \multicolumn{2}{c|}{ Field Core 2 } & \multicolumn{2}{c}{ Field-LC 1 } & \multicolumn{2}{c}{ Field-LC 2 } \\
\cline { 2 - 9 } & $\begin{array}{c}\text { Current } \\
(\mathbf{m A})\end{array}$ & $\begin{array}{c}\text { Charge } \\
\text { (Coulombs) }\end{array}$ & $\begin{array}{c}\text { Current } \\
(\mathbf{m A})\end{array}$ & $\begin{array}{c}\text { Charge } \\
\text { (Coulombs) }\end{array}$ & $\begin{array}{c}\text { Current } \\
(\mathbf{m A})\end{array}$ & $\begin{array}{c}\text { Charge } \\
\text { (Coulombs) }\end{array}$ & $\begin{array}{c}\text { Current } \\
(\mathbf{m A})\end{array}$ & $\begin{array}{c}\text { Charge } \\
\text { (Coulombs) }\end{array}$ \\
\hline 1 & 26 & 2 & 27 & 2 & 49 & 4 & 144 & 11 \\
\hline 5 & 26 & 8 & 27 & 8 & 50 & 15 & 153 & 44 \\
\hline 10 & 26 & 16 & 27 & 17 & 50 & 30 & 164 & 91 \\
\hline 15 & 27 & 24 & 28 & 25 & 51 & 45 & 183 & 144 \\
\hline 20 & 27 & 33 & 28 & 34 & 50 & 61 & 184 & 200 \\
\hline 25 & 26 & 41 & 28 & 43 & 51 & 77 & 191 & 257 \\
\hline 30 & 27 & 50 & 28 & 51 & 51 & 92 & 197 & 314 \\
\hline 35 & 27 & 58 & 28 & 60 & 52 & 108 & 202 & 375 \\
\hline 40 & 27 & 67 & 29 & 69 & 53 & 124 & 211 & 437 \\
\hline 45 & 27 & 76 & 29 & 79 & 52 & 141 & 216 & 504 \\
\hline 50 & 27 & 84 & 29 & 87 & 54 & 156 & 220 & 567 \\
\hline 55 & 29 & 99 & 29 & 103 & 53 & 184 & 230 & 683 \\
\hline 60 & 28 & 101 & 29 & 105 & 53 & 188 & 233 & 701 \\
\hline 90 & 29 & 154 & 30 & 160 & 57 & 287 & 261 & 1148 \\
\hline 120 & 29 & 209 & 31 & 217 & 58 & 390 & 285 & 1640 \\
\hline 150 & 30 & 264 & 32 & 275 & 61 & 498 & 315 & 2186 \\
\hline 180 & 31 & 320 & 32 & 334 & 65 & 610 & 350 & 2786 \\
\hline 210 & 31 & 377 & 33 & 395 & 68 & 730 & 388 & 3445 \\
\hline 240 & 32 & 434 & 33 & 457 & 69 & 854 & 421 & 4167 \\
\hline 270 & 32 & 492 & 34 & 520 & 69 & 979 & 435 & 4948 \\
\hline 300 & 32 & 550 & 35 & 583 & 70 & 1103 & 443 & 5768 \\
\hline 330 & 32 & 608 & 34 & 646 & 70 & 1229 & 409 & 6535 \\
\hline 360 & 32 & 667 & 36 & 711 & 71 & 1357 & 325 & 7208 \\
\hline & & & & & & & & \\
\hline
\end{tabular}




\begin{tabular}{c|c|c|c|c|c|c|c|c}
\hline \multicolumn{9}{c}{ Slab 2: Fly Ash + Silica Fume (35 Days) } \\
\hline \multirow{2}{*}{$\begin{array}{c}\text { Time } \\
(\mathbf{m i n})\end{array}$} & \multicolumn{2}{|c|}{ Field Core 1 } & \multicolumn{2}{c|}{ Field Core 2 } & \multicolumn{2}{c}{ Field-LC 1 } & \multicolumn{2}{c}{ Field-LC 2 } \\
\cline { 2 - 9 } & $\begin{array}{c}\text { Current } \\
(\mathbf{m A})\end{array}$ & $\begin{array}{c}\text { Charge } \\
\text { (Coulombs) }\end{array}$ & $\begin{array}{c}\text { Current } \\
(\mathbf{m A})\end{array}$ & $\begin{array}{c}\text { Charge } \\
\text { (Coulombs) }\end{array}$ & $\begin{array}{c}\text { Current } \\
\text { (mA) }\end{array}$ & $\begin{array}{c}\text { Charge } \\
\text { (Coulombs) }\end{array}$ & $\begin{array}{c}\text { Current } \\
\text { (mA) }\end{array}$ & $\begin{array}{c}\text { Charge } \\
\text { (Coulombs) }\end{array}$ \\
\hline 1 & 21 & 1 & 25 & 1 & 31 & 1 & 31 & 1 \\
\hline 5 & 21 & 6 & 25 & 7 & 30 & 9 & 30 & 9 \\
\hline 10 & 21 & 13 & 25 & 15 & 31 & 18 & 30 & 18 \\
\hline 15 & 21 & 20 & 25 & 23 & 30 & 28 & 30 & 28 \\
\hline 20 & 21 & 26 & 25 & 31 & 30 & 37 & 31 & 37 \\
\hline 25 & 21 & 33 & 25 & 39 & 31 & 47 & 31 & 47 \\
\hline 30 & 21 & 40 & 25 & 47 & 31 & 57 & 30 & 56 \\
\hline 35 & 22 & 47 & 25 & 55 & 32 & 67 & 31 & 66 \\
\hline 40 & 22 & 54 & 25 & 63 & 32 & 76 & 31 & 76 \\
\hline 45 & 22 & 61 & 26 & 70 & 31 & 86 & 32 & 85 \\
\hline 50 & 22 & 68 & 25 & 79 & 32 & 97 & 32 & 97 \\
\hline 55 & 22 & 74 & 26 & 86 & 32 & 106 & 33 & 105 \\
\hline 60 & 22 & 81 & 26 & 94 & 33 & 115 & 33 & 115 \\
\hline 90 & 23 & 123 & 26 & 143 & 33 & 176 & 34 & 176 \\
\hline 120 & 23 & 166 & 27 & 192 & 34 & 238 & 35 & 239 \\
\hline 150 & 23 & 210 & 28 & 243 & 35 & 301 & 35 & 303 \\
\hline 180 & 24 & 254 & 27 & 293 & 36 & 365 & 35 & 367 \\
\hline 210 & 23 & 297 & 27 & 344 & 36 & 430 & 35 & 431 \\
\hline 240 & 23 & 341 & 27 & 395 & 36 & 496 & 35 & 496 \\
\hline 270 & 23 & 384 & 27 & 446 & 36 & 562 & 36 & 561 \\
\hline 300 & 23 & 428 & 27 & 496 & 35 & 627 & 36 & 627 \\
\hline 330 & 23 & 471 & 26 & 546 & 36 & 693 & 35 & 692 \\
\hline 360 & 23 & 514 & 26 & 595 & 36 & 758 & 35 & 756 \\
\hline & & & & & & & & \\
\hline
\end{tabular}




\begin{tabular}{c|c|c|c|c|c|c|c|c}
\hline \multicolumn{9}{c|}{ Slab 3: Slag + Silica Fume (35 Days) } \\
\hline \multirow{2}{*}{$\begin{array}{c}\text { Time } \\
(\mathbf{m i n})\end{array}$} & \multicolumn{2}{|c|}{ Field Core 1 } & \multicolumn{2}{c|}{ Field Core 2 } & \multicolumn{2}{c}{ Field-LC 1 } & \multicolumn{2}{c}{ Field-LC 2 } \\
\cline { 2 - 9 } & $\begin{array}{c}\text { Current } \\
(\mathbf{m A})\end{array}$ & $\begin{array}{c}\text { Charge } \\
\text { (Coulombs) }\end{array}$ & $\begin{array}{c}\text { Current } \\
(\mathbf{m A})\end{array}$ & $\begin{array}{c}\text { Charge } \\
\text { (Coulombs) }\end{array}$ & $\begin{array}{c}\text { Current } \\
(\mathbf{m A})\end{array}$ & $\begin{array}{c}\text { Charge } \\
\text { (Coulombs) }\end{array}$ & $\begin{array}{c}\text { Current } \\
(\mathbf{m A})\end{array}$ & $\begin{array}{c}\text { Charge } \\
\text { (Coulombs) }\end{array}$ \\
\hline 1 & 16 & 1 & 15 & 1 & 18 & 1 & 19 & 1 \\
\hline 5 & 16 & 5 & 15 & 5 & 18 & 6 & 19 & 6 \\
\hline 10 & 16 & 11 & 15 & 11 & 18 & 12 & 19 & 13 \\
\hline 15 & 15 & 15 & 15 & 15 & 18 & 17 & 20 & 18 \\
\hline 20 & 16 & 20 & 15 & 19 & 18 & 22 & 20 & 24 \\
\hline 25 & 16 & 25 & 16 & 24 & 18 & 28 & 20 & 30 \\
\hline 30 & 16 & 30 & 15 & 29 & 18 & 33 & 20 & 36 \\
\hline 35 & 15 & 36 & 15 & 35 & 18 & 41 & 20 & 44 \\
\hline 40 & 15 & 40 & 16 & 39 & 18 & 45 & 20 & 49 \\
\hline 45 & 16 & 45 & 16 & 44 & 19 & 51 & 20 & 55 \\
\hline 50 & 16 & 50 & 16 & 49 & 19 & 56 & 19 & 61 \\
\hline 55 & 16 & 55 & 16 & 54 & 19 & 62 & 20 & 67 \\
\hline 60 & 15 & 60 & 16 & 59 & 18 & 68 & 21 & 74 \\
\hline 90 & 16 & 90 & 16 & 89 & 19 & 103 & 22 & 113 \\
\hline 120 & 16 & 121 & 16 & 120 & 20 & 139 & 22 & 153 \\
\hline 150 & 17 & 151 & 16 & 151 & 20 & 175 & 23 & 194 \\
\hline 180 & 16 & 182 & 17 & 182 & 20 & 212 & 22 & 235 \\
\hline 210 & 16 & 213 & 16 & 213 & 21 & 249 & 23 & 277 \\
\hline 240 & 15 & 243 & 16 & 244 & 20 & 286 & 23 & 319 \\
\hline 270 & 16 & 273 & 16 & 274 & 19 & 323 & 22 & 361 \\
\hline 300 & 16 & 304 & 16 & 305 & 20 & 360 & 23 & 402 \\
\hline 330 & 16 & 334 & 16 & 335 & 19 & 397 & 22 & 444 \\
\hline 360 & 16 & 364 & 16 & 365 & 19 & 433 & 23 & 485 \\
\hline & & & & & & & & \\
\hline
\end{tabular}


2. RCPT data for three different mixtures at 60 days.

\begin{tabular}{|c|c|c|c|c|c|c|c|c|}
\hline \multicolumn{9}{|c|}{ Slab 1: Slag + Metakaolin (60 Days) } \\
\hline \multirow[b]{2}{*}{$\begin{array}{l}\text { Time } \\
(\min )\end{array}$} & \multicolumn{2}{|c|}{ Field Core 1} & \multicolumn{2}{|c|}{ Field Core 2} & \multicolumn{2}{|c|}{ Field-LC 1} & \multicolumn{2}{|c|}{ Field-LC 2} \\
\hline & $\underset{(m A)}{\text { Current }}$ & $\begin{array}{c}\text { Charge } \\
\text { (Coulombs) }\end{array}$ & $\begin{array}{c}\text { Current } \\
(\mathrm{mA})\end{array}$ & $\begin{array}{c}\text { Charge } \\
\text { (Coulombs) }\end{array}$ & $\begin{array}{c}\text { Current } \\
(\mathrm{mA})\end{array}$ & $\begin{array}{c}\text { Charge } \\
\text { (Coulombs) }\end{array}$ & $\begin{array}{c}\text { Current } \\
(\mathrm{mA})\end{array}$ & $\begin{array}{c}\text { Charge } \\
\text { (Coulombs) }\end{array}$ \\
\hline 1 & 24 & 1 & 22 & 1 & 22 & 1 & 21 & 1 \\
\hline 5 & 24 & 7 & 21 & 7 & 22 & 7 & 21 & 6 \\
\hline 10 & 24 & 15 & 22 & 13 & 23 & 14 & 22 & 13 \\
\hline 15 & 24 & 22 & 21 & 20 & 22 & 21 & 22 & 20 \\
\hline 20 & 24 & 30 & 22 & 28 & 23 & 28 & 21 & 27 \\
\hline 25 & 24 & 38 & 22 & 34 & 23 & 35 & 22 & 34 \\
\hline 30 & 24 & 45 & 22 & 41 & 23 & 42 & 23 & 40 \\
\hline 35 & 24 & 53 & 22 & 48 & 23 & 49 & 23 & 47 \\
\hline 40 & 25 & 61 & 23 & 55 & 24 & 56 & 23 & 54 \\
\hline 45 & 25 & 68 & 22 & 62 & 23 & 64 & 23 & 61 \\
\hline 50 & 25 & 76 & 22 & 69 & 24 & 71 & 23 & 69 \\
\hline 55 & 25 & 84 & 22 & 76 & 23 & 78 & 23 & 76 \\
\hline 60 & 25 & 92 & 22 & 83 & 24 & 86 & 23 & 83 \\
\hline 90 & 26 & 140 & 23 & 126 & 25 & 131 & 24 & 126 \\
\hline 120 & 27 & 188 & 23 & 169 & 25 & 177 & 25 & 171 \\
\hline 150 & 26 & 237 & 23 & 212 & 25 & 224 & 25 & 216 \\
\hline 180 & 26 & 286 & 23 & 256 & 27 & 272 & 26 & 262 \\
\hline 210 & 26 & 335 & 24 & 299 & 26 & 320 & 24 & 308 \\
\hline 240 & 26 & 384 & 23 & 343 & 26 & 369 & 25 & 354 \\
\hline 270 & 26 & 432 & 23 & 386 & 27 & 418 & 25 & 401 \\
\hline 300 & 26 & 481 & 22 & 429 & 27 & 468 & 26 & 447 \\
\hline 330 & 26 & 529 & 23 & 471 & 27 & 517 & 25 & 493 \\
\hline 360 & 26 & 577 & 23 & 514 & 26 & 566 & 24 & 539 \\
\hline
\end{tabular}




\begin{tabular}{c|c|c|c|c|c|c|c|c}
\hline \multicolumn{9}{c}{ Slab 2: Fly Ash + Silica Fume (60 Days) } \\
\hline \multirow{2}{*}{$\begin{array}{c}\text { Time } \\
(\mathbf{m i n})\end{array}$} & \multicolumn{2}{|c|}{ Field Core 1 } & \multicolumn{2}{c|}{ Field Core 2 } & \multicolumn{2}{c}{ Field-LC 1 } & \multicolumn{2}{c}{ Field-LC 2 } \\
\cline { 2 - 9 } & $\begin{array}{c}\text { Current } \\
(\mathbf{m A})\end{array}$ & $\begin{array}{c}\text { Charge } \\
\text { (Coulombs) }\end{array}$ & $\begin{array}{c}\text { Current } \\
(\mathbf{m A})\end{array}$ & $\begin{array}{c}\text { Charge } \\
\text { (Coulombs) }\end{array}$ & $\begin{array}{c}\text { Current } \\
(\mathbf{m A})\end{array}$ & $\begin{array}{c}\text { Charge } \\
\text { (Coulombs) }\end{array}$ & $\begin{array}{c}\text { Current } \\
(\mathbf{m A})\end{array}$ & $\begin{array}{c}\text { Charge } \\
\text { (Coulombs) }\end{array}$ \\
\hline 1 & 21 & 1 & 16 & 1 & 23 & 1 & 24 & 1 \\
\hline 5 & 21 & 7 & 17 & 5 & 23 & 7 & 24 & 8 \\
\hline 10 & 20 & 12 & 15 & 10 & 22 & 14 & 24 & 15 \\
\hline 15 & 20 & 18 & 16 & 15 & 23 & 21 & 24 & 22 \\
\hline 20 & 21 & 25 & 16 & 20 & 23 & 28 & 24 & 30 \\
\hline 25 & 20 & 31 & 16 & 25 & 23 & 35 & 25 & 38 \\
\hline 30 & 20 & 37 & 16 & 30 & 23 & 42 & 25 & 46 \\
\hline 35 & 20 & 43 & 16 & 35 & 23 & 50 & 26 & 54 \\
\hline 40 & 21 & 50 & 16 & 40 & 23 & 57 & 26 & 62 \\
\hline 45 & 21 & 56 & 16 & 45 & 23 & 65 & 25 & 70 \\
\hline 50 & 21 & 63 & 16 & 50 & 24 & 72 & 26 & 78 \\
\hline 55 & 21 & 69 & 16 & 56 & 24 & 80 & 26 & 86 \\
\hline 60 & 21 & 75 & 16 & 61 & 24 & 87 & 27 & 94 \\
\hline 90 & 21 & 114 & 16 & 91 & 26 & 133 & 27 & 144 \\
\hline 120 & 21 & 154 & 16 & 122 & 26 & 181 & 27 & 195 \\
\hline 150 & 21 & 193 & 16 & 153 & 26 & 230 & 28 & 247 \\
\hline 180 & 20 & 233 & 16 & 184 & 26 & 279 & 28 & 300 \\
\hline 210 & 20 & 272 & 15 & 214 & 26 & 329 & 28 & 353 \\
\hline 240 & 21 & 311 & 15 & 243 & 26 & 378 & 28 & 406 \\
\hline 270 & 20 & 349 & 15 & 272 & 25 & 428 & 28 & 458 \\
\hline 300 & 20 & 387 & 15 & 301 & 25 & 476 & 28 & 511 \\
\hline 330 & 20 & 425 & 14 & 329 & 25 & 524 & 28 & 562 \\
\hline 360 & 19 & 462 & 12 & 356 & 25 & 571 & 27 & 614 \\
\hline & & & & & & & & \\
\hline
\end{tabular}




\begin{tabular}{|c|c|c|c|c|c|c|c|c|}
\hline \multicolumn{9}{|c|}{ Slab 3: Slag + Silica Fume (60 Days) } \\
\hline \multirow{2}{*}{$\begin{array}{l}\text { Time } \\
(\min )\end{array}$} & \multicolumn{2}{|c|}{ Field Core 1} & \multicolumn{2}{|c|}{ Field Core 2} & \multicolumn{2}{|c|}{ Field-LC 1} & \multicolumn{2}{|c|}{ Field-LC 2} \\
\hline & $\begin{array}{c}\text { Current } \\
(\mathrm{mA})\end{array}$ & $\begin{array}{c}\text { Charge } \\
\text { (Coulombs) }\end{array}$ & $\begin{array}{c}\text { Current } \\
(\mathrm{mA})\end{array}$ & $\begin{array}{c}\text { Charge } \\
\text { (Coulombs) }\end{array}$ & $\begin{array}{c}\text { Current } \\
(\mathrm{mA})\end{array}$ & $\begin{array}{c}\text { Charge } \\
\text { (Coulombs) }\end{array}$ & $\begin{array}{c}\text { Current } \\
(\mathrm{mA})\end{array}$ & $\begin{array}{c}\text { Charge } \\
\text { (Coulombs) }\end{array}$ \\
\hline 1 & 15 & 1 & 16 & 2 & 17 & 2 & 15 & 1 \\
\hline 5 & 15 & 4 & 15 & 5 & 18 & 5 & 16 & 5 \\
\hline 10 & 14 & 9 & 16 & 10 & 18 & 11 & 16 & 10 \\
\hline 15 & 15 & 14 & 16 & 15 & 18 & 17 & 15 & 15 \\
\hline 20 & 15 & 19 & 16 & 21 & 18 & 22 & 15 & 20 \\
\hline 25 & 15 & 24 & 16 & 26 & 19 & 29 & 16 & 25 \\
\hline 30 & 15 & 29 & 16 & 31 & 18 & 34 & 16 & 30 \\
\hline 35 & 16 & 34 & 17 & 36 & 18 & 40 & 16 & 35 \\
\hline 40 & 15 & 39 & 16 & 41 & 19 & 45 & 17 & 40 \\
\hline 45 & 15 & 43 & 16 & 46 & 19 & 51 & 16 & 45 \\
\hline 50 & 15 & 48 & 16 & 51 & 19 & 57 & 17 & 50 \\
\hline 55 & 16 & 53 & 16 & 57 & 19 & 63 & 16 & 56 \\
\hline 60 & 16 & 58 & 16 & 62 & 19 & 69 & 17 & 61 \\
\hline 90 & 16 & 88 & 17 & 93 & 20 & 106 & 17 & 93 \\
\hline 120 & 16 & 119 & 16 & 125 & 20 & 143 & 17 & 126 \\
\hline 150 & 17 & 149 & 17 & 157 & 20 & 181 & 18 & 159 \\
\hline 180 & 17 & 181 & 17 & 190 & 21 & 219 & 18 & 193 \\
\hline 210 & 16 & 212 & 17 & 223 & 20 & 256 & 18 & 227 \\
\hline 240 & 16 & 243 & 16 & 255 & 19 & 294 & 18 & 261 \\
\hline 270 & 17 & 274 & 17 & 288 & 20 & 332 & 17 & 294 \\
\hline 300 & 16 & 305 & 17 & 320 & 19 & 369 & 17 & 328 \\
\hline 330 & 17 & 336 & 16 & 352 & 20 & 406 & 17 & 361 \\
\hline 360 & 16 & 366 & 17 & 385 & 20 & 444 & 18 & 394 \\
\hline
\end{tabular}




\section{APPENDIX D}

1. Predicted and calculated compressive strength, the predicted strength was found using the strength-maturity calibration curves $(1 \mathrm{MPa}=145 \mathrm{psi})$.

\begin{tabular}{c|c|c|c|c}
\hline \multicolumn{5}{|c}{ Slab 1: Slag + Metakaolin } \\
\hline Age & $\begin{array}{c}\text { Field-MC } \\
\text { (MPa) }\end{array}$ & $\begin{array}{c}\text { Field-LC } \\
\text { (MPa) }\end{array}$ & $\begin{array}{c}\text { Field Core } \\
\text { (MPa) }\end{array}$ & $\begin{array}{c}\text { Field } \\
\text { Predicted } \\
\text { (Mpa) }\end{array}$ \\
\hline 4 & 25.4 & 24.7 & 0.0 & 29.6 \\
\hline 7 & 38.0 & 36.5 & 0.0 & 36.6 \\
\hline 14 & 0.0 & 44.9 & 0.0 & 47.1 \\
\hline 28 & 51.3 & 55.6 & 59.2 & 57.3 \\
\hline 56 & 51.6 & 57.0 & 64.6 & 65.6 \\
\hline 90 & 54.2 & 59.4 & 0.0 & 68.9 \\
\hline
\end{tabular}

\begin{tabular}{c|c|c|c|c}
\hline \multicolumn{5}{|c}{ Slab 2: Fly Ash + Silica Fume } \\
\hline Age & $\begin{array}{c}\text { Field-MC } \\
\text { (MPa) }\end{array}$ & $\begin{array}{c}\text { Field-LC } \\
\text { (MPa) }\end{array}$ & $\begin{array}{c}\text { Field Core } \\
\text { (MPa) }\end{array}$ & $\begin{array}{c}\text { Field } \\
\text { Predicted } \\
\text { (Mpa) }\end{array}$ \\
\hline 4 & 28.5 & 31.7 & 0.0 & 34.6 \\
\hline 7 & 38.3 & 39.7 & 0.0 & 40.4 \\
\hline 14 & 0.0 & 47.9 & 0.0 & 48.9 \\
\hline 28 & 52.0 & 55.2 & 58.2 & 57.2 \\
\hline 56 & 53.1 & 58.5 & 65.8 & 63.8 \\
\hline 90 & 56.0 & 60.6 & 0.0 & 66.5 \\
\hline
\end{tabular}

\begin{tabular}{c|c|c|c|c}
\hline \multicolumn{5}{|c}{ Slab 3: Slag + Silica Fume } \\
\hline Age & $\begin{array}{c}\text { Field-MC } \\
\text { (MPa) }\end{array}$ & $\begin{array}{c}\text { Field-LC } \\
\text { (MPa) }\end{array}$ & $\begin{array}{c}\text { Field Core } \\
\text { (MPa) }\end{array}$ & $\begin{array}{c}\text { Field } \\
\text { Predicted } \\
\text { (Mpa) }\end{array}$ \\
\hline 4 & 41.0 & 40.6 & 0.0 & 47.7 \\
\hline 7 & 51.2 & 50.8 & 0.0 & 51.4 \\
\hline 14 & 0.0 & 61.9 & 0.0 & 60.6 \\
\hline 28 & 65.1 & 65.6 & 69.5 & 69.5 \\
\hline 56 & 66.3 & 75.7 & 77.1 & 76.9 \\
\hline 90 & 76.6 & 83.1 & 0.0 & 79.8 \\
\hline
\end{tabular}

